\title{
CROSS-BOUNDARY INFORMATION SHARING BY KNOWLEDGE BROKERS \\ DURING A DISASTER
}

\author{
By \\ A Fahimi Md Ali
}

A thesis submitted to Victoria University of Wellington in fulfillment of the requirements for the degree of Doctor of Philosophy in Information Systems

Victoria University of Wellington

2016 



\section{THESIS ABSTRACT}

This thesis explores and investigates the process of cross-boundary information sharing by knowledge brokers $(\mathrm{KB})$ during a disaster using lenses of knowledge management and naturalistic decision making.

The study integrated interpretivist and positivist stances, conducted using qualitative methods. It used a multiple case embedded research design and in-depth face-to-face interviews as the method of inquiry and an inductive process of theory generation. The cases were in the context of disasters that occurred in New Zealand. The unit of analysis was the scenarios that $\mathrm{KB}$ experienced during disasters.

Based on a four stage analysis of the data, there were two phases that $\mathrm{KB}$ went through in assessing the veracity of the information they received and deciding to whom the information is relevant. In each phase, $\mathrm{KB}$ were relying on different cognitive resources to filter and to match the information. It was also found that there were different types of boundary, information and disasters. Interestingly, it was found that KB used different tactics to make the decision on the information's veracity and to whom it is relevant.

The primary contribution of this thesis is the generation and explanation of the theoretical model of cross-boundary information sharing by KB during a disaster. This theory can also be used by practitioners as a guide to improve disaster management training and for the community to prepare stronger resilience plans. 


\section{Acknowledgements}

I am most grateful to Professor Pak Yoong and Dr Jean-Gregoire Bernard for guiding me enthusiastically through this exciting journey. You give light whenever I am in the dark and passed the life-saver when I was about to drown.

To my wife Fiza, thanks for the companionship and having the highest degree of patience by sailing this exciting journey together, along with lil' Daem. Special thanks to my parents, Md Ali and Sabiah who supported me in many ways beyond what any words could describe. To my father-in-law, Ibrahim and the late mother-in-law, Azizah who passed away at the final stage of my journey, thanks for all the encouragement. To my family here in NZ, Ian and Marion Buckenberg and Tim and Suriah Burns, thanks for all the advice and motivations.

My sincere thanks to the wonderful and cheerful friends at SIM who have helped me untie lots and lots of knots (and partying) along the way: Diane, Marta, Geetha, Rashidah, Balsam, Edgar, Nicole, Balsam, Donelle, Rhys, Kathryn, Amitha, Thuan, Quang, Syahida, Alireza, Isaac, Arif and all the academic staff.

Thank you to all of the administrative staff at SIM especially Usha, who provided all the support that I needed. My thesis would not be the same without your support.

My thanks to the City of Wellington Pipe Band who have provided me with a space to release all the stress during this journey with lots of drumming. 
Table of Contents

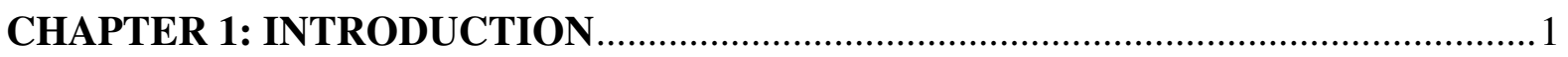

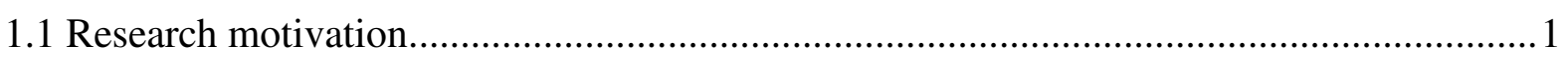

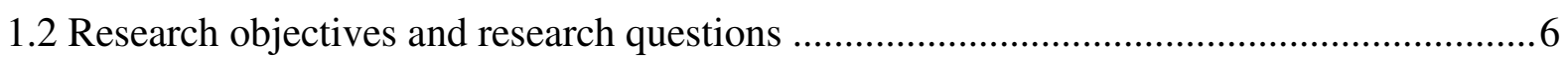

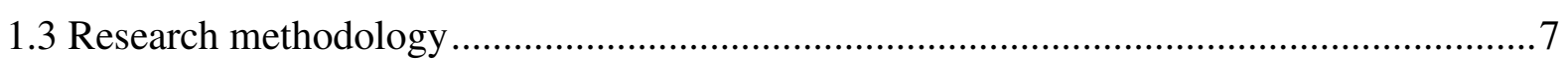

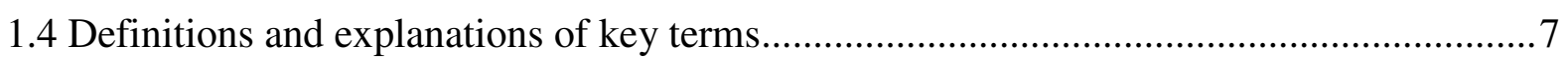

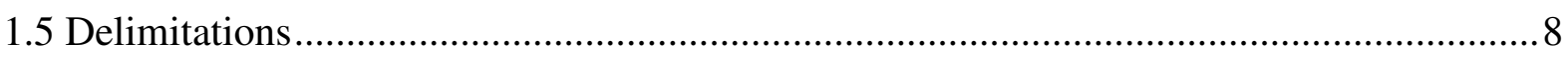

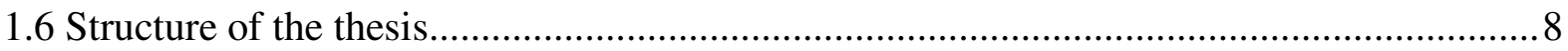

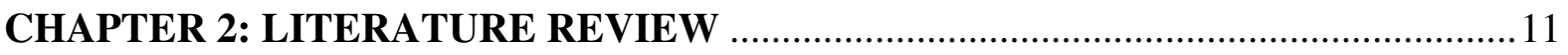

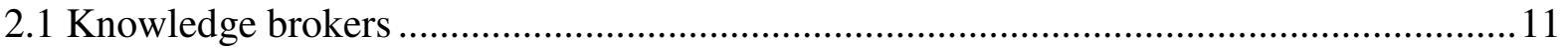

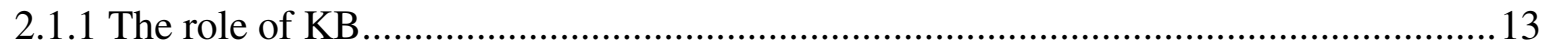

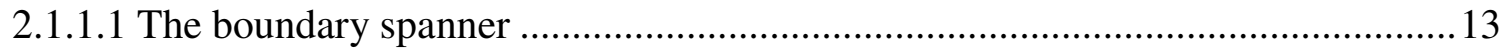

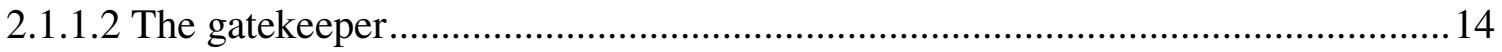

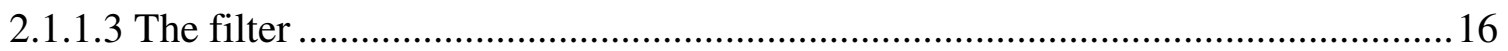

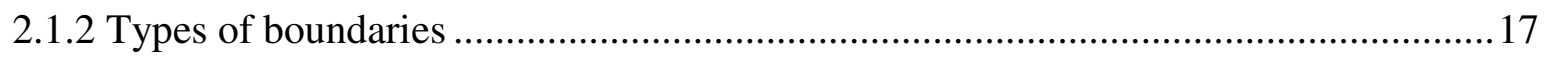

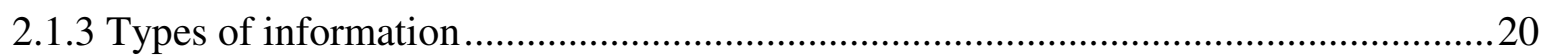

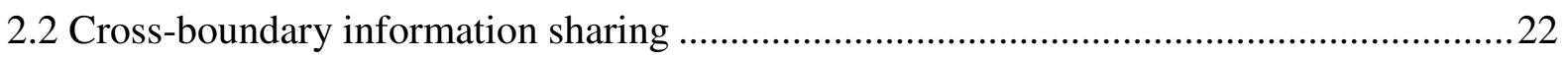

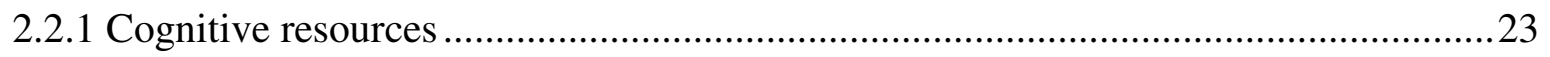

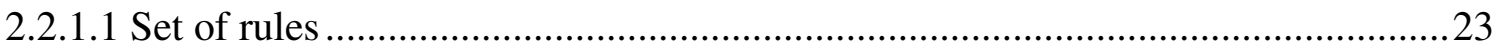

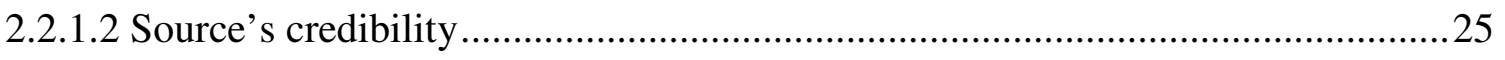

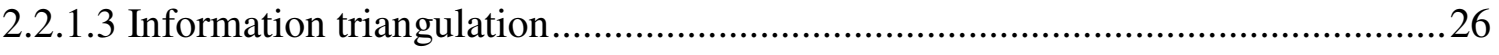

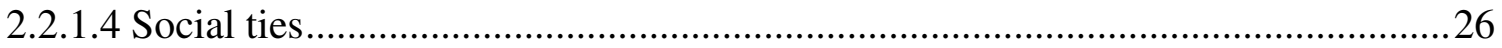

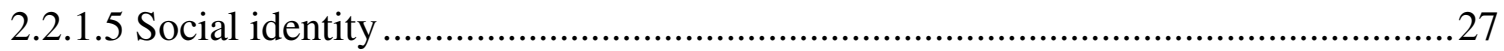

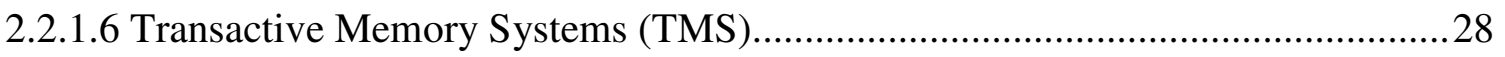

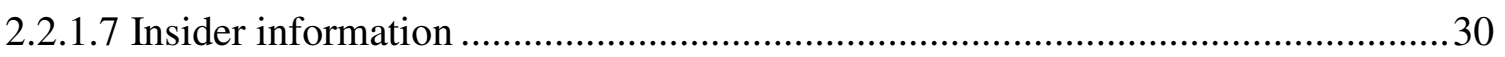

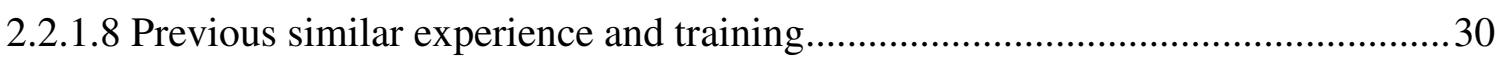

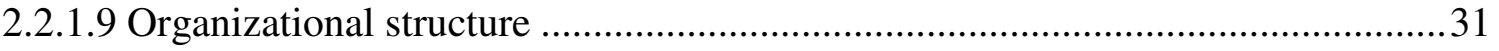

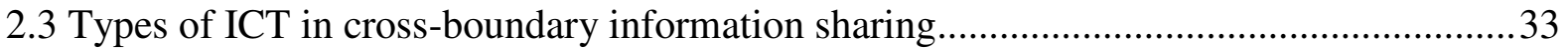

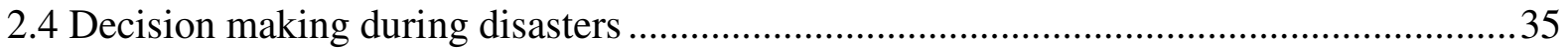

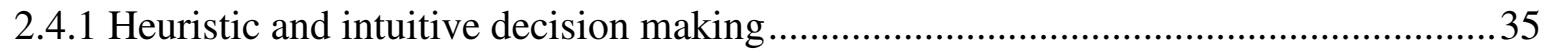

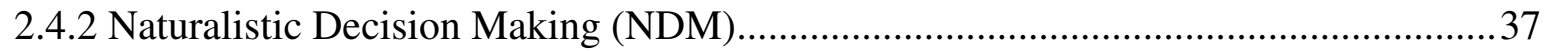

2.4.3 Decision-making tactics for coping with uncertainty ............................................4

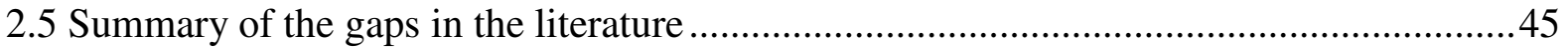

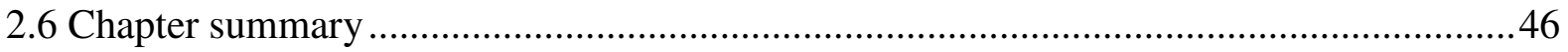




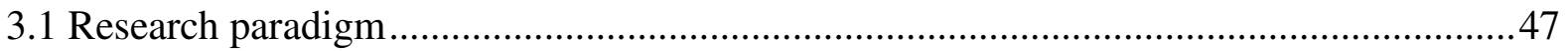

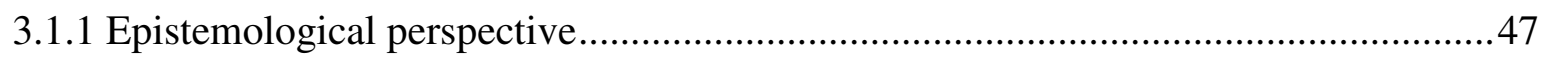

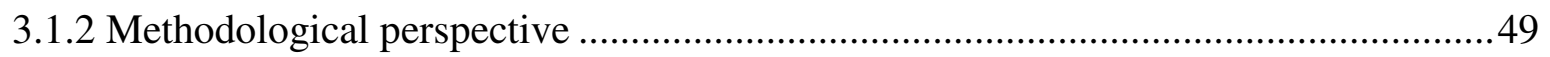

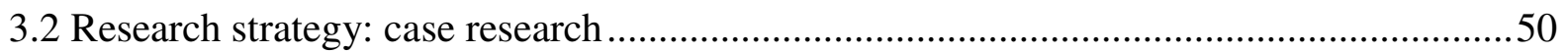

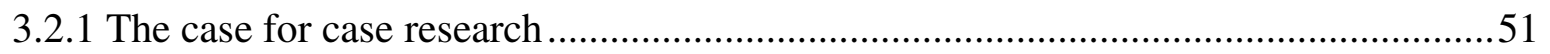

3.2.2 Case research design - multiple case, embedded design .......................................52

3.2.3 The cases: Disasters that occurred in New Zealand ..................................................52

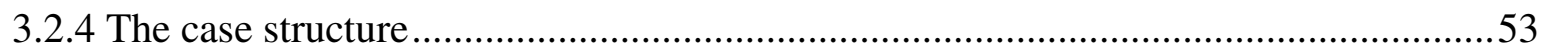

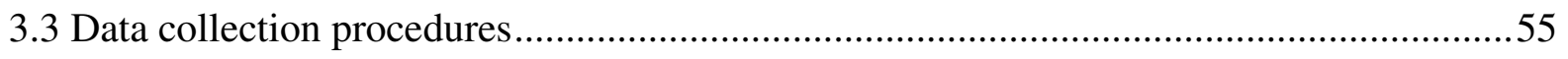

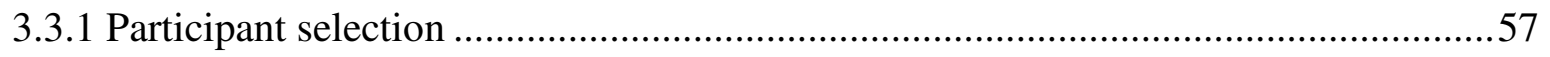

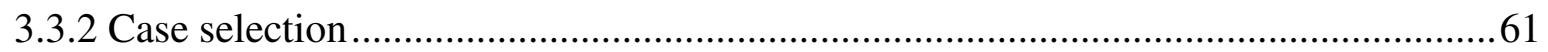

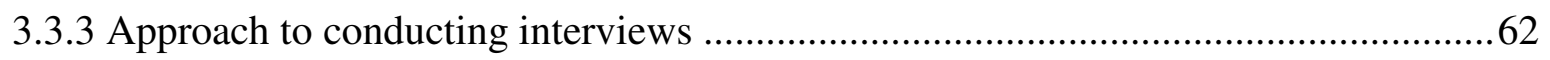

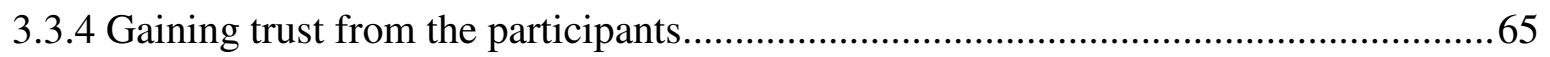

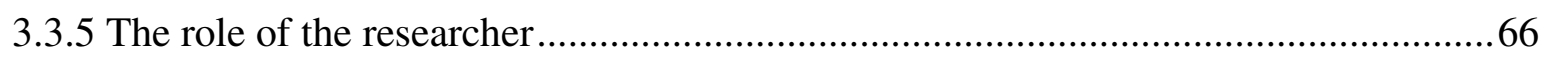

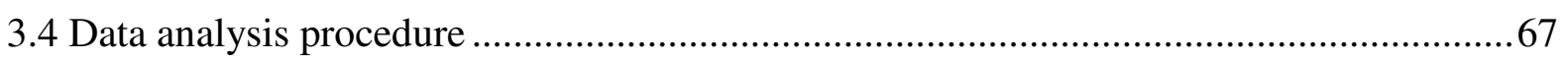

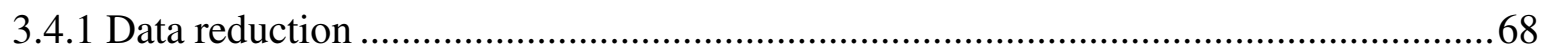

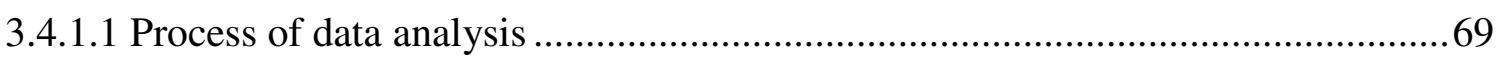

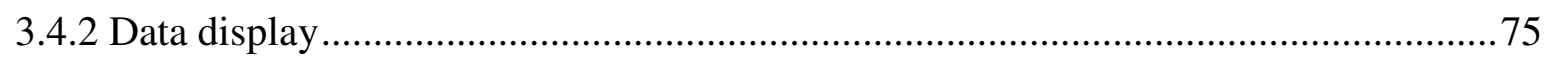

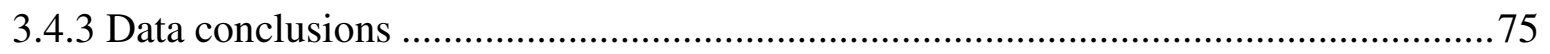

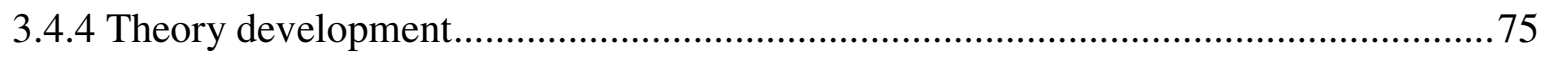

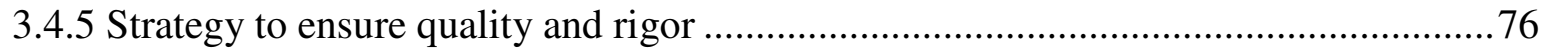

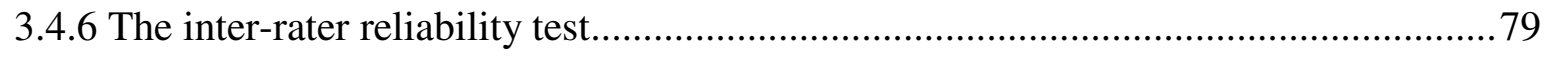

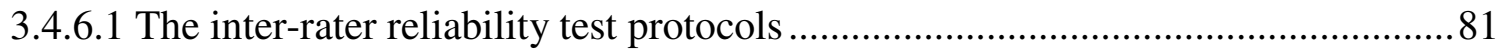

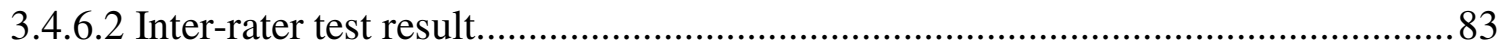

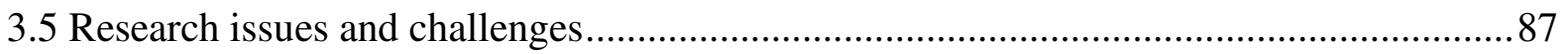

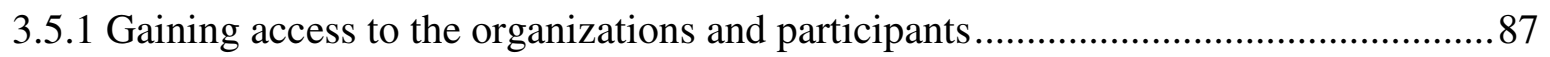

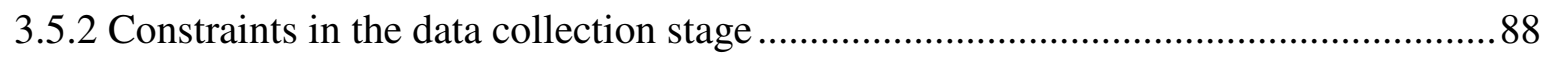

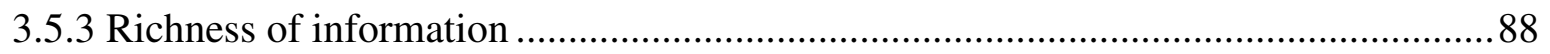

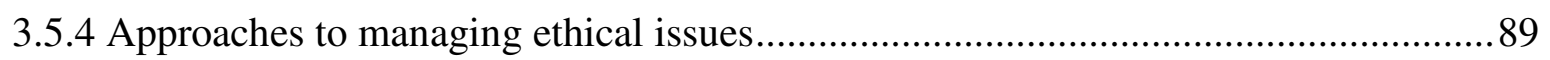

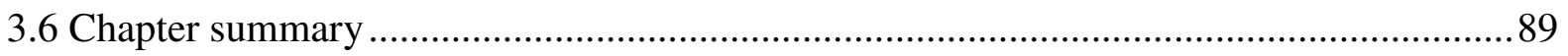

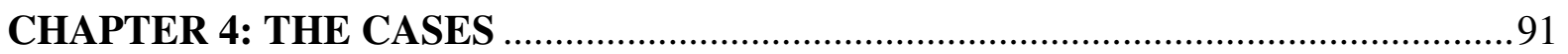

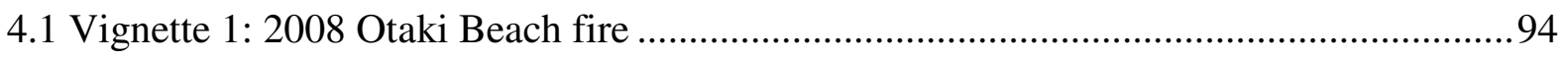

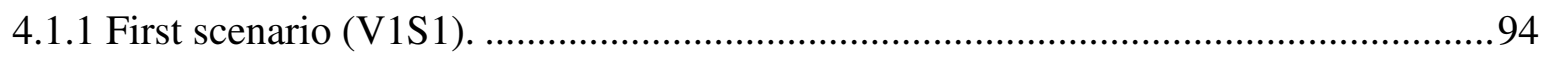




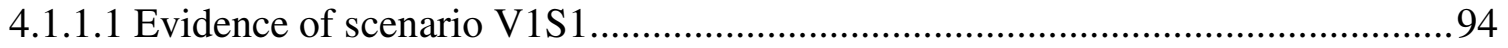

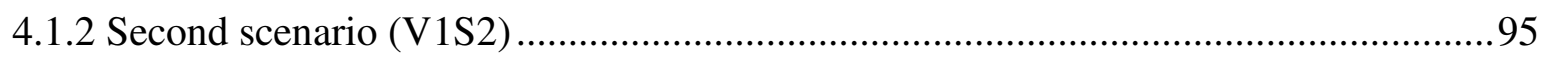

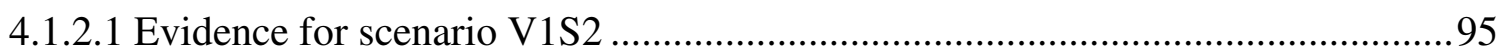

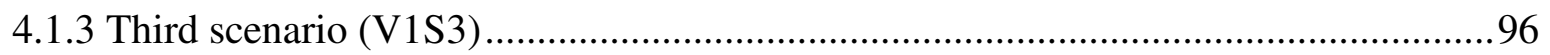

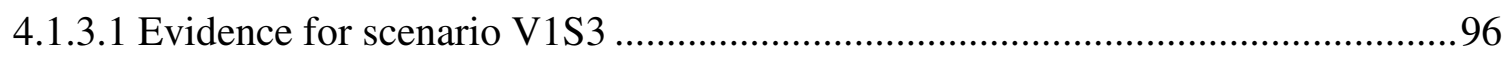

4.2 Vignette 2: 2013 Wellington earthquake (July)..........................................................97

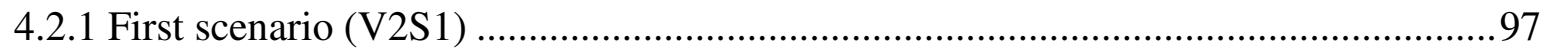

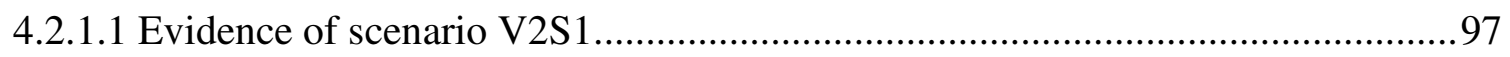

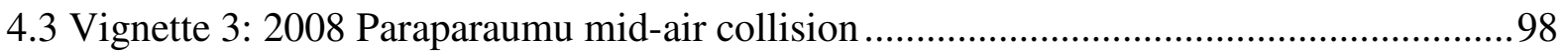

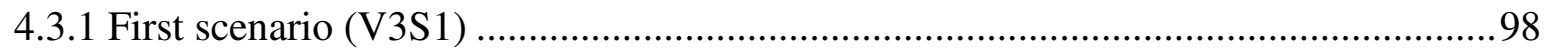

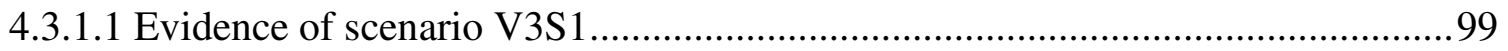

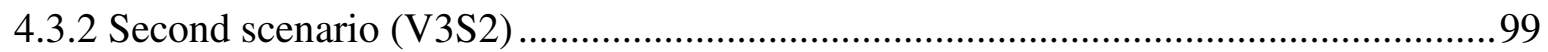

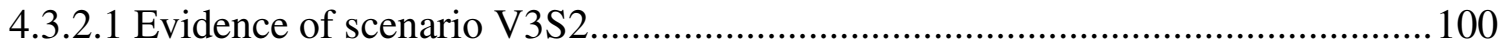

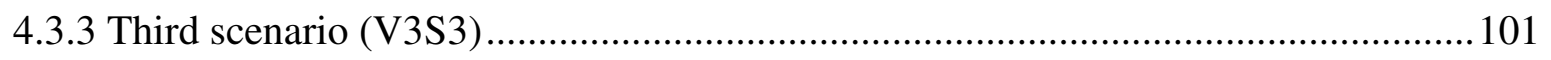

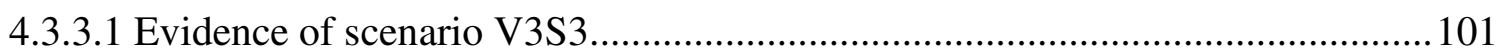

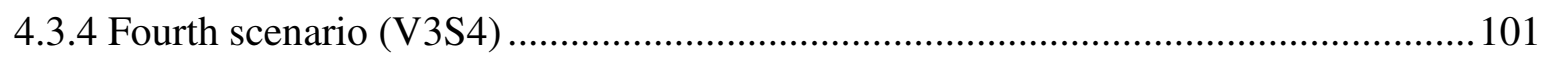

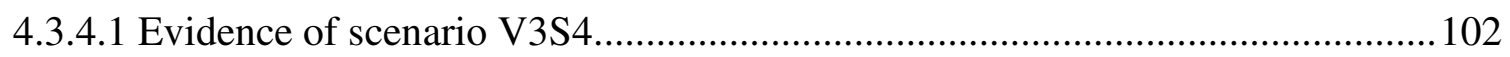

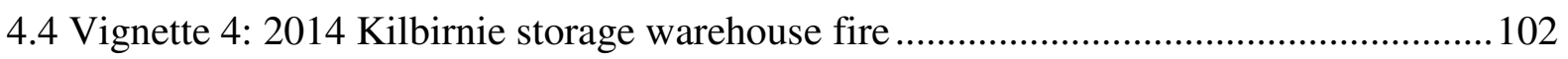

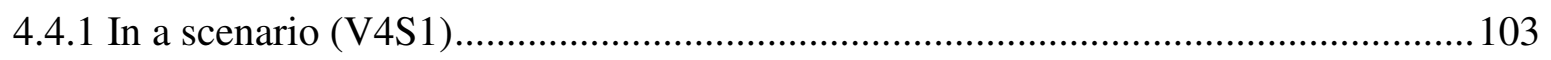

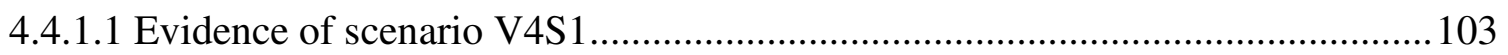

4.5 Vignette 5: 2010 Pike River Mine explosion............................................................... 104

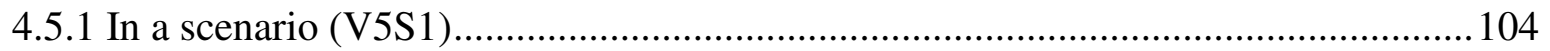

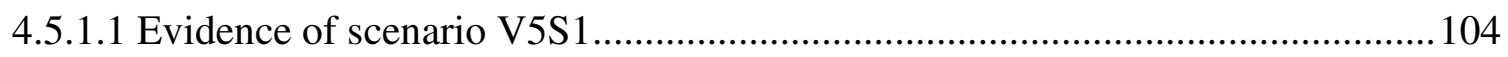

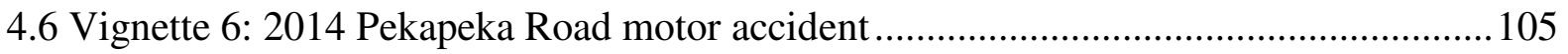

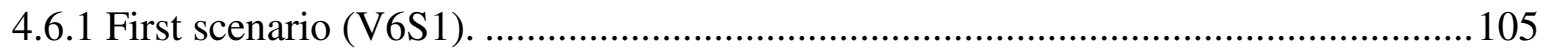

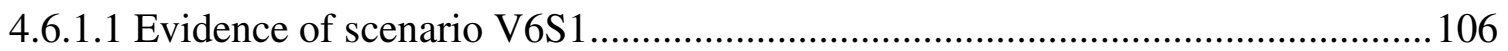

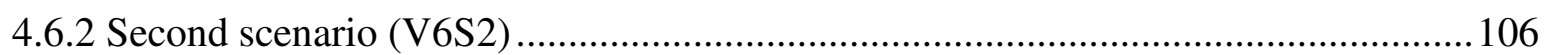

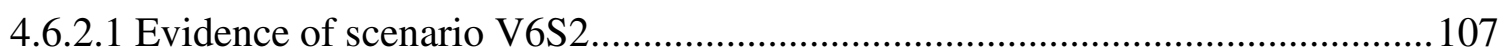

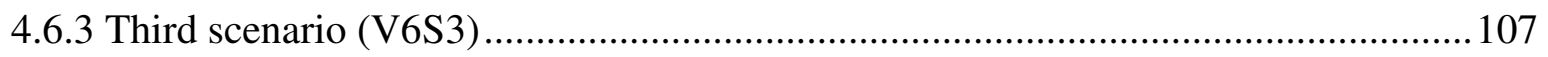

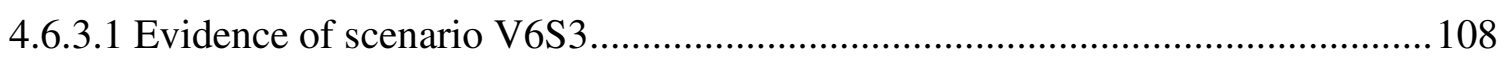

4.7 Vignette 7: 2001 Aotea Quay fatal motor accident .................................................... 108

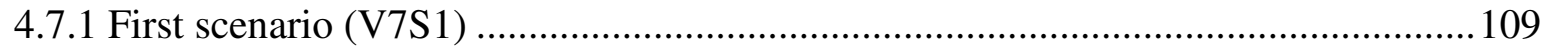

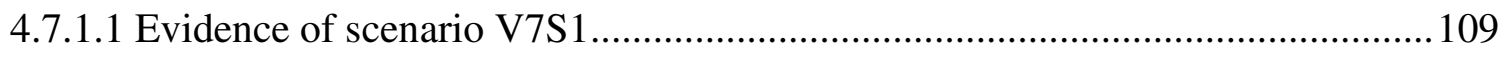

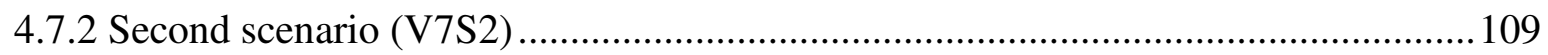




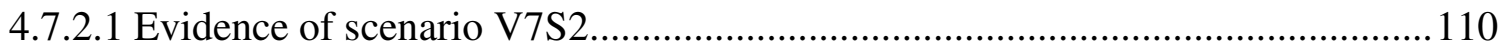

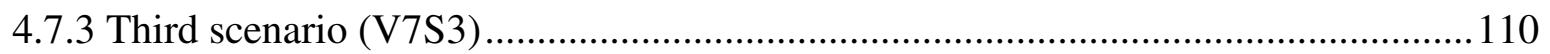

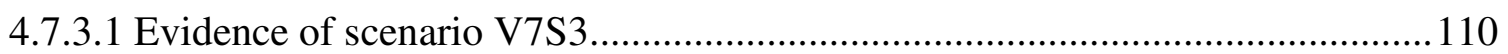

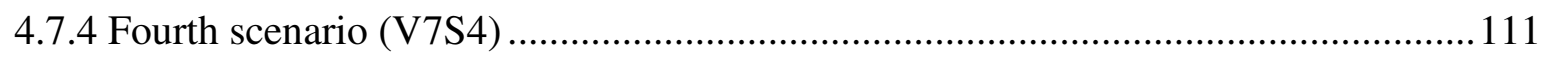

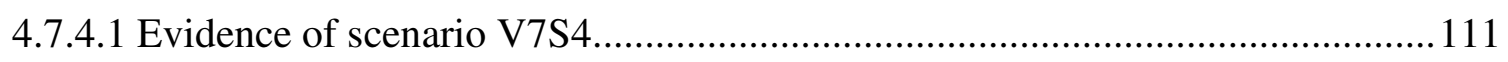

4.8 Vignette 8: 2012 Otaihanga motor vehicle accident.................................................... 111

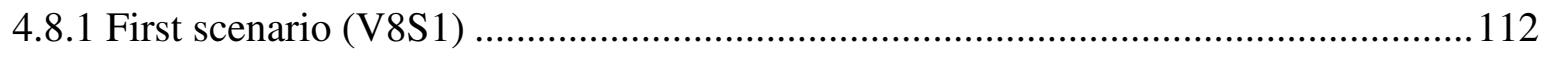

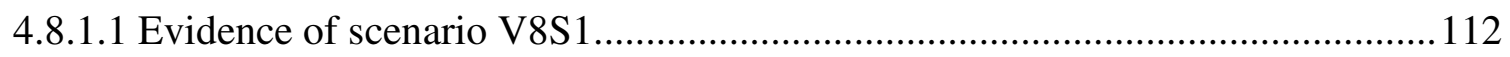

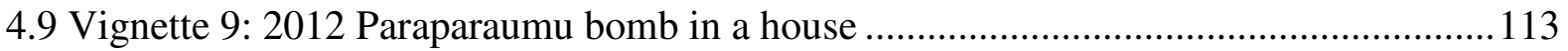

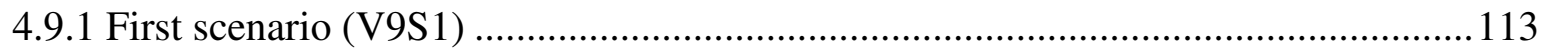

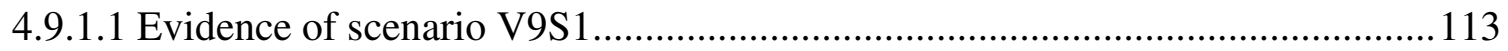

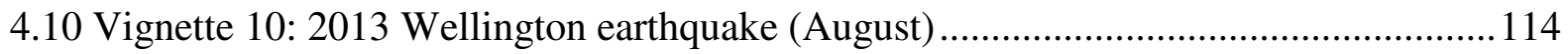

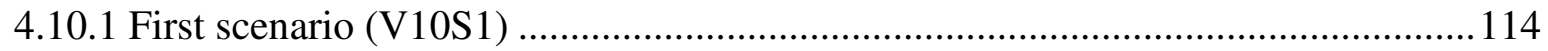

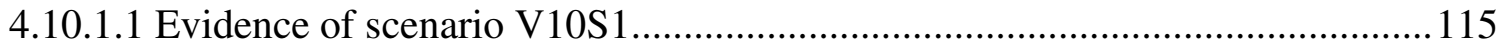

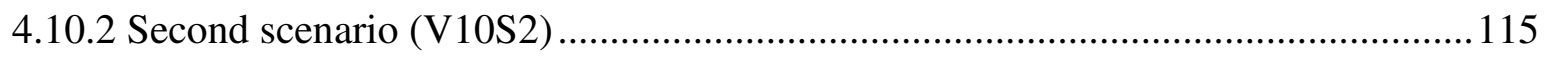

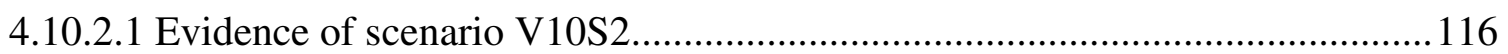

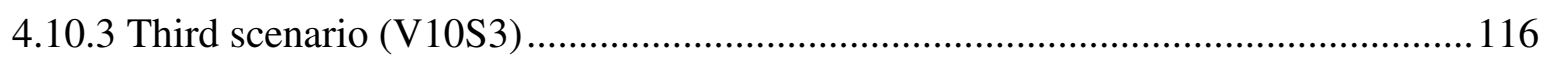

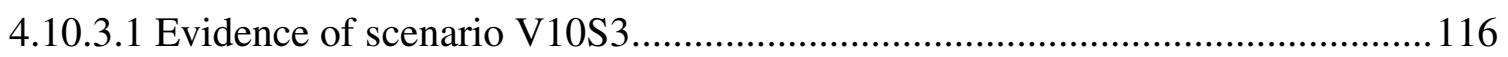

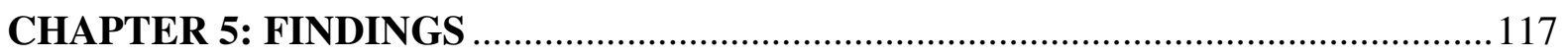

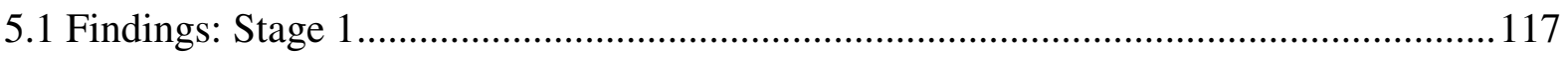

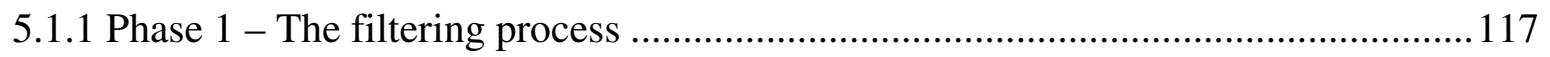

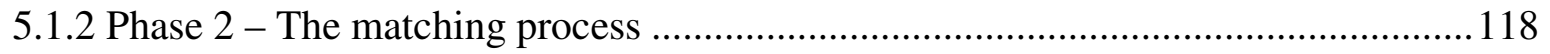

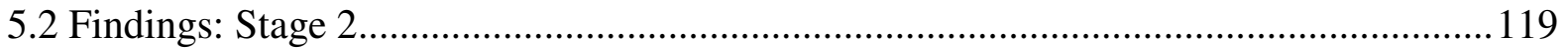

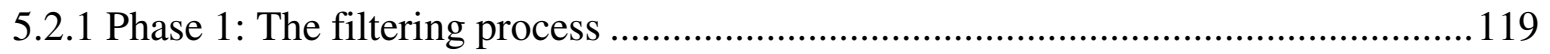

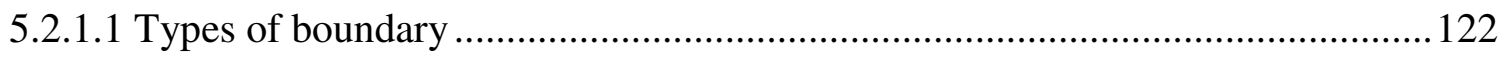

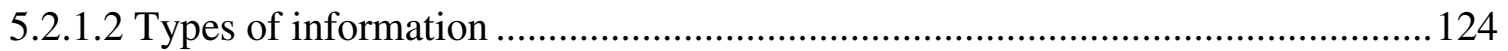

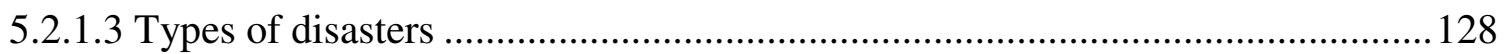

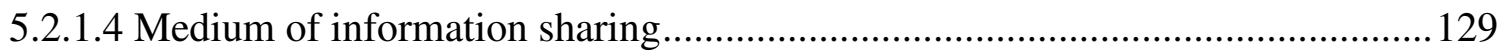

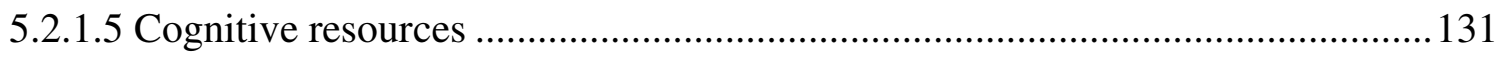

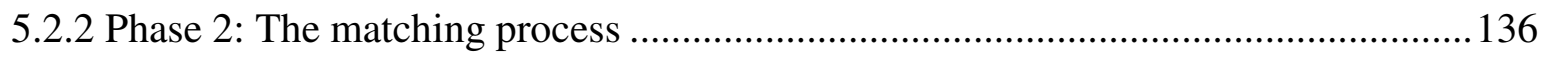

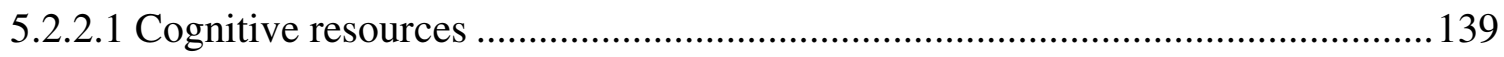

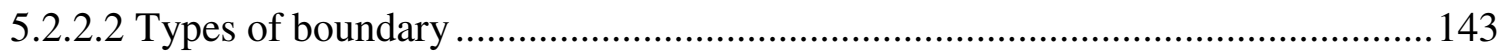

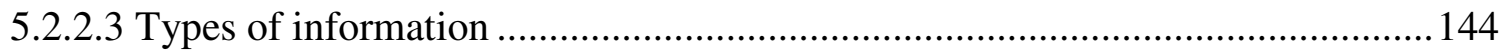


5.2.2.4 Types of disaster.

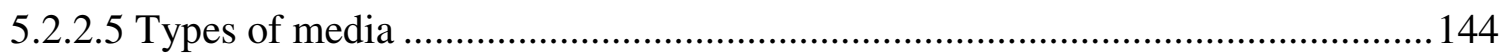

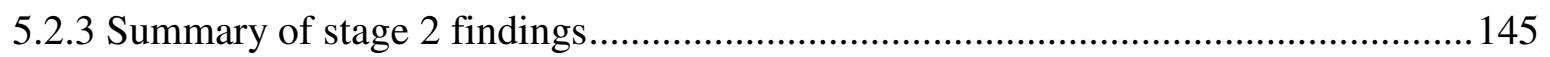

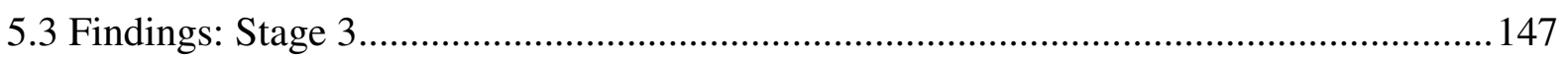

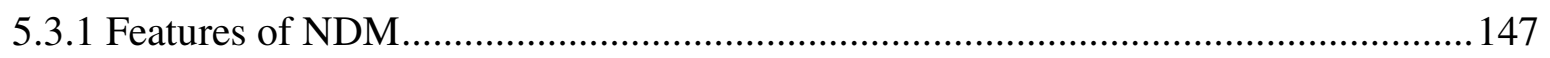

5.3.2 Tactics used for decision making in Phase 1 ....................................................... 150

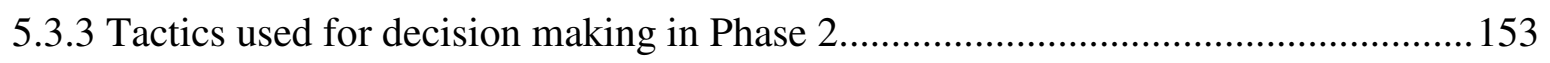

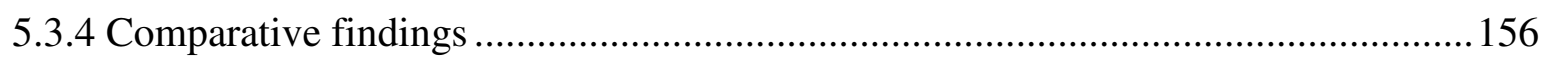

5.3.4.1 Comparison between tactics and types of boundary in Phase 1 .........................156

5.3.4.2 Comparison between tactics and types of information in Phase 1 ..................... 159

5.3.4.3 Comparison between tactics and types of disaster in Phase 1 ............................159

5.3.4.4 Comparison between tactics and types of boundary in Phase 2 ........................ 160

5.3.4.5 Comparison between tactics and types of information in Phase 2 ..................... 162

5.3.4.6 Comparison between tactics and types of disaster in Phase 2 ........................... 162

5.3.4.7 Comparison between tactics and type of boundaries used in combined Phase 1

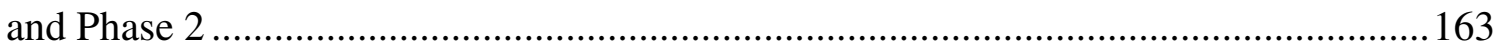

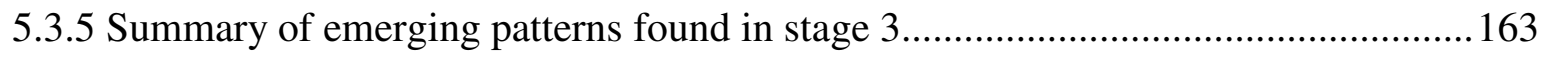

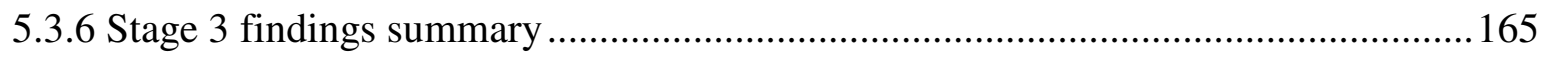

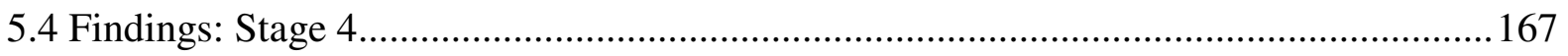

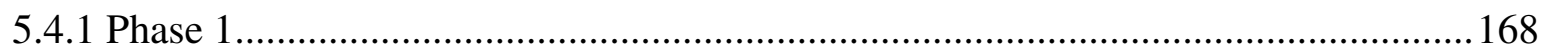

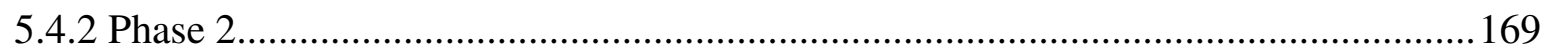

5.4.3 Theoretical model - Cross-boundary information sharing by KB during a disaster 170

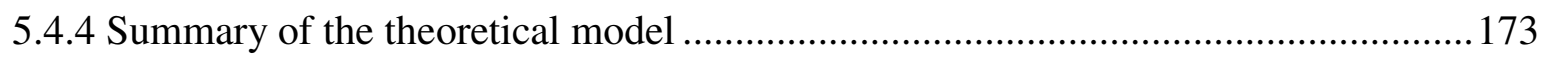

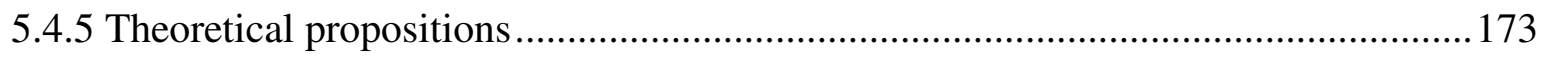

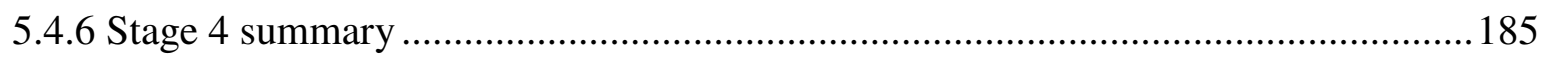

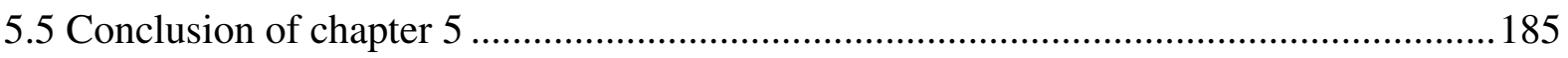

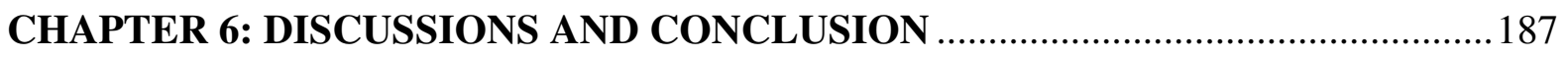

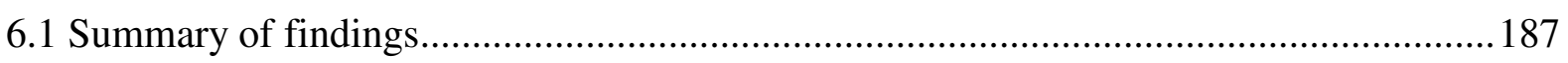

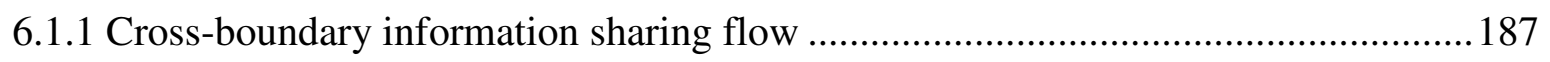

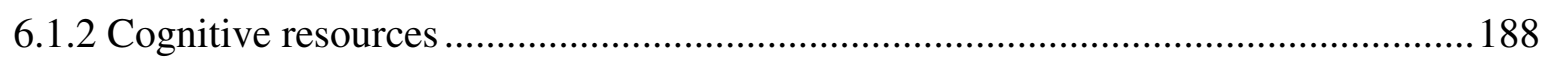

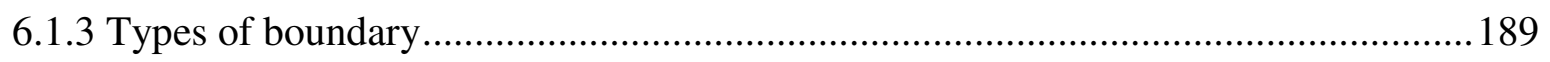

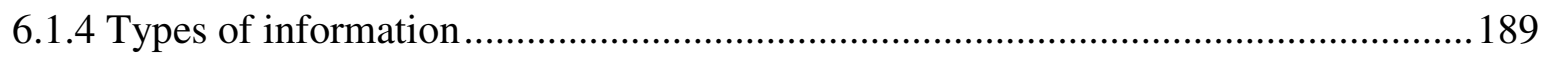

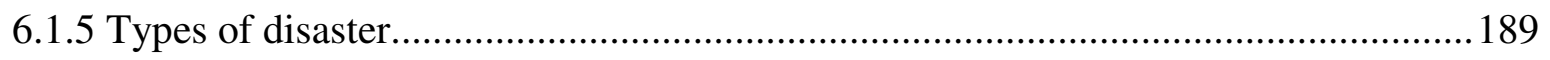

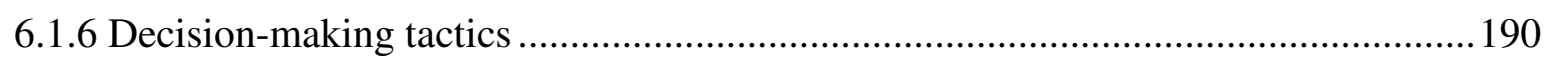




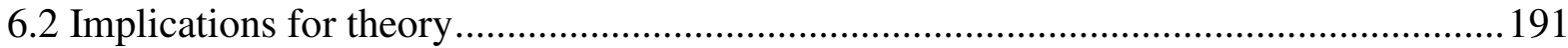

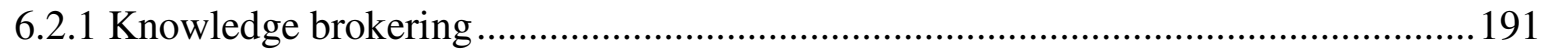

6.2.2 Disaster management ............................................................................................ 192

6.2.3 Naturalistic Decision Making (NDM) ....................................................................194

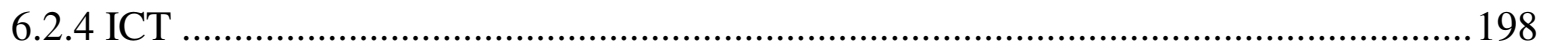

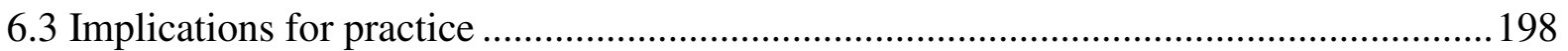

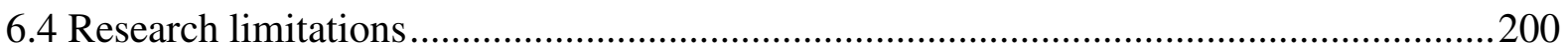

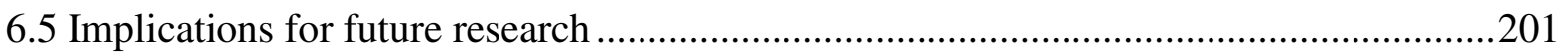

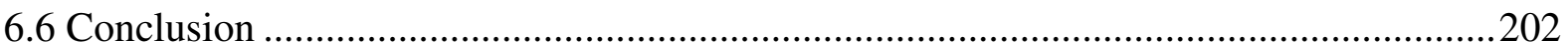

REFERENCES

Appendix A: SIM Human Ethics Committee approval

Appendix B: Participant information sheet

Appendix C: Participant consent form

Appendix D: Participant consent to the transcriber's involvement in research project

Appendix E: Interview protocols

Appendix F: Five levels of concept mapping

Appendix G: Combination and summary of findings in Phases 1 and 2 


\section{List of figures}

Figure 1: Summary of information flow through KB in Scenario 1 ........................................4

Figure 2: Summary of information flow through KB in Scenario 2 ......................................

Figure 3: The Recognition-Primed Decision (RPD) model................................................ 39

Figure 4: The Hourglass framework for the decision-making process (Adapted from Serfaty

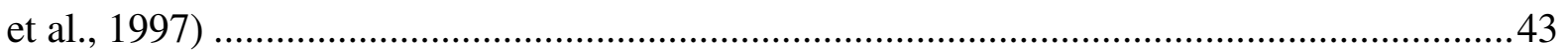

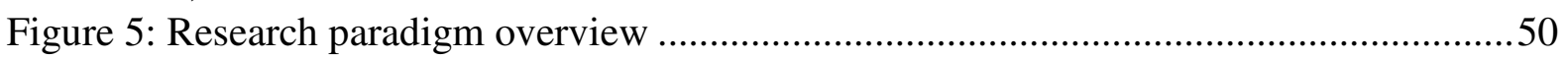

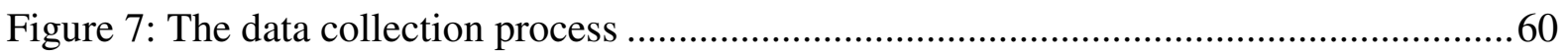

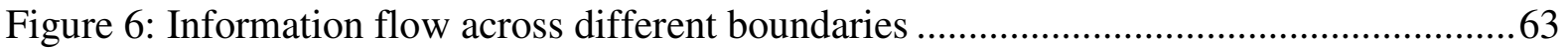

Figure 8: Components of data analysis (Source: Miles \& Huberman (1994) p. 12) ...............68

Figure 9: Components of data analysis, adapted from: Miles \& Huberman (1994, p. 10)......68

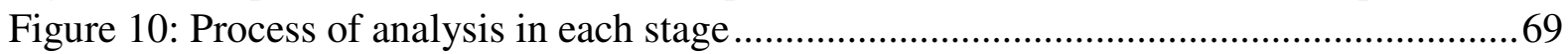

Figure 11: Inductive flow of theory generation (adapted from Creswell 2003, p. 132) ..........76

Figure 12: Locations of each disaster across New Zealand ...............................................93

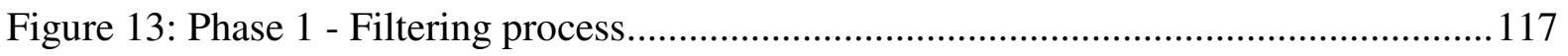

Figure 14: Phase 1 - Filtering process with evidence from V1S1 ....................................118

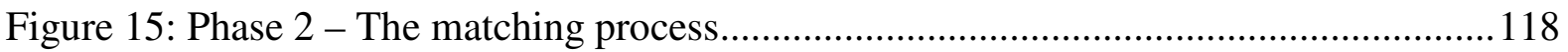

Figure 16: Phase 2 - Matching process with evidence from V1S1 .....................................119

Figure 17: Model of cross-boundary information sharing processes by KB during a disaster

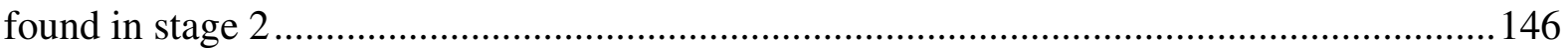

Figure 18: Decision-making process to identify the veracity of information using different

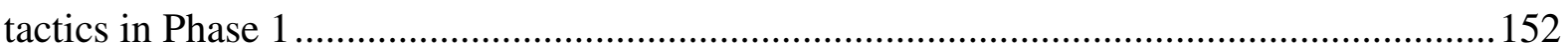

Figure 19: Decision-making process to identify the relevance of information using different

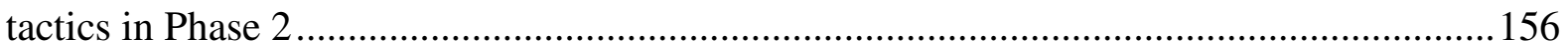

Figure 20: The process of cross-boundary information sharing by KB during a disaster in

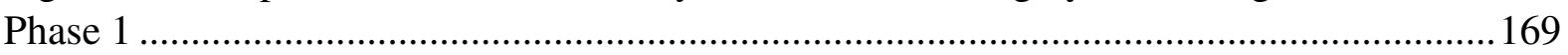

Figure 21: The process of cross-boundary information sharing by KB during a disaster in

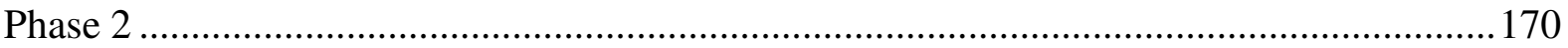

Figure 22: Theoretical model: Cross-boundary information sharing by KB during a disaster

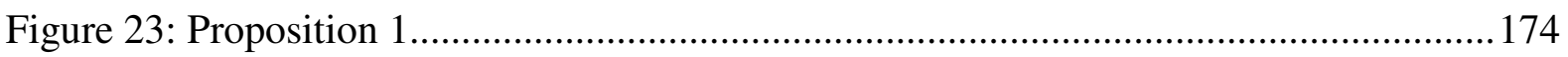

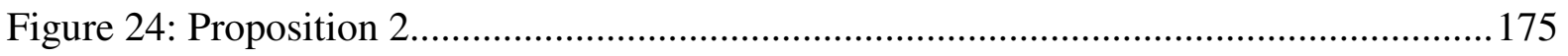

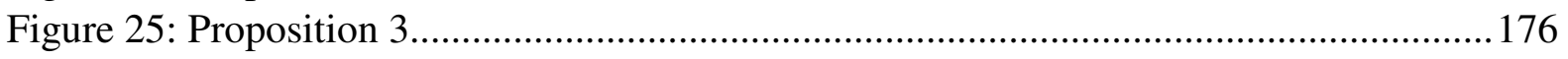

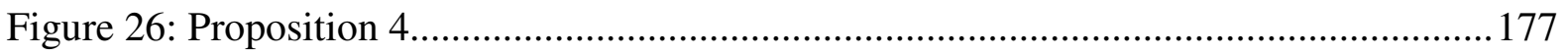

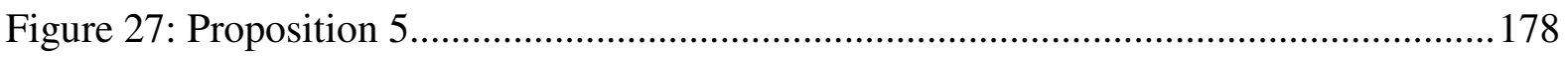

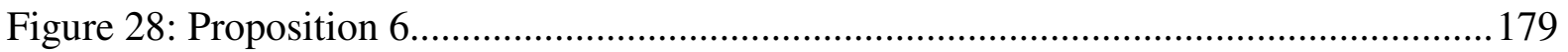

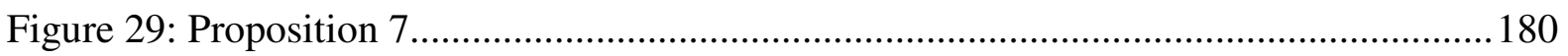

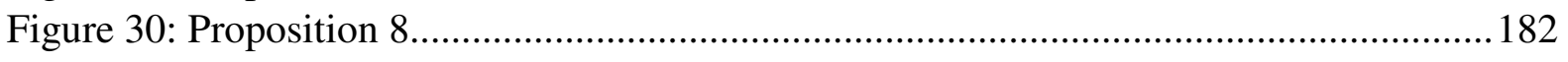

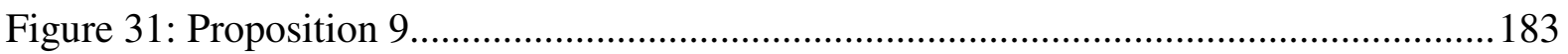

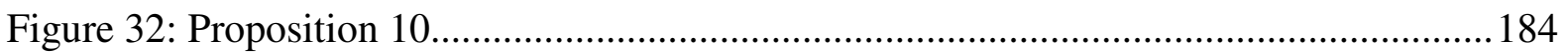

Figure 33: The Hourglass framework for the decision-making process, adapted from Serfaty

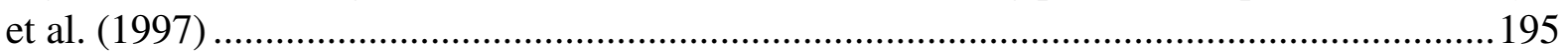

Figure 34: The Hourglass Framework for the decision-making process for Phase 1 ............ 196

Figure 35: The Hourglass Framework for the decision-making process for Phase 2 ............ 197 


\section{List of tables}

Table 1: Gatekeeper roles at each stage of cross-boundary information sharing (Adapted

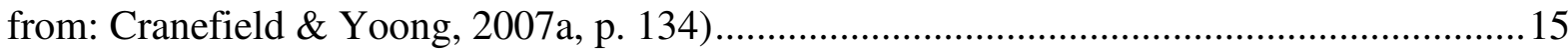

Table 2: Summary of the differences between a community of practice and team .................19

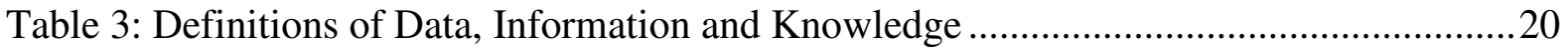

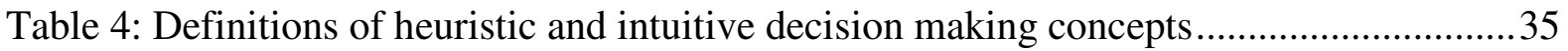

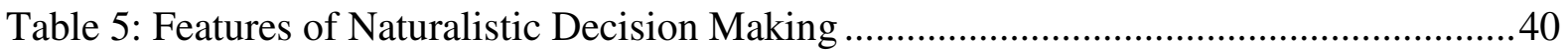

Table 6: Tactics used to cope with uncertainty (Adapted from Lipshitz \& Strauss, 1997).....45

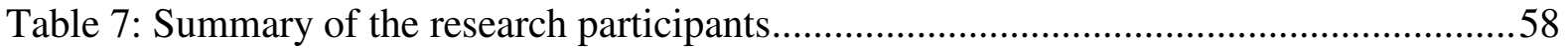

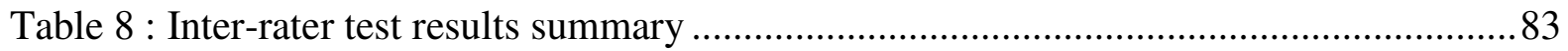

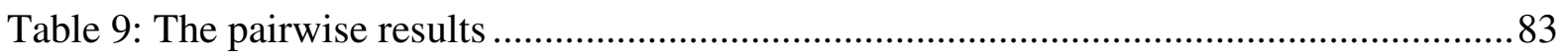

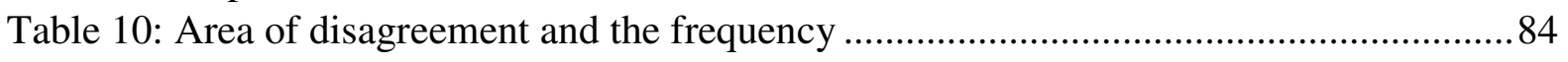

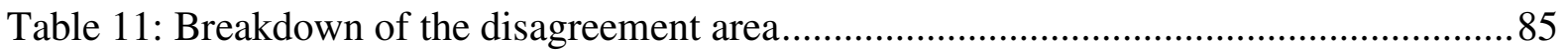

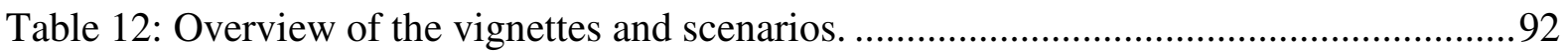

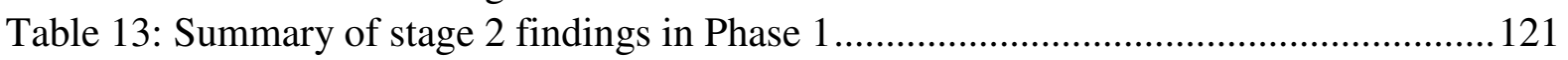

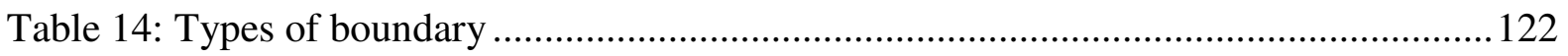

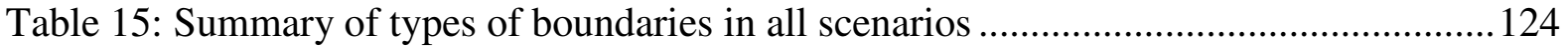

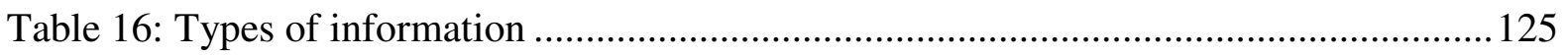

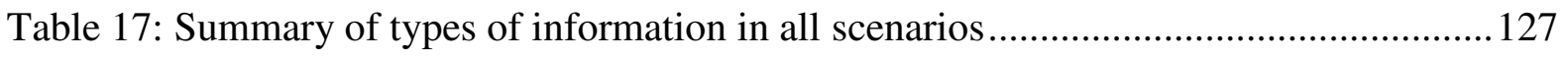

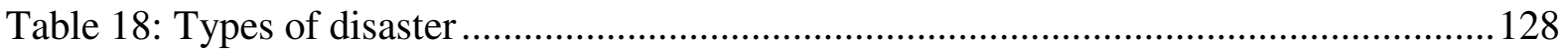

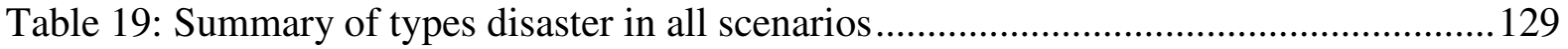

Table 20: Summary of information sharing media in all scenarios .....................................130

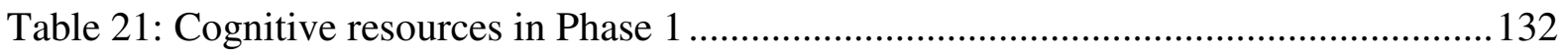

Table 22: Summary of cognitive resources in Phase 1 of all scenarios................................ 135

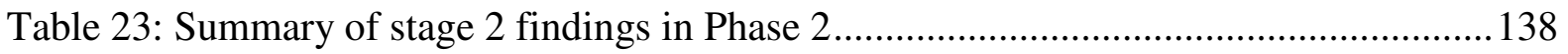

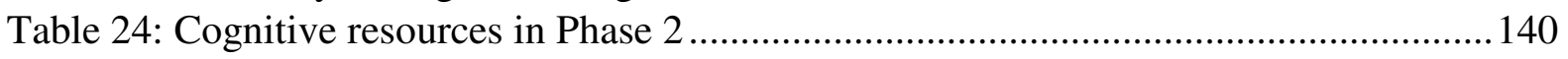

Table 25: Summary of cognitive resources in Phase 2 of all scenarios................................. 143

Table 26: Summary of NDM features in Phase 1 of all the scenarios ...................................148

Table 27: Summary of NDM features in Phase 2 of all the scenarios ...................................149

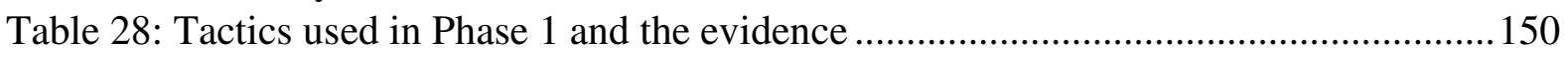

Table 29: Summary of tactics used to decide on the veracity of information in Phase 1 of all

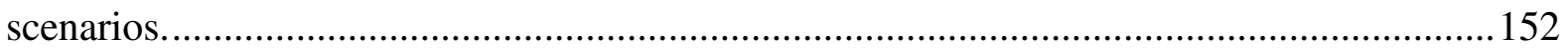

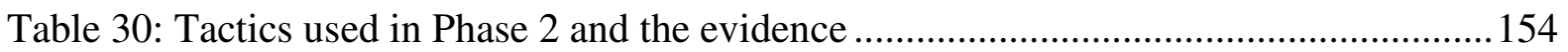

Table 31: Summary of tactics used to decide on the veracity of information in Phase 2 of all

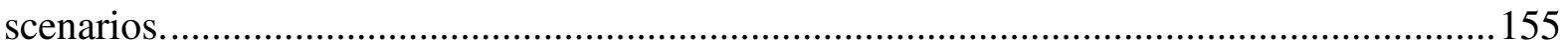

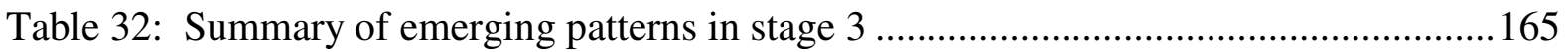

Table 33: Summary of findings and emerging patterns from Stages 1, 2 and 3.................. 167 


\section{CHAPTER 1: INTRODUCTION}

\subsection{Research motivation}

In recent years, many disasters and major incidents occurred around the world. For example, in the year 2015, there were 346 reported disasters with 22,773 people dead, 98.6 million people affected and US\$66.5 billion in economic damage (United Nations Office For Disaster Risk Reduction, 2016).

There are different types of disasters with different degrees of impact such as earthquakes, bombs, bush fires, other fires, pandemics, terrorism, floods, tsunamis and other severe weather events (Bunker, 2010; Ehnis \& Bunker, 2013). Despite the differences between the disasters in many aspects, an important issue is the coordination and information sharing among disaster agencies during their response. On a global level, the United Nations (UN), under its secretariat, the United Nations Office for Disaster Risk Reduction (UNISDR) has adopted the Sendai Framework for Disaster Risk Reduction 2015-2030 after the third UN World Conference on Disaster Risk Reduction held in Sendai, Japan (United Nations, 2015). The framework has four main priority areas to be focussed on across local, national, regional and global levels:

i) Priority 1: Understanding disaster risk;

ii) Priority 2: Strengthening disaster risk governance to manage disaster risk;

iii) Priority 3: Investing in disaster risk reduction for resilience; and

iv) Priority 4: Enhancing disaster preparedness for effective response and to "Build Back Better" in recovery, rehabilitation and reconstruction.

Interestingly, information sharing initiatives which include coordination among different agencies at different levels have been recommended for all of the priorities.

Coordination in disasters is "the way in which different agencies or parts of the same organization work or act together in order to achieve a common objective" (International Organization for Standardization, 2011). Information sharing in a disaster has been a central topic of discussion in major disasters locally and also globally since more than 10 years ago. 
It is important that information being shared is timely, relevant and accurate (Altay \& Pal, 2014).

Reports have shown that one of the factors that hinder prevention or mitigation of disasters such as 9/11 in the United States of America in 2001 is the failure to share information between the decision makers of various agencies (Kramer, 2005). In New Zealand, the report by the Royal Commission on the Pike River Coal Mine Tragedy (2012) shows that information was not being shared between agencies with regard to the safety issues in the company that operated the coal mine which resulted in a deadly explosion that killed 29 employees. These disasters have shown how the lack of information sharing and coordination among agencies has a major impact. As multiple-agency information sharing remains a central focus in disaster management, the people who manage the flow of information across different agencies are worthwhile studying and it is highly significant. These people, who receive and share information between different groups or agencies, are known as 'knowledge brokers' (KB) (Meyer, 2010).

To explain information sharing and knowledge brokers further, consider the following two scenarios:

\section{Scenario 1}

An 8.2 earthquake struck in Wellington. Many buildings were evacuated and public transport has stopped. No buildings collapsed. The public were panicking. The Emergency Services team were deployed to respond. In a residential apartment building in the CBD, the water tank located on the roof burst. Some of the residents were trapped inside their units. Some were injured due to falling down, falling items and shattered glass. The police, fire services, and ambulance arrived later.

Bob, who lives in one of the apartments, managed to get out from the building safely before the emergency services team arrived. Bob was unsure whether his disabled neighbour, Megan was trapped in the building. Bob tried to call Megan on her mobile but could not get through. The police was the first emergency service team to arrive at the location. Bob immediately shared this information about Megan who was potentially trapped in her unit with the police officer who just arrived. 
A few minutes later, the fire service team arrived and they set up a Critical Incident Unit vehicle which acted as a mobile emergency operation room at a safe nearby area to manage the search and rescue operation. The police officer who received the information from Bob about Megan then shared the information with the fire service officer and the ambulance staff who had just arrived. The fire service officer who received the information immediately shared the information with his chief who was in the Critical Incident Unit vehicle via radio. The fire service chief then instructed a few fire officers on the ground to search for Megan and he asked the ambulance to be on standby.

Later, the fire officers found Megan was trapped in the toilet of her unit and was badly injured. Megan was later rushed to the hospital by the ambulance.

\section{Scenario 2}

The City of Wellington Pipe Band (comprising 30 people) was about to land at Wellington Airport following a 3-week trip performing in some African countries. One of the passengers in the aeroplane who was not part of the marching band was a medical doctor (GP) who just returned from a vacation. Eight of the Pipe Band members in the aeroplane were really sick with flu-like symptoms and high fevers and the situation has been escalating. Before landing, the doctor told the air stewardess to let him inform the pilot about this. The doctor shared information with the pilot about a potential high risk of these symptoms given that there was a recent Ebola virus outbreak in Africa. The doctor shared the information with the pilot, suggesting that this could potentially be a quarantinable disease. The pilot then shared the information with the Wellington Airport control tower. The airport manager then shared the information with Regional Public Health and also Emergency Management to alert them. Regional Public Health then asked the NZ Army for the use of the Waiouru Army Airfield to re-route the aeroplane for landing away from the public and the NZ Army gave permission. Regional Public Health then shared this information with all emergency services organizations such as police, fire service, a non-governmental organization, the emergency management office and the ambulance to be prepared to handle the situation. All emergency services were notified and each of their communication units then disseminated the information to their relevant units to respond to the situation. 
These two scenarios illustrate the situation of information sharing by knowledge brokers $(\mathrm{KB})$ during a disaster. $\mathrm{KB}$ in my research are those who are experts in their field who receive information from a source and share them with a receiver.

Figure 1 illustrates the information flow by KB in Scenario 1.

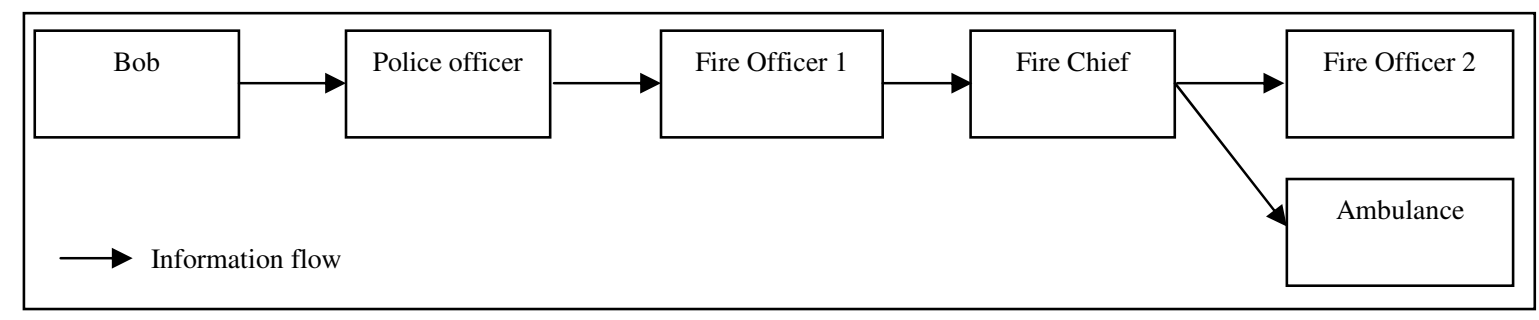

\section{Figure 1: Summary of information flow through KB in Scenario 1}

In scenario 1, the police officer, fire officer 1 and the fire chief had received information from a source and shared it with a receiver and thus they are the KB.

Figure 2 illustrates the information flow by KB in Scenario 2.

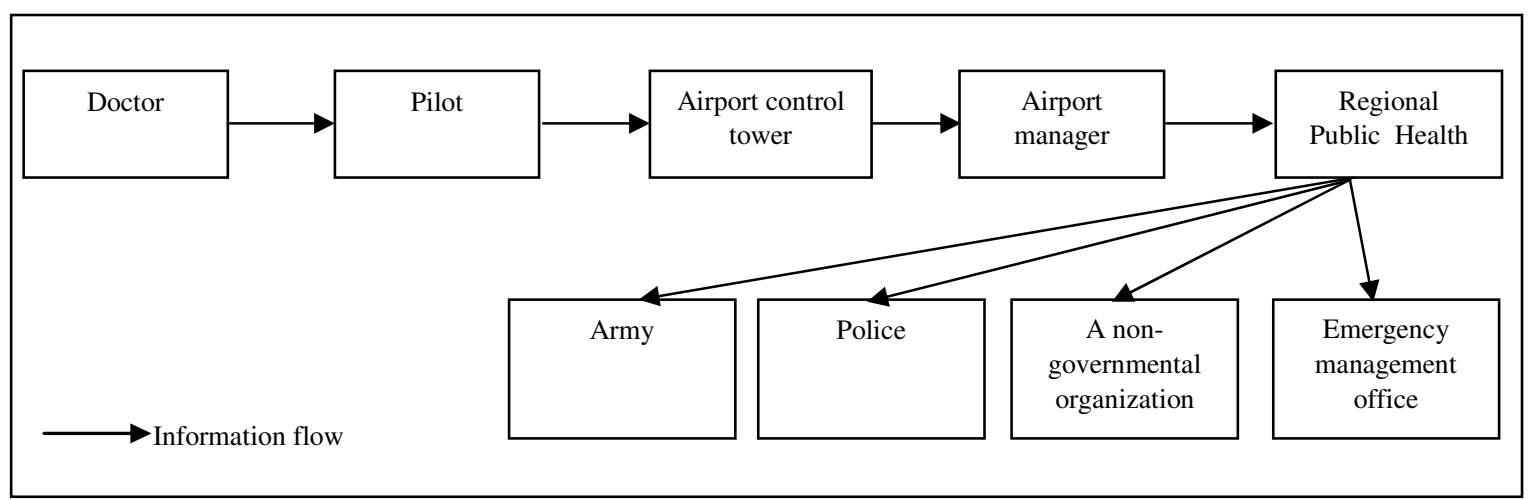

Figure 2: Summary of information flow through KB in Scenario 2

In scenario 2, the pilot, the airport control tower staff, the airport manager and the Regional Public Health staff had received information from a source and shared it with a receiver; therefore they are all $\mathrm{KB}$.

Based on the two scenarios, although the act of sharing information with another person is considered extremely important in a disaster, there is a lack of knowledge on the process of how KB assess and decide on the veracity and to whom the information they hold is relevant. This has led to a desire to explore these phenomena. 
The following are the problem statements which lead to the motivation for conducting this research.

\section{i) Poor understanding of knowledge broker activities during a disaster}

$\mathrm{KB}$ include individuals who might not gain any advantage from keeping the information to themselves. This is because the information is only relevant to the recipient and thus the knowledge broker's contribution lies in enhancing the sharing of information among members in the network (Fritsch \& Kauffeld-Monz, 2010; Meyer, 2010). Extensive studies have focused on KB in the business and innovation contexts. These studies suggest that the sharing of information across boundaries may result in growth acceleration, and higher profitability or lowering the costs of the organization (Ancona \& Caldwell, 1992; Guzzo \& Dickson, 1996). However, during a disaster, the activities of a KB and the outcome of the sharing of information are different and could potentially save lives or minimize the loss of life. In addition, the shared information might help others to make critical decisions. Therefore, the understanding of $\mathrm{KB}$ activities during a disaster is still unclear and is worth looking into.

\section{ii) Lack of evidence about the process of cross-boundary information sharing at individual level during a disaster}

There is extensive evidence on factors that facilitate or inhibit cross-boundary information sharing in a business context which could also be relevant to a disaster context. These include factors such as social identity (Gaertner, Dovidio, Anastasio, Bachman, \& Rust, 1993), motivation (Gupta, 2000), social ties (Easterby-Smith, Lyles, \& Tsang, 2008) and organization structure (Ghoshal, Korine, \& Szulanski, 1994). These factors can be useful to answer a 'why people share information' research question. There is still a lack of evidence about the process of information sharing which could assist in answering the how people share information' question that relates to a process.

There are also studies that describe the importance of cross-boundary information sharing during a disaster (Altay \& Pal, 2014; Baber, Cross, Smith, \& Robinson, 2007) but those studies are based on the organizational level rather than the individual level. Therefore, there is a need to look at cross-boundary information sharing at the individual level. 


\section{iii) The challenge of decision making in a disaster}

The study of decision-making theories has a very long history for example, the theory of decision making from 1954 (Edwards, 1954) and Behavioral Decision Theory (Edwards, 1961). However, these decision-making theories were based on a stable environment (Lipshitz, Klein, Orasanu, \& Salas, 2001). During a disaster, there are elements of uncertainty and time pressure which create instability. There are a few studies that centre around decision making during disasters, for example, Cosgrave (1996) argued that Vroom and Yetton (1973) normative decision-making model is cumbersome to apply in a disaster due to the procedures in the model. He found that people make decisions during a disaster depending on the characteristics of the problem such as low or high problem quality, urgent or non-urgent problem, and high or low need for acceptance of the problem. In order to make decisions quickly in highly urgent problem situations, decision makers need a pool of information. KB can play a role in contributing to this pool of information by managing the information available from different response agencies during a disaster. However, at the time when KB acquire information from a source from, there are possibility that they are unsure of the veracity of the information and to whom the information is relevant. Therefore, how KB make decisions during disasters is worthwhile to study.

\subsection{Research objectives and research questions}

This research addresses two research objectives (RO):

RO1: To explore and identify the process of how $\mathrm{KB}$ assess and decide the veracity of the information they receive from a source located across a boundary during a disaster.

RO2: To explore and identify the process of how $\mathrm{KB}$ assess and decide to whom the information is relevant across a boundary during a disaster.

To achieve these objectives, there are two research questions (RQ):

RQ1: How do $\mathrm{KB}$ assess and decide the veracity of the information they receive from a source located across a boundary during a disaster?

RQ2: How do $\mathrm{KB}$ assess and decide to whom the information is relevant across a boundary during a disaster? 
To understand and explore the objectives and address the two research questions, a qualitative case research was implemented and the multi-case research approach was used.

\subsection{Research methodology}

The aim of my research is to generate a theory explaining (Gregor, 2006) how KB assess and decide the veracity and relevance of the information they have across a boundary.

To generate the theory, I took an interpretivist stance as the research paradigm with a multiple case embedded research design. I adopted a face-to-face semi-structured interview approach for data collection. The theory was generated using an inductive flow of theory generation as suggested by Creswell (2003). The details of my methodology are explained in Chapter 3.

\subsection{Definitions and explanations of key terms}

A knowledge broker $(\mathrm{KB})$ is a person who worked in a disaster response or emergency service organization and has experience and involvement in any disaster response operation and is responsible for critically managing the information flow during disasters.

A boundary is an 'imaginary line of demarcation' that separates group members from those who are outside (Guzzo \& Dickson, 1996). The boundaries in my research include those 1) between organizations, 2) between units within organizations, 3) hierarchical boundaries between different levels of staff within an organization and 4) between an organization and the community.

Cross-boundary information sharing is when the information travels across boundaries such as unit, hierarchy, organization or community.

A disaster is an event "that may cause or contribute substantially to the cause of an emergency by negatively impacting on people, property or the environment" (Wellington Region Civil Defence Emergency Management, 2013). It has been noted that there have are no universally accepted definitions for disaster and crisis. "There is also no universally available criteria, to define the disaster in terms of the consequences, such as the casualties 
and the cost of damage" (Shaluf, Ahmadun, \& Mat Said, 2003). Recently, Mayner and Arbon (2015) found 128 different definitions of disaster: "There is, therefore, a need to better harmonise the definitions for many disaster terms, to build a more consolidated foundation for both research and practice". I have used the WREMO definition of a disaster (i.e. hazards) as it suits the context of my research and the participants.

'During a disaster' or the 'golden hour' is the time frame of the first 72 hours following a disaster because it is the most critical time period in a disaster (Lien, Chi, \& Huang, 2010).

\subsection{Delimitations}

There are three main foci in my research. First, the knowledge brokers are those who work with any emergency services organization and have experienced any disaster that has occurred. It does not cover KB who are from the public or the community.

Second, my research focuses on the process of how KB receive and share information and decide on the veracity and relevance of the information they have across boundaries. It does not aim to identify the factors that facilitate and inhibit the act of sharing the information. Although the factors were extensively discussed in the literature review chapter, that was done to give an in-depth understanding of 'why' people share the information before exploring the process (i.e. how) more deeply.

Third, the timing of information sharing activities in this research is only within the first 72 hours following the disaster, which are also called 'the golden hours'. It does not cover any information sharing activities beyond that time frame.

\subsection{Structure of the thesis}

Chapter 1 has defined the research motivation, research objectives and research questions, key terms and delimitations. 
Chapter 2 provides the literature review. Relevant studies from multiple domains are reviewed to explore what has been discussed and find the gap my research could fill.

Chapter 3 outlines the research methodology. The research paradigm is explained, and the selection of the multiple care research embedded design is justified. This chapter also includes the explanation of the research design, data collection and data analysis before ending with research issues.

Chapter 4 describes the cases. All ten cases collected from the interviews are described in separate vignettes. The KBs' 22 unique experiences in cross-boundary information sharing of different disasters are described in 22 scenarios. Evidence from the data is also presented. Chapter 5 provides the analysis and findings. The four-stage analysis and findings are described. The theory of cross-boundary information sharing and propositions are explained.

Chapter 6 concludes the thesis. The findings and answers to the two research questions are summarized. Implication for theory and practice are described, along with limitation and implications for future research. 


\section{CHAPTER 2: LITERATURE REVIEW}

This chapter presents, outlines and reviews the literature that is relevant to the context of this research exploring the cross-boundary information sharing activities by knowledge brokers (KB) during disasters. The selection of literature identifies the knowledge gap and creates a research space. This chapter is divided into four main sections.

The first section focuses on literature about $\mathrm{KB}$, their roles, the types of boundaries they broker information across, and types of information they handle. The second section discusses the background of cross-boundary information sharing and the relevant cognitive resources that $\mathrm{KB}$ refer to in handling the information they receive. The third section discusses the types of ICT used in relation to cross-boundary information sharing during disasters. The final section discusses decision- making concepts during disasters.

\subsection{Knowledge brokers}

Knowledge brokers $(\mathrm{KB})$ have attracted considerable interest in the literature (Cranefield, Yoong, \& Huff, 2011; Kauffeld-Monz \& Fritsch, 2013; Meyer, 2010). This type of broker is defined as an actor that facilitates the transfer of knowledge within a social network (Meyer, 2010). The social network members can consist of groups (Burt, 2004), units (Pawlowski \& Robey, 2004) and organizations (Fritsch \& Kauffeld-Monz, 2010; Lind \& Persborn, 2000).

These studies argue that KB play an important role in sharing information across their group boundaries. In the context of the impact on sharing information, KB might not gain any advantage from keeping the information to themselves because the information is only relevant to the recipient (Fritsch \& Kauffeld-Monz, 2010).

Burt (2004) explains that the negative space between members of a network who are not connected in any way except with a broker are called structural holes. He found that these unconnected members of the broker's network are likely to express ideas to the broker. In addition, he concludes that those who spanned through these structural holes are likely to express and discuss an idea and have the idea used by someone else. Therefore, KB might obtain good ideas or information from another member of a group and further, make it 
possible for the broker to share the information with a member of another group of which the broker is also a member.

As discussed above, many of the studies in knowledge brokering focus on employees as the $\mathrm{KB}$ in normal organizational settings involving business related information. Disaster situations have seldom been discussed in studies of KB (Altay \& Pal, 2014).

During a disaster, extensive information sharing flows between groups are required. KB might hold certain information that might be relevant to others. They also might share the information across their group boundary to members of different groups. These groups are those who are responsible for managing the situation. Some examples of the groups that might be involved during a disaster are police, fire services, ambulance and emergency offices. These groups may share information among them during a disaster for reasons such as collaborative decision making (Kapucu \& Garayev, 2011) or humanitarian operations (Altay \& Pal, 2014).

Many studies have explored the importance of inter-organization information sharing during emergency situations. Baber et al. (2007) for instance suggest the use of Geographical Information Systems (GIS) to make collaboration between agencies easier. Duffy, McMaster, Baber, and Houghton (2012) suggest the importance of having an ontology broker to analyze the information flow in communication channels during an emergency. Altay and Pal (2014) in their recent paper discuss knowledge brokering during humanitarian operations. They suggested that during disaster response operations, the existence of an information hub could make information diffusion faster. Schraagen, Veld, and De Koning (2010) examine the difference between hierarchical and network teams during emergencies in terms of information sharing.

While these studies discussed information sharing and knowledge brokering during disasters, they either focus on information systems as the KB (Baber et al., 2007; Duffy et al., 2012) or on knowledge brokering at the organizational level (Altay \& Pal, 2014; Schraagen et al., 2010). Although extensive research has been carried out at those levels, little attention has been given to $\mathrm{KB}$ at the individual level during disasters. These individual $\mathrm{KB}$ are the ones who critically manage the information flow during disasters. 


\subsubsection{The role of $\mathrm{KB}$}

KB play an important role in disasters to assist critical decision making by those who are outside the KB's group and involved in the same situation. For example, a person from an Emergency Management Office (EMO) could receive information from a railway worker that a nearby hospital is in need of a generator during a power outage following an earthquake. The person from the EMO is considered a KB as he obtains information from someone who is not a member of the EMO (i.e. the railway worker) and there is a possibility that the EMO person might pass it to a different person who is not a member of the EMO for the immediate supply of a generator (i.e. a generator supplier). In that situation, the EMO person is seen to be playing an important role to assist critical decision making by the supplier of the back-up generator.

Since there are very limited studies on KB roles during a disaster, I use studies from knowledge brokering in general to explore the roles of $\mathrm{KB}$. There are three possible roles of KB found in the literature: the boundary spanner, the gatekeeper and the filter. The following sections will explain each of these roles.

\subsubsection{The boundary spanner}

At the organizational level, a boundary spanner has been defined as performing "actions to establish linkages and manage interactions with parties in the external environment" (Marrone, 2010, p. 914).

From an innovation perspective, KB span boundaries and act as intermediaries (Howells, 2006) by linking those who are involved in the innovation process and those who are across boundaries such as market boundaries (Cillo, 2005) and industrial boundaries (Hargadon, 1998, 2002). In innovation, there is a need to cross boundaries to acquire extraordinary amounts of information and resources which may lead to generation of new ideas (Kanter, 1988). Brokers play an important role in innovation as they fit the boundary- crossing aspect of information sharing (Cillo, 2005; Kauffeld-Monz \& Fritsch, 2013).

Cillo (2005), for instance, describes KB who acquire relevant information from the market and supply it to the R\&D team. The study sample includes successful innovators in their 
respective industries: Barilla (food industry), Diesel (casual wear industry), Escada (fashion industry) and Tetra Pak (packaging industry). The study identified the role of KB who span across market boundaries in acquiring related information from the customers and then supplying this useful information to the R\& D unit for possible use in the process of innovation. Hargadon (1998) studies organizational KB such as consultants who serve clients from different industries. These $\mathrm{KB}$ engaged in a few activities that cross a variety of industries. The activities include accessing and learning the relevant information and linking it to the relevant industry.

From a disaster management perspective, it is crucial for $\mathrm{KB}$ to be boundary spanners to influence the cross-boundary information sharing with different agencies (Janssen, Lee, Bharosa, \& Cresswell, 2010). Recently, Curnin, Owen, and Trist (2014) found that KB play a boundary spanning role as representatives, communicators, networkers, legitimate enablers, information conduits, information analysts, resource coordinators, organizational experts and domain experts. These studies highlight the importance of the role during disasters.

While the literature has focused heavily on this role of $\mathrm{KB}$ in the context of information sharing across boundaries for organizational innovation purposes (Cillo, 2005; Howells, 2006; Kauffeld-Monz \& Fritsch, 2013), the role of boundary spanner can be seen as similar in disasters. This is because in disasters, although the nature of the information is different than in innovation, KB span boundaries and act as intermediaries by establishing linkages and managing interactions with different disaster agencies' members.

\subsubsection{The gatekeeper}

Gatekeepers are able to gather information from outside the organization and disseminate it within its borders and act as the knowledge interface of the boundaries (T. J. Allen, 1970; Cranefield \& Yoong, 2007a).

Cranefield and Yoong (2005) develop a six-stage model that is relevant to the cross-boundary information sharing context. Although the study focuses on inter-organizational knowledge transfer, the concept of cross-boundary information sharing is relevant where organizations can also be seen as having boundaries. The model identified six stages of cross-boundary 
information sharing: engaging, defining, seeking, articulating, integrating and disseminating. Following that study, the authors used the same model in identifying the role of gatekeepers in the context of cross-boundary information sharing (Cranefield \& Yoong, 2007a).

Cranefield and Yoong (2007a) found that gatekeepers perform multiple roles. Each role varies at each stage of the process. The roles that have been identified are: flag-bearer, advocate, translator, scout, facilitator, storyteller and expert. These roles are also predominantly performed at different stage of the sharing process. Table 1 summarizes gatekeeper roles in each stages of information sharing:

\begin{tabular}{|c|c|c|c|c|c|c|c|}
\hline Stage $\backslash$ Role & $\begin{array}{l}\text { Flag- } \\
\text { bearer }\end{array}$ & Advocate & $\begin{array}{c}\text { Translator } \\
\& \\
\text { Interpreter }\end{array}$ & Scout & Facilitator & Expert & Storyteller \\
\hline Engaging & $\mathrm{X}$ & $\mathrm{X}$ & & & & & \\
\hline Defining & & $\mathrm{X}$ & $\mathrm{X}$ & & $\mathrm{X}$ & & \\
\hline Seeking & $\mathrm{X}$ & $\mathrm{X}$ & $\mathrm{X}$ & $\mathrm{X}$ & $\mathrm{X}$ & & \\
\hline Articulating & & & $\mathrm{X}$ & & $\mathrm{X}$ & & \\
\hline Integrating & & & $\mathrm{X}$ & & $\mathrm{X}$ & $\mathrm{X}$ & \\
\hline Disseminating & & & & & & $\mathrm{X}$ & $\mathrm{X}$ \\
\hline
\end{tabular}

Table 1: Gatekeeper roles at each stage of cross-boundary information sharing (Adapted from: Cranefield \& Yoong, 2007a, p. 134)

In support, there are similar studies that focus on the roles of $\mathrm{KB}$ as gatekeepers. These include the role of translator and interpreter (Cranefield \& Yoong, 2007b), facilitator, advocate and expert (Kauffeld-Monz \& Fritsch, 2013; Pawlowski \& Robey, 2004), flagbearer and scout (Ancona \& Caldwell, 1992).

These studies, however, have defined KB as those who receive information from across their group's boundaries and share them within their group's boundary and in a stable environment. During an unstable environment (i.e. disaster), KB not only share the information they receive within their own group's boundary, but also across different boundaries which could affect the role of a gatekeeper. In support, A. L. Hughes and Palen (2012) argue that the Public Information Officer's (also seen as the KB) role has recently shifted from being the gate keeper to the translator, who is able to transform the information they received into another understandable format, in the presence of social media to those 
who are across their group's boundary such as the community and the other emergency service response teams.

\subsubsection{The filter}

This role occurs when KB have received information from someone across their group's boundary and then filter the information to decide on the veracity of the information before sharing it with others. Altay and Pal (2014) suggest that an information centre or information hub (which can be related to $\mathrm{KB}$ in my research) may act as a filter of incoming and outgoing information during humanitarian operations. They suggest that the information hub role "not only passes relevant information to agencies but also checks its reliability" (Altay \& Pal, 2014, p. 1018). The filtering role is important during disasters to support decision makers from across the organizational boundaries as these decision makers require accurate information to make good decisions and this can be supported by supplying them with filtered information (Kapucu \& Garayev, 2011) besides having a good understanding of the current situation (Zhang, Zhou, \& Nunamaker Jr, 2002).

However, it is also critical to acknowledge that during disasters, the stress factor should also be considered (Kowalski-Trakofler, Vaught, \& Scharf, 2003). This may affect the decisions of $\mathrm{KB}$ in identifying the validity of information they received while performing the role of filter. Kowalski-Trakofler et al. (2003) found that people who are under stress during disasters "frequently fail to gather the right kinds of information which prevents them from making appropriate responses" (p. 6). In addition, Kontogiannis and Kossiavelou (1999) suggest that stress reduces the capacity of working memory and causes premature closure in evaluating alternative options. This supports the argument that under certain degrees of stress, KB might fail to act as filters. Bharosa, Lee, and Janssen (2010) identify that some of the challenges of information sharing in disasters include information overload and the inability to determine what should be shared. These two factors support the proposition that KB might be unable to determine the type of information they received during disasters and further may affect the role of filtering.

To summarize, in order to explore the individual level of knowledge brokering during disasters, it is important to understand the three basic roles that they might be playing: the 
boundary spanner, the gatekeeper and the filter. The next section presents the boundaries literature.

\subsubsection{Types of boundaries}

"Boundaries at least partly define how a group needs to operate within its context to be effective" (Sundstrom, De Meuse, \& Futrell, 1990, p. 121). This research adopts the definition of boundary as an 'imaginary line of demarcation' that separates members from those who are outside (Guzzo \& Dickson, 1996). Many studies have discussed and identified the different boundaries of information sharing. These include team boundaries (Ancona \& Caldwell, 1992; Owen et al., 2013), organizational and group boundaries (Curnin \& Owen, 2014; Kapucu, 2012; Sundstrom et al., 1990) and community of practice boundaries (Redshaw, Ingham, \& Loftus, 2015; Wenger, 2005). In addition, there are also different boundaries that can be found in the literature and are relevant to the context of information sharing such as social or cultural boundaries (Abou-Zeid, 2005; Dawes, Gharawi, \& Burke, 2012) and legal boundaries (Pardo \& Burke, 2008).

The terms 'team' and 'group' have been used interchangeably in the literature (Ancona \& Caldwell, 1992; J. N. Choi, Sung, \& Kim, 2010; Guzzo \& Dickson, 1996). This may lead to the assumption that the difference between them is subtle. However, there is still a line to be drawn between the two.

There are a few studies in the literature which compare the characteristics of group, team and community of practice boundaries. Katzenbach and Smith (1993) compare team and group boundaries. McDermott (1999) compares teams and communities of practice and Gilley and Kerno (2010) compare all three (i.e. groups, teams and communities of practice). Before discussing the differences among the three, the following paragraphs describe each of them.

A team is made up of multiple individuals who are linked to each other and committed to a common purpose (Espinosa, Cummings, Wilson, \& Pearce, 2003; Gilley \& Kerno, 2010; Katzenbach \& Smith, 1993). There are many types of teams in an organization. A conceptual paper by Hollenbeck, Beersma, and Schouten (2012) lists and defines 42 team types which are identified in the organizational science domain. They suggest that these teams can be 
categorized based on constructs such as skill differentiation, authority differentiation and temporal stability. The types of teams that they listed include decision- making teams, adhoc teams, autonomous work teams and short- term teams. In addition, there are also hierarchical teams and network teams (Schraagen et al., 2010).

A group is a "collection of people who perform similar or complementary tasks as individuals" (Gilley \& Kerno, 2010, p. 47). A paper by Katzenbach and Smith (1993) identifies a few characteristics that differentiate teams and groups. They suggest that in a team, members may jointly contribute to produce a collective work product and have mutual accountability. In contrast, group members may share information to make decisions that help each member perform individual tasks better and members of the group have individual accountability.

A community of practice is a group of people who communicate and share information about common interests regularly; the main activities of the members are mostly knowledge sharing and learning and there is a connectedness between its members (Gilley \& Kerno, 2010; Wenger, 1998, 2005). This type of group has attracted growing interest in the literature (Cranefield \& Yoong, 2010; Cranefield et al., 2011). There are a few characteristic differences between communities of practice and teams. McDermott (1999) compares the studies by Wenger (1998) and Katzenbach and Smith (1993), to examine the characteristics of communities of practice and teams.

Gilley and Kerno (2010) in their conceptual paper compare the characteristics of groups, teams and communities of practice. From a human resource development perspective, they suggested that the characteristic difference is the degree of the management's versus the members' ability to influence or control direction. Groups have the highest management influence but the lowest members' influence. Teams fall in the middle of the intersection of both management's and members' ability to influence. Lastly, communities of practice have the lowest management influence but highest members' ability to influence. This comparative paper has opened the possibility of exploring the boundaries of these types of groups in connection with information and knowledge sharing across each of their boundaries. Table 2 summarizes the differences between communities of practice and teams: 


\begin{tabular}{|l|l|l|}
\hline \multirow{2}{*}{ Characteristics } & \multicolumn{2}{c|}{ Community of Practice } \\
\hline Driven by: & Shared interest & \multicolumn{1}{c|}{ Team } \\
\hline Boundaries: & Permeable & Clear \\
\hline Lead by: & Coordinator & Head/leader/manager \\
\hline Develops through: & Making connections & Objectives \& work plans \\
\hline Based on: & Trust & Agreement \\
\hline
\end{tabular}

Table 2: Summary of the differences between a community of practice and team

Based on the literature discussed, teams, groups and communities of practice can be seen as groups of people who are connected to each other (in a network) and have the capability and the possibility of sharing information to achieve certain goals. The difference between them includes how members are managed and the structure.

The boundaries in information sharing might not only involve a collective of people, but can also be knowledge boundaries. Carlile (2004) identifies three boundaries of knowledge sharing which were further supported by Kotlarsky, Hooff, and Huysman (2009). The three boundaries are pragmatic, semantic and syntactic. During a disaster, all three knowledge boundaries are possible. First, pragmatic boundaries relate to the political boundaries between the members of the group or the boundaries of interest. These can be seen as structural boundaries where each unit has different characteristics such as their mission and nature of operation. Second, semantic boundaries relate to the group members' interpretation or translation of the information that they have into common meanings that can be accepted by recipients across the boundary. This concerns how a member of a group is able to communicate and be understood by a recipient in another group. Finally, syntactic boundaries involve different groups using different terms in their daily operations and practice.

In a disaster, information travels across different boundaries: within an organization such as units, departments or hierarchy (Schraagen et al., 2010); across organizations such as different emergency response agencies (Bharosa et al., 2010); and from organization to community and from community to organization (Quarantelli, 1988). 
Schraagen et al. (2010) compare hierarchical and network teams during a disaster in terms of information sharing. They find that more information is shared it travels faster, and is more accurate in a networked team as compared to hierarchical teams in a disaster. Bharosa et al. (2010) study information sharing across multiple agencies during a disaster. They identify factors that affect the efficiency of inter-organizational information sharing at different levels such as the community level (e.g. structures and procedures), agency level (e.g. norms of information sharing and knowledge about other organizations' operations) and individual level (e.g. job responsibilities). Quarantelli (1988) identifies that information sharing between the community and the organizations involved in a disaster has often been done poorly. This is because organizations fail to understand what information the community needs and what it does not.

These studies support that information travels across different types of boundaries during a disaster.

\subsubsection{Types of information}

Many studies have discussed the differences between data, information and knowledge. Rowley (2007) and Stenmark (2002) have compiled an extensive comparison of different definitions from many scholars such as Nonaka and Takeuchi (1995), Choo (1996), Davenport and Prusak (1998), Wiig (1993) and Ackoff (1989). This is summarized in Table 3.

\begin{tabular}{|l|l|}
\hline Type & Definition \\
\hline Data & Have no meaning, are unorganized and unprocessed \\
\hline Information & $\begin{array}{l}\text { Organized data which have been interpreted, understood and given meaning } \\
\text { by the recipient }\end{array}$ \\
\hline Knowledge & $\begin{array}{l}\text { The synthesis of multiple sources of information over time with } \\
\text { understanding and capability of human minds }\end{array}$ \\
\hline
\end{tabular}

Table 3: Definitions of Data, Information and Knowledge

Using this definition of information - organized data which have been interpreted, understood and given meaning by the recipient (Rowley, 2007; Stenmark, 2002) - many information sharing studies have looked into the types of information. In organizational 
contexts, information types such as procedural (i.e. know-how) information (e.g. industrial design), declarative information (e.g. financial statements), marketing information and technical information have long been discussed in the literature (Gupta, 2000; Holm \& Sharma, 2006; von Hippel, 1994).

In disasters, the literature discusses the nature of information as types of information. Liu, Burton-Jones, and Xu (2013) for example explained the importance of categorizing the types of information in disasters when sharing the information using social media. Karlova and Fisher (2013) mention that many studies on information sharing during disasters assumed that information is always true, accurate and complete and they suggested looking into the understudied areas of misinformation.

Misinformation is defined as false information (Karlova \& Fisher, 2013; Liu et al., 2013; Loftus \& Hoffman, 1989). Karlova and Fisher (2013) analyze Twitter accounts in two events: the Fukushima nuclear radiation leak, and when Germany asked all European countries to follow their fiscal policy. Liu et al. (2013) analyze Twitter information during the Boston marathon bombing. This shows that studying misinformation is relatively new in the area of disaster management. In contrast, misinformation has long been discussed in other domains. Loftus and Hoffman (1989) study how misinformation has an effect on human memory. The IS domain had very little interest in misinformation studies until Appan and Browne (2012) build and test the theory of a 'misinformation effect'. In their study, a misinformation effect correlates with the false information that affects the accuracy of requirements gathered for organizational systems.

Another type of information that may arise during emergency situations is rumour which can be described as unsubstantiated but relatively relevant information (Liu et al., 2013; Marett \& Joshi, 2009; Rosnow, 1991). In the psychology domain, Rosnow (1991) defines that rumours are a type of information that deals with uncertainty. In the IS domain, not many studies discussed rumours until Marett and Joshi (2009) found that motivational rewards such as reputation and status building in online communities are the motivating factors of sharing rumours online. However, their study was based on a stable online discussion. In the disaster context, Oh, Agrawal, and Rao (2013) extend the traditional rumour theory to the social media context. They found that source ambiguity and personal involvement play an important role in sharing rumours during disasters. In a recent study, Liu, Burton-Jones, and Xu (2014) 
extend the study of Oh et al. (2013). They looked at the re-sharing of rumours (i.e. the second level of sharing) during disasters and found that the re-sharing of rumours relied on the sender's credibility and the attractiveness of the rumour content. Therefore, based on these studies, rumours are one of the types of information available during disasters.

Besides misinformation and rumours which mostly apply to information sharing in the community, there were also two other types of information during disasters specifically that were circulated among emergency services responders: incident notification and resource request. Iannella and Henricksen (2007) analyze the prototypical Crisis Information Management System to address the challenges of the system's incident notifications and resource requests. Their study on these types of information has been supported by other studies (Padilha, Borges, Gomes, \& Canós, 2010; Rohde, Weber, \& Wietfeld, 2010). Based on these studies, incident notifications and resource requests during disasters are the other types of information.

In summary, the literature in the disaster context has discussed misinformation, rumours, incident notifications and resource requests as some of the types of information available.

\subsection{Cross-boundary information sharing}

During a disaster, there is the need to go across the normal line of communication or information sharing protocols. The need to reduce bureaucracy arises in disasters as different decision makers will have to make decisions quickly. This means that the speed and accuracy of gathered information is critical. Bharosa et al. (2010) found that during disasters, individuals are aware of the importance of sharing information but often face challenges such as system usability, organizational norms and the emotional rewards that inhibit the intention to share information. Mendonça, Jefferson, and Harrald (2007) suggest that during a disaster, the line of communication should be more of an 'adhocracy' than bureaucracy. This is to make sure the information is being shared and reaches its target faster.

When KB receive the information from a source across their group's boundary, they have to decide on the veracity of the information. Although trust plays an important role in information sharing during disasters (Janssen et al., 2010), the factors that lead to trust need 
to be explored. Even if $\mathrm{KB}$ trust the information they received, sometimes KB will then pass the information to someone else. In this situation, KB "in one organization (e.g. fire brigade) decide what is relevant for another organization (e.g. police) without knowing enough to be able to decide whether or not the other organization really needs the information" (Bharosa et al., 2010, p. 62). Therefore, in order for KB to decide on the veracity of the information they receive and to whom the information is highly relevant, a reference to cognitive resources might be useful.

\subsubsection{Cognitive resources}

Cognitive resources in my research comprise a person's memory and intelligence based on experience. KBs' cognitive resources are essential to assist with the processing of information that they received and share across different boundaries during disasters. Their cognitive resources make sense of the information they receive to give meaning to the information before sharing it with others (Orton \& Weick, 1990). Furthermore, inadequate cognitive resources may affect decision making (Khalid, Helander, \& Hood, 2013). Bharosa et al. (2010) found that KB do not have enough time and cognitive resources to absorb and process information that they receive during a disaster.

Fiedler and Garcia (1987) develop the cognitive resources theory. The theory focuses on leaders' intelligence and their experience in performing under a certain level of stress. They propose that intelligent leaders would make more effective plans and strategies. Furthermore, the theory suggests that intelligence works better in a less stressful situation. In a more stressful situation, previous experience is more useful than intelligence (Fiedler, 2001).

There are different factors that lead to an increase of a person's cognitive resources. These are discussed in the following paragraphs.

\subsubsection{Set of rules}

In information sharing contexts, a set of rules or procedures may influence information sharing across boundaries. A seminal study on information sharing by Constant, Kiesler, and Sproull (1994, p. 418), for instance, stated "to encourage sharing of work information, 
organizations need a clear policy”. Morrison and Milliken (2000), in their conceptual study, identify organizational policy as one of the dynamics or factors that may influence the climate of information sharing. This has been supported by Bouquet and Birkinshaw (2008) in their study on multinational organizations as they found that a parent company plays an important role in determining a good policy which encourages different units to share information across boundaries.

In governmental organizations, the issue of inter-organization information sharing policy is relatively important. "Information sharing policies should help create an environment in which sharing is an effective, legitimate activity of public agencies" (Dawes, 1996, p. 392). In a disaster, governmental agencies are recommended to adhere to the standard operating procedures (SOP) to avoid mistakes. Groenendaal, Helsloot, and Scholtens (2013) suggest that the frontline unit activities within and across boundaries must be aligned and controlled which can be seen as following a certain set of rules. Similarly, Schneider (1992) also suggests that governmental agencies need to follow standard operating procedures during disasters.

The importance and impact of organizational policy on cross-boundary information sharing has been examined not only in governmental organizations but also in other organizations such as academic institutions (Haeussler, 2011) and businesses (Santangelo, 2012). This has demonstrated that organizational policy somehow plays an important role in influencing the cross-boundary information sharing.

Policies on information sharing across hierarchical boundaries have been discussed extensively in the literature and are seen to have an impact on the employees' willingness to share information (Milliken, Morrison, \& Hewlin, 2003; Morrison \& Milliken, 2000). If the organization's policy and practice are perceived to be supportive of sharing information, it can contribute to positive sharing behavior (Bartol \& Srivastava, 2002). However, if the organizational policy on information sharing is perceived to be unsupportive, employees might withhold the information, also known as 'employee silence'. Milliken et al. (2003) for example, in their 'model of choice to remain silent' suggest that unsupportive organizational policies contribute to employee silence. Similarly, Morrison and Milliken (2000), in their conceptual paper, argue that unsupportive organizational practice might be one of the contributors to employee silence affecting poor decision making. 
These studies support the idea that organizational policies might be a contributor to information sharing across hierarchical boundaries. However, whether the organizational policy is supportive or unsupportive, there may be other factors that influence the information sharing behavior as concluded by Saunders, Sheppard, Knight, and Roth (1992, p. 256): "simply instructing employees to discuss their concerns with their supervisors is no guarantee that organizations will receive employee input". The term 'instructing' represents policy and procedures and therefore, fits with other studies that have been discussed above.

In summary, the set of rules is one of the KB's cognitive resources in the process of deciding the veracity and relevance of the information they hold.

\subsubsection{Source's credibility}

In the process of receiving the information, the credibility of the information source plays an important role (Mayhorn \& McLaughlin, 2014; Peters, 1992; Pornpitakpan, 2004). "When an individual first encounters [information about a disaster] warning, he or she judges the credibility of the source" (Mayhorn \& McLaughlin, 2014, p. 44). In the business context, Pornpitakpan (2004) reviews 50 years of studies on the credibility of the source, arguing that highly credible sources have more impact than less credible sources. If $\mathrm{KB}$ receive information from a less credible source, they will tend to seek additional information from different sources. This is also seen as triangulating the information (see further discussion in the following subsection).

There are different factors that relates to a source's credibility. In a classic study, Whitehead Jr (1968) suggests that anyone who meets the criteria of being a professional, experienced and authoritative person might have higher source credibility than those who do not. However, there is a possibility that during a disaster, the ability to assess credibility of the source may be diminished by panic, leading people to assume all information is correct at that time. 


\subsubsection{Information triangulation}

As suggested by Mayhorn and McLaughlin (2014), KB who receive information from a less credible source might seek additional information from a different source, also known as information triangulation. Seeking additional information can be seen as increasing a person's cognitive resources by gaining a broader range of information (Hogan et al., 2008) and also providing complete, additional and more detailed information (Habraken \& Van der Schaaf, 2010; Thomson \& Pryce, 2009).

Therefore, by triangulating the information, $\mathrm{KB}$ increase their cognitive resources in deciding the veracity of the information they receive from across a boundary.

\subsubsection{Social ties}

Social ties or relationships between the individuals in the organizations may lead to crossboundary information sharing (Easterby-Smith et al., 2008; Ghoshal et al., 1994). For instance, Ghoshal et al. (1994) found that interpersonal relationships between the employees of different groups have a positive effect on cross-boundary information sharing. In addition, Easterby-Smith et al. (2008) identify social ties as one of the cross-boundary dynamics that support information sharing between organizations.

In contrast, T.-M. Yang and Maxwell (2011) compare the factors of information sharing both within boundaries (i.e. intra-organization) and across boundaries (i.e. inter-organization), suggesting that social ties are one of the factors relevant to the former. Their suggestion is supported by Van Wijk, Jansen, and Lyles (2008) who indicate within-boundary information sharing among employees contributes more to the organization's performance as compared to the cross-boundary type. This could be due to the relevance of the types of information being shared within the same boundary (Van Wijk et al., 2008). However, cross-boundary social ties will create trust between those involved in the sharing process. When trust is promoted between them, it may reduce the uncertainty feelings between the individuals that may contribute to the higher likelihood of information being shared across the boundary (Easterby-Smith et al., 2008; Tsai, 2002). 
Social ties in organizations or groups demonstrate the degree of closeness and the frequency of interaction between the members. They can range from weak ties where the members have a lesser degree of closeness and frequency of interaction to strong ties which are the opposite (Granovetter, 1973; Hansen, 1999).

There are arguments in the literature about the usefulness of social ties with regard to information sharing. Granovetter (1973) and Hansen (1999) found that weak ties are more likely to link members across different boundaries and allow novel or new information to be accessed by the information seekers. In contrast, strong ties are less advantageous in terms of seeking new information as the members normally hold the same information. However, strong ties are an advantage for accessibility and willingness to help as trust has been built between them (Krackhardt, 1992; Levin \& Cross, 2004).

\subsubsection{Social identity}

Members of the same group may see themselves as attached to and identified with a particular group, also known as social identity. The identification of one's group identity is important in influencing information sharing behavior as people will process and retain information differently with their own group than with others (Gaertner et al., 1993). This situation relates to social identity theory (SIT) which is defined as "any behavior displayed by one or more actors towards one or more others that is based on the actors' identification of themselves and the others as belonging to different social categories" (Tajfel \& Turner, 1979, p. 40). Following the definition in a broad context, scholars have discovered the relevance of SIT to organizational contexts (Haslam, 2004; Hogg \& Terry, 2000). Social identity may affect the employee's cross-boundary information sharing within their organization.

Studies in social identity have also been found focusing on intergroup (i.e. across boundary) behavior. Hewstone, Rubin, and Willis (2002) review past literature to discuss intergroup bias. They defined intergroup bias as a "systematic tendency to evaluate one's own membership group (the in-group) or its members more favorably than a non-membership group (the out-group) or its members" (p. 576). This definition has led to the concept of ingroup 'favouritism' and out-of-group 'derogation'. 
In-group favouritism and out-of-group derogation have been studied empirically by scholars in different settings. Gómez, Kirkman, and Shapiro (2000) compare collectivist (e.g. Mexico) and individualist countries (e.g. the USA) and found that the concept matters more in collectivist than individualist cultures. Bos, Shami, Olson, Cheshin, and Nan (2004) employ an experimental simulation in their study of a group online game setting and found that there were more sharing activities found in-group than out-group. Halevy, Bornstein, and Sagiv (2008) in their laboratory experiment found that "group members prefer to cooperate so as to maximize their absolute group gains" (p. 410), supporting the concept.

The social identity literature supports the concepts of in-group favouritism and out-of-group derogation. Those who identify as being attached to a group will share information among their fellow members rather than those who are outsiders. This leads to a possible critical question that concerns $\mathrm{KB}$ : whether the in-group of the $\mathrm{KB}$ and those in the different groups are perceived as the out-group as the nature of $\mathrm{KB}$ in this study concerns engagement with multiple groups.

For example, during a disaster, should a KB from a Police Investigation unit identify themselves as an in-group member of the same division and see other units in the Police (such as family support or traffic patrol units) as 'out-group'? Or, does the same KB identify their in-group as the whole Police organization, regardless of the different units and see other members outside the Police such as the Fire Service in the community of practice that the knowledge broker is engaged in as the 'out-group'? Therefore, social identity could contribute to increasing cognitive resources that $\mathrm{KB}$ rely on during a disaster.

\subsubsection{Transactive Memory Systems (TMS)}

Group members normally have some kind of relationship with each other as they work together during a certain period of time to achieve a common goal and somehow have a certain form of memory about what other members know in the group. This can be related to the concept of the transactive memory system (TMS) which was introduced by Wegner, Giuliano, and Hertel (1985). TMS is a set of shared cognitive situations in a close relationship (Wegner, 1987; Wegner et al., 1985). Jarvenpaa and Majchrzak (2008, p. 260) 
further explain, "Through TMS, team members know who knows what and who knows who knows what."

The earlier TMS studies focus on information processing among couples in an intimate relationship (Hollingshead, 1998; Wegner, 1987; Wegner, Erber, \& Raymond, 1991). Their studies emphasize how couples in intimate relationships memorize each other's summary information or knowledge. This situation helps couples who did not possess the full information to create a 'pointer' of where the information can be obtained and retrieved and can be termed as an 'external memory aid' (Peltokorpi, 2008). His comprehensive overview of TMS theory related papers found that most studies use the memory recall test in their methodology. Participants in many TMS studies of couples were asked to memorize various objects and tested for information retrieval. It can be concluded that a TMS shared cognitive resource might enable a person to know where relevant information is located and how to retrieve it.

The focus in later TMS research is not only on couples but also teams and groups (D. Nevo, Benbasat, \& Wand, 2012; Peltokorpi, 2008; Rau, 2005). Group members rely on each member to store information and the concept of TMS supports the ability of the members to access and retrieve the information from others (Jarvenpaa \& Majchrzak, 2008). In addition, TMS not only concerns information sharing in the same group, but it was also found to facilitate the sharing of information and knowledge across group boundaries that affect group performance and may contribute to innovation (Dorit Nevo \& Wand, 2005; Oshri, Van Fenema, \& Kotlarsky, 2008).

The concept of information 'pointers' in the TMS concept, which enable people in a close relationship to locate and retrieve information, is more than 'who knows what' and can be a basis of this study of 'who needs what'. For instance, (Kotlarsky et al., 2009) has included a scale item that is related to the context of 'who needs what' which is related to this study. The scale item in the TMS scale is "I know what knowledge is relevant to colleagues from other sectors" (Kotlarsky et al., 2009, p. 8). Their scale was adapted from the earlier TMS scales by (Jarvenpaa \& Majchrzak, 2008; Lewis, 2003). However, this scale item is only part of the TMS scale to predict the existence of a degree of TMS in the organization in their study. The question of 'who needs what' in the TMS concept is also as relevant as 'who knows what'.

Recent IS literature supports the concept of TMS to develop improved organization performance (S. Y. Choi, Lee, \& Yoo, 2010; D. Nevo et al., 2012). Many TMS studies 
highlight the connection between the closeness of relationships and the willingness to share information among team members (S. Y. Choi et al., 2010; Kotlarsky et al., 2009; Lewis \& Herndon, 2011; Oshri et al., 2008). Oshri et al. (2008) found that TMS in teams includes the processes of encoding, storing and retrieval of information among members. These processes may be supported by ICT as a platform. D. Nevo et al. (2012) found that ICT is an important facilitator of TMS in teams and across different units. The limitation of ICT has also been discussed as it reduces the richness of information compared to face-to-face interactions. This finding questioned the role of ICT in cross-boundary information sharing in a TMS environment by KB.

\subsubsection{Insider information}

Insider information has been discussed extensively in the financial domain (Benabou \& Laroque, 1992; Jaffe, 1974). From their perspective, insider information is non-public information about a publicly-owned company that is being shared or held by someone who works in the company to have an advantage in stock trading. The practice is illegal in most countries (Abdolmohammadi \& Sultan, 2002).

However, in the context of disasters, this concept can be seen as one of the cognitive resources that a $\mathrm{KB}$ might rely on to decide the veracity and relevance of the information they received (Austin, Liu, \& Jin, 2012). For example, following a major disaster, if a KB knows that the organization that she works for has been upgrading the technology of using text messages during a disaster rather than a voice call, when the $\mathrm{KB}$ receives information from a community leader to encourage the use of voice calls during a disaster, then the $\mathrm{KB}$ immediately decides that the information is not true.

Therefore, having insider information as one of the KB's cognitive resources could be of help in identifying the veracity of the information they receive.

\subsubsection{Previous similar experience and training}

Recalling previous similar experience that can be matched with the current situation as one of the cognitive resources has long been discussed in the literature. For example, in a classic 
study, Maier (1945) explains that a problem solver applies a solution procedure that previously has been successful with similar (or similar appearing) problems. More recently, Cunningham and MacGregor (2014) argue that personal experience did not correlate with success in solving problems. This also depends on whether the previous experience 'stays' in the memory. From a disaster victim's perspective, Mayhorn and McLaughlin (2014) argue that following a disaster, if a person had a good experience during that disaster (i.e. the disaster did not affect any part of their life), then the memory would fade away. These studies lead to the argument that $\mathrm{KB}$ rely on this type of cognitive resource to be able to identify to whom the information they hold is relevant by recalling previous similar experiences of with whom they shared the information before and match the experience with the similar current situation.

For example, a KB has experienced a flooding disaster before, and during that disaster, the $\mathrm{KB}$ received certain information that the river water level was rising extremely fast, but he did not share the information with the transport agency to manage the traffic flow in that river area. As a result, many cars were trapped in the flood in a short time. In a few years' time, when the $\mathrm{KB}$ receives the same type of information, the $\mathrm{KB}$ recalls that experience and shares the information he received with the transport agency as soon as possible. This shows that the $\mathrm{KB}$ is recalling the previous similar experience and training to match with the current situation and knows what to do.

\subsubsection{Organizational structure}

Organizational structure in the context of my research is the way that organizations are organized to operate and achieve their objectives. Organizational structure factors in the cross-boundary information sharing literature mostly concern the structural design of the organization and the hierarchies (Detert \& Burris, 2007; Wang \& Noe, 2010).

Cross-boundary information within the same organization is possible. Organizations may consist of different units such as the operations unit and the management unit which can be seen as separated by different boundaries - unit or hierarchical. There may be a different reporting structure between the units. Some organizations prohibit or restrict employees from sharing any information with other people outside their group even in the same environment due to security and the sensitivity of some information (Canestraro, Pardo, Raup-Kounovsky, 
\& Taratus, 2009; T.-M. Yang \& Maxwell, 2011) or the non-existence of cross-hierarchical boundary information sharing platforms or channels (Gupta, 2000; Morrison \& Milliken, 2000).

Upward information sharing has been explored in the organization and management domain (Detert \& Burris, 2007; Milliken et al., 2003; Morrison, 2011; Morrison \& Milliken, 2000). All of the studies concluded that upward information sharing (i.e. sharing information higher up in the hierarchy structure) is considerably affected by the hierarchy in the organization itself. For instance, Detert and Burris (2007), in their two-phase survey study, highlight the importance of those who are near the top of the hierarchy in the organization creating a sense of safety about upward information sharing for those who are at the lower levels of the hierarchy. Detert and Trevino (2010) conclude that the protocols of communication in a vertically stretched organization structure will affect communication from the employees to those higher up the hierarchy of the organization. They suggested that these employees will perceive that sharing information higher up is almost impossible or delayed due to hierarchical boundaries.

Furthermore, studies by Morrison and Milliken (2000) and Milliken et al. (2003) found that one of the factors that contributed to employees not sharing information in organizations is the hierarchy. In addition, the extensive integration of related literature throughout the years in upward information sharing by Morrison (2011) has led to the hope that upward information sharing is still much to be explored and she has identified a new guideline for future studies. As stated in the study (p. 381), "A central issue related to voice is the question of why employees do not speak up when they have organizationally relevant information, ideas or concerns".

There are also findings on information sharing across hierarchical boundaries. Tsai (2002) found that organizational structure, and hierarchy in particular, which was represented by centralization, served to impede cross-boundary information sharing. He explained that one of the impacts of centralization may be excessive intervention in information sharing by the controlling unit. This finding contradicts the few empirical studies and conceptual papers that found centralization in organizational structure facilitates information sharing as it provides integration and coordination of cross-boundary information sharing (Egelhoff, 1988; Kogut \& Zander, 1996). This has been echoed by studies that empirically found that even autonomy 
given to each organization as a decentralization strategy does not support cross-boundary information sharing (Ghoshal et al., 1994).

In the disaster management context, Manoj and Baker (2007) suggest that those who are accustomed to a highly hierarchical environment in their organization will find it a challenge to share information during a disaster when there is a less hierarchical environment. This is supported by Kapucu (2006) as he explains that hierarchical organizations perform well in normal or routine situations but not in a disaster. In addition, Schraagen et al. (2010) found that information travels faster across networked groups than hierarchical groups.

In summary, knowing the organizational structure of different groups is one of the factors that could increase cognitive resources that $\mathrm{KB}$ could rely on in the information sharing process during disasters.

\subsection{Types of ICT in cross-boundary information sharing}

The use of ICT in the information sharing during disasters has received much interest in the literature. The area of research includes both technical and socio-behavioral aspects (A. L. Hughes \& Palen, 2012; Shklovski, Palen, \& Sutton, 2008; Tuna, Nefzi, \& Conte, 2014). In the technical area, the studies focus on technological advancement aimed at better information sharing and communication during disasters.

In the socio-behavioral area, studies have looked into human behavior in relation to ICT during disasters. Shklovski et al. (2008) for example explore how ICT were used after the 2005 Hurricane Katrina. They found that people used ICT to locate friends and family and to seek additional information which was not available on the broadcasted news. Another study by A. L. Hughes and Palen (2012) suggests that the role of the Public Information Officer has changed from managing the information flow between the government and the public or community to translating the information so that the information is understood by others, with the presence of social media.

There are different types of ICT used in a disaster for cross-boundary information sharing. ICT that are normally used by those involved in response and recovery in disaster management (i.e. emergency service agencies) include radio (i.e. trunked radio), telephone 
and pager (Asplund, Nadjm-Tehrani, \& Sigholm, 2009; Huang \& Lien, 2012; McEntire, 2002). Another type of ICT used for information sharing during disasters is Geographical Information Systems (GIS) that manage geographical information (Chuvieco et al., 2010; Enders \& Brandt, 2007). Tuna et al. (2014) suggest the use of unmanned aerial vehicles (UAV) as one of the means to provide communication systems for information sharing during disasters. These ICTs are used among emergency responders to communicate and share information. Furthermore, L. Yang, Prasanna, and King (2009) suggest a prototype information system that can be used by on-site first responders during disasters. The prototype presents disaster-related information in three levels: i) perception - to form an accurate picture of the disaster's environment, ii) comprehension - to form a holistic picture of the disaster's environment, and iii) projection - to predict what will happen next.

Another type of ICT, social media, has also gained much attention in recent years in the information sharing during disasters area (Ehnis \& Bunker, 2013; Houston et al., 2015; Yates \& Paquette, 2011). Some studies found that the use of social media is a way to reduce bureaucracy in information sharing during disasters (A. L. Hughes \& Palen, 2009; Mendonça et al., 2007; Yates \& Paquette, 2011) and to assist with sharing information for updates, response and recovery (Simon, Goldberg, \& Adini, 2015). Based on the 2010 Haiti earthquake disaster, Yates and Paquette (2011) illustrate how the use of social media enabled effective information sharing for decision making and disaster response. Simon et al. (2015) highlight that social media is a reliable communication channel when all other communication channels are overwhelmed. They also outlined that disaster response agencies (i.e. emergency responders) could utilize social media to receive timely information for response and recovery. Despite the research on social media use during disasters gaining momentum in recent years, almost all studies have focused on information crossing the community type of boundary. This includes information sharing between the community members and also between community and relevant disaster response agencies. There is still a lack of studies involving the use of social media between the disaster response agencies.

In summary, there are different types of ICT being used during disasters to share information across different boundaries. While many studies found that ICT such as radios, telephones and pagers were used between the disaster response agencies (i.e. across organizational, unity and hierarchical boundaries), social media was only being used within the communities or between the emergency service agencies and the community (i.e. community boundary). 


\subsection{Decision making during disasters}

Decision making during disasters needs to be as fast and accurate as possible. There are a few decision-making concepts in the literature that are relevant to this study. These include heuristic decision making, intuitive decision making and naturalistic decision making.

\subsubsection{Heuristic and intuitive decision making}

Heuristic and intuitive decision making have a long history of research (Dane \& Pratt, 2007). Some of the definitions are listed in Table 4 below:

\begin{tabular}{|c|c|}
\hline Concept & Definition \\
\hline \multirow{3}{*}{ Heuristic decision making } & $\begin{array}{l}\text { "A heuristic is a strategy that ignores part of the information with } \\
\text { the goal of making decisions more quick[ly], frugally and/or } \\
\text { accurately than more complex methods" (Gigerenzer \& Gaissmaier, } \\
2011 \text {, p. 454) }\end{array}$ \\
\hline & $\begin{array}{l}\text { "Heuristics are the mental shortcuts commonly used in decision } \\
\text { making that can lead to faulty reasoning or conclusion[s]" (Elstein, } \\
1999, \text { p. } 791 \text { ) }\end{array}$ \\
\hline & $\begin{array}{l}\text { "Heuristics are strategies used during the decision-making process } \\
\text { to make inferences" (Cioffi, 2001, p. 592) }\end{array}$ \\
\hline \multirow[b]{2}{*}{ Intuitive decision making } & $\begin{array}{l}\text { "A cognitive conclusion based on the decision maker's previous } \\
\text { experience and emotional input" (Burke \& Miller, 1999) }\end{array}$ \\
\hline & $\begin{array}{l}\text { "A sense of feeling of pattern or relationships. Intuition can also be } \\
\text { holistic thinking, immediate insight, seeing the answer without } \\
\text { knowing how it was reached" Seal (1990) in Sauter (1999, p. 110) }\end{array}$ \\
\hline
\end{tabular}

Table 4: Definitions of heuristic and intuitive decision making concepts

In support, Dane and Pratt (2007) list definitions of intuition from the literature ranging from the year 1933 to 2004. Most of the definitions are similar to the definitions listed in Table 4 
above which covers intuition as the unconscious process linked to the previous experience that leads to decision making.

Based on all of the definitions mentioned above, both terms (intuition and heuristic decision making) have a similar context: where a person's previous experience was used to make an instant decision based on the current information available.

For example, one of the studies in heuristic decision making mentioned that "the mechanism of retrieving past experience is built on recognition between the prototypes in memory and representing data" (Cioffi, 2001, p. 592). In this study, nurses were found to use past experiences when dealing with patients to construct the assessment that led to judgment during a clinical emergency situation.

As for intuition, this decision-making strategy has been heavily discussed in less lifethreatening situations such as in businesses (Burke \& Miller, 1999; Dane \& Pratt, 2007; Sauter, 1999). These studies emphasized that intuition is a sudden awareness of information formed from previous experience (Sauter, 1999). This reinforces the argument that intuition also uses past experiences to make decisions.

In the context of 'speed' in reaching the decision, intuition and heuristics were compared. While an intuitive decision-making process is faster than rational decision making (Dane \& Pratt, 2007), no evidence was found in the literature for the intuitive decision-making process being faster than heuristic decision making. This is probably because heuristic decision making is similar to intuitive decision making in the using of previous experience to come to a conclusion or a decision. Therefore, both kinds of decision making are seen to be similar in terms of process speed as compared to rational decision making.

Looking at situational settings of studies or environment in both intuition and heuristics, there is a subtle difference. While many studies on intuitive decision making focused on a stable environment such as business settings, heuristic decision-making studies on the other hand focused more on uncertain environments such as clinical and hospital emergency situations (Cioffi, 1997, 2001; Marewski \& Gigerenzer, 2012). However, some studies on heuristic decision making under uncertainty have also discussed them in a general environment using the lens of psychology (Gigerenzer \& Gaissmaier, 2011; Tversky \& Kahneman, 1973, 1974). 
Interestingly, Cioffi (1997) argues that intuitive judgment of nurses in medical emergency situations has heuristic components as heuristics break down the judgment process into several categories. He concludes that "If heuristics are used to explore these judgements, an increased understanding of the construction of intuitive judgement may result" (p. 207). The heuristic categories include representativeness, availability and anchoring and adjustment. The difference between the categories is the degree of fitness between the current event (which requires decision making) and the previously experienced event's similarity. The three categories have also been discussed by earlier heuristic decision-making scholars (Tversky \& Kahneman, 1974).

To summarize, the heuristic and intuition decision-making concepts that have been long discussed centred around the use of previous similar experiences to make current decisions. However, most of the studies on these concepts which have been discussed earlier were conducted in either stable situations or those with no time pressure. In disaster management, $\mathrm{KB}$ make a decision to identify the veracity of information they receive and also to whom the information is relevant. The outcome of this decision is be able to identify whether the information is true or false and to be able to identify the appropriate receiver(s) of the information, which is critical. Furthermore, the decision-making process in disasters occurs in a context of stress, uncertainty and time pressure. Therefore, decision-making concepts that focus on these situations must be acknowledged as well.

The next section describes and discusses another area of decision making - Naturalistic Decision Making.

\subsubsection{Naturalistic Decision Making (NDM)}

This section starts with a disaster event that historically relates to the Naturalistic DecisionMaking concept. Butterfield (1988) reports that in 1988, the battleship USS Vincennes was being attacked by Iranian gunboats in the Persian Gulf. During the attack, the USS Vincennes' radar detected an aircraft flying above them. The Captain of the battleship decided, based on the descending movement pattern and altitudes of the aircraft, that it resembled the start of a jet fighter attack. The Captain gave the order to the crew to shoot the aircraft, which they did. Then they realized that it was not a jet fighter, but an Iranian 
commercial airplane. All 290 civilian passengers, including children, and crew on board were killed. The disaster received international attention.

Following the disaster, the U.S. Navy was interested in helping decision makers make important decisions under uncertainty and time pressure, starting with a conference in 1989 that assembled researchers studying decision making in field settings (G. Klein, 2008, 2015). Since then, NDM has gained much attention (Gore, Flin, Stanton, \& Wong, 2015).

"The study of NDM asks how experienced people, working as individuals or groups in dynamic, uncertain and often fast paced environment[s] identify and assess their situation, make decisions and take actions whose consequences are meaningful to them and to the larger organization in which they operate" Zsambok and Klein (1997, p. 5). In short, NDM is "the way people use their experience to make decisions in field settings" Zsambok and Klein (1997, p. 4).

One model that was devised from Klein's early study using a NDM lens was the recognitionprimed model (RPD) (G. Klein, 2008). This model was introduced after Klein conducted multiple field experiments to find out how fire commanders make decisions (Gore et al., 2015). Klein unsuccessfully attempted to fit his results into the traditional decision-making models and decision-tree frameworks. The responses that he received described a different cognitive process in their decision making under time pressure. The fire "Fore-ground commanders argued that they were not making choices, considering alternatives or assessing probabilities when making [a] decision under pressure. They saw themselves as acting and reacting on the basis of prior experience: they were generating, monitoring and modifying plans to meet the needs of the situations" (G. Klein \& Klinger, 1991, p. 17). The RPD model describes the decision-making process which experienced decision makers go through during a time pressured, high stakes and uncertain situation. Under this model, if decision makers recognize a similar situation from previous experience they will recognize suitable actions through goals, cues, expectations and the planned action (i.e. decision). Then they will mentally simulate what will happen if a certain decision is made. If the mental simulation confirms that the decision will work, they will proceed with implementing the decision. The RPD model is shown in Figure 3 which is adapted from G. Klein (2008). 


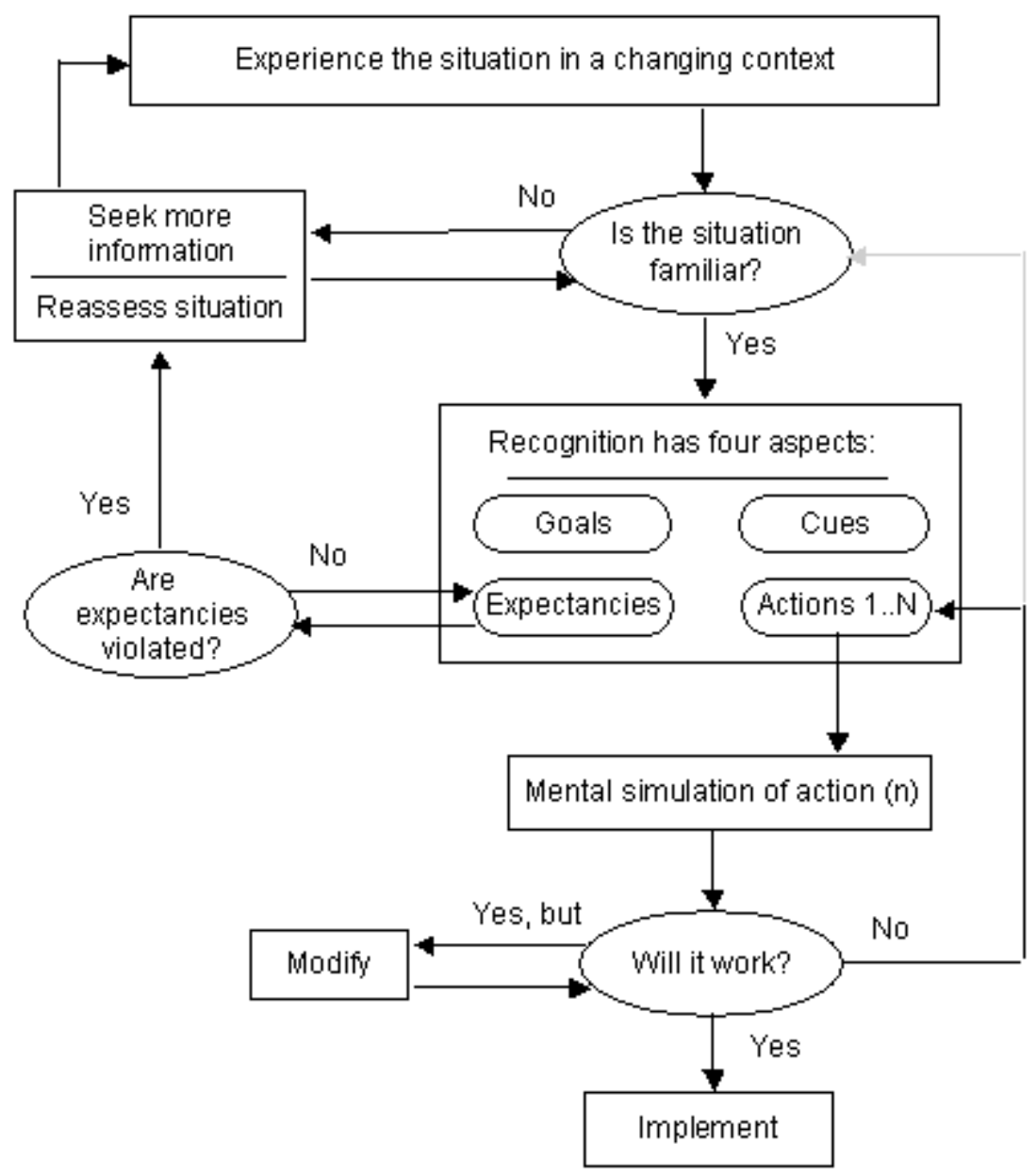

Figure 3: The Recognition-Primed Decision (RPD) model

Many traditional decision-making theories were based on stable environment settings, without time pressure and involving inexperienced decision makers. In the absence of those characteristics, a decision maker could evaluate choices and alternatives or delay the decision making to optimize the best option to choose. There are several key features of NDM to differentiate them from the traditional decision-making narratives or theories. These key features have been identified by G. Klein and Klinger (1991) to describe situations under NDM. The features are listed in Table 5 below:

\begin{tabular}{|l|l|l|}
\hline$\#$ & Features of NDM & Description \\
\hline 1 & $\begin{array}{l}\text { Ill-defined goals and ill-structured } \\
\text { tasks }\end{array}$ & $\begin{array}{l}\text { A situation where goals and tasks are not well- } \\
\text { defined. }\end{array}$ \\
\hline 2 & $\begin{array}{l}\text { Uncertainty, ambiguity and missing } \\
\text { data }\end{array}$ & $\begin{array}{l}\text { Unpredictable, confusing, partly unknown } \\
\text { situations }\end{array}$ \\
\hline
\end{tabular}




\begin{tabular}{|c|c|c|}
\hline 3 & Shifting and competing goals & $\begin{array}{l}\text { Goals keeps changing to suit the current } \\
\text { situation }\end{array}$ \\
\hline 4 & $\begin{array}{l}\text { Dynamic and continually changing } \\
\text { conditions }\end{array}$ & Unstable situations \\
\hline 5 & $\begin{array}{l}\text { Action-feedback loops (real-time } \\
\text { reactions to changed conditions) }\end{array}$ & $\begin{array}{l}\text { When feedback is given to a person after an } \\
\text { action and repeated regularly }\end{array}$ \\
\hline 6 & Time stress & Decision needs to be made urgently \\
\hline 7 & High stakes & A situation of high risk of negative impact \\
\hline 8 & Multiple players & Involves many people \\
\hline 9 & Organizational goals and norms & Goals are at organizational level \\
\hline 10 & Experienced decision makers & $\begin{array}{l}\text { Decision makers have a high level of work } \\
\text { experience. }\end{array}$ \\
\hline
\end{tabular}

Table 5: Features of Naturalistic Decision Making

In natural settings such as a disaster, a decision maker has to make a decision in a split second (or very limited time) because the stakes are high if wrong or delayed decisions are made. Lipshitz et al. (2001) have listed some of the traditional decision-making theories: CDM (Classical Decision Making), BDT (Behavioral Decision Theory), JDM (Judgment and Decision Making) and ODM (Organizational Decision Making). They mentioned that some of them were introduced as far back as 1738 (CDM), 1954 (BDT and JDM), and 1957 $(\mathrm{ODM})$. With a long history of research on those decision-making theories, their expansion would probably be impossible.

The growing attention to NDM indicates that it is a relatively new area. Even though it started around 27 years ago (in 1989), recent literature in NDM suggests that there is still much to be done to advance it (G. Klein, 2015). Scholars have shown interest by applying it in different areas and most of the studies are recent. For example, it has been used in contexts such as the army (Lipshitz \& Strauss, 1997; Militello, Sushereba, Branlat, Bean, \& Finomore, 2015; Pascual \& Henderson, 1997), fire-fighting (Comfort et al., 2013; G. Klein, Calderwood, \& Clinton-Cirocco, 1986), sports (Kermarrec \& Bossard, 2014; Macquet \& 
Fleurance, 2007), health care (Cristancho, Vanstone, Lingard, LeBel, \& Ott, 2013) and labour disputes (Ramiah \& Banks, 2015).

Interestingly, to my knowledge, not much attention has been paid to multiple agencies disaster management using the lens of NDM except for two studies: Smith and Dowell (2000) and recently, Alison et al. (2015).

Smith and Dowell (2000) investigate a case of a 1995 railway accident in Ais Gill, Cumbria in the UK. The multiple agencies involved were the Fire Brigade, Transport Police and Ambulance service. Data were collected through the Critical Decision Method interview procedure from six participants who played significant roles in the disaster response and also by documentation of observations. The study found that the decision makers discussed a few options before making a critical decision. The study argued that this technique (of considering multiple options) is in contrast to the RPD model in NDM where experienced decision makers did not consider options but matched the best experience they had with the current situation to identify the outcome (G. Klein, 2008; G. Klein \& Klinger, 1991).

Alison et al. (2015) study decision makers' failure to make decisions during a disaster, a situation called decision inertia. They were using the lens of NDM. The scenario of this study was based on a simulation training exercise of an airplane crash over a major city. Fourteen agencies with 194 participants were involved in the simulation exercise. Data were collected from the electronic communication logs that were passed between the participants and control room, both across different agencies and within the same agency. Their findings suggest that information sharing within the same agency increased if the disaster involved multiple agencies, there were no holistic superordinate (strategic) goals and the decision problem was not time-bounded. In contrast, information sharing across agencies decreased and some failed to make a decision i.e. they demonstrated decision inertia. This study recommends several avenues for future research such as comparing the degree of critical decision-making situations (i.e. critical vs less critical decisions) and also whether experts are willing to make decisions without deadlines. The recommendations suggest opportunities to explore NDM in more depth.

The two studies described above were conducted in natural settings with time pressure for decision making and in an uncertain environment. While both were studying multiple 
participants in a disaster, the number of disasters was limited to one for each study. To my knowledge, no studies have been found analyzing or comparing the process of individual decision making involving multiple agencies in multiple disasters. The nearest study that I found analyzing different disasters from the perspectives of different people was a study by Lipshitz and Strauss (1997) where they collected data from the personal experience of 102 defence force college students holding various positions from Captain to Lt. Colonel. The students were asked to write a case of decision making under uncertainty based on their personal experience at the beginning of the course and the cases were then analyzed. However, the study did not mention the exact type of event they collected from each of the students.

To illustrate the decision-making process during a disaster, Serfaty, MacMillan, Entin, and Entin (1997) Hourglass framework for the decision-making process will be used (see Figure 4: The Hourglass framework for the decision-making process (Adapted from Serfaty et al., 1997). They suggest that the decision-making process has three phases: recognition, exploration and matching. First, in the recognition phase, the experts recall previous experiences or memories that closely represent the current situation before the initial plan is suggested. Then the process goes to the second phase: exploration. In the second phase, experts ask the right questions about the initial plan of the decision. Then experts enter the third phase: matching. Here, they visualize what would happen if the decision is made, before making the decision. 


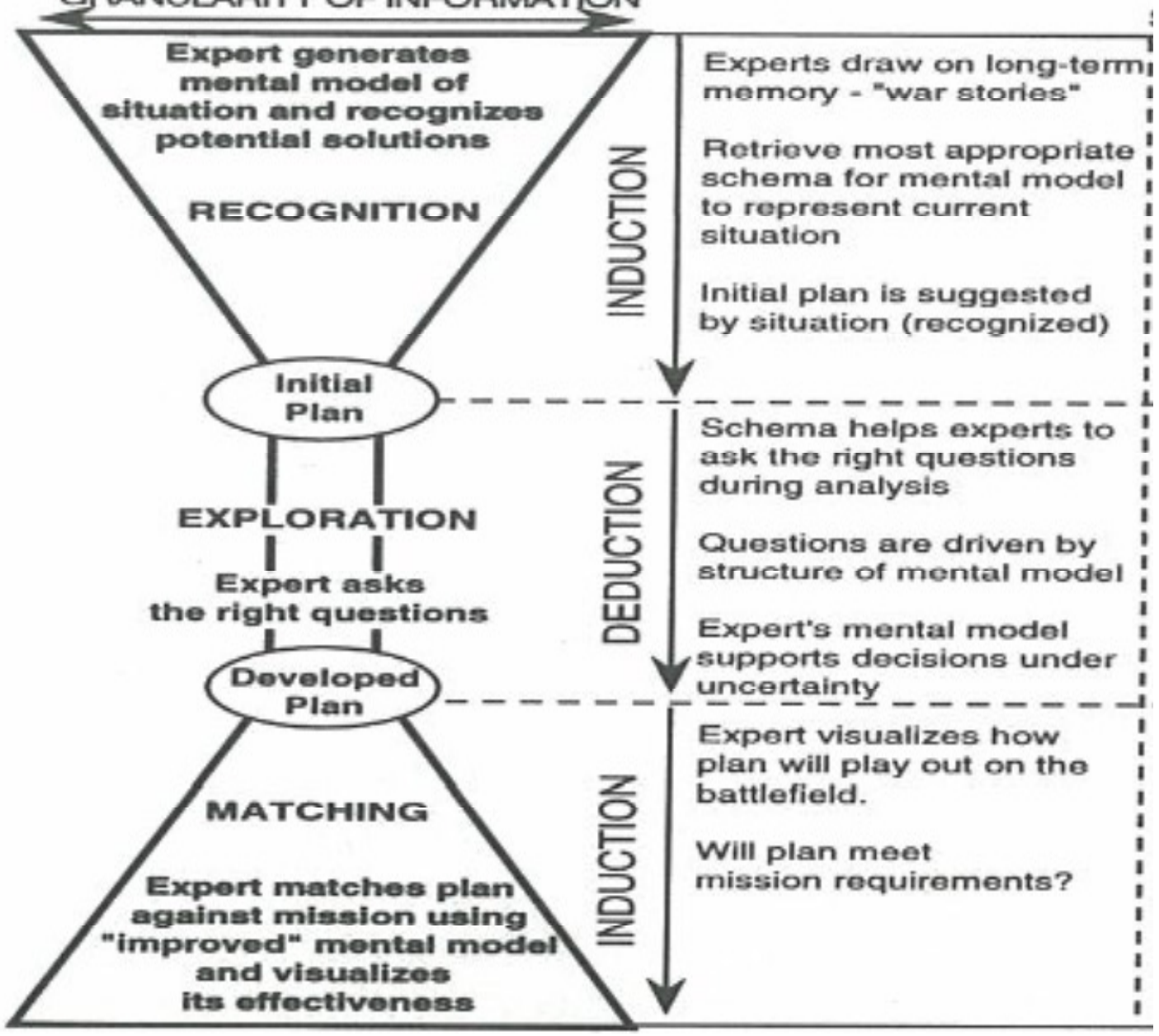

Figure 4: The Hourglass framework for the decision-making process (Adapted from Serfaty et al., 1997)

While the framework is seen as a complete process of decision making, it is at a highly contextual level. The framework did not unpack each of the phases. Unpacking the phases could potentially provide better understanding of the process of decision making during disasters. Furthermore, this framework was based on the military, an organization with a highly hierarchical structure, and the output of the decision was in the form of a military instruction or order.

The next section discusses the tactics that are used to make decisions. 


\subsubsection{Decision-making tactics for coping with uncertainty}

One way to explore how KB identify the veracity and relevance of the information they receive during a disaster is to examine the tactics they use to come to the decision. The tactics need to suit the NDM concept to distinguish decision making under time pressure and uncertainty from decision making in a stable environment.

Lipshitz and Strauss (1997) found 12 tactics being used by decision makers to cope with uncertainties. The tactics comprise: collecting additional information, delaying action, soliciting advice, following SOP/norms, assumption-based reasoning, preempting, improving readiness, avoiding irreversible action, weighing pros and cons, ignoring uncertainty, relying on intuition and taking a gamble. The definition of each tactic is listed in Table 6 below:

\begin{tabular}{|c|c|}
\hline Tactic name & Definitions \\
\hline Collect additional information & Conduct an active search for factual information \\
\hline Delay action & $\begin{array}{l}\text { Postpone decision making until additional information clarifies } \\
\text { the decision problem }\end{array}$ \\
\hline Solicit advice & Solicit opinions of experts, superiors, friends or colleagues \\
\hline Follow SOP/norms & Act according to formal or informal rules of conduct \\
\hline Assumption-based reasoning & Act based on logical reasoning \\
\hline Preempting & Generate specific responses to possible negative outcomes \\
\hline Improve readiness & $\begin{array}{l}\text { Develop a general capability to respond to anticipated negative } \\
\text { developments }\end{array}$ \\
\hline Avoid irreversible action & $\begin{array}{l}\text { Prefer or develop a reversible course of action, prepare } \\
\text { contingencies }\end{array}$ \\
\hline Weigh pros and cons & Choose among alternatives in terms of potential gains and losses \\
\hline
\end{tabular}




\begin{tabular}{|l|l|}
\hline \multicolumn{1}{|l|}{ Ignore uncertainty } & \multicolumn{1}{|l}{ Acts as if certain and very sure about something } \\
\hline Rely on intuition & Use informed guesses without sufficient justification \\
\hline Take a gamble & 'Take a chance', throw a coin, etc. \\
\hline
\end{tabular}

Table 6: Tactics used to cope with uncertainty (Adapted from Lipshitz \& Strauss, 1997)

These tactics, however, may only be used in military settings. KB in different disasters also face uncertainty when making decisions. Therefore, applying these tactics in a different uncertainty situation would be useful in expanding the NDM area.

To summarize, there are different concepts of decision making that have been discussed in the literature. While heuristic and intuitive decision-making concepts use a decision maker's previous experience to make the current decision, they were mainly based on stable environments. The naturalistic decision-making concept, which focused on decision making in disaster situations based on its features, has seen continued progress until recently. Under this concept, decision makers use different tactics under uncertainty situations to make a decision.

\subsection{Summary of the gaps in the literature}

In knowledge brokering literature, studies have been conducted in a stable organizational level; to my knowledge, no studies have looked at knowledge brokering under uncertainty situations (i.e. disasters) at the individual level.

In information sharing during disasters literature, cognitive resources are referred to in managing the information people hold; however, the use of cognitive resources in the process of decision making is yet to be explored. In addition, although there are types of information known to be shared during a disaster, there is a need to further explore the sub-categories of the types. 
Almost all of the studies in the decision making literature were of stable situations and many were conducted as experiments. Very little is known about decision making under time pressure, uncertainty situations and high stakes. This has led to the recent interest in Naturalistic Decision Making (NDM) literature where uncertainty is present when making decisions. Some of the NDM decision making strategies found were different tactics used to make a decision and the Hourglass Framework for the decision making process during a disaster. However, these studies were conducted in military settings. It would be interesting to know how these different tactics and the Hourglass Framework model are being used in different types of disaster. Also, unpacking the model would be useful to provide better understanding of the decision making process.

\subsection{Chapter summary}

This chapter has provided the background to my research on the process of cross-boundary information sharing by $\mathrm{KB}$ during disasters. The chapter was divided into different sections. This shows that the literature in cross-boundary information sharing by KB during disasters covers many topics and domains but lacks depth.

First, the concept of knowledge brokering across boundaries has been defined and discussed. The literature around $\mathrm{KB}$ and their different roles, types of boundaries, types of information has been reviewed. This provides the background understanding of different components that contributed to the process of cross-boundary information sharing by KB.

Second, I have reviewed the literature on cross-boundary information sharing. Nine cognitive resources were discussed in detail. This relates to the $\mathrm{KB}$ reliance on their cognitive resources in the process of information sharing during disasters.

Third, types of ICT used in information sharing during disasters were discussed. The literature discussed shows that different types of ICT are used with certain types of boundary. Finally, the literature on decision making was discussed. This includes the decision-making tactics and how they relate to the process of decision making during disasters in this research.

The next chapter describes the research methodology for this research. 


\section{CHAPTER 3: RESEARCH METHODOLOGY}

This chapter outlines the research methodology that has been used in order to achieve the goals of this research. The aim of my research is to generate theory that helps to explain the phenomenon of how knowledge brokers $(\mathrm{KB})$ identify the veracity and the relevance of the information they received during a disaster. To explore and explain this phenomenon, I integrated interpretivist and positivist epistemological stances, employing a qualitative case research method with data collection through interviews. The unit of analysis is the scenario of information sharing experienced by KB.

I start with a discussion of the research paradigm and the underlying philosophies which guide the research methodology and strategy. Then the detailed research design is discussed along with how it contributed to achieving the research goals. I also discuss the strategy that I took in ensuring quality and rigor in this research. Following this, I identify the issues and challenges that appeared and how I handled them. Before ending the chapter with a summary, I describe my style of result presentation.

\subsection{Research paradigm}

A research paradigm or world view is the framework that guides the researcher in achieving a research objective. It is "a set of beliefs and feelings about the world and how it should be understood and studied" (Denzin \& Lincoln, 2005, p. 22). It is normally expressed in terms of epistemological and methodological perspectives (Fitzgerald \& Howcroft, 1998) that are adopted as a guide for a study (Orlikowski \& Baroudi, 1991).

\subsubsection{Epistemological perspective}

The epistemological perspective is the stance taken by the researcher in respect to knowledge or "how we know it" (Creswell, 2003, p. 6). In IS, epistemology "concerns the criteria by which valid knowledge about a phenomenon may be constructed and evaluated" (Orlikowski \& Baroudi, 1991, p. 8). There are three widely accepted epistemological perspectives in IS: the positivist, interpretivist, and critical theory (Orlikowski \& Baroudi, 1991). 
Positivist epistemology, which has dominated IS research since its inception (Orlikowski \& Baroudi, 1991), studies a fixed relationship within phenomena with theory testing that uses pre-determined or structured instruments to examine the predictive understanding of the phenomena (Orlikowski \& Baroudi, 1991).

Interpretivist epistemology, which emerged in the IS domain in the 1990s, focuses on human interpretation and meanings (Walsham, 1995) and assumes that knowledge of reality is gained through social construction which does not involve predefined variables $(\mathrm{H}$. K. Klein \& Myers, 1999) .

Critical theory assumes that people will consciously act to change their social and economic conditions within the limitations of society, culture, politics, law and resources (H. K. Klein \& Myers, 1999)

The aim of my research is to explore how KB assess and decide the veracity and relevance of information they received during a disaster and this involves human interactions. These human interactions may have their own embedded interpretations and meanings through social and contextual considerations. In relation to the objective, this research will try to understand the phenomenon of information sharing during a disaster through meanings gathered from the participants (H. K. Klein \& Myers, 1999; Orlikowski \& Baroudi, 1991). With the limited literature found focusing on this context, there is a need for a better understanding through exploration of embedded meanings from the participants' interpretations. The understanding of these meanings which might be shaped by the complexity of individual attitudes and perceptions suggests the possibility of taking an interpretivist philosophical stance in this research. However, there is also a need to conduct some validation to strengthen the findings (Lee, 1989). Thereby, taking a positivist stance is also possible.

There are suggestions in the IS research to integrate stances, namely, the interpretivist and positivist, for example Lee (1991). He suggested an integrated framework that indicates "how interpretive research may benefit from using positivist procedures in addition to their interpretive procedures" (p. 355). By integrating the interpretivist and positivist stances, the research results will be strengthened by using diverse methods that can be combined (Lee, 1989). Therefore, my research epistemology integrates intepretivist and positivist stances. 


\subsubsection{Methodological perspective}

The methodological perspective identifies how knowledge is gained or the "process of studying it" (Creswell, 2003, p. 6). It is critical to have a suitable methodology for the study as it promotes the development of rigorous and compelling research (Edmondson \& McManus, 2007). There are three widely used methodological approaches in IS research: qualitative, quantitative and mixed method (Creswell, 2003; Fitzgerald \& Howcroft, 1998).

The quantitative method is used for variables that can be measured through statistics (Gefen \& Straub, 2005) and when the data is "in the form of numbers" (Punch, 2005, p. 3). This method usually measures the relationships between constructs and the correlations between variables (Gefen \& Straub, 2005; M. A. Hughes, Price, \& Marrs, 1986) and is normally used for testing a theory or explanations (Creswell, 2003).

Qualitative methods focus on phenomena that occur naturally in their own settings and are characterized by the richness of data (M.B. Miles \& Huberman, 1994). Qualitative methods are considered to suit any research that has an objective of trying to understand a phenomenon through the revealing of complex meanings of people (M.B. Miles \& Huberman, 1994). In addition, it is viewed as the best strategy for exploring a new area and generating new theories. This method also provides richness and holism with strong potential for revealing complexity by providing thick descriptions with vivid real contexts that convince the reader (M.B. Miles \& Huberman, 1994).

Mixed methods involve the combination of both qualitative and quantitative methods in a single study (Johnson, Onwuegbuzie, \& Turner, 2007). This can defuse the arguments between proponents of qualitative and quantitative methods. It integrates data at a different stage of inquiry (Creswell, 2003) and can have sequential and simultaneous approaches to data collection.

My research objective is to understand the phenomenon of how KB assess the veracity and relevance of the information they received. This can be seen as trying to reveal the complex meanings of people. Also, as discussed in the previous chapter, lack of knowledge in this area suggests that this phenomenon needs exploration and my research aims to contribute to the generation of new theory. All of these factors led my research to a justifiable selection of a qualitative methodological perspective. The selection of the qualitative methodological perspective was also driven by the aim to provide thick description in KBs' real context. 
To summarize below is the illustration of the overview of my research paradigm:

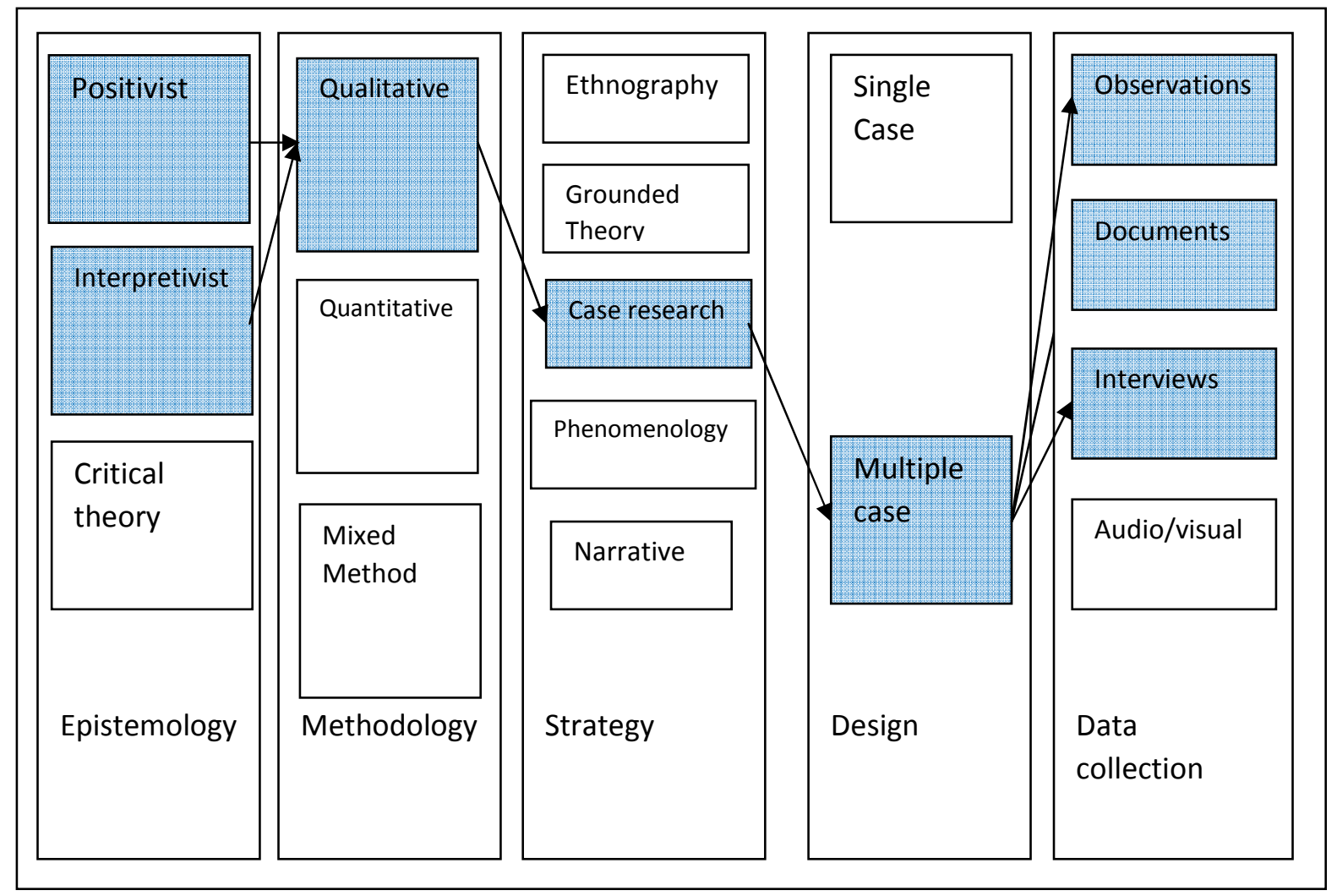

Figure 5: Research paradigm overview

\subsection{Research strategy: case research}

The selection of relevant perspectives in the research paradigm needs to be followed by selecting a strategy of inquiry to guide and frame the research. Creswell (2003) has identified five strategies that are associated with the qualitative research approach: ethnography, grounded theory, case research, phenomenology and narrative. My research used case research.

Yin (2009, p. 18) defined case research as "an empirical inquiry that investigates a contemporary phenomenon in depth and within its real-life context, especially when the boundaries between phenomenon and context are not clearly evident". Palvia et al. (2004) defined case research slightly differently as the study of a single phenomenon in an organization over a logical time frame. This broadens the scope of the case research which 
can be summarized as a study which includes a combination of phenomenon, context, and contemporary events and over a logical time frame.

In the IS domain, extensive literature has discussed the use of the case research strategy (Benbasat, Goldstein, \& Mead, 1987; Dubé \& Paré, 2003; Palvia et al., 2004; Walsham, 1995). These studies discussed and highlighted the detailed strategies which have been used in IS research using case studies. While almost all of the literature mentioned above takes a positivist stance in its case research, Walsham (1995) took an interpretivist stance and argued that interpretivist case research could employ strategies for empirical studies by including the identification of the role of the researcher, evidence generated from interviews and reporting methods. Case research is used for in depth investigation of a contemporary phenomenon and context is not clearly shown. This method is being used in IS research for theory generation (Pare; 2002, Eisenhardt; 1989).

Exploring the issue of generalization in IS case studies, Walsham (1995) discussed four major contributions from the types of generalization: development of concept, generation of theories, drawing specific implications and the contribution of rich information. Eisenhardt (1989) has identified that an interpretivist could take advantage of being similar to the positivist in conducting case research. Recently, IS scholars have been using the case research strategy in their studies (D. K. Allen, Karanasios, \& Norman, 2014). Case research has the ability to generate strong theory that could be tested and empirically validated (Darke, Shanks, \& Broadbent, 1998). This supports the selection of a case research method for this research.

\subsubsection{The case for case research}

Yin (2009) outlined that there are three conditions in selecting a research strategy: i) types of research question, ii) the extent of the control a researcher has over actual behavioral events, and iii) the degree of focus on contemporary events. In addition, Creswell (2003) described that one of case research's purposes is exploring in depth a process bounded by time and activity. My research asked the 'how' type of research question, I have very little control over an event, covers contemporary events and explores the depth of a process. Based on the presence of all of these criteria, the case research strategy is the most appropriate. 
Case research can be divided into three major categories: explanatory, descriptive and exploratory (Yin, 2009). Explanatory case research explains causal links in a real-life context that is too complex to be explained by other strategies such as surveys or experiments. Descriptive case research describes a real-life context by intervening between the causal links and the real-life context. Exploratory case research sheds light on any situation which has very limited or unknown defined outcomes prior to the research. My research suited exploratory case research because little is known about how knowledge brokers make their decisions during a disaster (Alison et al., 2015; Bharosa et al., 2010; Gore et al., 2015).

\subsubsection{Case research design - multiple case, embedded design}

There are two types of case research design: single case and multiple case. Yin (2009) explained that single case can be adopted either in testing a well formulated theory, or representing a unique case, typical case, revelatory case or longitudinal case. With multiple cases, each case is carefully selected to either predict similar results or predict contrasting but predictable results. Both single and multiple case designs are either holistic (single unit of analysis) or embedded (multiple units of analysis).

In this study, I adopted the multiple embedded type of case research. The cases were in the context of disasters that occurred in New Zealand. I present each case in 'vignettes'. Each disaster has its own embedded unit of analysis which in this study are called 'scenarios'. Vignettes and scenarios will be discussed further in section 3.6.1.1. This research also explores the similarities and differences within and between the cases by comparing scenarios (refer to section 3.6.1.1). All of this evidence corroborates the adoption of the case research type.

\subsubsection{The cases: Disasters that occurred in New Zealand}

The context of my research is any disaster that occurs in New Zealand. As discussed in Chapter 1 (i.e. the Introduction) this includes earthquakes, flooding, tsunami, storms, landslides, drought, volcanic eruptions, pandemics, lifeline utility failures, hazardous substance incidents, transport accidents, bomb threats/terrorism and fires (Wellington Region Civil Defence Emergency Management, 2013). All of the disasters are suitable cases for 
investigating my research question because they provide a specific event. Because there is more than one disaster and this research is comparing types of disaster, multiple cases are better suited to this research than a single case. The disasters covered in my research are earthquakes, a hazardous substance incident (mine explosion), transport accidents, a bomb threat and fires and they are presented in ten 'vignettes'. Each 'vignette' represents a case.

As embedded cases, the behavior of $\mathrm{KB}$ in a disaster was captured through unique 'scenarios' or situations in every disaster. By doing this, it allows my research to understand the information sharing behavior of $\mathrm{KB}$ in each of the 'scenarios' of each disaster.

Although the multiple case design was adopted in my research, it is possible to have a single embedded case design. This can be done by selecting a specific disaster, for example an earthquake. While choosing a single case may provide the benefit of having a greater degree of focus in my research, the benefits of multiple cases outweigh the single case design. By adopting a multiple case design, I could compare cases of different disasters. This allows this research to achieve a richer result due to the comparison of different disasters.

In summary, I found that the multiple case embedded design was more suitable for investigating the issues of information sharing by $\mathrm{KB}$ during a disaster because it allows comparison within and across different disasters.

\subsubsection{The case structure}

A unit of analysis is related to the fundamental problem of defining what the case is, and can be individuals, groups, organizations, specific projects or decisions (Benbasat et al., 1987; Yin, 2009) - in my study it is the information sharing behavior. The selection of the unit of analysis is also highly dependent on the way the researcher defined the research question and what is to be analyzed. Therefore, based on my research question of how KB make decisions to assess the veracity and relevance of the information they received in a disaster, the unit of analysis in my research is the scenarios of information sharing experienced by KB. The behavior of KB in each 'scenario' of a disaster was analyzed.

Originally, I planned to select disasters that occurred in New Zealand which resulted in a state of emergency being declared at both district and national level as the cases of my research. Based on the data from the Ministry of Civil Defence web page, (Ministry of Civil 
Defence \& Emergency Management, 2015), I found that there were 197 declarations of a state of emergency from the year 1967 to 2013 . When I narrowed the case search to the years between 2010 and 2013 for the most recent cases, I found 11 cases, including two from the Christchurch earthquakes, a possible tsunami, volcanic activity and flooding. From the four types of disasters found, two were events that did not have substantial impact, and only threatened to occur: the tsunami threat and volcanic activity. The states of emergency declared for these two events were lifted shortly after being declared due to the disaster not happening. Because of that, I could not select those two and I kept earthquakes and flooding in my plan.

After attending relevant seminars, and having discussions with those who are experts in the disaster management area (both academics and practitioners), I realized that disasters do not always involve declaration of a state of emergency.

I then changed my plan. Due to the relaxation of the selection criteria from the first plan, I started to look for suitable disasters for my cases from newspaper reports and online bulletins. However, I found that method was very challenging as the process started with a secondary source of data to investigate who were involved and then only I could assess the case. This took a lot of time.

After collecting thoughts and ideas from the experts around my network, I decided not to have a pre-selected disaster but let cases emerge naturally from the data instead.

In this research, cases emerged from data collected from the participants - who are the KB. The selection of KB was done very carefully so that they had experienced certain disasters, which allowed cases to emerge. My KB selection process is discussed in detail in section 3.3.1. 


\subsection{Data collection procedures}

Creswell (2003) indicates that there are four types of data collection procedures in qualitative research. The procedures are: i) observations, ii) interviews, iii) documents, and iv) audio/visual materials. In case research, Yin (2009) also suggested similar procedures as Creswell - except he subdivided them into six - direct observation, participant observation, documentation, archival records, interviews and physical artifacts. My research uses interviews as the data collection procedure. This is because my research is about behavioral events and interviews can provide insights into such events (Yin, 2009).

The unit of analysis of this research is the scenarios of information sharing experienced by $\mathrm{KB}$. In order to obtain the relevant data, KB were included in the selection process in order to include different organizations and types of disaster that they have experienced. This is to obtain richer data for comparison in the analysis stage.

Based on the two research questions, a semi-structured interview script was used as it allows flexibility and improvisation (Myers \& Newman, 2007). It is also useful for exploration and leads to interesting rich information which will reduce uncertainty and clarify ambiguity (Daft \& Lengel, 1983, p. 5) and may lead to a deeper context of meanings and explanation that suits the exploratory nature of this research.

The critical incidents technique (CIT) interview method was used. CIT is a method used in interviews to capture specific behavior or experiences which may yield rich behavioral data (Flanagan, 1954). This method has also been used by scholars to produce good research results in human behavior studies (Clawson, Bostrom, \& Anson, 1993; Faniel \& Majchrzak, 2007).

How I used CIT is illustrated by Clawson et al. (1993). In their study, the data is collected from respondents who are meeting facilitators from different industries such as consultants, business people and academics. Participants were asked to recall and describe experiences of specific behavioral incidents over the last two years, focusing on the most recent ones. As the study focuses on the role of the facilitators, the experience can involve either effective or 
ineffective behavior. These incidents can be seen as collecting both extremes of the facilitators' role (i.e. effective and ineffective).

Faniel and Majchrzak (2007) also used a similar interview technique. In focusing on innovations and cross-boundary information sharing, they collected data from participants using story elicitation. They collected data from engineers in the form of stories about when they looked for information to solve a problem but did not find any related information. That interview technique is closely related to CIT where participants are asked to recall certain experiences.

Building from the classic CIT in interviewing (Flanagan, 1954), (G Klein, Calderwood, \& Macgregor, 1989) also suggested using the critical decision method to elicit knowledge. This method "can be used to study the cognitive bases of judgment and decision making in naturalistic settings" (G Klein et al., 1989, p. 462).

Regarding Naturalistic Decision Making (NDM), Lipshitz et al. (2001) agreed that there are significant challenges in improving the quality and rigor of its empirical research. They suggested that one of the techniques that could achieve that is one that was built upon the CIT. “Based on Flanagan's (1954) CIT, this approach provides insights into challenging or unusual decisions" (Lipshitz et al., 2001, p. 343). This highlights the justification for my research using the CIT technique for data collection.

The CIT method has also been used in case study interviews in the disaster management area such as (Smith \& Dowell, 2000). In their study, interview participants were asked to present a chronology of events of a disaster (in this case it was the Ais Gill disaster that occurred in 1995, in Cumbria, UK). Then further questions were asked concerning each of the events. This is the method that my research used.

The interview protocol is in Appendix E. Next I describe the participant selection process. 


\subsubsection{Participant selection}

The participants in this research have been selected from those who are and have been working in emergency management and response organizations for at least 15 years and have experience leading a unit or organization at the district or national level and have managed information flow during a (or multiple) disaster(s) that involved two or more agencies.

The participant selection process started by obtaining insights into the current issues and policies in disaster management in New Zealand. This was done by scanning and reading an extensive array of related public information on disaster management in New Zealand from relevant websites and public documents. The websites included the Ministry of Civil Defence and Emergency Management (MCDEM) page and the Joint Centre for Disaster Research (JCDR), Massey University, New Zealand. I also attended a disaster management conference in 2014 for networking purposes, where I gained updated knowledge on disaster management in New Zealand and also identified the relevant participants in this area.

Next, I narrowed the search for participants to the Civil Defence group of Greater Wellington. This selection was because not only does the group coordinate Civil Defence and Emergency Management services on behalf of nine councils in the Wellington region which provides a larger pool of potential participants, it also provided convenience in time and reduced travel costs as it is located in the same region as mine.

Finally, I managed to gain initial access to one of the participants through my $\mathrm{PhD}$ supervisor's network. The participant works as an Emergency Management Office advisor in one of the district councils of the Greater Wellington Region. From there, a purposive sampling method was employed. 
Below is the summary of the background of my research participants.

\begin{tabular}{|c|c|c|c|c|c|}
\hline KB & Level & $\begin{array}{l}\text { Years of } \\
\text { experience }\end{array}$ & Role & $\begin{array}{l}\text { Scenarios } \\
\text { provided }\end{array}$ & Type of disaster \\
\hline \multirow[t]{2}{*}{ KB1 } & \multirow[t]{2}{*}{ District } & \multirow[t]{2}{*}{15} & Principal Rural Fire Officer & 3 & Fire \\
\hline & & & $\begin{array}{l}\text { Emergency Management } \\
\text { Advisor }\end{array}$ & 1 & Earthquake \\
\hline \multirow[t]{2}{*}{ KB2 } & District & 30 & $\begin{array}{l}\text { Civil Defence Senior } \\
\text { Advisor }\end{array}$ & \multirow[t]{2}{*}{4} & \multirow[t]{2}{*}{ Mid-air collision } \\
\hline & & & Principal Rural Fire Officer & & \\
\hline KB3 & $\begin{array}{l}\text { Nationa } \\
1\end{array}$ & 39 & $\begin{array}{l}\text { National coordinator of } \\
\text { Emergency Services for an } \\
\text { NGO }\end{array}$ & 2 & Fire, mine explosion \\
\hline KB4 & District & 20 & Police chief & 7 & Motor accidents \\
\hline KB5 & District & 28 & Senior Fire Service Officer & 5 & $\begin{array}{l}\text { Motor accidents, bomb } \\
\text { and earthquake }\end{array}$ \\
\hline & & & Total & 22 & \\
\hline
\end{tabular}

Table 7: Summary of the research participants

The data collection process was iterative to ensure findings emerged progressively and naturally from the data.

The data collection process was guided by the research questions. After the first $\mathrm{KB}$ interview, I transcribed it and at that point, I felt that I needed to have a deeper understanding of multi-agency information sharing situation in a real disaster. I attended a tabletop disaster simulation exercise that was organized by a District Emergency Service Committee as an observer. The disaster scenario was a pandemic. In the exercise, I took note of the common terminology and actions in a multi-agency disaster operation.

After gaining knowledge about real situations during a disaster, I interviewed the second KB. The third case emerged after the interview. It was the mid-air collision disaster. Using the same strategy as the first interview, I attended a field simulation exercise organized by a district Fire Service as an observer. The field simulation exercise was a plane crash disaster behind an airport. The Fire Service set up realistic situations with victims, fire and smoke. Three fire engines, two ambulances, four police cars, the airport manager and the district 
emergency management office were involved in the field simulation exercise. During the exercise, I positioned myself in the most effective area: i) at the crashed plane site (with real fire and smoke) in the bush area, ii) at the point of access to the crash site where firefighters, ambulance and police vehicles were stationed, and iii) inside the incident control point vehicle which was the information hub where the disaster operation leader made important plans and decisions. During the exercise, I was able to take note of what would happen in a real plane crash disaster which involved multiple agencies. This helped me to understand the second case better. At this stage I started to analyze the data from the two interviews which resulted in three cases.

The third KB was then interviewed. The fourth and fifth case emerged. One of the cases involved setting up a community information hub following a mine explosion. Again, as with the first and second interviews, I attended another simulation exercise. This time it was a district community simulation exercise where the Civil Defence Centre (a community gathering point in a disaster) was activated following a 40 second large impact earthquake. Around 50 community members were involved in this simulation exercise. The district emergency management office designed 53 different scenarios which community members went through following the disaster. The goals of the exercise were i) to establish a functioning Civil Defence Centre (i.e. gathering point), ii) to see evidence of good information management and a good level of service to the public, and iii) to see evidence of coordination, information sharing and priority setting. I was an observer in that exercise and also participated as an actor in some of the scenarios given. This again allowed me to gain insights from the perspective of the community during a disaster.

Then, the fourth and fifth KB were interviewed. Here I refined my interview questions according to the insights that I gained after interviewing the previous three $\mathrm{KB}$, attending three simulation exercises and analyzing the data. I obtained five additional cases in these two interviews. At this stage, my thinking became clearer as I had ten cases and the experience of attending the three simulation exercises. The data collection process is illustrated in Figure 6: 


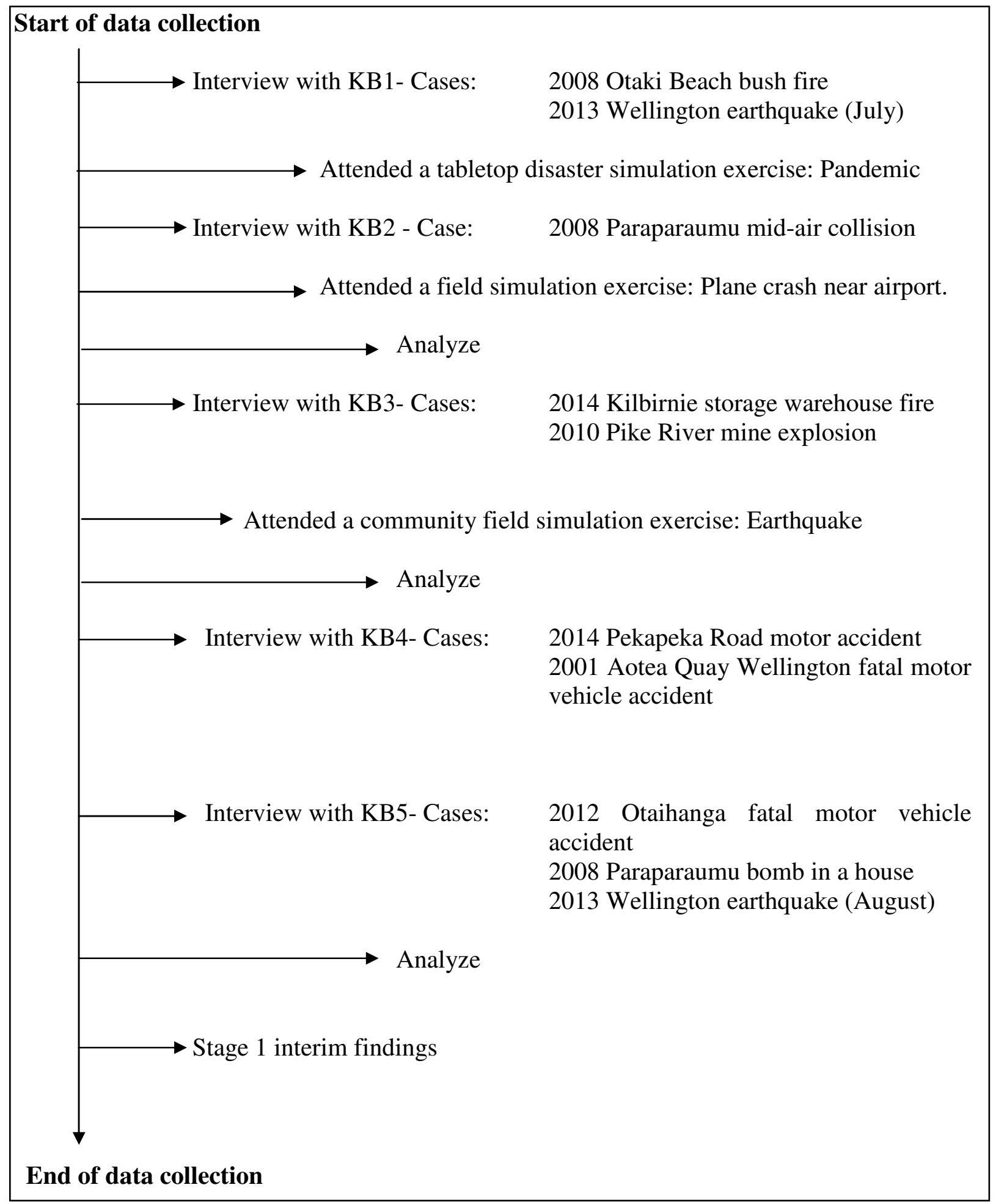

Figure 6: The data collection process

I analyzed the data iteratively after the third, fifth and tenth (i.e. final) cases were collected. I coded the data manually (using a color coding technique) guided by my research question. 
During the analysis after the tenth case, I discovered the two-phase process of information flow experienced by the KB. The KB were found to be filtering the information they received to assess its veracity and recalling an experience to identify the relevance of the information.

\subsubsection{Case selection}

A purposive sampling method to identify the cases was employed after the first case was found. In satisfying the characteristics of multiple-case research discussed earlier in section 3.2.2, ten different cases (i.e. disasters) were selected and analyzed. Eisenhardt (1989) recommended that in theory-building case research, 4-10 cases should be considered due to time limitations and handling complexity. It is acknowledged that Eisenhardt is taking a positivist stance in recommending the number of cases. To my knowledge, there is no study recommending the best number of cases for a research. There are some studies in IS such as that of Myers (1995) who used three case studies. This can be the foundation.

The selection of these different disasters enables this research to conduct a cross-case analysis for theoretical replication and generalization. The ten different disasters, spanning between 2001 and 2014, were identified and selected from five face-to-face interviews with five KB. All of the cases are presented in vignette format in Chapter 4.

The cases include (arranged in descending order of year):

i) 2014 Kilbirnie storage warehouse fire (Fire)

ii) 2014 Pekapeka Road motor accident (Motor accidents)

iii) 2013 Wellington earthquake (August) (Earthquake)

iv) 2013 Wellington earthquake (July) (Earthquake)

v) 2012 Otaihanga fatal motor vehicle accident (Motor accidents)

vi) 2010 Pike River mine explosion (Mine explosion)

vii) 2008 Paraparaumu mid-air collision (Mid-air collision)

viii) 2008 Otaki Beach bush fire (Fire)

ix) 2008 Paraparaumu bomb in a house (Bomb)

x) 2001 Aotea Quay Wellington fatal motor vehicle accident (Motor accidents) 
There are some other cases which I obtained through observations and interviews which were not included in the list because either the cases did not provide enough depth for this research or they happened too long ago. Cases which were identified as lacking depth include three simulation exercise observations: i) 2014 Paraparaumu Airport, airplane crash simulation exercise, ii) 2014 Waikanae community, large earthquake simulation exercise, and iii) 2014 Kapiti Emergency Service Committee SARS pandemic tabletop simulation exercise. One case which was identified through an interview occurred almost 50 years ago and because it was so long ago, it was not selected in order to avoid recall bias (1968 Wellington Wahine ferry sinking). However, my observation of the three simulation exercises contributed to the snowball technique in that two KB were identified and interviewed, leading to 5 of the 10 cases listed above. In addition, the notes from these unused cases were helpful for generating ideas in the analysis stage.

The selected ten cases also shared the following characteristics:

- The cases have the features of Naturalistic Decision Making (NDM) as discussed in Chapter 2 (i.e. literature review);

- Each of the cases has one to four unique scenarios that highlight the flow of information from receiving to sharing the information with someone else that relates to this research.

In summary, the cases were carefully selected to fit the context of this research which is disasters that occurred in New Zealand. The cases also met certain criteria that justify their selection.

\subsubsection{Approach to conducting interviews}

I conducted in depth interviews to obtain 22 scenarios (i.e. unit of analysis) from five experienced KB. There were three strategies that I used in all of the interview sessions.

The first strategy was as discussed in the section above: prior to the interview, I asked the KB to list any disasters that they had experienced, preferably in the last 2 years. Also, because I had mentioned the context of my research using the diagram of information flow (see Figure 
7 below), the KB had clear direction on which disasters to recall for the interview purposes. All five KB managed to list the disasters that they would like to discuss prior to the interview. At the start of the interview session, I asked the $\mathrm{KB}$ to start with the first on the list of disasters they had previously identified. I divided each disaster's discussion into two parts. In the first part, I let the KB 'tell the story' of a particular disaster experience according to their own 'version'. While they were 'telling their stories', I wrote down important incidents (i.e. scenarios) that I wanted to ask more about later. In the second part, once the participants had finished describing the first disaster, I referred to the scenarios that I had noted and I started to ask questions about the relevant information sharing incidents from the beginning of their 'story', which required them to explain more. This allowed me to obtain richer data from them.

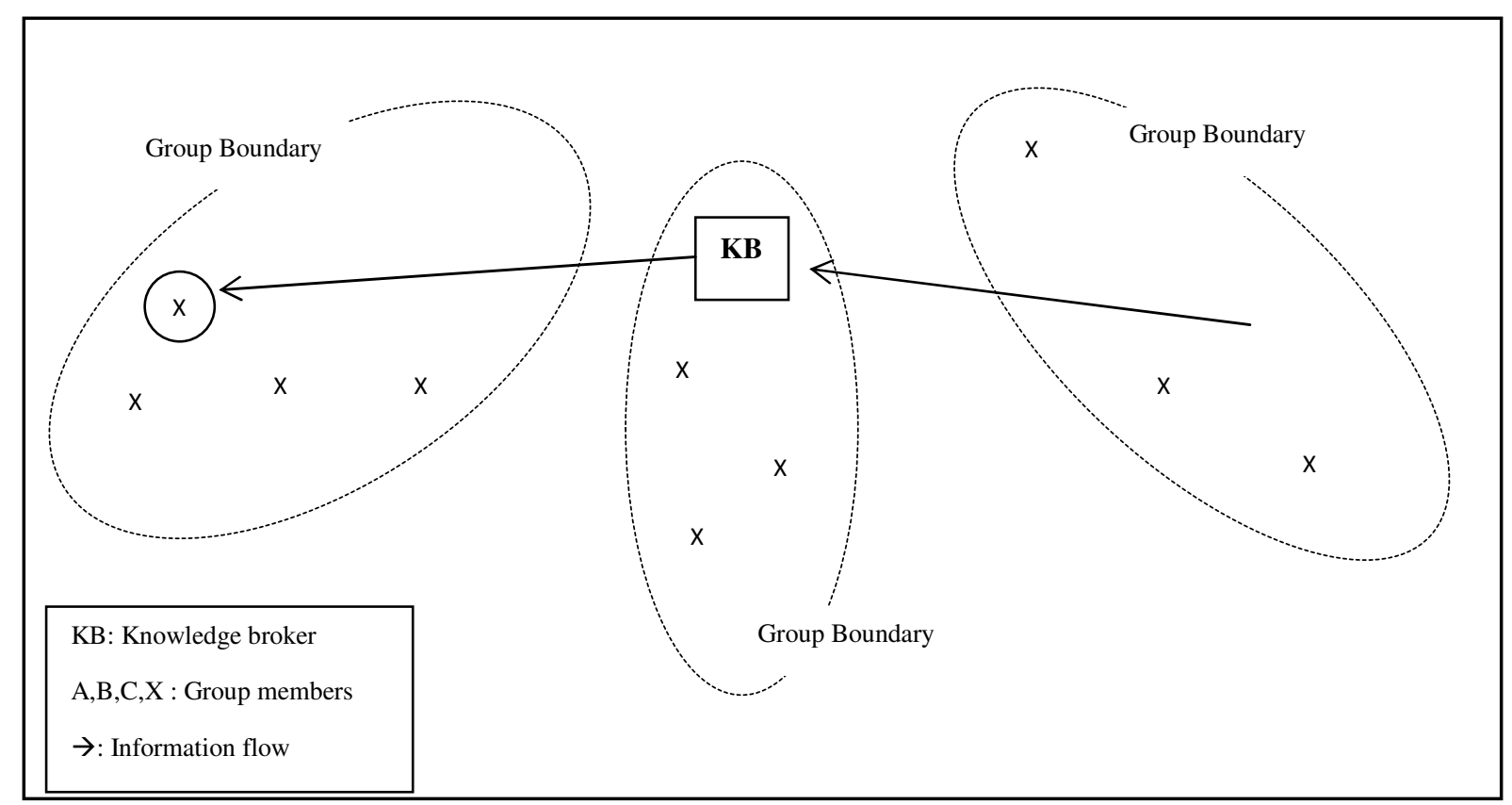

Figure 7: Information flow across different boundaries

An example of my interview strategy is as follows:

When KB2 was telling the story of the 2008 Paraparaumu mid-air collision disaster, he presented his story initially as:

"I had the feeling that it was a weekend at that time and I was in Johnsonville. But because I am on call, I had a work truck which was the Civil Defence and Rural Fire 
response vehicle. When the disaster hit... I was in a meeting and the pager went off and also it was an air accident so it did not involve me particularly anyway. So, I did not do anything to start with. And the other alarm went off, I realized we had a big disaster and something had happened. And I had better to response, because somebody from the council need to be there and it would be me. So, I then went back from Johnsonville, back to Paraparaumu, with sirens and lights going to get there and I followed the police car the whole way actually it was quite interesting...”

The story continued for another 10 minutes. When KB2 finished his story, based on my notes, I started to ask more questions to clarify the details in each scenario for deeper data. In the example above, I asked questions such as:

- "We get back to the moment when you were in Johnsonville. Who paged you at that time? Can you describe the situation?"

- "So you immediately went to your vehicle and turn on the radio channel... and what happened then, why did you do that?"

- "What did the page message said?"

The second strategy was aiming to collect data from as many disasters as possible from a single participant. This is in line with the multi-case research approach of my research. Also, by doing that it was hoped that I could select the cases (disasters) from a wider selection depending on their depth.

The third strategy was my interviewing style. In this strategy, I followed Walsham's (1995, p. 78) recommendation. I actively listened to the 'stories' of the participants and tried to prompt questions that would lead to new directions and also not offer my own ideas or opinions on the discussed issues. Social skills were necessary to make the KB comfortable during the interview session. I tried to emulate the KBs' relevant social level and language use which I had captured during the informal face-to-face social session with the $\mathrm{KB}$ prior to the interview. I developed these social skills throughout years of experience working in higher management and decision maker positions previously. 


\subsubsection{Gaining trust from the participants}

Gaining trust between the participant and the researcher is essential. This is because interview participants were asked to share their experience in information sharing during disasters and some might be sensitive either in their personal life or for their organization. LaRossa, Bennett, and Gelles (1981) and Corbin and Morse (2003) stated that gaining trust of the participant, especially regarding sensitive experiences or issues, might entice the participant to be more open and be willing to share information.

To gain trust between the participants and the researcher, one of the strategies that I employed was building a certain degree of rapport with the participant before the interview session took place. One of the strategies was through an informal face-to-face social session prior to the interview. Following the initial contact through telephone or email, I visited the participant at an agreed time and venue; most of them were during working hours and in the participant's office. During the first visit, both the participant and I interacted socially to get to 'know' each other better. The topics of discussion were family, personal interests and general issues. This took 10-15 minutes. Once I observed that the participant was comfortable and more open in interacting with me (i.e. through their personal life stories and a relaxed voice tone), I started introducing my research background. To give them a better understanding of my research, I showed them the information flow across boundaries diagram

Next, the participant was asked to recall and list a few disasters that they have experienced. This tactic was also to ensure that I would be interviewing the 'right' participant or KB. I then wrote down all of the disasters that they mentioned. At the end of the initial discussion session, I let them know which disasters they mentioned that I was interested in that suited my critical incident criteria (i.e. disasters that involved different agencies or group responses and within the first 3 days after the disaster) and let the participants know that I would interview them based on those selected disasters only. Between that stage and the actual interview day, I conducted a news scan through the internet and read about the incident. This was to ensure that I had a basic understanding of the disaster before interviewing them. However, in the pre-interview session with the last two participants, they did not provide a list of disasters that they had experienced because they said there were too many and they needed more time. Those two participants were given at least one week before the interview to recall them. 


\subsubsection{The role of the researcher}

According to Walsham $(1995,2006)$ there are two different roles of the researcher: the 'outside observer' and the 'involved researcher'. The former conducts the study through formal interviews with no direct involvement to provide significant feedback to the participants. The latter has the advantage of getting a deeper 'inside view' of the participants.

My role in this research is the outside observer. This role enabled me to conduct the research through interviews with no direct involvement (Walsham, 2006) as I was conducting exploratory case research. One of the reasons for the selection of an 'outside observer' for this research was due to the emergency service organizations not wanting me to be deeply involved in their organization as it involves critical and sensitive information and I would need to attend specific training sessions to be able to be involved in their organization.

Another reason was because this role required me to have some distance from the research settings and $\mathrm{KB}$. Because I neither engaged directly with the organization nor the KB, I had two advantages. First, the interpretation of data involved less personal bias and second, KB would be more open when sharing their experiences. Although Walsham (1995) acknowledges that an outside observer has some disadvantages such as that the researcher may not be present on many occasions which results in not getting a direct sense of the field and that the researcher may have limited data from the organization, I saw this was not the case. The disadvantages were more applicable to ethnographic research whereas my research was a case study and data were collected through face-to-face interviews, not through observations. Because of that, I did not have to attend many occasions to collect data. Furthermore, I built rapport with the KB in the informal session mentioned in section 3.3.2 prior to the interview, so KB were open to sharing their experiences. Therefore an outside observer role suited my research well.

The context of my research has to do with decision making as I was exploring how $\mathrm{KB}$ decide the veracity and relevance of the information they received during a disaster. Although I did not have experience in disaster management, my experience working for more than ten years in high level management and decision making provided both an advantage and a disadvantage. The advantage was that I had a degree of knowledge and background on the nature of decision making under pressure that helped in my generation of ideas from data 
gathering up to the final stage of my research. The disadvantage was that my background was from the business and corporate world which has minimal similarity with disaster management. However, with my social networking skills, I managed to gain entry into the disaster management network through both academics and practitioners while doing this research. Also, I attended three disaster simulation exercises involving the emergency service personnel and the community in between the interviews to develop a deeper understanding and knowledge in this area. These helped me to become familiar with the current issues and terminology of disaster management in New Zealand.

The next section details the research process by describing the phases of my research.

\subsection{Data analysis procedure}

Fundamentally, qualitative research requires interpretation of data (Creswell (2003). For ensuring a high standard of data analysis, Yin (2009) has outlined the following four basic principles: first, attend to all evidence (i.e. the data); second, address all major rival interpretations (i.e. all similar findings and interpretations by other scholars are discussed); third, address the most significant aspect of this study; and fourth, use one's own prior expert knowledge. My research followed all four principles.

Data analysis includes description development, theme scanning, data interpretation and conclusions. To ensure careful and systematic data analysis in this research, I used the data analysis framework outlined by M.B. Miles and Huberman (1994). This framework includes three major components: data reduction, data display and conclusion drawing (see Figure 8 below). 


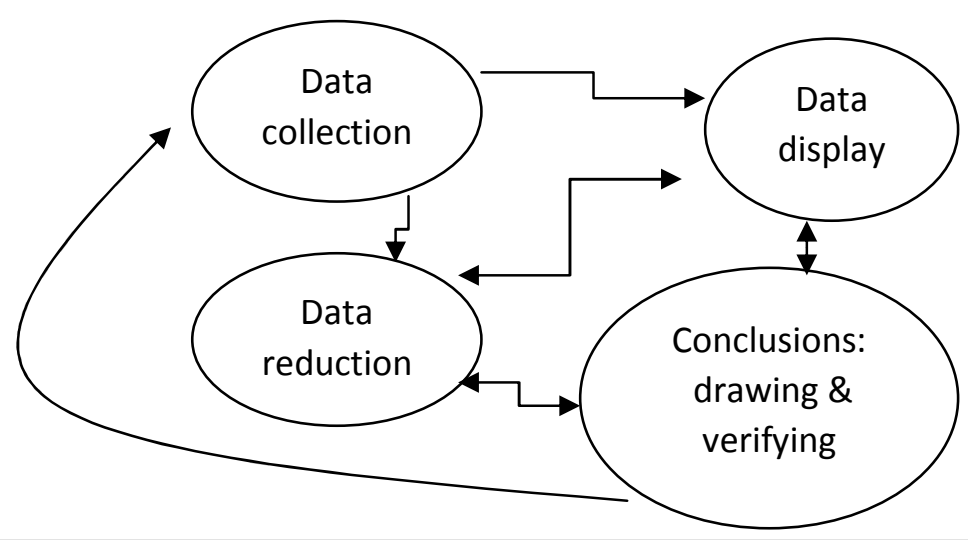

Figure 8: Components of data analysis (Source: Miles \& Huberman (1994) p. 12)

\subsubsection{Data reduction}

M.B. Miles and Huberman (1994) define data reduction as the process of selecting, focusing, simplifying, abstracting and transforming the data (see Figure 9 below).

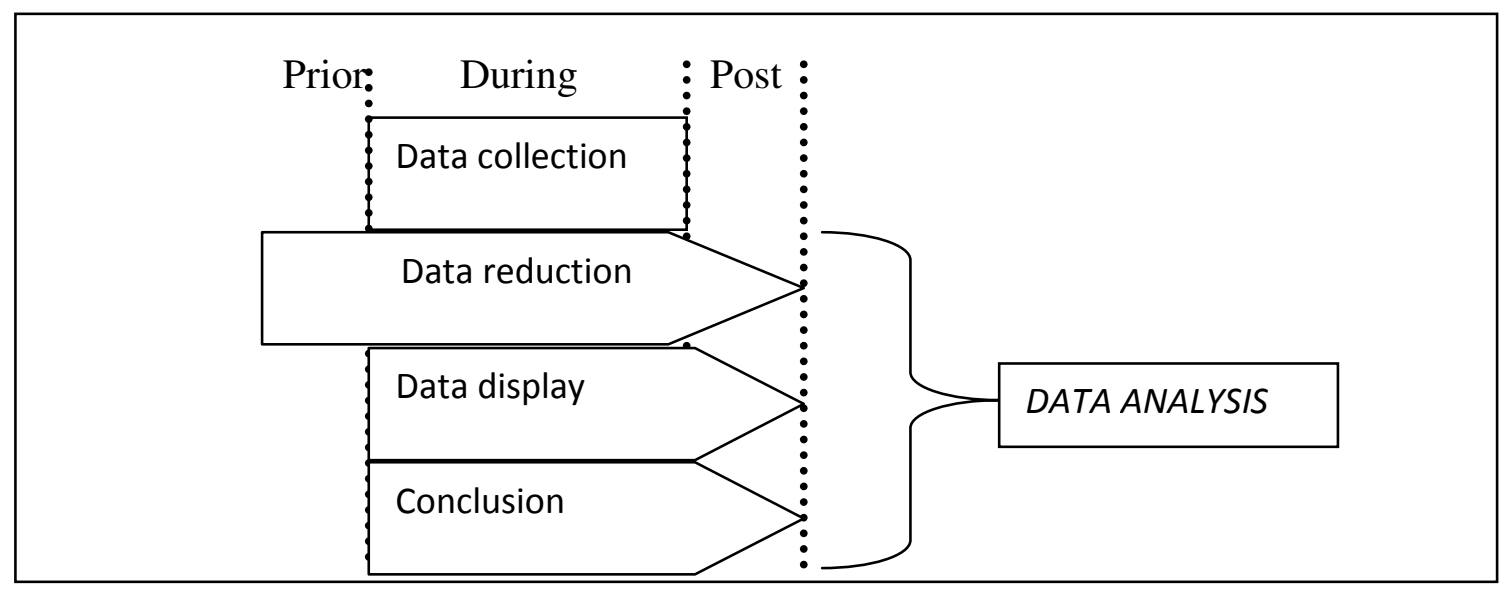

Figure 9: Components of data analysis, adapted from: Miles \& Huberman (1994, p. 10)

The next subsection describes the process of data reduction (i.e. analysis) in detail. 


\subsubsection{Process of data analysis}

As mentioned in the data collection and analysis process (see section 3.5), there were several stages of analysis. Figure 10 outlines the process of analysis in each stage of the research process:

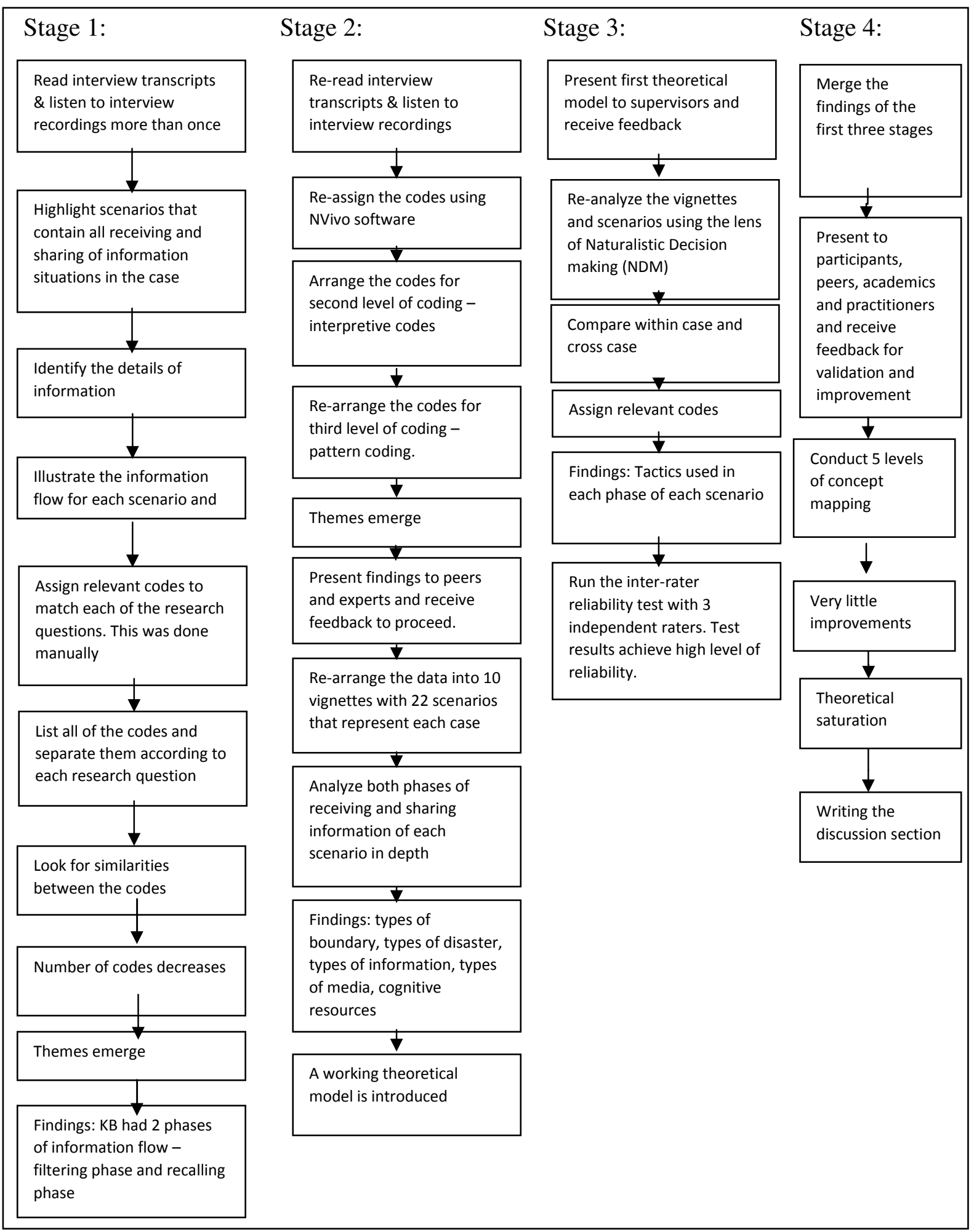

Figure 10: Process of analysis in each stage 


\section{Stage 1 data analysis}

At the beginning of this stage, I listened to the interview recordings and repeatedly read the interview transcriptions as well as my observation notes. This was done in order to gain a clear understanding of the collected data. Then, I highlighted the scenarios which focus on the process of receiving and sharing of information. Then, I arranged the chronology of the events. Codes were assigned according to the two research questions. Next, I looked for similarities between the codes to find any emerging themes. The number of codes decreased and themes emerged.

The themes were filtering and recalling. Based on those themes, I found that there were two phases of information flow that KB experience during a disaster - Phase 1, the filtering phase to assess the information's veracity; and Phase 2, the recalling phase when they recall an experience to identify the relevance of the information. The findings at this stage were presented to participants (i.e. in a one-to-one session), peers (i.e. through a presentation) and academics from the School of Information Management, Victoria University of Wellington (i.e. in a one-to-one session) for validation and further improvements. In order to gain greater depth, I moved to the next stage.

\section{Stage 2 data analysis}

The analysis process at this stage started with reading the interview transcript and listening to the interview recordings again. This was done in order to gain a deeper understanding of the KBs' meanings in the interviews. I started to learn how to use NVivo software to assist in the next round of analysis. Once I knew how to use the software, I started to assign new codes to the interview transcripts. This was done inductively when codes emerged from the data. I was impressed with the flexibility of NVivo's functions which allowed me to code, re-code and group the codes. This assisted me to think and conceptualize the themes that emerged. After my third level of coding (i.e. pattern coding), themes started to emerge. I found stimuli linked to the two phases found in my first stage of data analysis.

I then presented my interim findings to a group of experts, including academics (i.e. from School of Information Management, Victoria University of Wellington in a one-to-one session) and participants (i.e. in a one-to-one session). I received useful feedback. I considered all feedback combined with deep thinking on ways to achieve an acceptable level 
of depth in my research findings. After considering all feedback, more reading and thinking reflectively, I found a way to address the issue.

The next level of analysis started with listening to the interviews and reading the transcriptions again. At this point, I was immersed in the data until I could recall phrases from interviews and also imagine the exact situation that happened as told by the KB.

Then I 'told the story' of the KB's experience in each disaster. This was done by writing up the cases in vignettes. A vignette is one of the methods of describing data, especially actions. They are a "focused description of a series of events taken to be representative, typical or emblematic in the case you are studying" (Matthew B Miles, Huberman, \& Saldaña, 2014, p. 182). They have a narrative style and preserve the chronological flow. There are no specific guidelines on writing vignettes; however it is recommended that they have sufficient descriptive detail, which I included.

The vignettes in my research are descriptive in nature, so that the reader can imagine what happened during the disaster from the viewpoint of the $\mathrm{KB}$ who were interviewed. Each vignette represents a case (i.e. disaster). Since ten cases were identified from the five KB, there are ten vignettes in total.

Scenarios are included in each vignette. They describe the KB's experience in relation to the information sharing process. The process starts from receiving the information from someone, the process that follows and the final destination of the information (i.e. with whom the information is shared). While the number of scenarios varies in each vignette, there are a maximum of four scenarios in a vignette as told by the interview participants. A total of 22 scenarios were found from the five KB.

Evidence from scenarios follows each vignette. This is in the form of actual quotes from the interview transcript. The evidence corroborates the scenarios described in the vignettes to ensure data reliability. The order the sentences appear in has been re-arranged from the original sequence during the interview to reflect the KB's experience timeline and chronology of each scenario. Each piece of evidence was given a reference initial as the subheading. The initial is a reference linking the evidence with the scenarios described in the vignettes. The initial ' $\mathrm{V}$ ' stands for 'vignette'. The number following the ' $\mathrm{V}$ ' refers to the number of the vignette. Since there are ten vignettes in total, the number following the ' $\mathrm{V}$ ' is 
from 1 to 10 . The initial ' $S$ ' stands for 'scenario'. The number following the ' $S$ ' refers to the scenario number in each vignette. While the number of scenarios in each vignette varies, there was a maximum of four scenarios in a vignette. So the number following the ' $\mathrm{S}$ ' is from 1 to 4. For example, V1S1 refers to Vignette 1, scenario 1 and V7S4 refers to Vignette 7, scenario 4. Some pieces of evidence have superscript numbers. These refer to the analysis point number which is explained in the next paragraph.

Analysis was conducted on each piece of evidence. The analysis is presented in numbered points. The numbers of each analysis point are linked to the evidence. This was done to ensure evidence traceability. The analysis was divided into two phases: phase 1 and phase 2 . As found in stage one of the data analysis, Phase 1 is a process that starts from the $\mathrm{KB}$ receiving the information from the source and ends at the decision on the reliability of the information. Phase 2 is the process that starts after phase 1 and ends at the decision of to whom the information is relevant. The themes found in each scenario in the analysis were derived from a number of codes.

The themes that emerged following the analysis were types of boundary, types of disaster, types of information, medium of sharing, cognitive resources used and methods of matching the information to someone.

Next, I compared scenarios within cases and across cases. Within-case comparison was when I compared more than one scenario experienced by a KB in the same disaster. Across-case comparison was when I compared scenarios from different disasters, which could be from the same or different KB.

An example of within-case analysis is the comparison of V1S1, V1S2, and V1S3 which were experienced by the same KB (in this case KB1) and in the same disaster.

An across-cases example is the comparison of V1S1 and V2S1. V1 and V2 are two different disasters, but the scenarios were both experienced by KB1. However, the between-case analyses also include comparisons of scenarios between different $\mathrm{KB}$ and different disasters, for example, the comparisons of $\mathrm{V} 1 \mathrm{~S} 1, \mathrm{~V} 3 \mathrm{~S} 1$ and $\mathrm{V} 5 \mathrm{~S} 1$. The three scenarios were experienced by different $\mathrm{KB}-\mathrm{KB} 1, \mathrm{~KB} 2$ and $\mathrm{KB} 3$ - in different disasters.

The findings at this stage were presented to participants (i.e. in a one-to-one session), peers (i.e. in a $\mathrm{PhD}$ student's presentation sesssion), academics and practitioners (i.e. in an 
international disaster management conference held in Wellington) for validation and further improvements. After making improvements, the first theoretical model emerged. I then moved to stage three of the analysis.

\section{Stage 3 data analysis}

At the start of this analysis stage, I presented my theoretical model to experts and received feedback and suggestions. In accordance with the feedback I analyzed the model by looking in more depth. This means I aimed to investigate what was going on behind the KB's experience of the process of information flow. To do this, based on feedback, suggestions and readings, I used the Naturalistic Decision Making (NDM) theory. This was discussed in Chapter 2 (Literature review).

To confirm that my research could be analyzed using the lens of NDM, each scenario was matched with the relevant features of NDM as suggested by (G. Klein \& Klinger, 1991). All 22 scenarios have NDM characteristics, which confirmed the use of the NDM lens.

Then I analyzed all phases in the 22 scenarios of the 10 vignettes starting with assigning relevant codes. The codes are the tactics used by $\mathrm{KB}$ in each scenario to assess the veracity and relevance of the information they received. This was done deductively in that the tactic codes were taken from one of the relevant studies in the NDM field (Lipshitz \& Strauss, 1997). These tactics were discussed in the literature review chapter (Chapter 2, section 2.4.3). In addition, I combined the analysis in this stage using the themes that emerged in stage two. These are types of disaster, types of boundary and types of information.

To confirm the reliability of the codes, I conducted an inter-rater reliability test. The details of this test are discussed in section 3.6.6. The test was taken by three independent raters with the aim of achieving results that support the reliability of my codes. The codes from the test were compared between the raters. The result of the kappa rate $(\mathrm{k}=0.803)$ proved that my coding is reliable.

Once the reliability of the codes was confirmed, I went deeper into the analysis. Both phases (i.e. phase 1 and phase 2) in each scenario were compared and analyzed. The comparisons were made in both Phase 1 and Phase 2 separately. These were: 
i) Comparison between tactics $\mathrm{KB}$ used and types of boundary in each scenario;

ii) Comparison between tactics $\mathrm{KB}$ used and types of information in each scenario; and

iii) Comparison between tactics $\mathrm{KB}$ used and types of disaster in each scenario.

The reason for conducting this comparative analysis was to provide a comprehensive understanding and to prove that an in-depth analysis had been conducted to understand the tactics that KB used in both phases.

Following the comparative analysis, a number of themes emerged. The findings at this stage were presented to participants (i.e. in a one-to-one session), peers (i.e. in a $\mathrm{PhD}$ student's presentation session), academics and practitioners (i.e. in one of the disaster management seminar held in Wellington) for validation and further improvements. I then moved to the final stage of analysis.

\section{Stage 4 data analysis}

At this stage of analysis, I merged all the findings from all the previous stages of analysis with some modifications.

Then I presented the theoretical model to participants (i.e. in a one-to-one session), peers (i.e. in a $\mathrm{PhD}$ students' monthly meeting), academics (i.e. in a one-to-one session) and practitioners (i.e. in a special interest group for disaster management meeting, which included representatives from the NZ Earthquake Commission and NZ Geo Net) and received feedback for validation and improvement. I conducted five levels of conceptual mapping to achieve a high level conceptual model and propositions (See Appendix F for manual (i.e. hand-written) versions of mappings). Once I saw that there was very little room for modification in the working theoretical model - a situation called theory saturation - I finalized the theory and presented it to the participants for validation. Once the theoretical model was validated, I began to write my report. 


\subsubsection{Data display}

Miles and Huberman (1994) have identified a few methods of displaying data that has been or is being analyzed. These methods may include tables, matrices, scatter plots and composite sequences to link the data and final themes associated with different case studies. The rationale for using the display methods is to enable the reader to visualize the interpretations in a more understandable and practical format as compared to long paragraphs or writing (M.B. Miles \& Huberman, 1994). I have used diagrams, flowcharts, illustrations and vignettes.

\subsubsection{Data conclusions}

This final component of data analysis will attempt to draw conclusions based on the iterative process of the first two components: data reduction and data display. The generation of new theory emerged from the prior component processes. By ensuring that the development of a new theory was acceptable, I complied with the quality and rigor standards suggested by Guba (1981).

\subsubsection{Theory development}

There are five theory types in IS research (Gregor, 2006): i) analysis, ii) explanation, iii) prediction, iv) explanation and prediction, and v) design and action. My research findings come under the second type of theory: theory for explanation. This type of theory explains the 'how' and 'why' of a phenomenon: a process-type theory. It is also described as a theory for understanding which explains a situation where little or no relevant theory can be related to the phenomenon. This supports the categorization of my research as this type of theory. Furthermore, Gregor (2006) suggests that the approaches that can be adapted to develop a theory of explanation include case studies and interpretation with words, diagrams and tables as the means of theory representation; all of these have been adopted in my research.

During the data analysis stage, I refined the emerging themes iteratively in four stages (see section 3.6.1.1). This indicates that the theory emerged after rounds of analysis. This 
inductive flow of theory generation has also been recommended by Creswell (2003). Figure 11 below illustrates the flow of my research's theory generation and was adapted from Creswell (2003, p. 132).

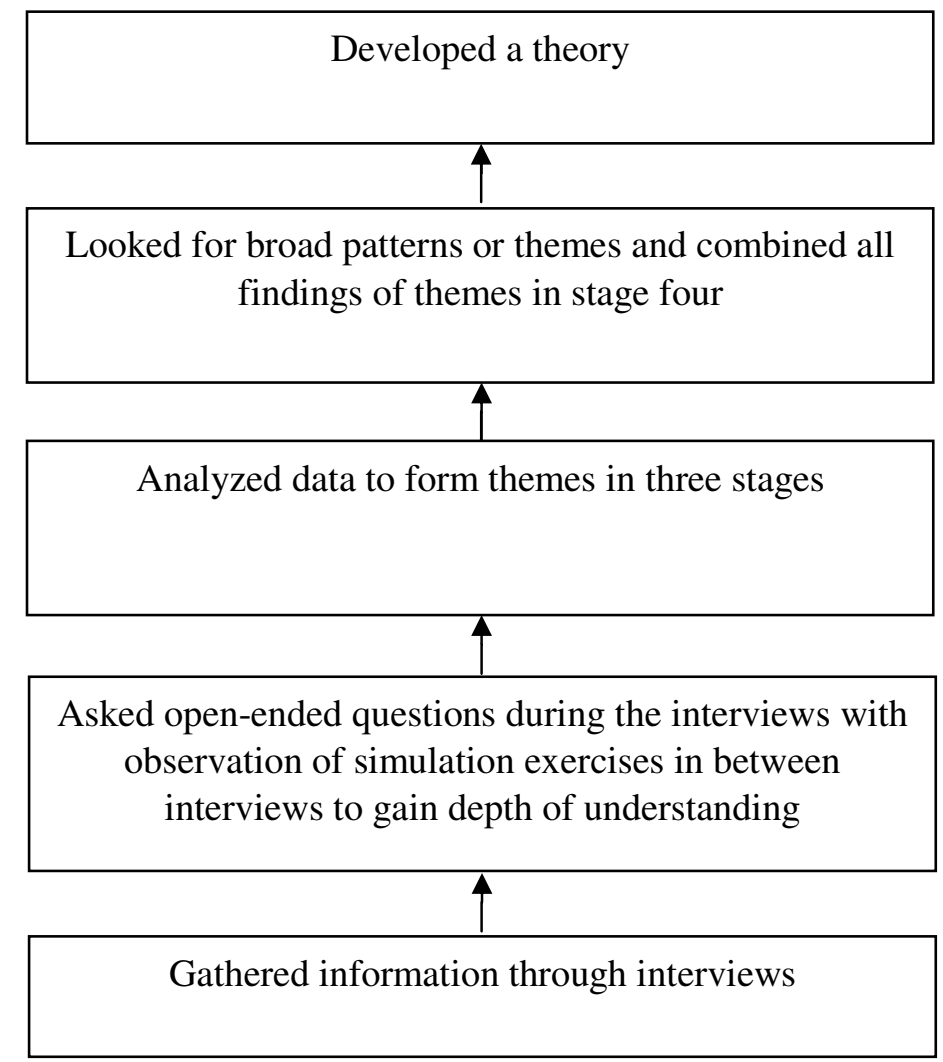

Figure 11: Inductive flow of theory generation (adapted from Creswell 2003, p. 132)

At the final stage of the theory development, I presented the theory to experts and received feedback which was done iteratively. When there was little room for improvement in my theory - a situation called 'achieving theory saturation' (Sandelowski, 1995) - I finalized the theory.

\subsubsection{Strategy to ensure quality and rigor}

Validity and reliability are central issues in research methodology. Studies in quantitative research are tested and evaluated using these two concepts. Given the definition of validity as "whether the intended object of measurement actually is measured" and the definition of 
reliability as "a measurement method's ability to produce the same research result over and over again" (Stenbacka, 2001, p. 551), neither concept seems relevant to qualitative studies. This is because in qualitative studies, no measurement is involved as it is a process of getting 'into' the data and interpreting it. Miles and Huberman (1994) mentioned that in qualitative studies, most analysis is done with words and these words can be assembled and clustered or broken into semiotic segments which then allow the researcher to contrast, compare, analyze and look for patterns among them. In addition, "qualitative research emphasizes the uniqueness of [the] human situation and the importance of experiences that are not necessarily accessible to validation" (Sandelowski, 1986, p. 33).

In ensuring the trustworthiness of this research, I followed the well-cited guidelines by Guba (1981) which comprise four factors: credibility, transferability, dependability and confirmability.

\section{1) Credibility}

Credibility in qualitative research is similar to internal validity in quantitative research which tries to ensure that the study measures what it actually intended to measure (Shenton, 2004). While methods such as prolonged engagement at a site were not feasible due to time constraints of this research, other methods such as persistent observations, the establishment of structural corroboration or coherence, a well-established research method and triangulation were adopted to ensure credibility in my research.

Persistent observations were made by revisiting data more than once. The establishment of structural corroboration or coherence can be seen in how I structured the data collection and analysis in stages. These two methods were evident in every stage of analysis as discussed in section 3.6.1.1. The implementation of a well-established research method was seen in the way I emulated well-cited studies' methods at each stage of my research as explained throughout this chapter.

Another effort to ensure the credibility of this research was member checks and also gaining approval from the Human Ethics Committee of Victoria University of Wellington. The latter is discussed in the 'Approaches to managing ethical issues' in section 3.7.6. 


\section{2) Transferability}

This aspect can be seen as analogous to external validity in quantitative research where it refers to the ability to apply the study's findings to a bigger population (Shenton, 2004). In qualitative research, the application of study findings to a bigger population is highly unlikely as the results are confined to the context of a particular research situation (Shenton, 2004). In my research, the case boundaries were made clear (see section 3.2.3) to ensure the criterion of transferability would be met. In addition, I collected and developed thick description of ideas, thoughts and data from the participants during the interviews. This will allow other investigators to gauge the relevance of the information in my research as well as to access the “degree of fittingness" of the selected participants' characteristics (Guba, 1981) to other characteristics.

\section{3) Dependability}

In quantitative research, this aspect of consistency is known as reliability whereby if the method used is repeated with the same participants, it should produce similar results. In qualitative research, handling reliability is a challenge. This is due to the nature of the research where meanings are interpreted in depth by the researcher and different realities are explored (Guba, 1981). Krefting (1991) suggested various techniques to improve dependability. Among them were in-depth description of the research method and code/recode procedures. I have achieved the former by describing my research methods in great detail throughout this chapter. The latter were conducted and have been explained in section

\subsection{1 (Data reduction).}

However, there was another method that I used to achieve dependability in my research: the inter-rater reliability test. This was conducted in stage three of my analysis. This test is described and discussed in the next section (section 3.6.6).

\section{4) Confirmability}

One strategy to achieve confirmability is in-depth coverage of the data processing. This was done by providing a detailed description of data collection, analysis notes and all data analysis methods. By including all of those, I have established an 'audit-trail' that allows future researchers or readers to trace the development of the research interpretation process to show that proper research practice has been followed (Lincoln \& Guba, 1985). 


\subsubsection{The inter-rater reliability test}

In his well-cited book, Patton (2002) emphasized that reliability is one of the important factors in determining the quality of qualitative research. One of the ways to achieve reliability is to ensure data is analyzed by multiple analysts. "A related strategy is triangulating analyst[s] - that is, having two or more persons independently analyze the same qualitative data and compare their findings" (Patton, 2002, p. 560).

The same strategy was echoed by another well-cited study, "to improve the analysis and understanding of construction of others, triangulation is a step taken by researchers to involve several investigators or peer researchers' interpretation of the data at [a] different time or location" (Golafshani, 2003, p. 604).

Pope, Ziebland, and Mays (2000) suggest that to overcome a researcher's bias in interpreting qualitative data, an audit measure such as achieving agreement with an independent researcher (i.e. a third party) on the findings could be undertaken.

While achieving a certain degree of agreement on the findings between the principal researcher and a third party is a relevant strategy to ensure reliability, some qualitative research method scholars do not mention the strategy when discussing achieving reliability in their studies. For example, Morse, Barrett, Mayan, Olson, and Spiers (2008) suggested verification strategies such as i) ensuring methodological coherence, ii) sampling sufficiency, iii) developing a dynamic relationship between sampling, data collection and analysis, iv) thinking theoretically, and v) theory development to ensure reliability and validity. Although they did not mention comparing findings or data results between two analysts as a strategy to ensure reliability, a significant number of other studies have used such strategies.

One of the methods is to put the data and findings through an inter-rater reliability test (Daly, McDonald, \& Willis, 1992; Pope et al., 2000).

In their well-cited paper, Pope et al. (2000) suggest that using an inter-rater reliability test in qualitative research may avoid the critique that findings were simply based on the subjective judgment of an individual researcher. In the study by Daly et al. (1992), the interview transcripts were analyzed by the principal researcher followed by a group of independent researchers. 
This suggests that the inter-rater reliability test is relevant and being used in qualitative studies to ensure the reliability of the findings. Interestingly, I found that there was an empirical study that argued for the effectiveness of the inter-rater reliability test (Armstrong, Gosling, Weinman, \& Marteau, 1997). In their method section, they sent one of their focus groups' interview transcriptions to six very experienced qualitative researchers to identify and 'package' the themes that the principal analyst found in the data. The study found that there was close agreement in identifying the basic themes. However, each analyst embedded or 'packaged' the themes differently. It was suggested that the differences could result from i) different geographical area, ii) discipline, and iii) personal experiences or views. This suggests that there may be some differences despite achieving acceptable inter-rater agreement in qualitative research. I then found that more recent studies still vary in their usage of inter-rater reliability tests for ensuring reliability in qualitative research. While some studies have referred to that research to support the usage of the inter-rater reliability test (O'Reilly, Karim, \& Lester, 2015) where they have used "two independent coders and consultation regarding final code labeling" (O'Reilly et al., 2015, p. 4), others have opted not to use this test and stated that the inter-rater reliability test is unusual in qualitative research (Naughton, Alexandrou, Dryden, Bath, \& Giles, 2013).

Despite the divergent opinions on using the test, a study by Burla et al. (2008) demonstrates the standard method of calculating inter-rater reliability in qualitative research. In addition, Elo et al. (2014) discussed the usage of inter-rater reliability tests in relation to the trustworthiness of qualitative research. These two studies served as guides for my study to achieve consistency in coding.

Almost all the literature reviewed so far were drawn from either the nursing or clinical domains. In contrast, I found very little literature from the IS domain supporting or opposing the use of the inter-rater reliability test. This can be seen in a recent critical review of qualitative studies in IS (Sarker, Xiao, \& Beaulieu, 2013) where no studies in IS that were reviewed in the paper used the inter-rater reliability test or at least explicitly mentioned a strategy to achieve reliability. Similarly, a well-cited paper from one of the leading IS journals (Walsham, 2006) also did not discuss the use of inter-rater reliability tests in qualitative interpretive research.

In the Naturalistic Decision Making (NDM) area, it was found that some qualitative research has used the inter-rater reliability test to achieve reliability. One example is Lipshitz and 
Strauss (1997) who collected data (i.e. cases from personal experiences) from 102 army college students ranking from Captain to Lt. Colonel. Although the research did not mention explicitly that they were conducting an inter-rater reliability test, it was clearly described in the method section that they used a method of achieving a certain degree of agreement with other analysts on their findings. In employing this method, first they trained one analyst to classify the tactics used in coping with uncertainty. Next, they trained and asked five independent judges to do the same (i.e. classify the tactics used in the cases). Both results were then compared. The inter-judge agreement (i.e. inter-rater reliability test, 'kappa') was between $\mathrm{k}=0.87$ and $\mathrm{k}=1.00$. This indicates that an inter-rater reliability test was also being used in the NDM area to achieve reliability and set a precedent to support the usage in my research.

To conclude, despite the disagreement about using the inter-rater reliability test in qualitative research discussed above, based on the solid justification from the supporters of this test (i.e. as discussed above) it can be considered relevant to qualitative research. This test was also found to be used in the area of NDM to ensure the reliability of the codes and findings, which supports its usage in my research. Therefore, my research employed the inter-rater reliability test for the codes in stage three of the data analysis.

The only reason that justifies why I only employed the test in stage three was that the coding was assigned both inductively and deductively: inductively when I used the themes that emerged from stage two, and deductively when I assigned the tactics used by KB in assessing the veracity and the relevance of the information they received.

The next subsection outlines the action and protocols that I used to test the reliability of my codes in stage three.

\subsubsection{The inter-rater reliability test protocols}

I began preparing for the test by listing and defining all of the codes that emerged inductively from the vignettes and scenarios, from stage two of the data analysis. Then, I listed and defined all of the codes that were found deductively based on previous studies. This includes tactics used in coping with uncertainty. I did not include the features of Naturalistic Decision Making (NDM) codes (Klein and Klinger, 1991) in this test because it was only being used to ensure all of the scenarios fit the research area of NDM. 
Purposive sampling was employed in this test. The sample was selected based on the criterion that they represent all of the 21 categories of codes. A sample of 63 scenarios from 6 vignettes from the total of 134 scenarios from 10 vignettes available from the data were selected $(n=47 \%)$. The 63 selected scenarios also included both phases 1 and 2 of the information sharing process. After the test had been conducted by the two raters, it was then analyzed using a pre-formatted spreadsheet.

Then, I revisited and rewrote all of the 12 scenarios by adding points from the interview transcripts for more clarity to ensure the readers would understand the 'story' well. Next, I recruited four (including 1 pilot) random $\mathrm{PhD}$ students who were doing qualitative research in a different area from Naturalistic Decision Making (NDM) as the testers to ensure expertise in coding yet maintain independence. Once the testers were recruited, I scheduled a session with the testers and ran the test.

At the beginning of the test session, I briefed the four testers about the background of my research and the meanings of all the codes involved. The testers were given a set of documents: the research brief, code details and all of the scenarios in six selected vignettes. The testers then took the test and assigned relevant codes according to their own judgment for both phases of each scenario in the six selected vignettes.

Once the test session was complete, I compared the three testers' (excluding the pilot tester) codes with my codes and calculated the agreement rate (i.e. 'kappa' rate) using a formatted spreadsheet. Finally, the test result report was written. 


\subsubsection{Inter-rater test result}

The Cohen's kappa value for the test was $(\mathrm{k}=0.803)$. Table 8 is the summary page of the spreadsheet where the test was run.

\begin{tabular}{|l|l|}
\hline \multicolumn{2}{|l|}{ Cohen's Kappa for Inter-Rater Reliability } \\
\hline File & F:[Cohen_s_Kappa_v4_fahimi2.xlsm]Report \\
\hline Date Run & 27 -Aug-15 \\
\hline Number of Items & 63 \\
\hline Number of Raters & 4 \\
\hline Number of Categories & 21 \\
\hline Raters & RATER 1, RATER 2, RATER 3, FAHIMI \\
\hline Items & $\begin{array}{l}\text { V1S2P1A, V1S2P1B, V1S2P1C, V1S2P2A, V1S2P2B, V1S2P2C, V1S3P1A, } \\
\text { V1S3P1B, V1S3P1C, V1S3P2A, V1S3P2B, V1S3P2C, V2TOD, V2S1P1A, } \\
\text { V2S1P1B, V2S1P1C, V2S1P2A, V2S1P2B, V2S1P2C, V3TOD, V3S1P1A, } \\
\text { V3S1P1B, V3S1P1C, V3S2P1A, V3S2P1B, V3S2P1C, V3S2P2A, V3S2P2B, } \\
\text { V3S2P2C, V3S3P1A, V3S3P1B, V3S3P1C, V3S3P2A, V3S3P2B, V3S3P2C, } \\
\text { V4TOD, V4S1P1A, V4S1P1B, V4S1P1C, V5TOD, V5S1P1A, V5S1P1B, } \\
\text { V5S1P1C, V5S1P2A, V5S1P2B, V5S1P2C, V6TOD, V6S1P1A, V6S1P1B, } \\
\text { V6S1P1C, V6S2P1A, V6S2P1B, V6S2P1C, V6S2P2A, V6S2P2B, V6S2P2C, } \\
\text { V6S3P1A, V6S3P1B, V6S3P1C, V6S3P2A, V6S3P2B, V6S3P2C, V9TOD }\end{array}$ \\
\hline Categories & $\begin{array}{l}\text { ABR, ACC, ADV, AWA, BOM, COL, COM, COR, EQK, EXP, FIR, HRC, } \\
\text { IGU, INF, INV, NOT, ORG, REQ, SOP, UNT, UPD }\end{array}$ \\
\hline Cohen's Kappa & $\mathbf{0 . 8 0 3 0 0 9 5 2 8 ~}$ \\
\hline
\end{tabular}

Table 8 : Inter-rater test results summary

The pairwise results are shown in Table 9.

\begin{tabular}{|l|c|l|l|}
\hline & RATER 2 & RATER 3 & FAHIMI \\
\hline RATER 1 & 0.7093623 & 0.897030782 & 0.794509 \\
\hline RATER 2 & & 0.777385159 & 0.759476 \\
\hline RATER 3 & & & 0.880293 \\
\hline
\end{tabular}

Table 9: The pairwise results

The pairwise results show that the lowest inter-rater agreement is between Rater 1 and Rater $2(\mathrm{k}=0.7093)$. The highest agreement is between Rater 1 and Rater $3(\mathrm{k}=0.897)$. Also, the result between Rater 3 and Fahimi is $\mathrm{k}=0.880293$ which has the second highest agreement among the raters. The next section analyzes the results. 


\section{Inter-rater test result analysis}

In this section, only the area of disagreement in the "tactics used" area is analyzed and discussed. This is because the area was the highest area of disagreement.

\section{Area of disagreement and discussion}

In this test, disagreement is defined as 'any result in each item that does not have $100 \%$ agreement among all raters', including the researcher. In total, there were 19 items involving disagreement from the total of 63 items tested $(n=30 \%)$. Interestingly, only 1 item from the 19 disagreements had $0 \%$ agreement (i.e. all raters coded the item differently). The balance of 18 disagreement items have agreement between at least two testers.

The breakdown of the frequency of the disagreements in the area of category is shown in Table 10

\begin{tabular}{|l|c|c|c|}
\hline Phase & $\begin{array}{c}\text { Phase 1 } \\
\text { (receiving info) }\end{array}$ & $\begin{array}{c}\text { Phase 2 } \\
\text { (sharing info) }\end{array}$ & Combined total \\
\hline Types of disaster (TOD) & 0 & N/A & 0 \\
\hline Types of boundary (TOB) & 3 & 1 & 4 \\
\hline Type of information (TOI) & 3 & 3 & 6 \\
\hline Tactics used (Tactics) & 5 & 4 & $\mathbf{1 9}$ \\
\hline Total & $\mathbf{1 1}$ & $\mathbf{8}$ & 9 \\
\hline
\end{tabular}

Table 10: Area of disagreement and the frequency 
Based on Table 10, Phase $1(n=11)$ has more disagreement than Phase $2(n=8)$. In the area of category, 'Tactics used' by knowledge brokers to identify the veracity and the relevance of the information has the most disagreements among the raters $(n=9)$. As mentioned earlier, only one item had $0 \%$ agreement and it is Vignette no. 5 - scenario 1 - phase 1 - tactics used. Also, almost all (i.e. 18 out of 19) of the disagreements were contributed by only one rater.

Then I focused more closely on the area of category with the highest disagreement: the area of 'tactics used' (i.e. $n=9$ ). The number of disagreements in this area is 9 items from the total of 19. This was then further analyzed.

Table 11 below is the breakdown of the nine items of disagreements in the 'tactics used' area:

\begin{tabular}{|r|l|l|l|l|l|}
\hline No. & Items & RATER 1 & RATER 2 & RATER 3 & $\begin{array}{l}\text { STUDY } \\
\text { RESEARCHER } \\
\text { (FAHIMI) }\end{array}$ \\
\hline 1 & $V 2 S 1 P 2 C$ & IGU & ABR & IGU & IGU \\
\hline 2 & $V 3 S 2 P 1 C$ & ABR & SOP & ABR & ABR \\
\hline 3 & $V 3 S 2 P 2 C$ & ABR & SOP & ABR & ABR \\
\hline 4 & $V 3 S 3 P 1 C$ & ABR & SOP & ABR & ABR \\
\hline 5 & $V 3 S 3 P 2 C$ & IGU & ABR & IGU & IGU \\
\hline 6 & $V 5 S 1 P 2 C$ & IGU & SOP & IGU & IGU \\
\hline 7 & $V 2 S 1 P 1 C$ & IGU & SOP & IGU & SOP \\
\hline 8 & $V 3 S 1 P 1 C$ & ABR & SOP & SOP & SOP \\
\hline 9 & $V 5 S 1 P 1 C$ & IGU & SOP & IGU & ABR \\
\hline
\end{tabular}

Table 11: Breakdown of the disagreement area

It was found that of the 9 disagreements in this area, Rater 3 had 6 agreements with Rater 1 and Fahimi (see items 1-6 in the table above). To further illustrate this result, if Rater 2 were not included in the 'tactics used' area, the total number of disagreements between Rater 1, Rater 3 and Fahimi is only 3 out of 19 items (see items 7-9 in the table above). Moreover, the pairwise values between Rater 1 and Rater $3(\mathrm{k}=0.897)$, Rater 3 and Fahimi $(\mathrm{k}=0.880)$ and Rater 1 and Fahimi $(\mathrm{k}=0.794)$ were the three highest values in agreement. 
Armstrong et al. (1997) suggested that any differences in the inter-rater results could be based on i) different geographical area, ii) discipline, and iii) personal experiences or views. In this test, Rater 1 has approximately 9 years of work experience as a practitioner, Rater 2 has very limited working experience (i.e. 3 years) in academia, and Rater 3 has 20 years of work experience as a practitioner. The researcher (i.e. Fahimi) has more than 15 years of work experience as a practitioner especially in high level decision making in organizational settings.

This shows that there is a high possibility that Rater 2 either did not understand the meaning of the codes or the lack of work experience especially in the decision making area affected the test results.

\section{Cohen's kappa value test result analysis}

"Cohen's kappa coefficient [kappa] relates the number of concordant ratings to the number of discordant ratings while taking into account the agreement of ratings that could be expected by chance" (Burla et al., 2008, p. 114). As for the meaning of the values, "Kappa values between .41 and .60 can be regarded as moderate, and values above .60 as satisfactory or solid agreements. Values above .80 are regarded as nearly perfect agreements" (Burla et al., 2008, p. 114).

The inter-rater agreement value in Lipshitz and Strauss (1997), which is in the NDM field, was 0.87 which was a nearly perfect agreement. However there are some studies that accept a lower kappa value than 0.80. Burla et al. (2008) have an inter-rater agreement of 0.67 and they argued that their kappa value "provides empirical support for sufficient agreement between the two coders" and suggest "that coding of the remaining transcripts by single coders is a feasible and reliable procedural option" (p. 115). Based on the spectrum between the lower accepted kappa rate $(\mathrm{k}=0.67)$, the known kappa rate in NDM studies $(\mathrm{k}=0.87)$ and the recommended nearly perfect agreement rate $(\mathrm{k}=0.80)$, my result $(\mathrm{k}=0.8030)$ sits at the higher end of the spectrum, which is acceptable. 
To conclude, based on the results of this test, the kappa value $(\mathrm{k}=0.803)$ is categorized as a nearly perfect agreement (i.e. $\mathrm{k}>0.80$ ), providing evidence of high reliability in my research. This demonstrates that my research has a high degree of dependability as discussed in section 3.6.5 to ensure research quality and rigor. Therefore, a single coder is feasible and provides code reliability, but it is acknowledged that it could be improved with additional information in some of the vignettes' scenarios, especially those with inter-rater disagreements.

\subsection{Research issues and challenges}

The following sub-sections describe the research issues and challenges that my research has faced.

\subsubsection{Gaining access to the organizations and participants}

Emergency service organizations are a complex type of organization where there are many levels. There are units at district, area and national level. There are also units under the city councils. Gaining access to these types of organization needs to be done strategically and formally. A detailed letter was prepared including procedures and limitations in collecting data for my research.

I have discussed the method of participant recruitment using the purposive sampling method. Gaining the first $\mathrm{KB}$ was a challenge as I have no experience working in the emergency management area. However, after gaining access to the first $\mathrm{KB}$, the process of recruiting further KB was easier. Social skills based on my personal background and experience have also been an important factor in gaining the trust of the first $\mathrm{KB}$ to recommend other $\mathrm{KB}$ in his network. Most of the KB confirmed that approval from a higher authority was unnecessary as they saw that my research had taken steps to ensure anonymity and confidentiality. Also, again, the trust that I gained from them was mainly through my social skills. This can be seen through my research process where I participated in three disaster simulation exercises which helped me to gain access to more $\mathrm{KB}$ and also in refining my interview questions. 


\subsubsection{Constraints in the data collection stage}

The schedule of KB is highly dependent on shift work. There were a number of occasions that I had to re-schedule the interview time due to an unexpected emergency. On one occasion I had travelled around $45 \mathrm{~km}$ and was just about a minute away from the KB's office when she called and informed me that she needed to attend an emergency and had to postpone the interview session to another day. This happened twice. Also, I had to reschedule an interview with another $\mathrm{KB}$ because his shift changed at short notice and he was only working night shifts. I had to wait for another three weeks until he was available. This cost me time and money. Also, in almost all of the interview sessions, I was made aware that the interview session could be disrupted by an emergency call. There were some disruptions due to the volume of the radio in three of the interviews, but they were minimal. Fortunately, none of the interview sessions was disrupted by an emergency call.

\subsubsection{Richness of information}

Data richness is essential in qualitative research to generate theory (H. K. Klein \& Myers, 1999). Before the first interview with the KB, I was concerned that the data collected through the interview session would not be rich enough to contribute to the generation of theory. This was mainly due to the experience of the first two years of my $\mathrm{PhD}$ where my data was not rich enough to generate a theory. Although I had carefully crafted the interview protocols and recruited the relevant $\mathrm{KB}$, I was unsure of the outcome at that stage (i.e. the richness of information). In addressing this I implemented a few strategies, which I have discussed in section 3.5 (Research process). The strategies include having an informal session prior to the interview to explain about my research and ask the KB to think about the disaster 'stories' that they have experienced. This helped in gaining rich data as the participant know my research context and had been given a few days to recall the experience.

Another strategy was attending three disaster simulation exercises - both tabletop and field exercises - in between the interviews. This strategy helped with gaining a deep understanding of what actually happens in a real disaster and allowed me to ask questions in the interview which lead to achieving richness of information. 


\subsubsection{Approaches to managing ethical issues}

My research involved people as participants (i.e. KB) who share information across different boundaries. There was a high likelihood to gain insights from the KB in terms of sensitive issues which may in turn affect the psychological safety as well as the job stability of the KB. In addition to the $\mathrm{KB}$ issue, the status of the emergency service organization itself might be jeopardized as a result of this research if sensitive data was made known to the public, victims or their supervisors. In dealing with this issue, $\mathrm{KB}$ were reassured by being informing that this research would follow certain regulatory guidelines. In ensuring that this research would adhere to ethical principles, I obtained approval from the Human Ethics Committee, Victoria University of Wellington prior to the data collection (see Appendix A). This approval is in accordance with the VUW Human Ethics Policy, Appendix A paragraph 2 (http://www.victoria.ac.nz/documents/policy/research-policy/appendix-a-human-ethicscommittee-guidelines.pdf) which states the researcher will:

i) Seek the informed consent of the respondent

ii) Respect the rights of privacy and confidentiality of respondents

iii) Minimize any risk of harm to respondents

iv) Show cultural and social sensitivity

v) Avoid conflict of interest

vi) Respect property rights.

All evidence was documented and included in this thesis as Appendix B, Appendix C and Appendix D.

\subsection{Chapter summary}

In this chapter, I have explained, described and justified my research paradigm, research strategy and research process. I have also justified my selection of a multiple case embedded design. I have described the research process in great detail, starting from data collection to data analysis which led to a theory. I have described my strategies of ensuring quality and 
rigor. I have also addressed research issues and the challenges that I faced throughout my research.

My research integrated interpretivist and positivist stances, using the case study and inductive method to generate a theory. These strategies suited my research which asked 'how' in an area lacking in relevant theory.

The case for my research was disasters that occurred in New Zealand and there were ten cases which were described in ten vignettes. It was a multiple case embedded design where 22 scenarios were embedded in ten disasters.

My research method was iterative as described extensively in the four stages of the research process. The data was collected using a semi-structured interview approach. The data allows me to look in depth at the process of how $\mathrm{KB}$ assess the veracity and relevance of the information they received during a disaster.

The next chapter describes the ten cases in ten vignettes and the evidence. 


\section{CHAPTER 4: THE CASES}

This chapter describes the cases of my research. There are ten cases where each of the cases emerged from the interview data that was collected from the knowledge brokers (KB). Each case was written in separate vignettes. Each vignette described the experience that the KB went through from their point of view. These experiences are written in scenarios embedded vignettes.

The unique scenarios are snapshots of situations where KB received and share information. There were 22 scenarios in all ten cases. The discussion, process of writing and analysis of the vignettes were described in detail in section 3.6.1.1 of the previous chapter (Chapter 3: Methodology) under the Stage 2 heading. The findings of the analysis are reported in the next Chapter (Chapter 5: Findings). All vignettes and scenarios were numbered for traceability.

$\mathrm{KB}$ were numbered to ensure anonymity. The overview of the vignettes and scenarios is shown in Table 12 below.

\begin{tabular}{|c|c|c|c|c|}
\hline Disaster name & Vignette & Number & $\begin{array}{c}\text { Scenario } \\
\text { reference } \\
\text { number }\end{array}$ & $\mathbf{K B}$ \\
\hline \multirow{3}{*}{2008 Otaki Beach bush fire } & \multirow{3}{*}{$\begin{array}{c}\text { Vignette } \\
1\end{array}$} & 1 & V1S1 & KB1 \\
\hline & & 2 & V1S2 & KB1 \\
\hline & & 3 & V1S3 & KB1 \\
\hline 2013 Wellington earthquake (July) & $\begin{array}{c}\text { Vignette } \\
2\end{array}$ & 4 & V2S1 & KB1 \\
\hline \multirow{4}{*}{2008 Paraparaumu mid-air collision } & \multirow{4}{*}{$\begin{array}{c}\text { Vignette } \\
3\end{array}$} & 5 & V3S1 & $\mathrm{KB} 2$ \\
\hline & & 6 & V3S2 & KB2 \\
\hline & & 7 & V3S3 & KB2 \\
\hline & & 8 & V3S4 & KB2 \\
\hline 2014 Kilbirnie storage warehouse fire & $\begin{array}{c}\text { Vignette } \\
4\end{array}$ & 9 & V4S1 & KB3 \\
\hline 2010 Pike River mine explosion & $\begin{array}{c}\text { Vignette } \\
5\end{array}$ & 10 & V5S1 & KB3 \\
\hline \multirow{3}{*}{2014 Pekapeka Road motor accident } & \multirow{3}{*}{$\begin{array}{c}\text { Vignette } \\
6\end{array}$} & 11 & V6S1 & KB4 \\
\hline & & 12 & V6S2 & KB4 \\
\hline & & 13 & V6S3 & KB4 \\
\hline \multirow{3}{*}{2001 Aotea Quay, Wellington fatal motor vehicle accident } & \multirow{3}{*}{$\begin{array}{c}\text { Vignette } \\
7\end{array}$} & 14 & V7S1 & KB4 \\
\hline & & 15 & V7S2 & KB4 \\
\hline & & 16 & V7S3 & KB4 \\
\hline
\end{tabular}




\begin{tabular}{|c|c|c|c|c|}
\hline & & 17 & V7S4 & KB4 \\
\hline 2012 Otaihanga fatal motor vehicle accident & $\begin{array}{c}\text { Vignette } \\
8\end{array}$ & 18 & V8S1 & KB5 \\
\hline 2008 Paraparaumu bomb in a house & $\begin{array}{c}\text { Vignette } \\
9\end{array}$ & 19 & V9S1 & KB5 \\
\hline \multirow{3}{*}{2013 Wellington earthquake (August) } & \multirow{3}{*}{$\begin{array}{c}\text { Vignette } \\
10\end{array}$} & 20 & V10S1 & KB5 \\
\hline & & 21 & V10S2 & KB5 \\
\hline & & 22 & V10S3 & KB5 \\
\hline
\end{tabular}

Table 12: Overview of the vignettes and scenarios.

Figure 12 below shows the location of each disaster. The initial ' $V$ ' represents 'Vignette' and the number that follows represents the Vignette number. 


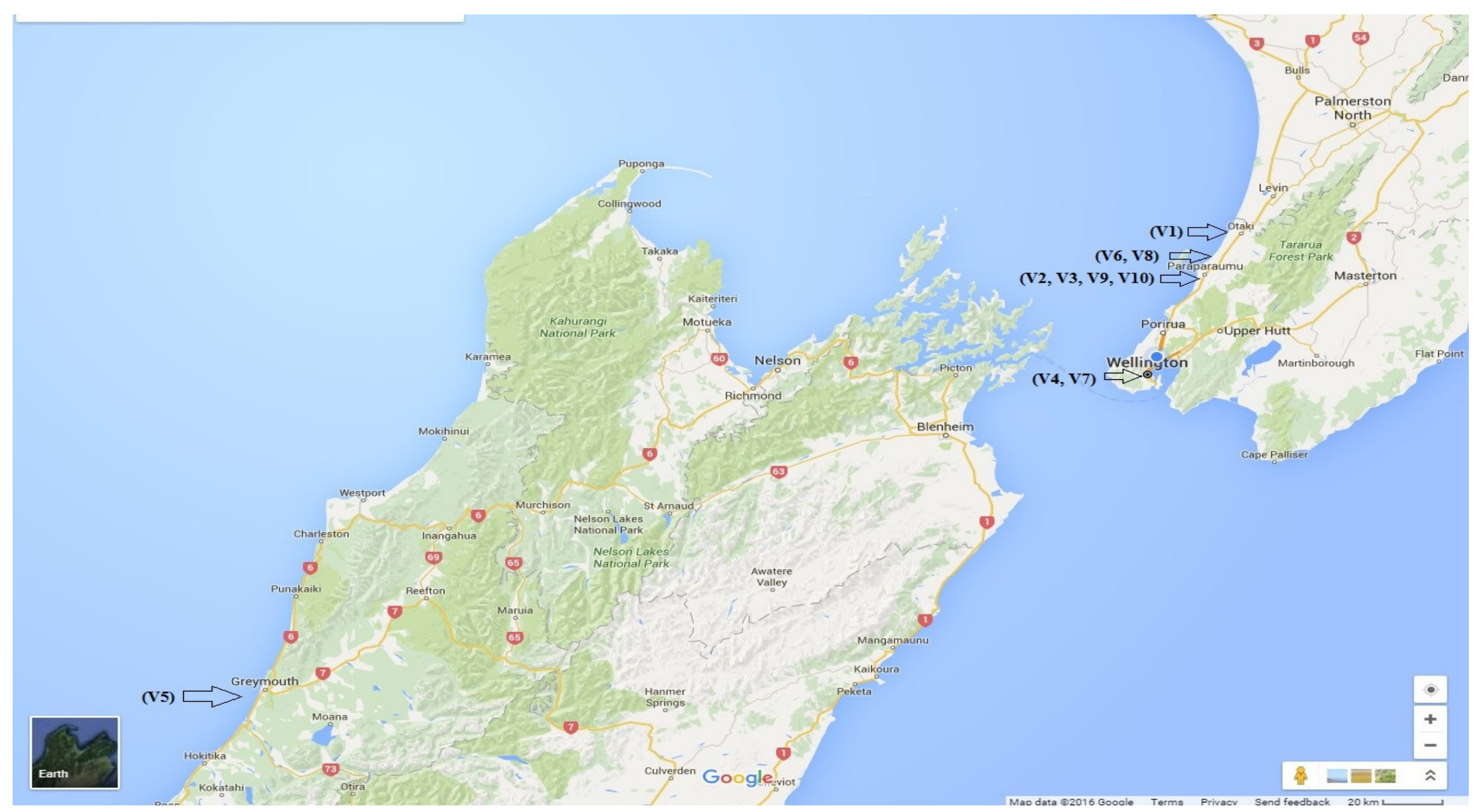

Figure 12: Locations of each disaster across New Zealand 


\subsection{Vignette 1: 2008 Otaki Beach fire}

Knowledge broker no. 1 (KB1) was a senior Rural Fire Officer and the incident controller in this fire disaster. Multiple agencies involved in this disaster were Rural Fire, Fire Service from two different districts, Police, Fire Scene Investigator, and the Department of Conservation.

A bush fire began about a kilometre north of Otaki. The fire was spreading fast. The fire front was about $200 \mathrm{~m}$ to $300 \mathrm{~m}$. The Rural Fire was the first in attendance to the fire. They wanted to make sure it wouldn't burn the nearby forest and farmland. The area was cordoned off to avoid inland burning. The Rural Fire brigade maintained the edge of the fire and the inland flank to stop the fire spreading into the farmland. They could not attack the fire front because it was too high and moving too fast. KB1 received a message through a pager 20 minutes after the Rural Fire brigade arrived at the disaster scene. Two helicopters and several fire brigades from two different districts were called. An officer from the Department of Conservation was also called to assist. The fire was put out on the same day. Investigations were carried out to identify the cause of fire.

\subsubsection{First scenario (V1S1).}

KB1 was on his way to the disaster scene. A fire officer at the disaster site asked KB1 to request a helicopter from a different unit to help managing the fast-spreading fire. Due to his rank, KB1 was authorized to call in additional resources from different units. KB1 knew the fire officer through training sessions and they had been working together for the six months before the disaster. The fire officer had more than 20 years of experience dealing with fires. KB1 decided that the information was valid and called in the helicopter through the fire communication unit by radio.

\subsubsection{Evidence of scenario V1S1}

“...I actually get a call [from the senior fire-fighter who is a subordinate] over the radio while I was en route to the [disaster] recommending that the helicopter [is to be] paged...I knew that they were making a responsible call...[I knew the senior fire fighters] probably 6 months before the fire happened and there was just enough time to oversee a little bit of relationships with those key individuals...I use to attend [the Fire 
Officer's] trainings. [I] obviously go and oversee their training. It is a management role to make sure that the brigade is up to scratch...[therefore] I often refer to the experience of my actual Fire Officers on fire ground. Those guys in the brigade have got 20 odd years of fire experience, dealing with rural fires...So, I definitely refer to their advice and recommendations...I am quite happy because of my relationship with the senior fire fighters within the brigade...it is [also] based on [my] experience, intuition...the authority to call the helicopter rest with [me]...And I [request for a helicopter through the Fire communications unit] on their advice... Primarily, it was me on the radio with Communications Centre $^{11}$ providing [information]... and resource request ..."

\subsubsection{Second scenario (V1S2)}

$\mathrm{KB} 1$ arrived at the disaster site. KB1 was briefed by the fire officer. Due to the size of the fire and the recommendation of the fire officer, $\mathrm{KB} 1$ requested additional fire brigades and officers from Levin and Wellington. The Department of Conservation was also called to help KB1 manage the fire. Each head of the additional units was given a different task, such as aerial liaison for helicopter movements, planning and intelligence. KB1 was relying on each unit's previous experience and checklists to assist him to make decisions. KB1 focused on communicating with the communication centre using radio for updates and also requesting additional resources.

\subsubsection{Evidence for scenario V1S2}

"In that incident, the [senior fire officer] from [two different districts] came up and I usually delegate a role for them with one of those same functions and on the day, the [senior fire officer from a district] acted as the aerial liaison officer, so he coordinated the helicopter movements... the Conservation Department was [also] there and she assisted with the planning of the intelligence and some of the [communication] functions there...there are a lot of information coming at you and you need to make a lot of decisions very quickly. What we have got is a lot of internal checklist that we tick off, have you consider this, have you consider that, have you contact that person, so, there are a lot of process already in place that really took away that guessing game or can't remember what I have to do here...[we have] develop [the processes and check list] from other [senior fire officers] that has been in the role in other districts for quite some time. And obviously, also from [the other 
[senior fire officers] experience that [has helped with the development of the checklist]...Primarily, it was me on the radio with Communications Centre providing [information] ... and resource request...but relying on the experience on my fire officers, from the experiences of other [senior fire officers] that show up [to share information with me] was a big factor"

\subsubsection{Third scenario (V1S3)}

The fire was put out. KB1 and his team were on the ground assessing the fire's impact and ignition point and looking for evidence of its cause. A fire officer found the evidence and informed KB1 verbally (face-to-face). It was evidence of possible arson. KB1 trusted the information was correct. It was based on the fire officer's experience. First, KB1 passed the information to the Police verbally (face-to-face). Next KB1 passed the information to the Fire Scene Investigator using radio. KB1 knew he would share the information with the Police. KB1 was recalling his previous eight years of experience as a police officer. KB1 was aware that the Police need to be informed if there is any criminal matter found. KB1 was also aware that the Fire Scene Investigation unit is for cost recovery purposes.

\subsubsection{Evidence for scenario V1S3}

"Well, I was informed of the ignition points and some evidence there that suggest that it was arson. The Fire Officer on the ground [informed me]. Not the Fire Chief but one of the Fire Officers...Once we identified the initial where the fire started, we also discovered some evidence at that scene... [and I decided to inform the police]...so, it was a case making sure the police were aware of it, cordon the scene. Making sure the evidence was collected in a way so that it would not be damaged. So, that will be very much part of that investigative process...I mean my experience is in the police background... for about 8 years ...so that would probably a bit of experience that I also call upon to recognize the importance of preserving the scene and have the evidence which is not tarnish and can be use for evidential purposes...As well as that we had to call in the Fire Scene Investigator who also conducted a review of the fire so that they can make the assessment...well, the Fire Scene Investigator is more around investigating the cause of the fire especially for cost recovery reasons... That is part of the training programme that the RNFA provides to fire officers, when you first go 
through an induction programme as a Rural Fire Officer, is the importance of preserving and protecting the fire scene particularly for the investigative analysis...one of the big roles of the fire officer is actually the cost recovery from any liable party...It certainly helps [when your mind is recalling the experience you had]...well, [I shared information using] primarily radio [in this disaster].

\subsection{Vignette 2: 2013 Wellington earthquake (July)}

KB1 was the local Emergency Management Office Advisor during this disaster. KB1 did not mention any other agency involved in this disaster during this interview.

It was a 6.5 magnitude earthquake centred in Seddon at a depth of $17 \mathrm{~km}$ in July 2013. The earthquake caused minor damage to many Wellington CBD buildings. Shortly after the incident, KB1 scanned the social media for information updates from the community and individuals. He was looking for any situational updates from the community that might require responses from different departments.

\subsubsection{First scenario (V2S1)}

A newly elected member of the community board asked a Fire Service officer what to do next and then posted a status on the community Facebook page. She posted a message mentioning that people have to wait for the Tsunami siren to go off before initiating the evacuation plan. When KB1 read the Facebook posting, he knew the information was wrong because he was working with the department that was communicating to the public about the Tsunami sirens no longer being used in the Wellington Region for the past 5 years. The member of the community board then corrected the Facebook post.

\subsubsection{Evidence of scenario V2S1}

"We had a classic example [from the Wellington earthquake back in July 2013] where one of the [Facebook page of] community in the [district] issue advise to the community saying, wait for the Tsunami siren to go off, before you initiate your evacuation plan. ...It was false information. By doing the scanning of the internet and scanning those Facebook entries, we are able to quickly dispel that kind of rumour and correct the advice for the community..... At the time she posted that information, she wouldn't know that it is false information because 
she got it from the Fire Service....she got it from what she thought was a reputable source. It was no fault with her. She tries to do her best to support the community, just unfortunate she got it from a wrong person.... Everyone was pretty unsure what was going on, we got a lot of questions about the Tsunami, was it big enough for them to evacuate. They all are waiting for Tsunami sirens. We don't have tsunami sirens pretty much anywhere in Wellington region ...MCDEM [Ministry of Civil Defence and Emergency Management] has recommended against Tsunami sirens and about 5-6 years ago, we stop using Tsunami sirens, and I guess that have not been filtered out to everyone in the community that Tsunami sirens are not operating in this districts anymore.. We do a lot of effort out there to educate the public about hazards warnings but still a lot of people still has not filtered down yet. .... And it [the Community Facebook page] was managed by one of the elective members in that community. So, I was being able to contact her directly... ...just introduce her myself as the controller, and [said] look, you got a piece of information on your Facebook page which people are reading, which is incorrect and you need to fix it... we spoke afterwards and we laughed about it, it's all good"

\subsection{Vignette 3: 2008 Paraparaumu mid-air collision}

KB2 was the Civil Defence staff for a District Council and also the senior Rural Fire Officer during the disaster. The multiple agencies involved in this disaster were Police, Fire Services, Emergency Management, a District Council and the ambulance.

A small plane and a helicopter collided mid-air in the Paraparaumu area. Three people died: both pilots and a flight examiner. The helicopter fell into a local hardware store building. The small plane plummeted into a residential area. The plane's propeller landed in the hallway of a nearby house. The plane's battery landed in the lounge. Other parts were scattered on the street. No one on the ground was injured.

\subsubsection{First scenario (V3S1)}

KB2 was at Johnsonville (i.e. around 40km from the disaster scene) when he received a message on his pager. The message was short and read: "Aircraft crash Paraparaumu Airport". He did not do anything at that time as he thought that the disaster only involved airport personnel and others. He then received the second message. He knew that he needed 
to be involved as the procedure outlined that he should be involved if a second message comes through the pager. KB2 went to his truck and listened to the Rural Fire radio channel to learn more about the incident. After listening to the radio communications, he then realized that he needed to get to the disaster scene quickly as it was a large-scale disaster. While driving to the disaster scene, he was feeling curious about what actually happened. He did not share the information with others at that time.

\subsubsection{Evidence of scenario V3S1}

"When the disaster hit, I think I was in a meeting... it was a weekend at that time, I was in Johnsonville... and the pager went off and also it was an air accident so it did not involve me particularly anyway. It says [in the] tiny little pager..it's just a brief statement of what happened. I think it must said, "Aircraft crash Paraparaumu Airport"... When the 2nd and 3rd alarm when off, and the 4th alarm went off, I was getting a page all the time. So, I realise it was more than a little thing... So, fortunately I had a radio in my truck...I got back to my truck where I monitor the Fire Service radio...because that is the only way that could monitor of what was happening... It was in the Fire Band radio wave... and of course I could hear all what was going on... I could hear the radio chatter, I realise something big was going down... and I realise that we had something pretty big had happened, two aircrafts involved. So that was when I thought I better get motoring... I had better to response, because somebody from the council need to be there and it would be me... I was off like a dog. [Fahimi asked: did you gave any instruction to your colleague after that?] No I did not have a team working under me directly [in the Civil Defence] apart from the Rural Fire guys [in the Rural Fire]. They had not been called by the Fire Service so it wasn't anything to do with Rural Fire and it really wasn't anything to do with Civil Defence. So I went really as a liaison between the District Council and the responding services. So, my role was and ad-hoc sort of role... [The Rural Fire] would never trained or practice anything like this before. Not even discussed it... I knew the Fire Service has done training for the crash aircraft on landing...”

\subsubsection{Second scenario (V3S2)}

KB2 arrived at the disaster scene and immediately went to the incident control point. He saw a multi-agency temporary structure was being formed with the Police as the leader. The 
temporary structure called a Coordinated Incident Management System (CIMS) is a standard procedure in New Zealand. A CIMS is formed in any disaster involving multiple responding agencies. Because KB2 had been trained in and been a trainer for the CIMS, he knew that he was capable and needed to be the Logistics Manager. KB2 took up the position by informing the Police chief who was the leader of CIMS in the disaster. KB2 then offered the Emergency Operation Centre to the Police. The offer was turned down. This was because the Police did not have any knowledge about the operation centre as they had not visited the centre before. A small Police station with limited resources was selected to be the operation centre.

\subsubsection{Evidence of scenario V3S2}

"And I arrived almost an hour after the event and they had already setup the command truck, fire brigade had already setup a command vehicle. They were running the Coordinated Incident Management System, CIMS. Well, under CIMS I went in [the command truck] and saw the controller...met the Incident Controller whom I knew and he knew me and we decided that I take the Liaison Manager role because there was no one doing that...and it was decided I'd be the Logistic Manager... I was prepared to take it up because I had taught and trained in the CIMS and I knew that role was sort a role that adopt in that disaster... II did not offer any advice or share information to others at that time because] they knew who I was and I made myself available as the Logistic Manager. So I have done that which is all that I could really do. I did not interfere with the running of the scene at all... The only disappointment for me was... we offered to the police...[that] we had a huge...complete facility...operation centre...built it at the Council....but the police decided that no, they will use the police station. They were jammed into the police station. Police station does not designed for that many people...our facility would have handled it easily...we had all the radios, computers and phones and everything that they wanted...they [the Police] did not have the time to have a look I guess. So, I dismissed it. I guess if they have seen it, they could have jumped at it...so that whole facility was made available to them but they did not want it. Because the Police Inspector had not been looked at it, even though he was invited, because he was relatively new at that stage. I was disappointed at that." 


\subsubsection{Third scenario (V3S3)}

In a briefing session, KB2 was asked by the operation leader for a truck to transport the plane debris and the victim to an investigation warehouse nearby. KB2 phoned his contacts from the council asking for a truck. KB2 then got his truck and transported the debris and victim. KB2 covered the truck with a tarpaulin. The media was taking photos under the tarpaulin and KB2 was upset with the media.

\subsubsection{Evidence of scenario $\mathrm{V} 3 \mathrm{S3}$}

"So, next they had to get rid of the aircraft, move [the] aircraft...they need to hire a truck to do that... [the Police] asked me for the truck...because [I was]... providing logistical support... I called the council depot...my depot was down by the side of the council depot and actually was in it those days. And my office was in the council's depot yard. So I knew all these guys [from the Council depot] personally. Every morning tea time we use to say good day to them, you now, and I knew all the managers of course in the council, so it was just a case of ringing up their manager and say we need to hire a truck and a couple of guys, the disposal guy, just what ever, Hazmat guys... This [relationship] was first name all boy terms... I just call and say.. Good day [mate], I need to borrow your truck, there is a helicopter crash and we need to take it away. Can you give me couple of guy? [and] the mate said Yeah, No problem, we will do it for you. Well, that sort of arrangement. Very personal because we work together all the time...So [I managed to get the] council vehicle... a big truck... and a couple of the council employees...we loaded the aircraft on to the truck...It was big enough for a light airplane...cover it with the tarpaulin"

\subsubsection{Fourth scenario (V3S4)}

On the second day of the disaster, KB2 received information when he was asked verbally, face-to-face by the operation's leader if KB2 knew any undertakers to send the victims to. Because he had experience dealing with the morgue before, KB2 called a nearby morgue by phone and asked them to manage the situation. 


\subsubsection{Evidence of scenario V3S4}

"So, it was that incident and we did that. I think it was about all we did until the next day because all the victims identification unit, the police unit was moving in to take over. No one was allowed there of course, in the warehouse. So, at some point the next day, I went in and had a talk to [the Sergeant] who was running it and see if I could do anything to help her and her team. And she had a problem with what she was going to do with the bags of human remains and the aircraft bits and pieces that was scattered around. It was in bags but she has not decided for what to do with them. So, we decided we would take them to the undertakers in Waikanae who was dealing with the whole business...got my truck and loaded up quite easily and put the bags at the back. It was a Ute [i.e. a utility/pickup vehicle]...so, I just took them to the undertakers so they could dispose it."

\subsection{Vignette 4: 2014 Kilbirnie storage warehouse fire}

KB3 was the National Coordinator of Emergency Services for a non governmental organization during the disaster. The multiple agencies involved in this disaster were Police, Fire Services and a non-governmental organization.

The fire started at 12:45a.m. at a storage facility in Kilbirnie. The storage facilities did not have a sprinkler system. Five blocks were in the vicinity of the storage facilities. Only one block was affected by the fire. Around 80 fire fighters were involved. KB3 received a phone call at 3 a.m. from the Fire Service's Commander in charge of the fire. KB3 was asked to prepare meals for 65 fire fighters at the scene. KB3 tried to call other non-governmental organization volunteers for help but no one answered their phones. KB3 arrived at the scene and set up a barbecue and rice cooker, alone. KB3 cooked sausages, vegetables and rice for the fire fighters who were controlling the fire. Later, KB3 managed to call other volunteers from to help him to prepare meals. Fire fighters were taking turns to put the fire out and come and eat a meal prepared by KB3 and his team when needed. The police cordoned off the fire scene and where the meal was served from the public. The building owner arrived and KB3 was asked by the Police to support him if needed. While KB3 was serving meals KB3 could hear the fire fighters were talking among themselves about the disaster. They were sharing information informally. At times they also talked with KB3 and shared information. 


\subsubsection{In a scenario (V4S1)}

KB3 overheard a conversation among the fire fighters who were having a cup of coffee and a meal that the fire was due to arson and that the fire temperature was $2000^{\circ} \mathrm{c}$. At that time KB3 believed the information was true because the information came from a professional fireman who was fighting the fire. KB3 did not share the information with anyone else because it was not his responsibility. KB3 also mentioned that the media might distort the story and because of that, he did not want to be blamed for giving false information or leaking unconfirmed information so he did not share the information.

\subsubsection{Evidence of scenario V4S1}

"It was very early, it was running around that there was an arson and it was not just an accident...Just heard the firemen talking when they are having a cup of coffee or having a meal. And they say, well somebody have done this... [the researcher, Fahimi, asked why the fire fighters were chatting with KB3] We [KB3 and the volunteers] are treated as equally [with all the fire fighters]...Personally, I just treat this conversation that I am over heard and they are the professional fireman and they would know more than what anybody else was saying. They are the people who were fighting the fire. They see how it is started and how quickly it was on the way so if they are saying it, it [the information] would probably right. But even they could not confirm at that stage... We had a team of 3-4 at that stage. Some of us had a chat with them [the fire fighters] and at some point, they said that the estimated centre of the fire was about 2000'c...No [I did not share the information with someone else], I did not know anything about it. Because we were feeding them, they [the fire fighters] just share about their findings...To me, it was not my responsibility to pass that on. I heard that but I don't tell anybody. If someone raises, than, I would say yes I heard about it but nobody knows. So, we have to keep the lid on it and you have to be very very careful because the media can come and ask anything." 


\subsection{Vignette 5: 2010 Pike River Mine explosion}

KB3 was the National Coordinator of Emergency Services for a non-governmental organization during the disaster. The multiple agencies involved in this disaster were Fire Service, Police, ambulance, a non-governmental organization and the Pike River Mine management.

There were multiple explosions at a coal mine in Greymouth during the disaster. In the first explosion, 31 miners and contractors were at the mine. Two people managed to walk out of the mine and were treated by the hospital. 29 people were trapped in the mine. 5 days later, the second explosion occurred. By then, the Police declared that no one had survived. The fourth and fifth explosions occurred two and four days later. Pike River Mine management had set up an information centre for the workers and families only. They realized that there was a need for an information centre for the public and community as well. KB3 was asked by the Pike River Mine management to set up the centre. The reason was to give the public and community correct information. KB3 served hot beverages and light refreshments to the community in the centre. He received updates on the disaster regularly from the Pike River Mine management.

\subsubsection{In a scenario (V5S1)}

While serving the beverages and light refreshments, KB3 noticed certain false information and rumours being talked about by people in the centre. Because he had been briefed by the Pike River management, he knew that the information was wrong and he stopped the spreading of false information and rumours.

\subsubsection{Evidence of scenario V5S1}

"Because the management of the Pike River has asked us to setup this [the community information hub] up and they knew we had to have that information so we can help dispel rumors... when you were doing that [managing the community information hub], the [Pike River mine] management will ensure that we kept fairly up to date what the situation was... Well the [Pike River Mine] management would have briefed us on what is the actual statement were...we need to be kept in the loop so that we can as much as possible [having] 
accurate information going out... and we are very careful not to pass on what we are not have confirmed as truth... we had fairly accurate information so we are able to say which information is not quite right... and [when there were false information circulating in the information hub]... [and we don't want the rumors or false information to expand and] as soon as possible... we...say, "sorry that is not correct, there is other information that is not yet being released"...[We] always give out the exact information [in the community information Hub]...So it is trying to diffuse what can get out there. It's difficult but you have to do your best with it...I think it probably come to the fact that you are ascertain all the time, is this helpful for him, is it information they need to know or not. Like if you are in an accident for example and some heard someone saying this, this and this. You don't tell them the fact that you know but you can say, " the official information that we have, is not correct"

\subsection{Vignette 6: 2014 Pekapeka Road motor accident}

KB4 was a local Police Chief during the disaster. The multiple agencies involved in this disaster were the Fire Service, Police, Westpac helicopter and ambulance.

A car had overturned on Pekapeka Road. The driver was going fast, lost control; the car went down a little ditch, came up and became airborne, passed through a fence, and landed upside down on a paddock. The emergency phoneline 111 was called. The Fire Service arrived first, then the ambulance. The Police arrived later. The car's driver was found lying on the dirt and badly injured, with no sign of other passengers. The Fire Service removed the driver as they were afraid the car might explode. The ambulance staff called the Westpac helicopter due to the severity of the driver's condition and it was sent to Wellington Hospital. The Police communication unit notified all Police units in the area about the incident. KB4 was issuing traffic tickets to another car near the disaster scene when she heard the notification through the radio. She rushed to the disaster scene. She talked to eyewitnesses to gather information on how the disaster happened for investigation purposes.

\subsubsection{First scenario (V6S1).}

KB4 asked the eyewitness about what happened for investigation purposes. She received information from the eyewitness verbally (face-to-face) describing the accident moment by moment. Considering the appearance of the eyewitness, matching the information with the 
current surroundings and her past experience, she decided that the information was correct. She did not mention to whom she shared the information with.

\subsubsection{Evidence of scenario V6S1}

“...and so part of the examination and investigation [was] speaking to witnesses, and we'd spoken to the witnesses who'd seen that he'd been driving at speed up and down the road... and looking at the scene what that said to us was that he was driving at a fair amount of speed...so looking at the skid marks...with what that tells us, you could see the marks of the tire and as I said in fact for him to have gone down there and cleared that, he was going bloody fast... [and I] assume that [the information] is true because unless you have any reason to doubt them. Whereas here are two look like Joe Average members of the public driving along, and you take, you take into account face value as well, what the person present like. And it is would be different if I spoke to you and say I've just seen a car drive past me at speed and it lost control blah blah blah, he looked like he was going really fast. If I spoke to you, I'd believe you, because there'd be no reason for you to lie to me. Now, if the person who'd crashed was a gang member, and you're a gang member, and you say yeah, I saw it and someone bloody came out and waved a gun at him and so he lost control and crashed into there, I'd go "bullshit!". So, it certainly is on appearances and whether or not a person has anything to gain from... So they had nothing to gain from lying to us... [the decision was also made out of] own experience. ...It's a common sense. A lot of police work is common sense, common sense plus say your gut feeling and in my experience the fact of being a police officer for 17 years. And dealt with a number of these. So, all of that goes into making up your decision. So we, our scene examination and me having been a police officer for so long and some of the people that, some experienced traffic officers came..that scene suggested to us that he was speeding"

\subsubsection{Second scenario (V6S2)}

The ambulance asked KB4 verbally (face-to-face) what happened to assess the driver's injury. She did not know. She asked another police officer verbally (face-to-face) to look for the information. The police staff asked the public who were first at the disaster scene and helped 
the driver to get out of the car. They got the information and passed it to KB4 verbally (faceto-face). KB4 trusted the information was correct because it was from her colleague who got it from the eyewitness. KB4 realized that the eyewitness would gain nothing by lying, based on their appearance. KB4 shared the information with the ambulance verbally (face-to-face).

\subsubsection{Evidence of scenario V6S2}

"Yes, I think at one stage...the ambulance had asked us when we were there...they [the ambulance] were too busy dealing with [the driver] because he was in a bad way... they were wanting to know what position was he in the car, had he fallen out of the car, was he in a seatbelt...was he thrown out, what position was he in...all those sorts of things...he [the driver] wasn't going to die, but they [the ambulance] were not in a position to go and ask those questions because they were too busy helping him.. We didn't know [the information that were asked], obviously, [because] we were not there... we could not tell them that [information]...so what I did is I got one of my staff members to go and find those people some of those people who were first at the scene...so I went and found those people who'd pulled him out of the car... it was some of the people at a house nearby who heard the crash and came out... who actually got him out of the car... to ask them those questions... yep, absolutely [that we worked together]. So, any as you're aware any incident like this, each agency has their little role to do, the fire is to make the car safe for us all, ambulance is to help the people, we're there for either traffic control initially and then to investigate the cause of the crash... [so] we got the information [and] tell ambulance staff."

\subsubsection{Third scenario (V6S3)}

The wife of a fire fighter who just got home after responding to the disaster informed her husband that she thought she saw a second person in the car. The fire fighter shared the information with the Fire Service communication centre. The Police communication centre was then informed. KB4 then received information about the possibility there was a second victim in the car by radio. KB4 asked her colleague to ask the driver at Wellington Hospital to confirm that information by radio. KB4 also arranged for a search and rescue dog unit to search for the passenger using radio. The injured driver confirmed that no one was with him during the accident. The search and rescue dog did not find any other victim. 


\subsubsection{Evidence of scenario V6S3}

"One of the fire men actually lived along that [Pekapeka] road and when actually got home..the fireman said to his wife that there was one person in the car, and the wife said oh, I'd seen that car racing up and down earlier, there were two people, she'd seen two people in the car.. He would've rung possibly his work, and said hey, can you let the police know?... So fire communications would have told police communications... [the Police Communications unit] called me up, I got a phone call.. say hey, there may be another person, there may be another person in that car, and we thought "Oh, shit!" and we rushed back up there... So we weren't sure if there was someone else in the car... we actually got a tow truck there to see if there was someone squashed underneath it, because we weren't sure of that, and we got a dog handler back to check in the paddock to check in the paddock to see if the person hadn't been thrown from the car...and then we actually got someone from Wellington police to go in and speak to him [the driver] in Wellington Hospital to see was there anyone else in the car with him. And he said no. He had had his friend with him and then dropped him off earlier"

\subsection{Vignette 7: 2001 Aotea Quay fatal motor accident}

KB4 was a Senior Sergeant with the Police during the disaster. The multiple agencies involved in this disaster were Police, Fire Service, and ambulance. There was also a different unit from the Police called the Serious Crash Unit involved.

A car crashed on a southbound motorway off-ramp near a ferry terminal at around 9 p.m. Three people were in the car. The driver was stuck in the car. Two people were thrown out of the car, one landed in front of the car and was seriously injured. The other person landed down the ramp on a ferry terminal car park and died. KB4 was helping sort out some disorder at the nearby stadium after a rugby game. KB4 was with one of her staff. Once KB4 received the notification of the disaster through the radio, KB4 rushed to the scene. Traffic was at a standstill. KB4 missed the turnoff and was stuck handling traffic not far from the scene as KB4 felt that she needed to redirect the traffic coming through Ngauranga Gorge, a road leading to the motorway where the disaster scene was. KB4 remotely and calmly gave orders to the staff on what action to take from where KB4 was. The Fire Service and ambulance arrived later. The Fire Service cut the driver out of the car. The ambulance treated the person 
who was lying on the road and the driver. They were sent to the hospital later. KB4 managed to get to the scene and collected information from eyewitnesses.

\subsubsection{First scenario (V7S1)}

KB4 received the disaster notification through the radio. Immediately she thought of five possible actions. These were: need to get someone to the scene, close the motorway, preserve the scene, get the Serious Crash Unit to assist and need to confirm whether there are any fatalities. When she was informed that a person had been thrown out of the car, she suspected that there might be a fatality. She knew the first five actions to take because of her experience. All of the actions were taken during the disaster.

\subsubsection{Evidence of scenario V7S1}

"We got told by radio that there was a serious crash on the motorway just Southbound just before Aotea Quay off-ramp. And got two people lying on the road, so yes, we left there and came racing around...I think first thing [that came across my mind] was, "holy shit!" and then starting to think, right, I'm going to need to get someone to the scene, I need to close the motorway, I need to try to preserve the scene, I need to get serious crash unit there to assist, and I need to confirm whether or not there have been fatalities... [the thinking process was based on] just experience... it's the experience is that [when] you first put a call is you need to preserve life so that's sending police officers so you've got to do that so you've got to go and make sure is there anything that we can do to save the people... So that's all going through my mind thinking oh I've gotta do this that that and you just do it, you just years of doing it, you just it's not a conscious thing. You just do it because of the experience, you gain years of experience... [Then]I have to start directing my staff. So the staffs are waiting for me to give them instructions... So I said one of my staff go there, this staff that staff that car that car you go directly to the scene."

\subsubsection{Second scenario (V7S2)}

KB4 knew that she needed to stop and divert the traffic coming from the Hutt Valley. KB4 was not able to share the information with the Hutt police as they were on a different radio channel. Based on her experience, KB4 shared the information with the central police 
communication unit. KB4 assumed that the communication unit would share the information with the Hutt police.

\subsubsection{Evidence of scenario V7S2}

"I was thinking of I need to stop off the traffic coming from The Hutt and I need to stop the traffic coming down the gorge, so I said to Communications [because] the Hutt Valley police and the Wellington police are on a different radio channel, so I had to say our Communication [centre] say can you get someone from Hutt to go and stop traffic and divert it down to go old Hutt Road to stop them coming through. So that's [a hassle], I can't talk directly to Hutt police but so I just tell my communicator that and expect that she's going to get that done for me."

\subsubsection{Third scenario (V7S3)}

Her most senior staff arrived at the disaster scene. KB4 shared with her staff on the updates of the disaster. She instructed the staff to get the undertakers to move the deceased person to the mortuary.

\subsubsection{Evidence of scenario V7S3}

"But up until then I was saying to my staff at the scene and rang and found out it was Joe was one of the most senior of my staff there, so I rang her on the mobile and said make sure we do this, make sure we do that, I'll be there, just keeping them calm, saying cool, do this do that do that do that try and find out [because] another thing we need to do at stage three with [because] straightaway you knew then two people dead so we know that straightaway we're then gonna have to follow on with dealing with the sudden death procedures for those people and get undertakers eventually and get them moved to the mortuary. And but we also had one person who was still alive, and they said that he was our priority, then making it safe for [the public]... What stops junior staff from panicking is if their boss is all calm saying do this do that do that, and that's how I, yeah. So when you're confident and you know what to do and you're saying do this do that and I had people ring me on my mobile so that's cool...I said to him, don't come too bloody fast [because] I missed that turn, so and [KB4's staff] got to the scene, so I had my sergeant who's a bloody good sergeant, I had him there." 


\subsubsection{Fourth scenario (V7S4)}

KB4 arrived at the scene. She was collecting information from the eyewitness. She called the eyewitness a few days later. She trusted the information given by the eyewitness was correct because of two reasons. First was because the eyewitness was in the first 5 or 6 cars behind the crashed car. Second was because the eyewitnesses were saying the same thing and by the appearance of the eyewitnesses.

\subsubsection{Evidence of scenario V7S4}

“..And at that time, all you're going to do is take their name and details and quickly say, what did you see...to see if had they seen the car speeding, had they seen what happened, was another car involved and has it gone... It's part of our scene examination. [and the witness say] Oh, I saw the car just suddenly do this and that. [KB4 said] Cool, we'll follow up. And so they got interviewed in the later days. So we don't deal with that then. We just get as many details as we can from people who are witnesses, then we deal with it later... So that we could follow up to get statements from them... Yeah, again... trust of the information. You go back to the first incident, you just know from the appearance of the people... you expect that people who members of the public who aren't involved and this is like there were probably yeah in that first build up [because] there's three lanes of the motorway, so there were like 100 cars, so and you've got you know the first maybe five or six, they saw the car, they saw the crash happen. They're all saying the same sorta thing, and there's no reason for them to lie to us. And there was a lot of there's no reason for them to lie unless you're involved in the situation, unless as I said earlier, you're a gang member, the person car's a gang member, you might be bullshitting me to get your friend out of trouble"

\subsection{Vignette 8: 2012 Otaihanga motor vehicle accident}

KB5 was the Station Officer with the Fire Service during the disaster. The multiple agencies involved in this disaster were the Fire Service, Police and ambulance.

Two cars collided. KB5 arrived at the disaster scene with his team. He saw the public were trying to get the victim out of the car. KB5 asked them to stop. He was trying to avoid more 
injury to the victim. While scanning the situation, he saw another car 70 metres away. The ambulance was there. He planned to go to the second car. He asked his subordinate to provide him with updates about the first car while he went to the second car. He started to move his fire vehicle to the second car. The Police told him off for upsetting the crime scene. He respected that. The victim in the second car was then pronounced dead by the ambulance staff. KB5 stopped what he was doing and allowed the Police to investigate.

\subsubsection{First scenario (V8S1)}

The ambulance shared information with KB5, mentioning that the victim in the second car was dead. KB5 then stopped what he was doing. He then passed all information he had relating to the situation to the Police for investigation purposes. The information included what he had done. He was aware of the Police's needs and responsibility. He knew what information to share with them. He knew to whom the information was relevant through the different jerkins that they wore.

\subsubsection{Evidence of scenario V8S1}

"...if in this case I was the incident controller when we arrived, so then when the police arrive, so, well you're now going to be the lead agency, and they go yep, or some of them go what? You want what?...[then] unfortunately one female deceased, and then again it's understanding the requirements around other services, so, in a case like that, the ambulance service will obviously make the decision that the person's deceased, and at that point we must stop doing what we're doing, and allow the police to have \total control over that scene. So we don't carry on doing what we have to do because nothing anymore is time critical in terms of trying to rescue that person because they're deceased... I then had to release [the task to rescue the victim] away...because the police handled that..because it's continually changing, is I will then in this case when that person deceased, I went back to the police and said this is where we are with that situation, this is where we are with this situation, this is what I've got coming in terms of resources, or I've completed the resources, I've got everybody here. Are you happy if we do XYZ, or this is what I'm planning on doing and this is critical to me or this is flexible, I can change my plan, if you want this road open, I'm happy providing that you put XYZ in place to protect our guys or whatever... [I gave a few options to the Police] Because I mean we have to be mindful. While we do have some very critical responsibilities, we've also got to be in the back of our mind that they've got 
responsibility...and personally, I respect their needs. So you're always looking and searching and trying to-you have to think on your feet, move on your feet, so you have to be aware of the other organizations...so I suppose from an emergency management perspective is that the parties knowing and understanding each other's requirements...[because if we know other's organization's needs, we]communicate with them in terms of going what's your line of thinking here? I go XYZ and you go ok, yep, that's fine, we'll live with that, or we'll pull back because there's no need for us to be here. We'll go back to this point and wait further instructions or whatever"

\subsection{Vignette 9: 2012 Paraparaumu bomb in a house}

KB5 was the Station Officer with the Fire Service during the disaster. The multiple agencies involved in this disaster were the Fire Service, Police and bomb squad.

The Police were attending a house believed to contain a bomb. They called the Fire Service. When KB5 arrived, he could not do much as it was beyond his job responsibility. $\mathrm{He}$ evacuated the house and ensured nobody got back in. He called the bomb squad. Once the bomb squad arrived, they became the incident leader. KB5 discussed and updated the bomb squad leader on the situation. The bomb squad made all the decisions from that point onwards. KB5 trusted any decision they would make. KB5 did not mention how things ended in this disaster.

\subsubsection{First scenario (V9S1)}

Immediately when KB5 arrived at the disaster scene, he asked the Police to share what information they had prior to his arrival. He was happy with the information he received from the police. He decided to call the bomb squad. When the bomb squad arrived, KB5 shared the information he had with them. He trusted all decisions made by the bomb squad because he did not know how to diffuse the bomb.

\subsubsection{Evidence of scenario V9S1}

"So when we turned up [at the scene], I immediately went to the police and said, ,[and asked] so what have you got... I got a briefing from the police. So when he gave me that 
briefing, I then went ok, I've got my own organization needs, so I thought, I'm happy with our information that he's given me that everything being equal, nothing will happen until we go to the next phase, and the next phase was to get specialized bomb disposal people out.. [we] waited for that vehicle [bomb squad] to arrive... when that vehicle arrived.. he introduced himself, I introduced myself. And I said, so, what's your needs... and the command structure changed, so then the bomb disposal guy then become the incident controller...I was Fire OIC only, I had no decision input into how they were going to diffuse this bomb...the bomb squad guy turned up that that's his responsibility... I would assume that the internal protocol decides that... you've got your responsibility and again I've got mine....this guy said to me, he

said, ok, so if I go in there and I'm [going to] look at this [bomb], and if it is alive as such then we'll need to evacuate... [it is] important in any inter-agency [emergency management] is you've [have to] trust that the guy that you're talking with knows his business or understands those requirement"

\subsection{Vignette 10: 2013 Wellington earthquake (August)}

KB5 was the Station Officer with the Fire Service during the disaster. The multiple agencies involved in this disaster were Fire Services from different areas, Emergency Management Office, Fire Communication Unit, and a District Council.

The disaster was a 6.6 magnitude earthquake centred in Lake Grasmere at a depth of $8 \mathrm{~km}$ in August 2013. The earthquake caused minor damage to a few Wellington CBD buildings. The earthquake also was felt at Paraparaumu and further up the North Island.

The Emergency Management Office set up the Emergency Operation Centre (EOC) immediately following the earthquake. KB5 arrived at the EOC shortly after the earthquake struck and collected information from the Fire Brigades in his area. He then shared the information with the relevant people. All agencies' representatives were listening to each other's updates.

\subsubsection{First scenario (V10S1)}

KB5 arrived at the EOC. He called his subordinates from different areas by phone for updates. The Emergency Management Advisor was also at the EOC. After a while, the 
KEMA called for a multi-agency briefing in the EOC. KB5 shared the information with the multiple agency representatives from the Fire Service point of view. He wrote it on the whiteboard in the EOC. He was happy with the current situation and required no further assistance from any other agencies.

\subsubsection{Evidence of scenario V10S1}

"I was [the Emergency Operation Centre] within two minutes of the earthquake striking and went ahead and set up and gathered the information from these brigades [from different area] as to their status... I was ringing them by phone and said, I need you to text me or update me or call me on the radio, whichever means I don't care, I need you to give me the information on your brigade, so it's filtering that information down.... so you've got a good clear picture...and then [the operation leader] called a briefing of all the agencies... what happened was that the EOC room was that [the operation leader] gave us each time to concentrate on what we had to do each organization like the council works department, the

fire service, police and whatnot. [Then] he said we'll have a briefing, an update briefing... so basically...each head of the department sat around the table and [the operation leader] said, right, we'll start with police, what's your status? Fire service, what information are you getting from out in the field? So everybody's sitting around listening to that information coming in... and I was able to give him a status, I just wrote it up on the white board and said this is what [was] committed and this is what [was] not committed, so I'm happy with the resources that we have and are utilizing at the moment I don't need any additional resources from the local authorities or anything, the brigade is quite capable of handling those situations at the moment"

\subsubsection{Second scenario (V10S2)}

KB5 received information from his subordinates updating him on the situation. He then shared the information with his area manager who has higher authority than him. He knew that the area management team was looking at a bigger perspective. KB5 also knew that he was contributing information to the higher authority people. 


\subsubsection{Evidence of scenario V10S2}

"...gathered the information from these brigades [from different area] as to their status... I was ringing them by phone and said, I need you to text me or update me or call me on the radio, whichever means I don't care, I need you to give me the information on your brigade, so it's filtering that information down and getting it back up to the top again so you've got a good clear picture... I was feeding information back...to my area management team so that they were comfortable, they knew again I was looking at that picture they were looking at the bigger picture, so I was only part or we were only part of that picture but rather than them breaking down into bite size chunks of what you can achieve in context... and I mean in this case here, one of the first things that I did was I phoned up my assistant area manager who I'm directly responsible and I said I'm sitting out here I've got my butt on the ground...[the Assistant Area Manager said] It's good. Perfect carry on and let me know. So he was able to go off and do other things without worrying about what was happening here because he knew he had somebody on the ground. And again hopefully trusted me in passing that information back to him."

\subsubsection{Third scenario (V10S3)}

KB5 received updates about bridges and road status and later supply from the District Council during regular roundtable disaster updates held in the EOC. The status did not require any action from KB5, so he did not share the information with his subordinates.

\subsubsection{Evidence of scenario V10S3}

“...one of the biggest [information that I received from a different agency] was that the Council staff were able to give us an update...on bridges and road status and water supply. So that was information that I was getting..., If they had said, well we've got no water in Otaki, then that would raise alarm bells for me.

The next Chapter describes the findings of my research. 


\section{CHAPTER 5: FINDINGS}

This chapter describes the findings of my research according to four stages. In stage 1, two phases of the cross-boundary information sharing process (i.e. Phase 1 and Phase 2) are described. In stage 2, different types of boundary, types of information, types of disaster, types of information sharing medium and different cognitive resources related to each of the two phases are explained. In stage 3, different decision-making tactics used by knowledge brokers to identify the veracity and relevance of the information are described and compared with the different types of boundary, information and disaster in each of the two phases. The emerging patterns are described. In stage 4, the theoretical model of cross-boundary information sharing by knowledge brokers and the ten theoretical propositions are explained.

\subsection{Findings: Stage 1}

There were two phases of information flow that knowledge brokers (KB) experience during a disaster: Phase 1, the filtering phase to assess the information's veracity; and Phase 2, the matching phase when they recall an experience and match the information to the relevant people.

\subsubsection{Phase 1 - The filtering process}

Figure 13 illustrates the filtering process in Phase 1.

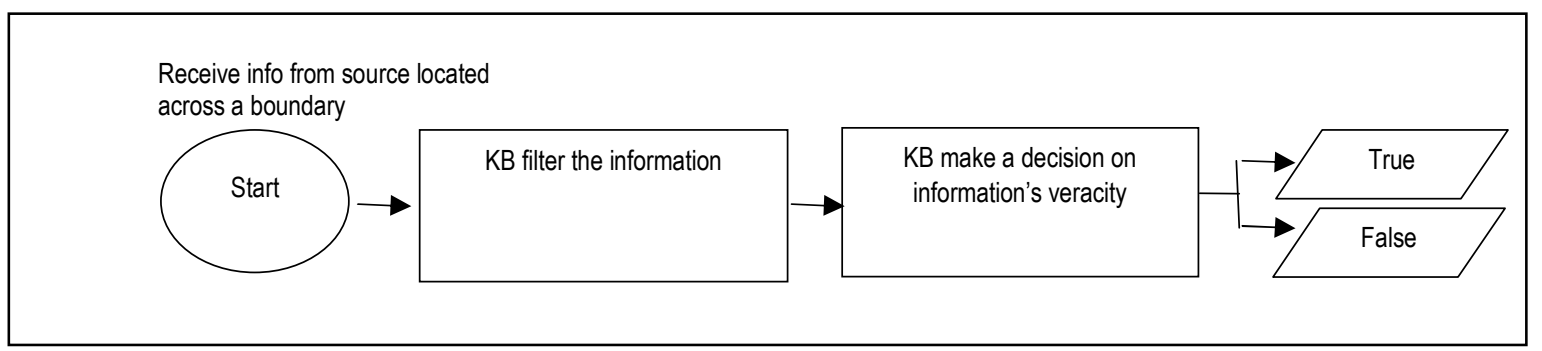

Figure 13: Phase 1 - Filtering process

In Phase 1, the process starts when $\mathrm{KB}$ receive information from a source located across a boundary. Then KB filter the information they received before making the decision on the information's veracity. The process in Phase 1 ends when KB decide either the information is true or false. For example, in V1S1, KB1 (see section 4.1 for description of KB1) received information from a source, who was his subordinate (i.e. a fire officer), to call in a helicopter 
for additional help in controlling the fire. KB1 then filtered the information and decided to trust the information source and decided that the information was true (see Figure 14).

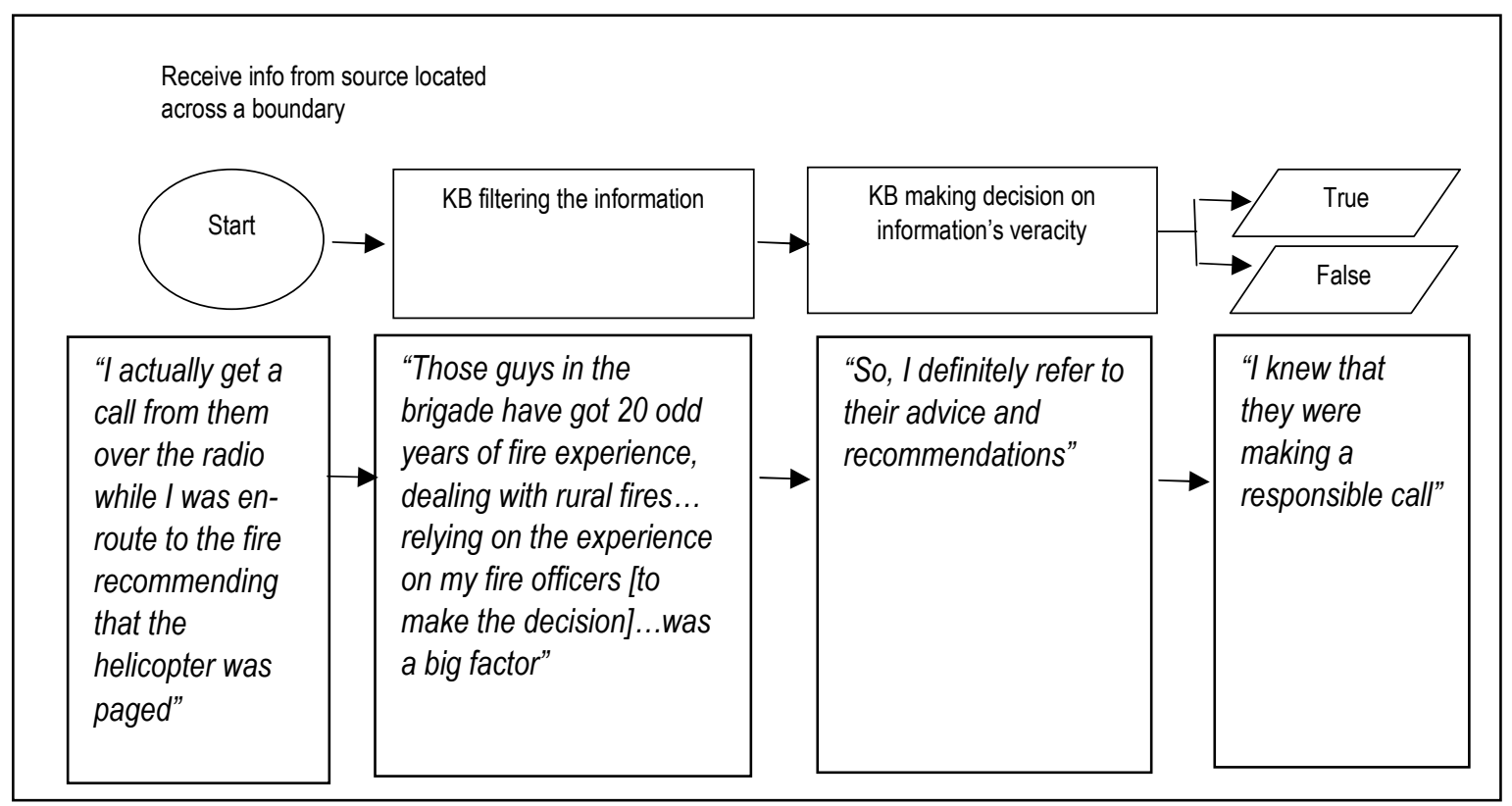

Figure 14: Phase 1 - Filtering process with evidence from V1S1

When KB have decided on the veracity of the information they received, a second process follows: Phase 2.

\subsubsection{Phase 2 - The matching process}

Figure 15 illustrates the matching process in Phase 2.

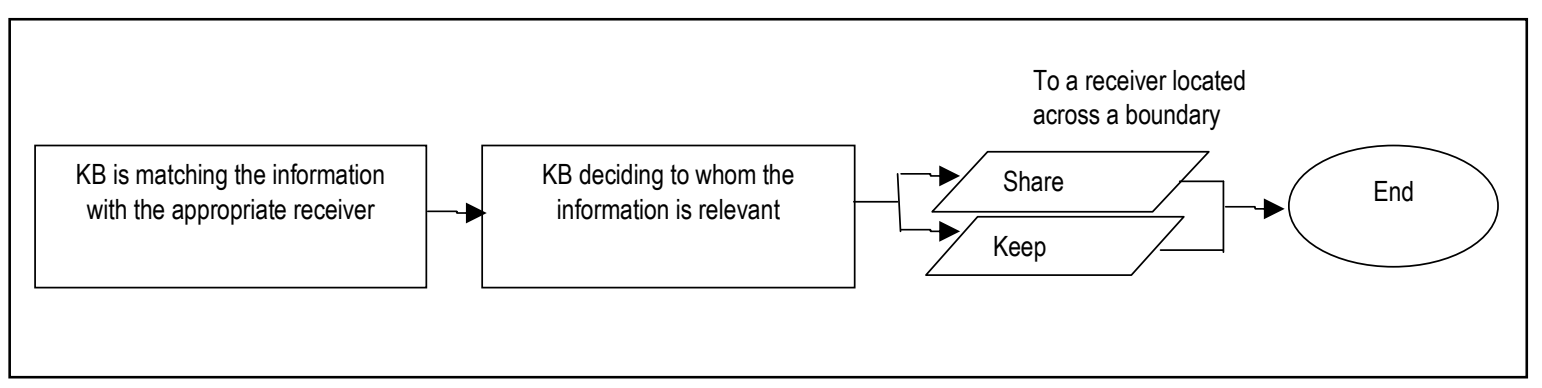

Figure 15: Phase 2 - The matching process

The process starts immediately following the end of Phase 1, when KB have decided on the veracity of the information they received from a source located across a boundary. In this phase, the process starts when $\mathrm{KB}$ recall previous experience to match the information with the relevant receiver. Then $\mathrm{KB}$ decide to whom the information is relevant. The process in 
this phase ends when $\mathrm{KB}$ make the decision to either share the information with a receiver located across a boundary or to keep the information to themselves.

Using V1S1, the process starts immediately following the end of Phase 1 when KB1 decided that the information was true. KB 1 recalled his previous working experience and matched the information with the relevant receiver. The process ends when KB1 decides to share the information with the Fire Communication unit (see Figure 16).

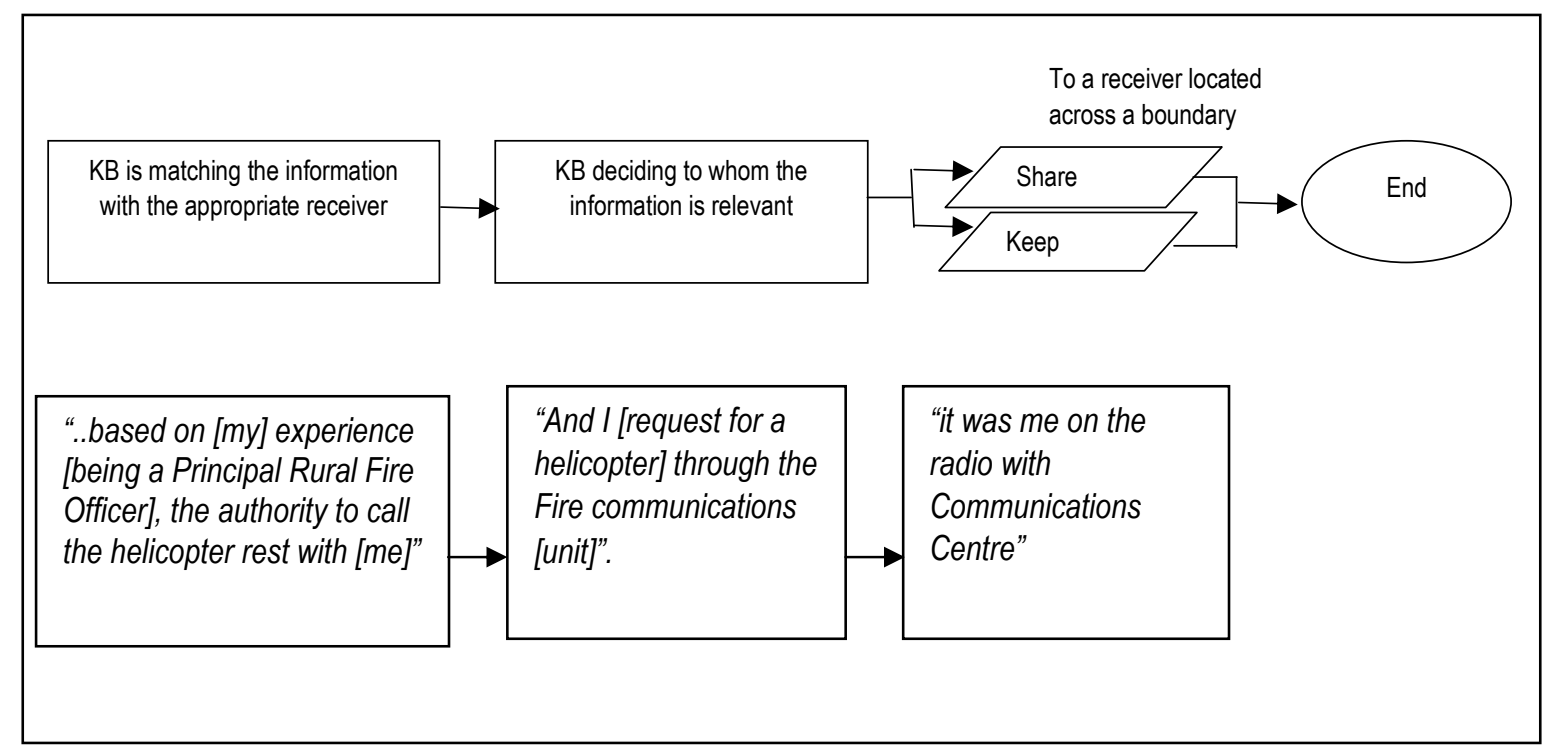

Figure 16: Phase 2 - Matching process with evidence from V1S1

The next sections describe the findings of stage two.

\subsection{Findings: Stage 2}

Stage 2 findings are presented in the following two phases: Phase 1 (the filtering process) and Phase 2 (the matching process).

\subsubsection{Phase 1: The filtering process}

Table 13 summarizes the findings of Phase 1 followed by sections that describe and explain the findings. 


\begin{tabular}{|c|c|c|c|c|c|c|c|}
\hline \# & KB & $\begin{array}{l}\text { Vignette \& } \\
\text { Scenario }\end{array}$ & $\begin{array}{l}\text { Types of } \\
\text { boundary } \\
\text { between KB \& } \\
\text { the information } \\
\text { source }\end{array}$ & $\begin{array}{l}\text { Types of information } \\
\text { received }\end{array}$ & Type of disaster & Medium of sharing & Cognitive resources \\
\hline 1 & KB1 & V1S1 & Hierarchy & Recommendation & Fire & Radio & $\begin{array}{l}\text { Feeling confidence in the source's credibility } \\
\text { Having social ties }\end{array}$ \\
\hline 2 & KB1 & V1S2 & $\begin{array}{l}\text { Hierarchy, Unit } \\
\text { and Organization }\end{array}$ & Update & Fire & Not mentioned & $\begin{array}{l}\text { Feeling confidence in the source's credibility } \\
\text { Following a set of rules }\end{array}$ \\
\hline 3 & KB1 & V1S3 & Hierarchy & Investigative & Fire & Radio & Feeling confidence in the source's credibility \\
\hline 4 & KB1 & V2S1 & Community & False advisory & Earthquake & Facebook & Holding insider knowledge \\
\hline 5 & KB2 & V3S1 & Unit & Notification & Mid-air collision & Pager & Triangulating the information \\
\hline 6 & KB2 & V3S2 & Unit & Awareness & Mid-air collision & None & Recalling previous experience \\
\hline 7 & KB2 & V3S3 & Organization & Request & Mid-air collision & Face to face & Feeling confidence in the source's credibility \\
\hline 8 & KB2 & V3S4 & Organization & Request & Mid-air collision & Face to face & Feeling confidence in the source's credibility \\
\hline 9 & KB3 & V4S1 & Organization & Informative & Fire & Face to face & Feeling confidence in the source's credibility \\
\hline 10 & KB3 & V5S1 & Community & False update & Coal mine explosion & Face to face & Having insider knowledge \\
\hline
\end{tabular}




\begin{tabular}{|c|c|c|c|c|c|c|c|}
\hline 11 & KB4 & V6S1 & Community & Investigative & Motor accident & Face to face & Triangulating the information \\
\hline 12 & KB4 & V6S2 & Community & Update & Motor accident & Face to face & Feeling confidence in the source's credibility \\
\hline 14 & KB4 & V7S1 & Unit & Notification & Motor accident & Radio & Following a set of rules \\
\hline 15 & KB4 & V7S2 & $\begin{array}{l}\text { None (personal } \\
\text { observation) }\end{array}$ & N/A & Motor accident & None & N/A \\
\hline 16 & KB4 & V7S3 & $\begin{array}{l}\text { None (personal } \\
\text { observation) }\end{array}$ & N/A & Motor accident & None & N/A \\
\hline 17 & KB4 & V7S4 & Community & Investigative & Motor accident & Face to face & Scanning for vested interests \\
\hline 18 & KB5 & V8S1 & Organization & Update & Motor accident & Face to face & Feeling confidence in the source's credibility \\
\hline 19 & KB5 & V9S1 & Organization & Update & Bomb in a house & Face to face & Following a set of rules \\
\hline 20 & KB5 & V10S1 & Hierarchy & Update & Earthquake & Phone & Following a set of rules \\
\hline 21 & KB5 & V10S2 & Hierarchy & Update & Earthquake & Phone & Following a set of rules \\
\hline 22 & KB5 & V10S3 & Organization & Update & Earthquake & Face to face & Feeling confidence in the source's credibility \\
\hline
\end{tabular}

Table 13: Summary of stage 2 findings in Phase 1 


\subsubsection{Types of boundary}

Based on the 22 scenarios, KB received information from across four types of boundaries. They are hierarchical, unit, organization and community. The definitions and evidence of each boundary are given in Table 14 followed by explanations of the evidence:

\begin{tabular}{|c|c|c|}
\hline Boundary type & Definition & Evidence \\
\hline Hierarchical & $\begin{array}{l}\text { Those who work in the same organization } \\
\text { but have different levels of authority }\end{array}$ & $\begin{array}{l}\text { “...I actually get a call [from the senior fire- } \\
\text { fighter who is a subordinate]..." (VIS1) } \\
\text { "The Fire Officer on the ground [informed } \\
\text { me]..." (VIS3) }\end{array}$ \\
\hline Unit & $\begin{array}{l}\text { Those who work in the same organization } \\
\text { but in different business units / } \\
\text { departments }\end{array}$ & $\begin{array}{l}\text { "[the Police Communications unit] called me } \\
\text { up, I got a phone call.. say hey, there may be } \\
\text { another person, there may be another person in } \\
\text { that car..." (V6S3) } \\
\text { "We got told by radio that there was a serious } \\
\text { crash on the motorway just southbound..." } \\
\text { (V7S1) }\end{array}$ \\
\hline Organization & Those who work in different organizations & $\begin{array}{l}\text { "[the Police] asked me for the truck" (V3S3) } \\
\text { "the ambulance had asked us when we were } \\
\text { there..." (V6S2) }\end{array}$ \\
\hline Community & Community members & $\begin{array}{l}\text { “...and we'd spoken to the witnesses who'd seen } \\
\text { that he'd been driving at speed up and down the } \\
\text { road...” (V6S1) } \\
\text { "We just get as many details as we can from } \\
\text { people who are witnesses...” (V7S4) }\end{array}$ \\
\hline
\end{tabular}

Table 14: Types of boundary 


\section{1) Hierarchical boundary}

In V1S1 and V1S3, KB1, who is a Principal Rural Fire Officer, received the information from a senior firefighter (V1S1) and a fire officer (V1S3); they all work in the same organization (i.e. Rural Fire) but have different levels of authority. In the hierarchy, KB1 is ranked higher than the senior firefighter (in V1S1) and the fire officer (in V1S3) who KB1 received the information from. Therefore, KB1 received information from across a hierarchical type of boundary.

\section{2) Unit boundary}

In V6S3 and V7S1, KB4, who is a Police Chief, received the information from the Police Communication Unit; they both work in the same organization (i.e. Police) but in different business units/ departments. Therefore, KB4 received information from across a unit type of boundary.

\section{3) Organizational boundary}

In V3S3, KB2, who is a Civil Defence staff (i.e. under the City Council), received the information from the police so they work in different organizations. Similarly, in V6S2, KB4 who works for the Police received information from someone who works for the Ambulance Service which is a different organization. Therefore, both KB2 and KB4 received information from across an organization type of boundary.

\section{4) Community boundary}

In V6S1 and V7S4, KB4, who works for the Police, received the information from a civilian witness who is a community member. Therefore, KB4 received information from across a community type of boundary.

Table 15 below presents the summary of all types of boundaries found in the scenarios.

\begin{tabular}{|l|l|l|l|}
\hline$\#$ & $\begin{array}{l}\text { Vignette \& } \\
\text { Scenario no. }\end{array}$ & KB & Types of boundary \\
\hline 1 & V1S1 & KB1 & Hierarchy \\
\hline 2 & V1S2 & KB1 & Hierarchy, Unit and Organization \\
\hline 3 & V1S3 & KB1 & Hierarchy \\
\hline 4 & V2S1 & KB1 & Community \\
\hline
\end{tabular}




\begin{tabular}{|l|l|l|l|}
\hline 5 & V3S1 & KB2 & Unit \\
\hline 6 & V3S2 & KB2 & None (personal observation) \\
\hline 7 & V3S3 & KB2 & Organization \\
\hline 8 & V3S4 & KB2 & Organization \\
\hline 9 & V4S1 & KB3 & Organization \\
\hline 10 & V5S1 & KB3 & Community \\
\hline 11 & V6S1 & KB4 & Community \\
\hline 12 & V6S2 & KB4 & Organization \\
\hline 13 & V6S3 & KB4 & Unit \\
\hline 14 & V7S1 & KB4 & Unit \\
\hline 15 & V7S2 & KB4 & None (self-observation) \\
\hline 16 & V7S3 & KB4 & None (self-observation) \\
\hline 17 & V7S4 & KB4 & Community \\
\hline 18 & V8S1 & KB5 & Organization \\
\hline 19 & V9S1 & KB5 & Organization \\
\hline 20 & V10S1 & KB5 & Hierarchy \\
\hline 21 & V10S2 & KB5 & Hierarchy \\
\hline 22 & V10S3 & KB5 & Organization \\
\hline
\end{tabular}

Table 15: Summary of types of boundaries in all scenarios

To summarize, $\mathrm{KB}$ were found to receive information from across four different types of boundaries during a disaster in all scenarios except V3S2, V7S2 and V7S3 where the KB received the information from personal observation. The next section presents the findings on different types of information.

\subsubsection{Types of information}

Based on the 22 scenarios, $\mathrm{KB}$ received the following seven types of information from a source located across a boundary: request, recommendation, update, investigative, notification, advisory and informative. The definitions of each type of information are provided in Table 16 below followed by the explanations.

\begin{tabular}{|l|l|l|}
\hline Type of information & Definition & Evidence \\
\hline Request & $\begin{array}{l}\text { Requesting something and hope } \\
\text { to receive a response }\end{array}$ & "Ithe Police] asked me for the truck” (V3S3) \\
\hline Recommendation & Suggesting an action to solve a & “... I actually get a call [from the senior \\
\hline
\end{tabular}




\begin{tabular}{|c|c|c|}
\hline & problem & $\begin{array}{l}\text { firefighter who is a subordinate] over the } \\
\text { radio while I was en route to the [disaster] } \\
\text { recommending that the helicopter [is to be] } \\
\text { paged..." (VISI) }\end{array}$ \\
\hline Update & $\begin{array}{l}\text { Updating on a certain event } \\
\text { when the situation changes }\end{array}$ & $\begin{array}{l}\text { “... Ithe Police Communications unit] called me } \\
\text { up, I got a phone call.. say hey, there may be } \\
\text { another person, there may be another person in } \\
\text { that car...” (V6S3) }\end{array}$ \\
\hline Investigative & Used for investigation purposes & $\begin{array}{l}\text { “..we just get as many details as we can from } \\
\text { people who are witnesses, then we deal with it } \\
\text { later... So that we could follow up to get } \\
\text { statements from them...” (V7S4) }\end{array}$ \\
\hline Notification & $\begin{array}{l}\text { Letting someone know about an } \\
\text { event for the first time }\end{array}$ & $\begin{array}{l}\text { "It says [in the] tiny little pager...it's just a brief } \\
\text { statement of what happened. I think it must said, } \\
\text { "Aircraft crash Paraparaumu Airport..." (V3SI) }\end{array}$ \\
\hline Advisory & Suggesting an action as a guide & $\begin{array}{l}\text { "We had a classic example [from the Wellington } \\
\text { earthquake back in July 2013] where one of the } \\
\text { [Facebook page of] community [in the district] } \\
\text { issue advise to the community saying, wait for } \\
\text { the Tsunami siren to go off, before you initiate } \\
\text { your evacuation plan." (V2S1) }\end{array}$ \\
\hline Informative & $\begin{array}{l}\text { Description about a situation to } \\
\text { expand the current knowledge } \\
\text { without expecting to receive any } \\
\text { response }\end{array}$ & $\begin{array}{l}\text { "Just heard the firemen talking when they are } \\
\text { having a cup of coffee or having a meal. And } \\
\text { they say, well somebody have done this..." } \\
\text { (V4S1) }\end{array}$ \\
\hline
\end{tabular}

Table 16: Types of information

\section{1) Request}

In V3S3, KB2 received the request type of information when the source (i.e. the Police officer) shared information requesting something and hoped to receive a response, i.e. asking for a truck. 


\section{2) Recommendation}

In V1S1, KB1 received the recommendation type of information when the source (i.e. the senior firefighter) shared information suggesting an action to solve a problem: recommending a helicopter be called to help with the quickly-spreading fire.

\section{3) Update}

In V6S3, KB4 received the update type of information when the source (i.e. the Police Communication Unit) shared information updating about a certain event when the situation changed, which was that there could be another victim trapped in the crashed car.

\section{4) Investigative}

In V7S4, KB4 received the investigative type of information when the source (i.e. the witness) shared information used for investigation purposes, i.e. the crash details.

\section{5) Notification}

In $\mathrm{V} 3 \mathrm{~S} 1, \mathrm{~KB} 2$ received the notification type of information when the source (i.e. the communication centre) shared information letting KB2 know about an event, which was the aircraft crash.

6) Advisory

In $\mathrm{V} 2 \mathrm{~S} 1, \mathrm{~KB} 1$ received the advisory type of information when the source (i.e. a community board member) shared information suggesting an action, which was to wait for the tsunami siren to go off before initiating the evacuation plan. 


\section{7) Informative}

In V4S1, KB3 received the informative type of information when the source (i.e. firefighters) shared information describing a situation to expand their current knowledge, which was the possibility that the fire could be arson.

These examples of evidence show that $\mathrm{KB}$ receive different types of information from a source located across a boundary during a disaster. The summary of all of the types of information found in the scenarios is given in Table 17.

\begin{tabular}{|c|c|c|c|}
\hline$\#$ & $\begin{array}{l}\text { Vignette \& } \\
\text { Scenario no. }\end{array}$ & KB & $\begin{array}{l}\text { Types of information } \\
\text { received }\end{array}$ \\
\hline 1 & V1S1 & KB1 & Recommendation \\
\hline 2 & $\mathrm{~V} 1 \mathrm{~S} 2$ & KB1 & Update \\
\hline 3 & V1S3 & KB1 & Investigative \\
\hline 4 & $\mathrm{~V} 2 \mathrm{~S} 1$ & KB1 & False advisory \\
\hline 5 & V3S1 & KB2 & Notification \\
\hline 6 & V3S2 & KB2 & None \\
\hline 7 & V3S3 & KB2 & Request \\
\hline 8 & V3S4 & KB2 & Request \\
\hline 9 & V4S1 & KB3 & Informative \\
\hline 10 & V5S1 & KB3 & False Update \\
\hline 11 & V6S1 & KB4 & Investigative \\
\hline 12 & V6S2 & KB4 & Update \\
\hline 13 & V6S3 & KB4 & Update \\
\hline 14 & V7S1 & KB4 & Notification \\
\hline 15 & V7S2 & KB4 & None \\
\hline 16 & V7S3 & KB4 & None \\
\hline 17 & V7S4 & KB4 & Investigative \\
\hline 18 & V8S1 & KB5 & Update \\
\hline 19 & V9S1 & KB5 & Update \\
\hline 20 & V10S1 & KB5 & Update \\
\hline 21 & V10S2 & KB5 & Update \\
\hline 22 & V10S3 & KB5 & Update \\
\hline
\end{tabular}

Table 17: Summary of types of information in all scenarios 
To summarize, KB were found to receive eight different types of information during a disaster in all scenarios. The next section presents the findings on different types of disaster.

\subsubsection{Types of disasters}

There were six types of disasters that KB experienced in the scenarios. The disaster types are fire, earthquake, mine explosion, mid-air collision, bomb in a house and motor accident (see Table 18). These types of disasters are similar and included in the types of disasters listed by Bunker (2010), Ehnis and Bunker (2013) and Wellington Region Civil Defence Emergency Management (2013). All of these types of disaster were found in all 10 cases (i.e. vignettes).

\begin{tabular}{|c|c|c|c|}
\hline $\begin{array}{l}\text { Type of } \\
\text { disaster }\end{array}$ & Definition & Evidence & $\begin{array}{l}\text { Vignette } \\
\text { number }\end{array}$ \\
\hline Fire & Events that occur by the spreading of fire & $\begin{array}{l}2008 \text { Otaki Beach bush fire } \\
2014 \text { Kilbirnie storage warehouse fire }\end{array}$ & $\begin{array}{l}\text { Vignette } 1 \\
\text { Vignette } 4\end{array}$ \\
\hline Earthquake & $\begin{array}{l}\text { Events that occur when there is a } \\
\text { noticeable movement of the earth }\end{array}$ & $\begin{array}{l}2013 \text { Wellington earthquake (July) } \\
2013 \text { Wellington earthquake (August) }\end{array}$ & $\begin{array}{l}\text { Vignette } 2 \\
\text { Vignette } 10\end{array}$ \\
\hline $\begin{array}{l}\text { Mine } \\
\text { explosion }\end{array}$ & $\begin{array}{l}\text { Events that occur in a mine which } \\
\text { involve accidental explosions }\end{array}$ & 2010 Pike River mine explosion & Vignette 5 \\
\hline $\begin{array}{l}\text { Mid-air } \\
\text { collision }\end{array}$ & $\begin{array}{l}\text { Events that occur when two flying } \\
\text { vehicles collide in the air }\end{array}$ & 2008 Paraparaumu mid-air collision & Vignette 3 \\
\hline $\begin{array}{l}\text { Bomb in a } \\
\text { house }\end{array}$ & $\begin{array}{l}\text { Events that occur when it was reported } \\
\text { that there was a thing that resembled a } \\
\text { bomb found in a residential building }\end{array}$ & 2008 Paraparaumu bomb in a house & Vignette 9 \\
\hline $\begin{array}{l}\text { Motor } \\
\text { accident }\end{array}$ & $\begin{array}{l}\text { Events that occur when a vehicle collides } \\
\text { with another vehicle or other object on } \\
\text { the road }\end{array}$ & $\begin{array}{l}2014 \text { Pekapeka Road motor accident } \\
2001 \text { Aotea Quay Wellington fatal motor } \\
\text { vehicle accident } \\
2012 \text { Otaihanga fatal motor vehicle } \\
\text { accident }\end{array}$ & $\begin{array}{l}\text { Vignette } 6 \\
\text { Vignette } 7 \\
\text { Vignette } 8\end{array}$ \\
\hline
\end{tabular}

Table 18: Types of disaster

The summary of all of the types of disaster found in the 22 scenarios is in Table 19. 


\begin{tabular}{|l|l|l|l|}
\hline$\#$ & $\begin{array}{l}\text { Vignette } \\
\text { Scenario no. }\end{array}$ & KB & Types of disaster \\
\hline 1 & V1S1 & KB1 & Fire \\
\hline 2 & V1S2 & KB1 & Fire \\
\hline 3 & V1S3 & KB1 & Fire \\
\hline 4 & V2S1 & KB1 & Earthquake \\
\hline 5 & V3S1 & KB2 & Mid-air collision \\
\hline 6 & V3S2 & KB2 & Mid-air collision \\
\hline 7 & V3S3 & KB2 & Mid-air collision \\
\hline 8 & V3S4 & KB2 & Mid-air collision \\
\hline 9 & V4S1 & KB3 & Fire \\
\hline 10 & V5S1 & KB3 & Mine explosion \\
\hline 11 & V6S1 & KB4 & Motor accident \\
\hline 12 & V6S2 & KB4 & Motor accident \\
\hline 13 & V6S3 & KB4 & Motor accident \\
\hline 14 & V7S1 & KB4 & Motor accident \\
\hline 15 & V7S2 & KB4 & Motor accident \\
\hline 16 & V7S3 & KB4 & Motor accident \\
\hline 17 & V7S4 & KB4 & Motor accident \\
\hline 18 & V8S1 & KB5 & Motor accident \\
\hline 19 & V9S1 & KB5 & Bomb in a house \\
\hline 20 & V10S1 & KB5 & Earthquake \\
\hline 21 & V10S2 & KB5 & Earthquake \\
\hline 22 & V10S3 & KB5 & Earthquake \\
\hline
\end{tabular}

Table 19: Summary of types disaster in all scenarios

\subsubsection{Medium of information sharing}

$\mathrm{KB}$ were found to receive information from a source located across a boundary through different media. The media include face to face, radio, telephone, pager and Facebook. In some scenarios, the medium of information sharing was unidentified, either because it was not mentioned or no medium was present due to the KB having observed the information themselves. Table 20 summarizes the findings on the media of information sharing through which $\mathrm{KB}$ received the information. 


\begin{tabular}{|l|l|l|}
\hline$\#$ & $\begin{array}{l}\text { Vignette \& } \\
\text { Scenario }\end{array}$ & $\begin{array}{l}\text { Medium of information } \\
\text { sharing }\end{array}$ \\
\hline 1 & V1S1 & Radio \\
\hline 2 & V1S2 & Not mentioned \\
\hline 3 & V1S3 & Radio \\
\hline 4 & V2S1 & Facebook \\
\hline 5 & V3S1 & Pager \\
\hline 6 & V3S2 & None \\
\hline 7 & V3S3 & Face to face \\
\hline 8 & V3S4 & Face to face \\
\hline 9 & V4S1 & Face to face \\
\hline 10 & V5S1 & Face to face \\
\hline 11 & V6S1 & Face to face \\
\hline 12 & V6S2 & Face to face \\
\hline 13 & V6S3 & Radio \\
\hline 14 & V7S1 & Radio \\
\hline 15 & V7S2 & None \\
\hline 16 & V7S3 & None \\
\hline 17 & V7S4 & Face to face \\
\hline 18 & V8S1 & Face to face \\
\hline 19 & V9S1 & Face to face \\
\hline 20 & V10S1 & Telephone \\
\hline 21 & V10S2 & Telephone \\
\hline 22 & V10S3 & Face to face \\
\hline & $20: S 47$ & informats \\
\hline
\end{tabular}

Table 20: Summary of information sharing media in all scenarios

In short, the most common medium of information sharing being used by a source located across a boundary to share information in the 22 scenarios was face-to-face in ten scenarios. ICT media such as radio, telephone, pager and Facebook were used in eight scenarios, of which radio was the most popular (i.e. four scenarios). 
After $\mathrm{KB}$ receive information from a source located across a boundary, $\mathrm{KB}$ then assess the veracity of the information by filtering the information they received (refer to Figure 13 in section 5.1.1). The next section presents the findings.

\subsubsection{Cognitive resources}

$\mathrm{KB}$ filter the information they receive by relying on their cognitive resources (see section 2.2.1 in Chapter 2 for the discussion on cognitive resources). The cognitive resources found include: the process of feeling confidence in the source's credibility, having social ties with the source, triangulating the information, following a set of rules, having insider knowledge, recalling previous experience and scanning for vested interests. The definition and evidence of each cognitive resource is listed in Table 21 followed by the explanation of each cognitive resource in relation to evidence.

\begin{tabular}{|c|c|c|c|}
\hline$\#$ & Cognitive resources & Definition & Evidence \\
\hline 1 & $\begin{array}{l}\text { Feeling confidence in } \\
\text { the source's credibility }\end{array}$ & $\begin{array}{l}\text { Any situation during the } \\
\text { incident where the KB is } \\
\text { confident about the information } \\
\text { source's credibility due to the } \\
\text { source's credible past } \\
\text { experience or the credibility of } \\
\text { the organization that the source } \\
\text { belongs to }\end{array}$ & $\begin{array}{l}\text { "Those guys in the brigade have got 20- } \\
\text { odd years of fire experience, dealing with } \\
\text { rural fires...So, I definitely refer to their } \\
\text { advice and recommendations" (V1S1) } \\
\text { "the ambulance service will obviously } \\
\text { make the decision that the person's } \\
\text { deceased" (V8S1) } \\
\text { "[it is] important in any inter-agency } \\
\text { [emergency management] is you've [have } \\
\text { to] trust that the guy that you're talking } \\
\text { with knows his business or understands } \\
\text { those requirements" } \\
\text { (V9S1) }\end{array}$ \\
\hline 2 & $\begin{array}{l}\text { Having social ties with } \\
\text { the source }\end{array}$ & $\begin{array}{l}\text { Any situation during the } \\
\text { incident where the KB knows } \\
\text { the information source and has a } \\
\text { certain degree of relationship } \\
\text { with them }\end{array}$ & $\begin{array}{l}\text { "[I knew the senior fire fighters] } \\
\text { probably } 6 \text { months before the fire } \\
\text { happened and there was just enough time } \\
\text { to oversee a little bit of relationships with } \\
\text { those key individuals" (VIS1) }\end{array}$ \\
\hline 3 & $\begin{array}{l}\text { Triangulating the } \\
\text { information }\end{array}$ & $\begin{array}{l}\text { Any situation during the } \\
\text { incident where the KB compares } \\
\text { the information across different } \\
\text { sources }\end{array}$ & $\begin{array}{l}\text { "the pager went off... I got back to my } \\
\text { truck where I monitor the Fire Service } \\
\text { radio" (V3S1) } \\
\text { "looking at the skid marks...with what } \\
\text { that tells us, you could see the marks of } \\
\text { the tyre and as I said in fact for him to } \\
\text { have gone down there and cleared that, } \\
\text { he was going bloody fast.." (V6S1) }\end{array}$ \\
\hline
\end{tabular}




\begin{tabular}{|c|c|c|c|}
\hline & & & $\begin{array}{l}\text { "because we weren't sure of that, and we } \\
\text { got a dog handler back to check in the } \\
\text { paddock to see if the person hadn't been } \\
\text { thrown from the car... and then we } \\
\text { actually got someone from Wellington } \\
\text { police to go in and speak to him [the } \\
\text { driver] in Wellington Hospital to see was } \\
\text { there anyone else in the car with him" } \\
\text { (V6S3) }\end{array}$ \\
\hline 4 & Following a set of rules & $\begin{array}{l}\text { Any situation during the } \\
\text { incident where the KB follows a } \\
\text { certain set of rules or procedures } \\
\text { in determining the reliability of } \\
\text { the information received }\end{array}$ & $\begin{array}{l}\text { "What we have got is a lot of internal } \\
\text { checklists that we tick off, have you } \\
\text { considered this, have you considered that, } \\
\text { have you contacted that person, so, there } \\
\text { are a lot of processes already in place" } \\
\text { (V1S2) } \\
\text { "[The number of alarm notifications is] } \\
\text { generally agreed between Fire Service } \\
\text { and Rural Fire" (V3S1) }\end{array}$ \\
\hline 5 & $\begin{array}{l}\text { Having insider } \\
\text { knowledge }\end{array}$ & $\begin{array}{l}\text { Any situation during the } \\
\text { incident where the KB knows } \\
\text { how to determine veracity of the } \\
\text { information because the KB is } \\
\text { working with the organization } \\
\text { that the information belongs to }\end{array}$ & $\begin{array}{l}\text { "We don't have tsunami sirens pretty } \\
\text { much anywhere in Wellington region } \\
\text {...MCDEM [Ministry of Civil Defence and } \\
\text { Emergency Management] has } \\
\text { recommended against tsunami sirens and } \\
\text { about 5-6 years ago, we stop using } \\
\text { tsunami sirens, and I guess that has not } \\
\text { been filtered out to everyone in the } \\
\text { community that tsunami sirens are not } \\
\text { operating in this district anymore" } \\
\text { (V2S1) }\end{array}$ \\
\hline 6 & $\begin{array}{l}\text { Recalling previous } \\
\text { experience }\end{array}$ & $\begin{array}{l}\text { Any situation during the } \\
\text { incident where the KB recalls } \\
\text { previous experience and links } \\
\text { the experience to the current } \\
\text { situation to determine the } \\
\text { reliability of the received } \\
\text { information }\end{array}$ & $\begin{array}{l}\text { "[the decision was also made out of my] } \\
\text { own experience. ...It's common sense. A } \\
\text { lot of police work is common sense, } \\
\text { common sense plus say your gut feeling } \\
\text { and in my experience the fact of being a } \\
\text { police officer for } 17 \text { years" (V6S1) }\end{array}$ \\
\hline 7 & $\begin{array}{l}\text { Scanning for vested } \\
\text { interests }\end{array}$ & $\begin{array}{l}\text { Any situation during the } \\
\text { incident where the KB scans the } \\
\text { information source for any } \\
\text { vested interests to determine the } \\
\text { reliability of the received } \\
\text { information }\end{array}$ & $\begin{array}{l}\text { "Now, if the person who'd crashed was a } \\
\text { gang member, and you're a gang } \\
\text { member, and you say yeah, I saw it and } \\
\text { someone bloody came out and waved a } \\
\text { gun at him and so he lost control and } \\
\text { crashed into there, I'd go "bullshit!". So, } \\
\text { it certainly is on appearances and } \\
\text { whether or not a person has anything to } \\
\text { gain from it" (V6S1) }\end{array}$ \\
\hline
\end{tabular}

Table 21: Cognitive resources in Phase 1 


\section{1) Feeling confidence in the source's credibility}

The evidence found in V1S1, V8S1 and V9S1 shows that KB filter the information they receive by relying on the cognitive resource of feeling confidence in the source's credibility. In V1S1 for example, KB1 received information from his subordinate who has more than 20 years of work experience recommending he call for a helicopter. KB1 was filtering the information he received by feeling confident about the information source's credibility due to the source's credible past experience.

\section{2) Having social ties with the source}

The evidence found V1S1 shows that KB filter the information they receive by relying on the cognitive resource of having social ties with the source. In this scenario, KB1 received information from his subordinate who he knew for six months to call for a helicopter. KB1 was filtering the information he received by using his cognitive resource of having social ties with the source and having a certain degree of relationship with them.

\section{3) Triangulating the information}

The evidence found in $\mathrm{V} 3 \mathrm{~S} 1, \mathrm{~V} 6 \mathrm{~S} 1$ and $\mathrm{V} 6 \mathrm{~S} 3$ shows that KB filter the information they receive by relying on the cognitive resource of triangulating the information. In V3S1 for example, KB2 received information from his communication unit through a pager. KB2 then immediately compared the information he received through the pager with the information received through the radio channel. KB2 was filtering the information he received by comparing the information across different sources.

\section{4) Following a set of rules}

The evidence found in V1S2 and V3S1 shows that KB filter the information they receive by relying on the cognitive resource of following a set of rules. In V3S1 for example, $\mathrm{KB} 2$ received information from the communication unit through a pager more than once. KB2 was following a set of rules agreed on by the emergency services organizations that the higher the authority the more frequently the notifications would be sent to the pager. The agreement in the set of rules outlined that the lowest authority will only receive the 
notification once. KB2 was filtering the information he received a few times through his pager by following a set of procedures.

\section{5) Having insider knowledge}

The evidence found in $\mathrm{V} 2 \mathrm{~S} 1$ shows that $\mathrm{KB}$ filter the information they receive by relying on the cognitive resource of holding insider knowledge. In the scenario, KB1 received information from a community leader advising the community members through the community Facebook page to wait for the tsunami sirens before initiating the evacuation plan. KB1 filtered the information he received by having insider information as he was working with the agency who tried to educate the community that the tsunami sirens are no longer in use. Therefore, KB1 filtered the information he received and knew how to determine the veracity of the information because he was working for the organization that the information (i.e. the discontinuation of tsunami sirens) belonged to.

\section{6) Recalling previous experience}

The evidence found in V6S1 shows that KB filter the information they receive by relying on the cognitive resource of recalling previous experience. In the scenario for example, KB4 received information about the accident from an eye witness and then used previous experience to filter the information. KB4 was relying on her cognitive resources by recalling the previous experience of working with the Police for 17 years to filter the information. Therefore, KB4 recalled previous experience to determine the veracity of the information received.

\section{7) Scanning for vested interests}

The evidence found in $\mathrm{V} 6 \mathrm{~S} 1$ shows that $\mathrm{KB}$ filter the information they receive by relying on the cognitive resource of scanning for vested interests. In the scenario, KB4 received information from the witness on how the crashed car driver drove which lead to the crash. KB4 filtered the information he received by scanning the information source's appearance to see whether the source had anything to gain by providing false information. 
Therefore, KB4 filtered the information he received and determined the veracity of the information he received by scanning the information source for any vested interests.

Table 22 is the summary of the cognitive resources found in Phase 1 of all of the scenarios.

\begin{tabular}{|c|c|c|}
\hline$\#$ & $\begin{array}{l}\text { Vignette \& } \\
\text { Scenario }\end{array}$ & Cognitive resources \\
\hline 1 & V1S1 & $\begin{array}{l}\text { Feeling confidence in the source's credibility } \\
\text { Having social ties }\end{array}$ \\
\hline 2 & V1S2 & $\begin{array}{l}\text { Feeling confidence in the source's credibility } \\
\text { Following a set of rules }\end{array}$ \\
\hline 3 & V1S3 & Feeling confidence in the source's credibility \\
\hline 4 & V2S1 & Holding an insider knowledge \\
\hline 5 & V3S1 & Triangulating the information \\
\hline 6 & V3S2 & Recalling previous experience \\
\hline 7 & V3S3 & Feeling confidence in the source's credibility \\
\hline 8 & V3S4 & Feeling confidence in the source's credibility \\
\hline 9 & V4S1 & Feeling confidence in the source's credibility \\
\hline 10 & V5S1 & Having insider knowledge \\
\hline 11 & V6S1 & $\begin{array}{l}\text { Recalling previous experience } \\
\text { Scanning for vested interest }\end{array}$ \\
\hline 12 & V6S2 & Feeling confidence in the source's credibility \\
\hline 13 & V6S3 & Following set of rules \\
\hline 14 & V7S1 & Following set of rules \\
\hline 15 & V7S2 & N/A \\
\hline 16 & V7S3 & N/A \\
\hline 17 & V7S4 & Scanning for vested interests \\
\hline 18 & V8S1 & Feeling confidence in the source's credibility \\
\hline 19 & V9S1 & Following set of rules \\
\hline 20 & V10S1 & Following set of rules \\
\hline 21 & V10S2 & Following set of rules \\
\hline 22 & V10S3 & Feeling confidence in the source's credibility \\
\hline
\end{tabular}

Table 22: Summary of cognitive resources in Phase 1 of all scenarios

In summary, $\mathrm{KB}$ were found to have relied on one or more cognitive resources to filter the information they received from a source located across a boundary before making decisions on the veracity of the information they received except in V7S2 and V7S3. In the two exceptional scenarios, KB did not receive any information from a source located across a 
boundary. The seven cognitive resources found have been presented in the above subsections and tables.

After relying on their cognitive resources, $\mathrm{KB}$ then decide on the veracity of the information they received. The process ends when KB decide whether the information is true or false.

The next section presents the findings of Phase 2: the matching process.

\subsubsection{Phase 2: The matching process}

When KB decide on the veracity of the information they received in Phase 1, the process enters Phase 2. In this phase, KB match the information they received with someone who is located across a boundary that they think it might be relevant to by going through a matching process (see section 5.1.2: Phase 2 - The matching process).

Table 23 summarizes the findings of Phase 1 followed by sections that describe and explain the findings. 


\begin{tabular}{|c|c|c|c|c|c|c|}
\hline$\#$ & KB & $\begin{array}{l}\text { Vignette \& } \\
\text { Scenario }\end{array}$ & Cognitive resources & Types of boundary with the receiver & Medium of sharing & $\begin{array}{l}\text { Types of information } \\
\text { shared }\end{array}$ \\
\hline 1 & KB1 & V1S1 & Following a set of rules & Unit & Radio & Request \\
\hline 2 & KB1 & V1S2 & Following a set of rules & Unit & Radio & Request \\
\hline 3 & KB1 & V1S3 & $\begin{array}{l}\text { Following a set of rules } \\
\text { Recalling the training } \\
\text { Recalling past experience }\end{array}$ & Organization \& unit & Not mentioned & Investigative \\
\hline 4 & KB1 & V2S1 & Following a set of rules & Community & Telephone & Correction \\
\hline 5 & KB2 & V3S1 & $\begin{array}{l}\text { Following the organizational } \\
\text { structure }\end{array}$ & N/A & N/A & Did not share \\
\hline 6 & KB2 & V3S2 & Recalling the training & Organization & Face to face & Advisory \\
\hline 7 & KB2 & V3S3 & Having social ties & Organization & Telephone & Request \\
\hline 8 & KB2 & V3S4 & Recalling previous experience & Organization & Telephone & Request \\
\hline 9 & KB3 & V3S1 & Following a set of rules & N/A & N/A & Did not share \\
\hline 10 & KB3 & V5S1 & Following a set of rules & Community & Face to face & Corrective \\
\hline 11 & KB4 & V6S1 & Following a set of rules & N/A & N/A & Did not share \\
\hline 12 & KB4 & V6S2 & Being asked by someone & Organization & Face to face & Informative \\
\hline 13 & KB4 & V6S3 & Following a set of rules & Unit \& hierarchy & Radio & Request \\
\hline 14 & KB4 & V7S1 & $\begin{array}{l}\text { Following the organizational } \\
\text { structure }\end{array}$ & Unit & Radio & Request \\
\hline 15 & KB4 & V7S2 & $\begin{array}{l}\text { Following the organizational } \\
\text { structure }\end{array}$ & Unit & Radio & Request \\
\hline 16 & KB4 & V7S3 & Following a set of rules & Hierarchy & Face to face & Request \\
\hline
\end{tabular}




\begin{tabular}{|l|l|l|l|l|l|l|}
\hline 17 & KB4 & V7S4 & Following a set of rules & N/A & N/A \\
\hline 18 & KB5 & V8S1 & Following the organizational & Hierarchy & Face to face & Request \\
\hline 19 & KB5 & V9S1 & Following a set of rules & Organization & Face to face & Face to face \\
\hline 20 & KB5 & V10S1 & Being asked by someone & Organization & Radio & Update \\
\hline 21 & KB5 & V10S2 & $\begin{array}{l}\text { Following the organizational } \\
\text { structure }\end{array}$ & Organization & & N/A \\
\hline 22 & KB5 & V10S3 & Following a set of rules & N/A & Did not share & \\
\hline
\end{tabular}

Table 23: Summary of stage 2 findlings in Phase 2 


\subsubsection{Cognitive resources}

The process in phase 2 starts when KB match the information they hold to the relevant person by relying on several cognitive resources. The cognitive resources include: being asked by someone, recalling the training, having social ties, following set of rules, following the organizational structure and recalling previous experience. The definition and evidence of each cognitive resource is listed in Table 24 followed by the explanation of each cognitive resource in relation to evidence.

\begin{tabular}{|c|c|c|c|}
\hline \# & Cognitive resource & Definition & Evidence \\
\hline 1 & Being asked by someone & $\begin{array}{l}\text { Any situation during the } \\
\text { incident where the KB knows } \\
\text { to whom the information is } \\
\text { relevant after being asked by } \\
\text { the information seeker }\end{array}$ & $\begin{array}{l}\text { “...the ambulance had asked us when } \\
\text { we were there...” (V6S2) } \\
\text { "so basically...each head of the } \\
\text { department sat around the table and } \\
\text { [the operation leader] said, right, we'll } \\
\text { start with police, what's your status? } \\
\text { Fire service, what information are you } \\
\text { getting from out in the field? So } \\
\text { everybody's sitting around listening to } \\
\text { that information coming in... and I was } \\
\text { able to give him a status" (V10S1) }\end{array}$ \\
\hline 2 & Recalling the training & $\begin{array}{l}\text { Any situation during the } \\
\text { incident where the } \mathrm{KB} \text { knows } \\
\text { to whom the information is } \\
\text { relevant after the } \mathrm{KB} \text { recalls } \\
\text { the training they had relating } \\
\text { to the situation }\end{array}$ & $\begin{array}{l}\text { "That is part of the training } \\
\text { programme that the RNFA provides to } \\
\text { fire officers, when you first go through } \\
\text { an induction programme as a Rural } \\
\text { Fire Office, is the importance of } \\
\text { preserving and protecting the fire scene } \\
\text { particularly for the investigative } \\
\text { analysis" (V1S3). }\end{array}$ \\
\hline 3 & Having social ties & $\begin{array}{l}\text { Any situation during the } \\
\text { incident where the KB knows } \\
\text { to whom the information is } \\
\text { relevant because the KB has a } \\
\text { certain degree of relationship } \\
\text { with the information receiver }\end{array}$ & $\begin{array}{l}\text { "I called the council depot...my depot } \\
\text { was down by the side of the council } \\
\text { depot and actually was in it those days. } \\
\text { And my office was in the council's depot } \\
\text { yard. So I knew all these guys [from } \\
\text { the Council depot] personally. Every }\end{array}$ \\
\hline
\end{tabular}




\begin{tabular}{|c|c|c|c|}
\hline & & $\begin{array}{l}\text { and therefore, knows what } \\
\text { information they want }\end{array}$ & $\begin{array}{l}\text { morning tea time we use to say good } \\
\text { day to them" (V3S3) }\end{array}$ \\
\hline 4 & Following a set of rules & $\begin{array}{l}\text { Any situation during the } \\
\text { incident where the KB knows } \\
\text { to whom the information is } \\
\text { relevant after recalling the } \\
\text { standard organizational } \\
\text { procedure for the situation }\end{array}$ & $\begin{array}{l}\text { "one of the big roles of the fire officer } \\
\text { is actually the cost recovery from any } \\
\text { liable party.." (VIS3). } \\
\text { "Because the management of the Pike } \\
\text { River has asked us to set up this [the } \\
\text { community information hub] up and } \\
\text { they knew we had to have that } \\
\text { information so we can help dispel } \\
\text { rumours" (V5S1) }\end{array}$ \\
\hline 5 & $\begin{array}{l}\text { Following the organizational } \\
\text { structure }\end{array}$ & $\begin{array}{l}\text { Any situation during the } \\
\text { incident where the KB knows } \\
\text { to whom the information is } \\
\text { relevant after recalling the } \\
\text { organizational structure in } \\
\text { terms of who needs what } \\
\text { information }\end{array}$ & $\begin{array}{l}\text { "So, any as you're aware any incident } \\
\text { like this, each agency has their little } \\
\text { role to do" (V6S2) } \\
\text { "I was feeding information back...to } \\
\text { my area management team so that they } \\
\text { were comfortable, they knew again I } \\
\text { was looking at that picture they were } \\
\text { looking at the bigger picture, so I was } \\
\text { only part or we were only part of that } \\
\text { picture" (VIOS2) }\end{array}$ \\
\hline 6 & Recalling previous experience & $\begin{array}{l}\text { Any situation during the } \\
\text { incident where the KB knows } \\
\text { to whom the information is } \\
\text { relevant after recalling } \\
\text { previous experience and } \\
\text { linking the experience to the } \\
\text { current situation to determine } \\
\text { who needs this information }\end{array}$ & $\begin{array}{l}\text { "I mean my experience is in the police } \\
\text { background"... for about } 8 \text { years }{ }^{7} \text {... so } \\
\text { that would probably a bit of experience } \\
\text { that I also call upon to recognize the } \\
\text { importance of preserving the scene and } \\
\text { have the evidence which is not tarnish } \\
\text { and can be used for evidential } \\
\text { purposes" (VIS3) }\end{array}$ \\
\hline
\end{tabular}

Table 24: Cognitive resources in Phase 2 


\section{1) Being asked by someone}

The evidence found in V6S2 and V10S1 shows that KB match the information they hold by relying on the cognitive resource of being asked by someone. In V6S2 for example, KB4 who is a police officer, was asked by the ambulance person whether she knew certain information about the condition of the crashed car driver, which she did not know at that stage. The moment KB4 received that request, she knew that the information was needed by the ambulance. Therefore, KB4 was matching the information she held and knew it was relevant to the ambulance because KB4 was relying on the cognitive resource of being asked about the information by the information seeker.

\section{2) Recalling the training}

The evidence found in V1S3 shows that KB match the information they hold by relying on the cognitive resource of recalling the training. In that scenario, the moment KB1 received the information of the possible evidence of the fire being caused by arson, he knew that the information was needed by the police and the Fire Investigation Unit because he had been trained to handle the situation. Therefore, KB1 was matching the information he held with the people to whom it was relevant because KB1 was relying on the cognitive resource of recalling the training relating to the situation.

\section{3) Having social ties}

The evidence found in V3S3 shows that KB match the information they hold by relying on the cognitive resource of having social ties. In that scenario, the moment KB2 received the information of a request for a truck, he knew to whom the information was relevant, which was the council depot because KB2 had social ties with them and knew they could provide the truck. Therefore, KB2 was matching the information he held with those to whom it was relevant because KB2 had a certain degree of relationship with the information receiver.

\section{4) Following a set of rules}

The evidence found in V5S1 shows that $\mathrm{KB}$ match the information they hold by relying on the cognitive resource of following a set of rules. In that scenario, the moment KB3 received 
the information of the disaster update, he knew that the information was needed by the community members because he had been briefed by the organization to handle the situation. Therefore, KB3 was matching the information he held with those to whom it was relevant after recalling the standard organizational procedure for the situation.

\section{5) Following the organizational structure}

The evidence found in V6S2 and V10S2 shows that KB match the information they hold by relying on the cognitive resource of following the organizational structure. In V10S2 for example, the moment KB5 received information about the updates on the disaster, he knew that the information was needed by his superior who was the area manager. Therefore, KB5 was matching the information he held and knew it was relevant to his superior after recalling the organizational structure in terms of who needs what information.

\section{6) Recalling previous experience}

The evidence found in V1S3 shows that KB match the information they hold by relying on the cognitive resource of recalling previous experience. In the scenario, the moment KB1 received information about the evidence regarding the fire, he knew that the information was needed by the police because KB1 had previous experience working for the police for eight years. Therefore, KB1 was matching the information he held and knew it was relevant to the police after recalling his previous experience and linking the experience to the current situation to determine who needed this information.

Table 25 is the summary of the cognitive resources found in Phase 2 of all the scenarios.

\begin{tabular}{|l|l|l|}
\hline$\#$ & Vignette \& Scenario & Cognitive resources \\
\hline 1 & V1S1 & Following a set of rules \\
\hline 2 & V1S2 & Following a set of rules \\
\hline 3 & V1S3 & $\begin{array}{l}\text { Following a set of rules } \\
\text { Recalling the training } \\
\text { Recalling past experience }\end{array}$ \\
\hline 4 & V2S1 & Following a set of rules \\
\hline 5 & V3S1 & Following the organizational structure \\
\hline
\end{tabular}




\begin{tabular}{|l|l|l|}
\hline 6 & V3S2 & Recalling the training \\
\hline 7 & V3S3 & Having social ties \\
\hline 8 & V3S4 & Recalling previous experience \\
\hline 9 & V4S1 & Following a set of rules \\
\hline 10 & V5S1 & Following a set of rules \\
\hline 11 & V6S1 & Following a set of rules \\
\hline 12 & V6S2 & Being asked by someone \\
\hline 13 & V6S3 & Following the organizational structure \\
\hline 14 & V7S1 & Following the organizational structure \\
\hline 15 & V7S2 & Following a set of rules \\
\hline 16 & V7S3 & Following a set of rules \\
\hline 17 & V7S4 & Following the organizational structure \\
\hline 18 & V8S1 & Following a set of rules \\
\hline 19 & V9S1 & Being asked by someone \\
\hline 20 & V10S1 & Following the organizational structure \\
\hline 21 & V10S2 & Following a set of rules \\
\hline 22 & V10S3 & \\
\hline
\end{tabular}

Table 25: Summary of cognitive resources in Phase 2 of all scenarios

The following sections presents other findings in Phase 2.

\subsubsection{Types of boundary}

After KB match the information they hold using their cognitive resources, they then decide to whom the information is relevant. $\mathrm{KB}$ then decide either to share the information with a receiver located across a boundary or to keep the information to themselves if they could not identify to whom the information was relevant at that time.

When KB share the information with the receiver, they share across boundaries. The types of boundaries that KB share across are found to be similar to the types of boundaries in Phase 1 . They are hierarchical, unit, organization and community. The definitions of each boundary have been presented in Table 14 on page 122. 


\subsubsection{Types of information}

The types of information shared are also similar to those in Phase 1. They are request, recommendation, update, investigative, notification, advisory and informative. The definitions of each type of information have been presented in Table 16 on page 125 .

\subsubsection{Types of disaster}

The types of disaster remain exactly the same as in Phase 1 because they are the same disasters in both phases of each scenario. The types of disaster have been presented in Table 18 on page 13.

\subsubsection{Types of media}

The media of sharing that $\mathrm{KB}$ use to share the information with the receiver across a boundary were found mostly to be similar to those in Phase 1 except KB did not use a pager or Facebook in Phase 2. The media are face to face, radio and telephone. In some scenarios, there were no media used to share the information because either KB kept the information to themselves or did not mention them. The media that KB most often used to share the information with the receiver across a boundary were the radio and telephone (ICT) in nine scenarios, of which radio was used the most (i.e. in six scenarios). The face to face medium was used in seven scenarios. 


\subsubsection{Summary of stage 2 findings}

In stage 2, I found that the processes of both Phase 1 and Phase 2 were more complex than the process found in Stage 1. The process starts in Phase 1 when KB receive different types of information from a source located across a type of boundary through various types of media. Then KB rely on different types of cognitive resources to filter the information before deciding on the veracity of the information. The process in Phase 1 ends when KB make their decision whether the information they receive is true or false. Then the process in Phase 2 starts when KB rely on various types of cognitive resources to match the information they hold with the relevant receiver. Then $\mathrm{KB}$ decide either to share the various types of information with the relevant receiver located across a type of boundary using various types of media or to keep the information to themselves. The process in Phase 2 ends when KB share or keep the information they hold. Table 23 summarizes all of the stage 2 Phase 2 findings in all 22 scenarios.

Finally,

Figure 17 illustrates the model of cross-boundary information sharing processes by $\mathrm{KB}$ during a disaster as found after the analysis in stage 2 . The next section presents the findings of stage 3 . 


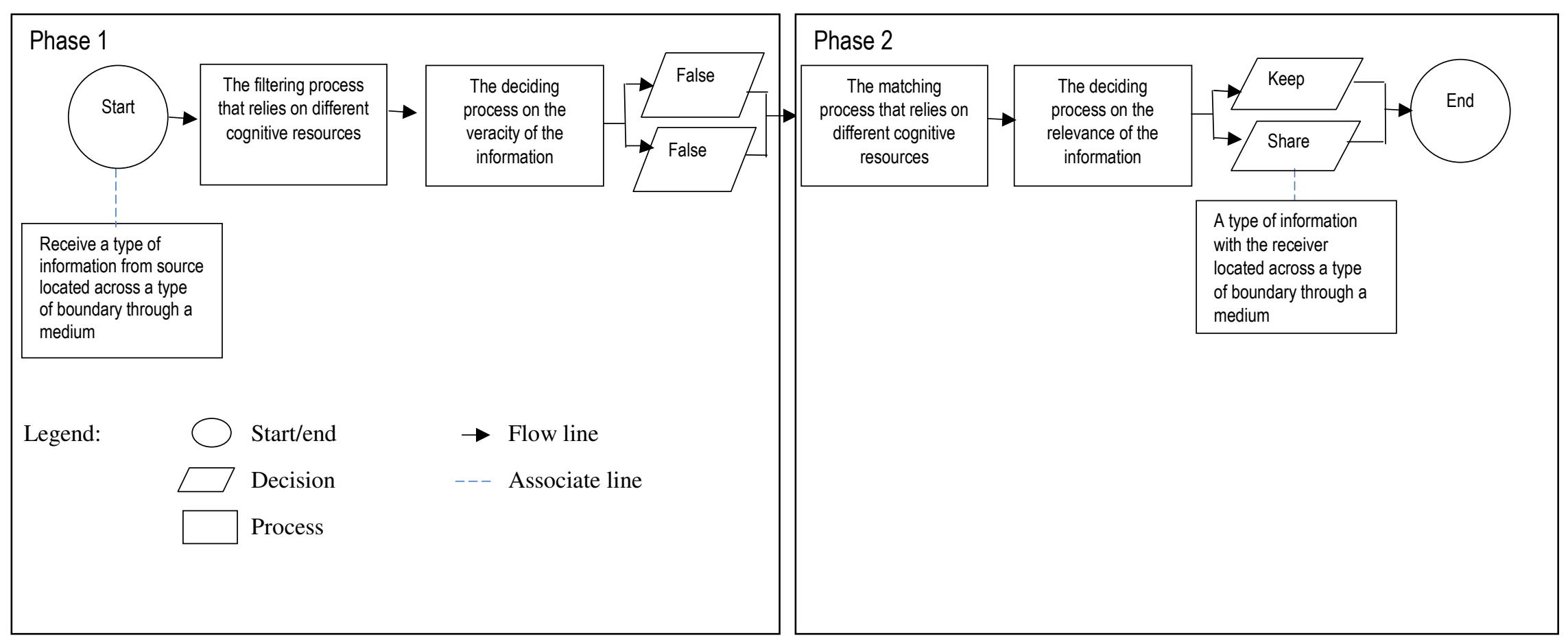

Figure 17: Model of cross-boundary information sharing processes by KB during a disaster found in stage 2 


\subsection{Findings: Stage 3}

In this stage, I analyzed the data using the lens of Naturalistic Decision Making (NDM). The detail process of analysis was described in Chapter 3 (Methodology), section 3.6.1.1 (Process of data analysis, Stage 3). To recap, I matched all of the 22 scenarios with the features of NDM (G. Klein \& Klinger, 1991). This was done to confirm that the analysis in this stage could be conducted using a NDM lens.

Then I analyzed the process of decision making in both Phase1 and Phase2 using the tactics of coping with uncertainty adapted from Lipshitz and Strauss (1997). The tactics' names and their definitions were presented in Chapter 2 (see section 2.4.3).

\subsubsection{Features of NDM}

I found that each of the 22 scenarios in both Phase 1 and Phase 2 contain the relevant features of NDM. Almost all of the scenarios included the NDM features of time stress, high stakes, multiple players, organizational goals and norms and experienced decision makers. As well as the five features mentioned, most of the scenarios also involved either one or both of the other two NDM features: 1) uncertainty, ambiguity and missing data, and 2) dynamic and continually changing conditions (for example in V1S1 and V10S3).

None of the scenarios contained any of three NDM features: 1) ill-defined goals and illstructured task, 2) shifting and competing goals, and 3) action-feedback loops (real-time reaction to changed conditions).

Table 26 and Table 27 summarize the findings of the features of NDM in each scenario in Phase 1 and Phase 2. Therefore, all of the scenarios included some features of NDM which proves that this research can be further analyzed using the lens of NDM.

The next section reports the findings on the tactics used by KB in Phase 1 to decide the veracity of the information they received. 


\begin{tabular}{|c|c|c|c|c|c|c|c|c|c|c|c|}
\hline \multirow[b]{2}{*}{$\#$} & \multirow[b]{2}{*}{$\begin{array}{l}\text { Vignette } \\
\text { \& } \\
\text { Scenario } \\
\text { no. } \\
\end{array}$} & \multicolumn{10}{|c|}{ Features of NDM } \\
\hline & & $\begin{array}{l}\text { Ill-defined } \\
\text { goals \& ill- } \\
\text { structured } \\
\text { task }\end{array}$ & $\begin{array}{l}\text { Uncertainty, } \\
\text { ambiguity \& } \\
\text { missing data }\end{array}$ & $\begin{array}{l}\text { Shifting } \\
\& \\
\text { competing } \\
\text { goals }\end{array}$ & $\begin{array}{l}\text { Dynamic } \\
\& \\
\text { continually } \\
\text { changing } \\
\text { conditions } \\
\end{array}$ & $\begin{array}{l}\text { Action- } \\
\text { feedback } \\
\text { loops (real- } \\
\text { time reaction } \\
\text { to change } \\
\text { conditions) } \\
\end{array}$ & Time stress & $\begin{array}{l}\text { High } \\
\text { Stakes }\end{array}$ & $\begin{array}{l}\text { Multiple } \\
\text { players }\end{array}$ & $\begin{array}{l}\text { Organizational } \\
\text { goals and } \\
\text { norms }\end{array}$ & $\begin{array}{l}\text { Experienced } \\
\text { decision maker }\end{array}$ \\
\hline 1 & V1S1 & & & & $\mathrm{x}$ & & $\mathrm{x}$ & $\mathrm{x}$ & $\mathrm{x}$ & $\mathrm{x}$ & $\mathrm{x}$ \\
\hline 2 & V1S2 & & & & $\mathrm{x}$ & & $\mathrm{x}$ & $\mathrm{x}$ & $\mathrm{x}$ & $\mathrm{x}$ & $\mathrm{x}$ \\
\hline 3 & $\mathrm{~V} 1 \mathrm{~S} 3$ & & $\mathrm{x}$ & & & & $\mathrm{x}$ & $\mathrm{x}$ & $\mathrm{x}$ & $\mathrm{x}$ & $\mathrm{x}$ \\
\hline 4 & V2S1 & & & & & & $\mathrm{x}$ & $\mathrm{x}$ & $\mathrm{x}$ & $\mathrm{x}$ & $\mathrm{x}$ \\
\hline 5 & V3S1 & & $\mathrm{x}$ & & $\mathrm{x}$ & & $\mathrm{x}$ & $\mathrm{x}$ & $\mathrm{x}$ & $\mathrm{x}$ & $\mathrm{x}$ \\
\hline 6 & $\mathrm{~V} 3 \mathrm{~S} 2$ & & $\mathrm{x}$ & & $\mathrm{x}$ & & $\mathrm{x}$ & $\mathrm{x}$ & $\mathrm{x}$ & $\mathrm{x}$ & $\mathrm{x}$ \\
\hline 7 & $\mathrm{~V} 3 \mathrm{~S} 3$ & & & & & & $\mathrm{x}$ & $\mathrm{x}$ & $\mathrm{x}$ & $\mathrm{x}$ & $\mathrm{x}$ \\
\hline 8 & $\mathrm{~V} 3 \mathrm{~S} 4$ & & & & & & $\mathrm{x}$ & $\mathrm{x}$ & $\mathrm{x}$ & $\mathrm{x}$ & $\mathrm{x}$ \\
\hline 9 & V4S1 & & $\mathrm{x}$ & & $\mathrm{x}$ & & $\mathrm{x}$ & $\mathrm{x}$ & $\mathrm{x}$ & $\mathrm{x}$ & $\mathrm{x}$ \\
\hline 10 & V5S1 & & $\mathrm{x}$ & & & & $\mathrm{x}$ & $\mathrm{x}$ & $\mathrm{x}$ & $\mathrm{x}$ & $\mathrm{x}$ \\
\hline 11 & V6S1 & & $\mathrm{x}$ & & & & $\mathrm{x}$ & $\mathrm{x}$ & $\mathrm{x}$ & $\mathrm{x}$ & $\mathrm{x}$ \\
\hline 12 & V6S2 & & $\mathrm{x}$ & & & & $\mathrm{x}$ & $\mathrm{x}$ & $\mathrm{x}$ & $\mathrm{x}$ & $\mathrm{x}$ \\
\hline 13 & V6S3 & & $\mathrm{x}$ & & $\mathrm{x}$ & & $\mathrm{x}$ & $\mathrm{x}$ & $\mathrm{x}$ & $\mathrm{x}$ & $\mathrm{x}$ \\
\hline 14 & V7S1 & & $\mathrm{x}$ & & & & $\mathrm{x}$ & $\mathrm{x}$ & $\mathrm{x}$ & $\mathrm{x}$ & $\mathrm{x}$ \\
\hline 15 & V7S2 & & & & & & $\mathrm{x}$ & $\mathrm{x}$ & $\mathrm{x}$ & $\mathrm{x}$ & $\mathrm{x}$ \\
\hline 16 & V7S3 & & & & & & & & $\mathrm{x}$ & $\mathrm{x}$ & $\mathrm{x}$ \\
\hline 17 & V7S4 & & $\mathrm{x}$ & & & & $\mathrm{x}$ & $\mathrm{x}$ & $\mathrm{x}$ & $\mathrm{x}$ & $\mathrm{x}$ \\
\hline 18 & V8S1 & & & & & & $\mathrm{x}$ & $\mathrm{x}$ & $\mathrm{x}$ & $\mathrm{x}$ & $\mathrm{x}$ \\
\hline 19 & V9S1 & & $\mathrm{x}$ & & & & $\mathrm{x}$ & $\mathrm{x}$ & $\mathrm{x}$ & $\mathrm{x}$ & $\mathrm{x}$ \\
\hline 20 & V10S1 & & $\mathrm{x}$ & & $\mathrm{x}$ & & $\mathrm{x}$ & $\mathrm{x}$ & $\mathrm{x}$ & $\mathrm{x}$ & $\mathrm{x}$ \\
\hline 21 & V10S2 & & $\mathrm{x}$ & & $\mathrm{x}$ & & $\mathrm{x}$ & $\mathrm{x}$ & $\mathrm{x}$ & $\mathrm{x}$ & $\mathrm{x}$ \\
\hline 22 & V10S3 & & & & $\mathrm{x}$ & & $\mathrm{x}$ & $\mathrm{x}$ & $\mathrm{x}$ & $\mathrm{x}$ & $\mathrm{x}$ \\
\hline
\end{tabular}

Table 26: Summary of NDM features in Phase 1 of all the scenarios 


\begin{tabular}{|c|c|c|c|c|c|c|c|c|c|c|c|}
\hline \multirow[b]{2}{*}{ \# } & \multirow[b]{2}{*}{$\begin{array}{l}\text { Vignette \& } \\
\text { Scenario no. } \\
\end{array}$} & \multicolumn{10}{|c|}{ Features of NDM } \\
\hline & & $\begin{array}{l}\text { Ill- } \\
\text { defined } \\
\text { goals \& } \\
\text { ill- } \\
\text { structure } \\
\text { d task } \\
\end{array}$ & $\begin{array}{l}\text { Uncertainty, } \\
\text { ambiguity \& } \\
\text { missing data } \\
\end{array}$ & $\begin{array}{l}\text { Shifting } \\
\& \\
\text { competi } \\
\text { ng goals } \\
\end{array}$ & $\begin{array}{l}\text { Dynamic \& } \\
\text { continually } \\
\text { changing } \\
\text { conditions } \\
\end{array}$ & $\begin{array}{l}\text { Action- } \\
\text { feedback } \\
\text { loops (real- } \\
\text { time } \\
\text { reaction to } \\
\text { change } \\
\text { conditions) }\end{array}$ & Time stress & $\begin{array}{l}\text { High } \\
\text { Stakes } \\
\end{array}$ & $\begin{array}{l}\begin{array}{l}\text { Multiple } \\
\text { players }\end{array} \\
\end{array}$ & $\begin{array}{l}\begin{array}{l}\text { Organizational } \\
\text { goals \& norms }\end{array} \\
\end{array}$ & $\begin{array}{l}\begin{array}{l}\text { Experienced } \\
\text { decision maker }\end{array} \\
\end{array}$ \\
\hline 1 & V1S1 & & & & $\mathrm{x}$ & & $\mathrm{x}$ & $\mathrm{x}$ & $\mathrm{x}$ & $\mathrm{x}$ & $\mathrm{x}$ \\
\hline 2 & V1S2 & & & & $\mathrm{x}$ & & $\mathrm{x}$ & $\mathrm{x}$ & $\mathrm{x}$ & $\mathrm{x}$ & $\mathrm{x}$ \\
\hline 3 & V1S3 & & $\mathrm{x}$ & & & & $\mathrm{x}$ & $\mathrm{x}$ & $\mathrm{x}$ & $\mathrm{x}$ & $\mathrm{x}$ \\
\hline 4 & V2S1 & & & & & & $\mathrm{x}$ & $\mathrm{x}$ & $\mathrm{x}$ & $\mathrm{x}$ & $\mathrm{x}$ \\
\hline 5 & V3S1 & & & & & & $\mathrm{x}$ & $\mathrm{x}$ & $\mathrm{x}$ & $\mathrm{x}$ & $\mathrm{x}$ \\
\hline 6 & V3S2 & & & & & & $\mathrm{x}$ & $\mathrm{x}$ & $\mathrm{x}$ & $\mathrm{x}$ & $\mathrm{x}$ \\
\hline 7 & V3S3 & & & & & & $\mathrm{x}$ & $\mathrm{x}$ & $\mathrm{x}$ & $\mathrm{x}$ & $\mathrm{x}$ \\
\hline 8 & V3S4 & & & & & & $\mathrm{x}$ & $\mathrm{x}$ & $\mathrm{x}$ & $\mathrm{x}$ & $\mathrm{x}$ \\
\hline 9 & V4S1 & & & & & & $\mathrm{x}$ & $\mathrm{x}$ & $\mathrm{x}$ & $\mathrm{x}$ & $\mathrm{x}$ \\
\hline 10 & V5S1 & & & & & & $\mathrm{x}$ & $\mathrm{x}$ & $\mathrm{x}$ & $\mathrm{x}$ & $\mathrm{x}$ \\
\hline 11 & V6S1 & & & & & & $\mathrm{x}$ & $\mathrm{x}$ & $\mathrm{x}$ & $\mathrm{x}$ & $\mathrm{x}$ \\
\hline 12 & V6S2 & & & & & & $\mathrm{x}$ & $\mathrm{x}$ & $\mathrm{x}$ & $\mathrm{x}$ & $\mathrm{x}$ \\
\hline 13 & V6S3 & & $\mathrm{x}$ & & & & $\mathrm{x}$ & $\mathrm{x}$ & $\mathrm{x}$ & $\mathrm{x}$ & $\mathrm{x}$ \\
\hline 14 & V7S1 & & & & & & $\mathrm{x}$ & $\mathrm{x}$ & $\mathrm{x}$ & $\mathrm{x}$ & $\mathrm{x}$ \\
\hline 15 & V7S2 & & & & & & $\mathrm{x}$ & $\mathrm{x}$ & $\mathrm{x}$ & $\mathrm{x}$ & $\mathrm{x}$ \\
\hline 16 & V7S3 & & & & & & $\mathrm{x}$ & $\mathrm{x}$ & $\mathrm{x}$ & $\mathrm{x}$ & $\mathrm{x}$ \\
\hline 17 & V7S4 & & & & & & $\mathrm{x}$ & $\mathrm{x}$ & $\mathrm{x}$ & $\mathrm{x}$ & $\mathrm{x}$ \\
\hline 18 & V8S1 & & & & & & $\mathrm{x}$ & $\mathrm{x}$ & $\mathrm{x}$ & $\mathrm{x}$ & $\mathrm{x}$ \\
\hline 19 & V9S1 & & & & & & $\mathrm{x}$ & $\mathrm{x}$ & $\mathrm{x}$ & $\mathrm{x}$ & $\mathrm{x}$ \\
\hline 20 & V10S1 & & & & $\mathrm{x}$ & & $\mathrm{x}$ & $\mathrm{x}$ & $\mathrm{x}$ & $\mathrm{x}$ & $\mathrm{x}$ \\
\hline 21 & V10S2 & & & & $\mathrm{x}$ & & $\mathrm{x}$ & $\mathrm{x}$ & $\mathrm{x}$ & $\mathrm{x}$ & $\mathrm{x}$ \\
\hline 22 & V10S3 & & & & & & $\mathrm{x}$ & $\mathrm{x}$ & $\mathrm{x}$ & $\mathrm{x}$ & $\mathrm{x}$ \\
\hline
\end{tabular}

Table 27: Summary of NDM features in Phase 2 of all the scenarios 


\subsubsection{Tactics used for decision making in Phase 1}

In Phase 1, KB make a decision to identify the veracity of the information they received from the source located across a boundary. I found that $\mathrm{KB}$ only use three decision-making tactics. They are: following SOP/norms, assumption-based reasoning and ignoring uncertainty. From the twelve tactics found by Lipshitz and Strauss (1997), there were eight tactics that were not used at all in any of the scenarios: delaying action, soliciting advice, pre-empting, improving readiness, avoiding irreversible action, weighing pros and cons, relying on intuition and taking a gamble.

Example of evidence for each tactic's use is summarized in Table 28 and followed by the explanation of each cognitive resource in relation to evidence.

\begin{tabular}{|l|l|l|}
\hline$\#$ & Tactics used & Evidence \\
\hline 1 & Following SOP/norms & $\begin{array}{l}\text { "I often refer to the experience of my actual Fire Officers } \\
\text { on fire ground" (VIS1) } \\
\text { “... when] you first put a call is you need to preserve life so } \\
\text { that's sending police officers so you've got to do that so } \\
\text { you've got to go and make sure is there anything that we } \\
\text { can do to save the people..." (V7S1) }\end{array}$ \\
\hline 2 & $\begin{array}{l}\text { Assumption-based } \\
\text { reasoning }\end{array}$ & $\begin{array}{l}\text { "Just heard the firemen talking... and they say, well } \\
\text { somebody have done this... I just treat this conversation that } \\
\text { I overheard and they are the professional fireman and they } \\
\text { would know more than what anybody else was saying. They } \\
\text { are the people who were fighting the fire." (V4S1) }\end{array}$ \\
\hline 3 & $\begin{array}{l}\text { Ignoring uncertainty } \\
\text { "I was thinking of I need to stop off the traffic coming from } \\
\text { The Hutt and I need to stop the traffic coming down the }\end{array}$ \\
\hline
\end{tabular}

Table 28: Tactics used in Phase 1 and the evidence 


\section{1) Following SOP/norms}

The evidence found in V1S1 and V7S1 shows that KB use the following SOP/norms tactics to identify the veracity of the information they received. In V1S1 for example, KB1 decided that the information he received from his subordinate on the recommendation to call a helicopter to help control the fire was true because KB1 normally takes their advice and trusts their information was true.

\section{2) Assumption-based reasoning}

The evidence found in $\mathrm{V} 4 \mathrm{~S} 1$ shows that $\mathrm{KB}$ use the assumption-based reasoning tactic to identify the veracity of the information they received. In V4S1 for example, KB3 decided that the information he received when he overheard the fire fighter about the possibility of arson is true because KB3 assumed that the firefighter would know what they are talking about and trusted their information was true.

\section{3) Ignoring uncertainty}

The evidence found in V7S2 shows that KB use the ignoring uncertainty tactic to identify the veracity of the information they received. In that scenario, KB4 received the information by personal observation about the possible heavy traffic at the car crash location and the need to control the traffic. KB4 decided that the information she observed was true as she was thinking about stopping the traffic from both directions.

Table 29 summarizes the findings of the tactics used by KB to identify the veracity of information in Phase 1.

\begin{tabular}{|l|l|l|}
\hline$\#$ & $\begin{array}{l}\text { Vignette \& } \\
\text { Scenario no. }\end{array}$ & Tactics used \\
\hline 1 & V1S1 & Following SOP/norms \\
\hline 2 & V1S2 & Following SOP/norms \\
\hline 3 & V1S3 & Following SOP/norms \\
\hline 4 & V2S1 & Following SOP/norms \\
\hline 5 & V3S1 & Following SOP/norms \\
\hline 6 & V3S2 & Assumption-based reasoning \\
\hline 7 & V3S3 & Assumption-based reasoning \\
\hline
\end{tabular}




\begin{tabular}{|c|c|c|}
\hline 8 & V3S4 & Assumption-based reasoning \\
\hline 9 & V4S1 & Assumption-based reasoning \\
\hline 10 & V5S1 & Assumption-based reasoning \\
\hline 11 & V6S1 & Assumption-based reasoning \\
\hline 12 & V6S2 & Assumption-based reasoning \\
\hline 13 & V6S3 & Assumption-based reasoning \\
\hline 14 & V7S1 & Following SOP/norms \\
\hline 15 & V7S2 & Ignoring uncertainty \\
\hline 16 & V7S3 & Ignoring uncertainty \\
\hline 17 & V7S4 & Following SOP/norms \\
\hline 18 & V8S1 & Assumption-based reasoning \\
\hline 19 & V9S1 & Assumption-based reasoning \\
\hline 20 & V10S1 & Following SOP/norms \\
\hline 21 & V10S2 & Following SOP/norms \\
\hline 22 & V10S3 & Assumption-based reasoning \\
\hline
\end{tabular}

Table 29: Summary of tactics used to decide on the veracity of information in Phase 1 of all scenarios.

The two tactics that were used the most are: following SOP/norms $(n=9)$ and assumptionbased reasoning $(n=11)$. The tactic of ignoring uncertainty was used in two scenarios $(n=2)$.

Figure 18: Decision-making process to identify the veracity of information using different tactics in Phase 1 illustrates the decision-making process in Phase 1.

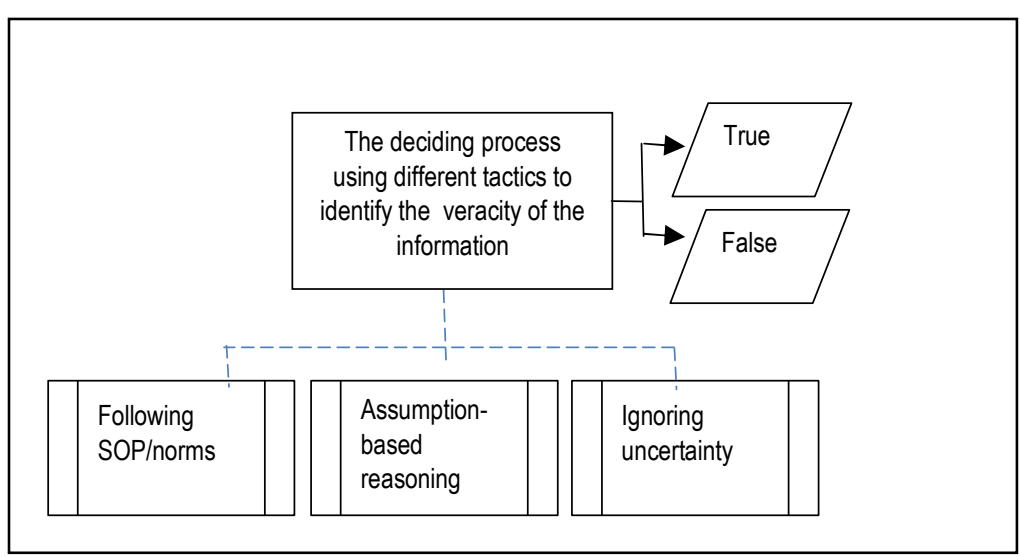

Figure 18: Decision-making process to identify the veracity of information using different tactics in Phase 1

The next section presents the findings on the tactics used in Phase 2. 


\subsubsection{Tactics used for decision making in Phase 2}

In Phase 2, KB make a decision to identify to whom the information they hold is relevant across a boundary. Similar to Phase 1, I found that KB only use three tactics. They are: following SOP/norms, assumption-based reasoning and ignoring uncertainty. Examples of evidence for each tactics use are summarized in Table 30 and followed by the explanation of each cognitive resource in relation to evidence.

\begin{tabular}{|c|c|c|}
\hline$\#$ & Tactics used & Evidence \\
\hline 1 & Following SOP/norms & $\begin{array}{l}\text { "...the authority to call the helicopter rest with [me]... it } \\
\text { was me on the radio with Communications Centre providing } \\
\text { [information]... and resource request..." (VISI) } \\
\text { "...that is part of the training programme that the RNFA } \\
\text { provides to fire officers, when you first go through an } \\
\text { induction programme as a Rural Fire Officer, is the } \\
\text { importance of preserving and protecting the fire scene } \\
\text { particularly for the investigative analysis...” (VIS3) }\end{array}$ \\
\hline 2 & $\begin{array}{l}\text { Assumption-based } \\
\text { reasoning }\end{array}$ & $\begin{array}{l}\text { “...we offered to the police...[that] we had a huge...complete } \\
\text { facility...operation centre...built it at the Council....but the } \\
\text { police decided that no, they will use the police station. They } \\
\text { were jammed into the police station. Police station does not } \\
\text { designed for that many people...our facility would have } \\
\text { handled it easily...we had all the radios, computers and } \\
\text { phones and everything that they wanted” (V3S2) } \\
\text { “...the bomb squad guy turned up that that's his } \\
\text { responsibility... I would assume that the internal protocol } \\
\text { decides that... you've got your responsibility and again I've } \\
\text { got mine....” (V9S1) }\end{array}$ \\
\hline
\end{tabular}




\begin{tabular}{|l|l|l|}
\hline 3 & Ignoring uncertainty & $\begin{array}{l}\text { "...[We] always give out the exact information [in the } \\
\text { community information Hub]...” (V5S1) }\end{array}$ \\
\hline
\end{tabular}

Table 30: Tactics used in Phase 2 and the evidence

\section{1) Following SOP/norms}

The evidence found in V1S1 and V1S3 shows that KB use the following SOP/norms tactic to identify to whom the information is relevant. In V1S1 for example, KB1 decided that the information request to call a helicopter to help to control the fire is relevant to the communication centre, not directly to the helicopter unit. The decision was made because KB1 was following the SOP/norm according to his 'authority' which is seen to be following the SOP/norm of requesting additional resources.

\section{2) Assumption-based reasoning}

The evidence found in $\mathrm{V} 3 \mathrm{~S} 2$ and $\mathrm{V} 9 \mathrm{~S} 1$ shows that $\mathrm{KB}$ use the assumption-based reasoning tactic to identify to whom the information is relevant. In V9S1 for example, KB5 decided that the information he held about the updates of the disaster was relevant to the bomb squad team. The decision was made because KB4 was 'assuming' that a relevant protocol decides that the bomb squad team need the updates because of their responsibility.

\section{3) Ignoring uncertainty}

The evidence found in V5S1 shows that KB use the ignoring uncertainty tactic to identify to whom the information is relevant. In that scenario, KB3 decided that the information he held about the updates of the disaster was relevant to the community in the information hub. The decision was made because KB3 was asked to do so. Therefore, KB3 was certain that the updated information he held was for the community. 
Table 31 summarizes the findings of the tactics used by KB to identify the veracity of information in Phase 2.

\begin{tabular}{|c|c|c|}
\hline$\#$ & $\begin{array}{l}\text { Vignette \& } \\
\text { Scenario no. }\end{array}$ & Tactics used to decide information relevance \\
\hline 1 & V1S1 & Following SOP/norms \\
\hline 2 & V1S2 & Following SOP/norms \\
\hline 3 & V1S3 & Following SOP/norms \\
\hline 4 & V2S1 & Ignoring uncertainty \\
\hline 5 & V3S1 & Ignoring uncertainty \\
\hline 6 & V3S2 & Assumption-based reasoning \\
\hline 7 & V3S3 & Ignoring uncertainty \\
\hline 8 & V3S4 & Ignoring uncertainty \\
\hline 9 & V4S1 & Following SOP/norms \\
\hline 10 & V5S1 & Ignoring uncertainty \\
\hline 11 & V6S1 & Following SOP/norms \\
\hline 12 & V6S2 & Ignoring uncertainty \\
\hline 13 & V6S3 & Following SOP/norms \\
\hline 14 & V7S1 & Following SOP/norms \\
\hline 15 & $\mathrm{~V} 7 \mathrm{~S} 2$ & Following SOP/norms \\
\hline 16 & V7S3 & Following SOP/norms \\
\hline 17 & V7S4 & Following SOP/norms \\
\hline 18 & V8S1 & Assumption-based reasoning \\
\hline 19 & V9S1 & Following SOP/norms \\
\hline 20 & V10S1 & Following SOP/norms \\
\hline 21 & V10S2 & Following SOP/norms \\
\hline 22 & V10S3 & Following SOP/norms \\
\hline
\end{tabular}

Table 31: Summary of tactics used to decide on the veracity of information in Phase 2 of all scenarios.

The most common tactic used in Phase 2 was following SOP/norms $(n=14)$. The tactic of ignoring uncertainty was increasingly used from just a single scenario in Phase 1 to six scenarios in Phase $2(n=6)$. One of the most used tactics in Phase 1, the tactic of assumptionbased reasoning, was only used in two scenarios $(n=2)$.

Figure 19 illustrates the decision making process in Phase 2. 


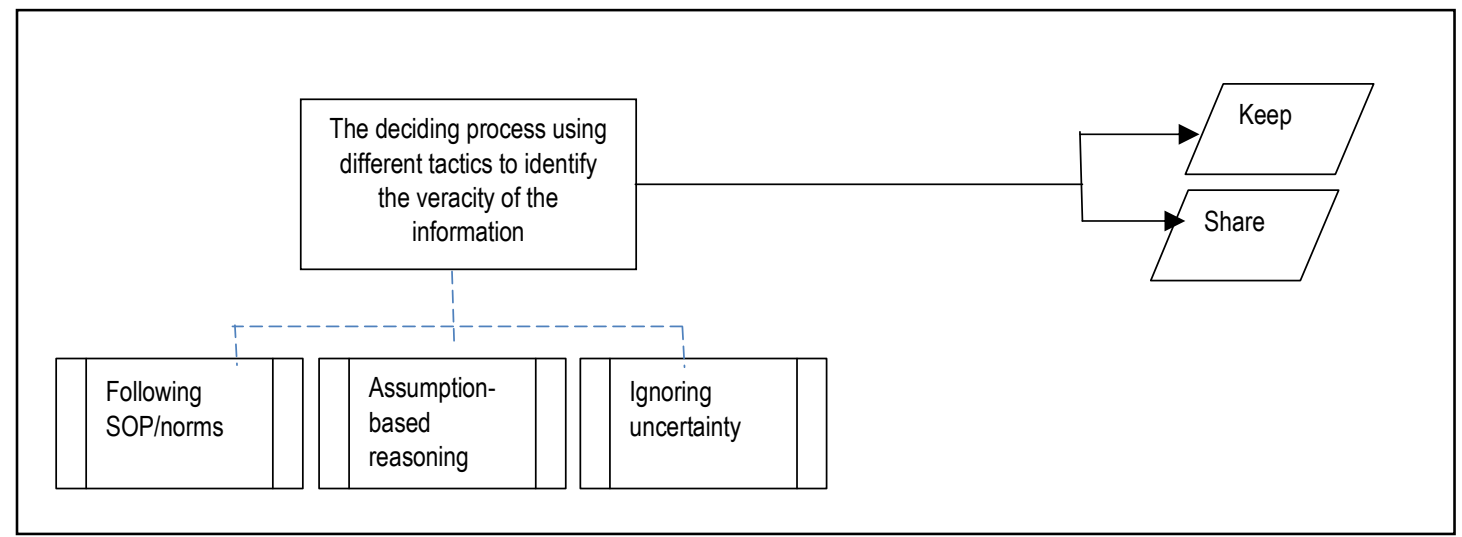

Figure 19: Decision-making process to identify the relevance of information using different tactics in Phase 2

Next, the findings of the comparison analysis are discussed.

\subsubsection{Comparative findings}

The findings of different tactics that KB used in both Phase 1 and Phase 2 to make decisions were compared with the findings in stage 2 . This was done to provide a more comprehensive understanding of the process and to prove that an in-depth analysis had been conducted to understand the tactics that KB used in both phases.

The three comparisons were made in both Phase 1 and Phase 2 separately. These were:

i) Comparison between tactics KB used and types of boundary in each scenario;

ii) Comparison between tactics $\mathrm{KB}$ used and types of information in each scenario; and

iii) Comparison between tactics $\mathrm{KB}$ used and types of disaster in each scenario.

Next is the report of the findings of the three comparisons in Phase 1 followed by Phase 2.

\subsubsection{Comparison between tactics and types of boundary in Phase 1}

The comparison was made between each of the tactics used in each scenario with the types of boundary that $\mathrm{KB}$ received the information from. This comparison was done to explore whether there was any emerging pattern between the tactic used and the types of boundary. 
To recap, four types of boundary were identified in Stage 2. They were hierarchical, unit, organization and community.

i) Comparison between tactic of assumption-based reasoning and types of boundaries

$\mathrm{KB}$ used the tactic of assumption-based reasoning in all scenarios where the type of boundary that $\mathrm{KB}$ received the information across is organization to decide the veracity of the information they received. Using the findings in stage 2 (i.e. cognitive resources, see Table 21 on page 132), I then investigated further why KB used this tactic with the organization boundary type in those scenarios. I found that most KB trusted the information source based on the organization's credibility. For example, in V4S1, KB3 (who is from the community disaster management agency) said:

“...they are the professional firemen and they would know more than what anybody else was saying. They are the people who were fighting the fire. They see how it is started and how quickly it was on the way so if they are saying it, it [the information] would probably right".

Another example is in V8S1 where KB5 (who is from the Fire Service) said:

“..and then again it's understanding the requirements around other [organization's] services, so, in a case like that, the ambulance service will obviously make the decision that the person's deceased, and at that point we must stop doing what we're doing, and allow the police to have total control over that scene".

In summary, this tactic is found to be used in all scenarios where $\mathrm{KB}$ received information across organizational types of boundary. This means that if KB receive information across an organizational type of boundary, they only use the assumption-based reasoning tactic to make the decision to identify the veracity of the information they received. 
$\mathrm{KB}$ used the tactic of following SOP/norms in all scenarios where the boundary type was hierarchical to decide the reliability of the information they received. When I investigated further why KB used this tactic with the hierarchical type of boundary in those scenarios, I found that $\mathrm{KB}$ trusted the information they received was true because they felt confidence in the source's credibility or were following a set of rules. For example, in V1S1, KB1 who is a Principal Rural Fire Officer said:

“...[therefore] I often refer to the experience of my actual Fire Officers on fire ground 5 . Those guys in the brigade have got 20 odd years of fire experience, dealing with rural fires...So, I definitely refer to their advice and recommendations".

In that scenario, KB1 received the information from his officer suggesting he call a helicopter to manage the fire. KB1 was following norms when he said "I often refer..." and feeling confidence in the source's credibility when he said "Those guys in the brigade have got 20odd years of fire experience, dealing with rural fires...So, I definitely refer to their advice and recommendations".

In summary, the tactic of following SOP/norms was used in all hierarchical types of boundary across which $\mathrm{KB}$ received the information. This means that if $\mathrm{KB}$ receive information across a hierarchical type of boundary, they only use the following SOP/norms tactic to make the decision to identify the veracity of the information they received.

iii) Comparison between tactic of ignoring uncertainty and types of boundaries

$\mathrm{KB}$ used the tactic of ignoring uncertainty in a scenario where no boundary type existed (i.e. V7S2). In this scenario, KB4 did not receive the information from someone else across a boundary, and ignored uncertainty because she observed the situation herself and decided the information (on the situation) was true. Thus, KB4 did not doubt the information she had. This means that no emerging patterns were found between the use of this tactic and types of boundaries in Phase 1. 
The next section report the findings of comparison between tactics use and types of information in Phase 1.

\subsubsection{Comparison between tactics and types of information in Phase 1}

Also, it would have been interesting if I had found that KB used certain tactics for certain types of information. Unfortunately, they did not. For example, KB used the tactic of assumption-based reasoning not only for the update type of information, but also in situations where they received other types of information for example requests (e.g. V3S4), investigative (e.g. V6S1), informative (e.g. V4S1), false update (e.g. V5S1).

This finding means that there were no emerging patterns between the tactics used to identify the veracity of information and types of information received.

\subsubsection{Comparison between tactics and types of disaster in Phase 1}

$\mathrm{KB}$ used different tactics for the same type of disaster. For example, KB attended a motor accident they used either the tactic of following SOP/norms (e.g. V7S1) or the tactic of assumption-based reasoning (e.g. V6S2)

It would also have been interesting if I had found that KB used only certain tactics for certain types of disaster. Unfortunately, they did not. For example, KB used the tactic of assumptionbased reasoning not only for the motor accident type of disaster but also in other types of disaster such as fire (e.g. V1S3), mid-air collision (e.g. V3S4), earthquake (e.g. V10S3), mine explosion (e.g. V5S1) and bomb in a house (e.g. V9S1).

This finding means that there were no emerging patterns between the tactics used and types of disaster. KB used different tactics in the same type of disaster and also the same tactic in different types of disaster.

Next is the report of the findings of the comparisons in Phase 2. 


\subsubsection{Comparison between tactics and types of boundary in Phase 2}

The comparison was made between each of the tactics used in each scenario and the types of boundary that $\mathrm{KB}$ shared the information across. This comparison was done to explore whether there was any emerging pattern between the tactic used and the types of boundary.

\section{i) Comparison between tactic of following SOP/norms and types of boundaries}

$\mathrm{KB}$ only used the tactic of following SOP/norms in all scenarios where the types of boundary were unit and hierarchy to decide to whom the information was relevant.

Using the findings in stage 2 (i.e. cognitive resources, see Table 24 on page 140), I then investigated further why $\mathrm{KB}$ used this tactic with the organization boundary type in those scenarios. I found that most $\mathrm{KB}$ were recalling previous experience and following a set of rules. For example, in V1S1, KB1 who is the Rural Principal Fire Officer who shared the information with the Fire Communication unit (i.e. crossing a unit boundary) said:

“...the authority to call the helicopter rest with [me]”.

In this scenario, KB1 is using the tactic of following SOP/norms to decide to whom the information is relevant by matching them through following a set of rules.

Another example is in V7S1 where KB4, who is from the Police, shared the information with her subordinates (i.e. crossing a hierarchical boundary):

“... it's the experience is that [when] you first put a call is you need to preserve life...you've got to go and make sure is there anything that we can do to save the people... So that's all going through my mind thinking 'oh I've gotta do this that that' and you just do it, you just years of doing it, you just it's not a conscious thing. You just do it because of the experience, you gain years of experience... [Then] I have to start directing my staff".

In this scenario, KB4 is using the tactic of following SOP/norms to decide to whom the information is relevant before matching them with her previous experience. 
The two examples above illustrate that $\mathrm{KB}$ use the tactic of following SOP/norms to decide to whom the information is relevant across the boundary types of unit and hierarchy.

In summary, the tactic of following SOP/norms was used in all hierarchical and unit types of boundary across which $\mathrm{KB}$ received the information. This means that if $\mathrm{KB}$ shared information across unit or hierarchical types of boundary, they only used the following $\mathrm{SOP} /$ norms tactic to make the decision to identify to whom the information they hold was relevant.

ii) Comparison between tactic of assumption-based reasoning and types of boundaries

$\mathrm{KB}$ used the tactic of assumption-based reasoning twice in scenarios where the type of boundary was organizational to decide the relevance of the information they were about to share (e.g. V3S2, V8S1). However, KB also used other tactics when they shared information across organizational boundaries.

This means that no emerging patterns were found between the use of this tactic and types of boundaries in Phase 2.

iii) Comparison between tactic of ignoring uncertainty and types of boundaries

$\mathrm{KB}$ only used the tactic of ignoring uncertainty in all community types of boundary (e.g. V2S1, V5S1).

For example in V5S1, in which KB3, who was from the community disaster response team, shared the information with a community member (i.e. crossing a community boundary). KB3 said:

“...we had fairly accurate information... and [when there were false information circulating in the information hub]...as soon as possible... we say, 'sorry that is not correct, there is other information that is not yet being released".... 
KB3 was confident when he shared the information with the community member because he had the correct information and he knew that the information that the community member had was wrong, a case where KB3 ignored uncertainty as the tactic to decide to whom the information he had was relevant.

This means that if KB shared information across the community type of boundary, they only used the ignoring uncertainty tactic to make the decision to identify to whom the information they hold was relevant.

The next section reports the findings of comparison between tactics use and types of information in Phase 2.

\subsubsection{Comparison between tactics and types of information in Phase 2}

Interestingly, unlike the same type of comparison for Phase 1 (section 5.3.4.2 on page 159), there were two types of information where $\mathrm{KB}$ used only one tactic for one type of information. They were the corrective and investigative types of information. KB only used the tactic of ignoring uncertainty for all corrective type of information and the tactic of following SOP/norms for all investigative information.

This means that there was some emerging patterns between the tactics used and types of information shared. KB only used the tactic of ignoring uncertainty for the corrective type of information and the tactic of following SOP/norms for the investigative type of information.

\subsubsection{Comparison between tactics and types of disaster in Phase 2}

$\mathrm{KB}$ used different tactics for the same type of disaster. For example, when KB attended a motor accident, they used either the tactic of following SOP/norms (e.g. V6S3) the tactic of assumption-based reasoning (e.g. V8S1) or the tactic of ignoring uncertainty (e.g. V6S2).

This means that there were no emerging findings between the tactics used and types of disaster. KB either used different tactics in the same type of disaster or the same tactic in different types of disaster. 
The comparisons in the previous sections were conducted separately in each phase. Tactics used by KB to make their decision were compared to types of boundary, types of information and also types of disaster in a single phase of each scenario. I thought it would be interesting to also compare the tactics used by $\mathrm{KB}$ in both phases of each scenario to examine any similarities and differences.

Interestingly, there were four scenarios where $\mathrm{KB}$ used the same tactics in both phases where the types of boundary were also the same in both phases (i.e. V1S2, V7S1, V8S1, V10S2). For example, in V10S2, KB5 received information across a hierarchical boundary and then shared it across the same type of boundary (i.e. hierarchical). In both phases, KB5 used the following SOP/norms tactic to decide on the veracity of information and to whom the information was relevant.

In another example, in V8S1, KB5 received information across an organizational boundary and then shared it across the same type of boundary (i.e. organizational). In both phases, KB5 used the assumption-based reasoning tactic to decide on the veracity of information and to whom the information was relevant.

This means that there are some emerging patterns between the same tactics being used when the information crosses the same types of boundary in both phases. KB used the same tactics to decide the veracity of information they received and to decide its relevance if the information crossed the same types of boundary. This emerging pattern further helped with the theory development.

Next, I summarized the emerging patterns found in stage 3.

\subsubsection{Summary of emerging patterns found in stage 3}

Based on the extensive analysis and comparisons in stage 3, I found some emerging patterns. These patterns were found in each of the two phases. 
In Phase 1, KB only used the following SOP/norms tactic when they received information across a hierarchical boundary. In addition, they only used the assumption-based reasoning tactic when they received information from across an organizational boundary.

In Phase 2, similarly, KB only used the following SOP/norms tactic when they shared the information across hierarchical and also unit types of boundary. Interestingly, KB only used the ignoring uncertainty tactic when they shared information across a community boundary. In contrast with Phase $1, \mathrm{~KB}$ were found to use certain tactics with certain types of information. $\mathrm{KB}$ only used the following $\mathrm{SOP} /$ norms tactic when they shared the investigative type of information. Also, KB only used the ignoring uncertainty tactic when they shared the corrective type of information.

In the combined phases (i.e. Phase 1 and Phase 2), if $\mathrm{KB}$ received the information from across a hierarchical boundary and shared the information across the same type of boundary (i.e. hierarchical), they used the following SOP/norms tactic in both phases. In addition, if $\mathrm{KB}$ received the information from across an organizational boundary and shared the information across the same type of boundary (i.e. organizational), they used the assumptionbased reasoning tactic in both phases. Furthermore, if $\mathrm{KB}$ received the information from across a unit boundary and shared the information across the same type of boundary (i.e. unit), they used the following SOP/norms tactic in both phases.

Table 32 summarizes the emerging patterns found in stage 3. 


\begin{tabular}{|c|c|c|c|}
\hline Phase & $\begin{array}{l}\text { Information flow from/to type of } \\
\text { boundary }\end{array}$ & Only use the tactic of: & $\begin{array}{l}\text { Types of } \\
\text { information } \\
\text { used with } \\
\text { certain tactics }\end{array}$ \\
\hline \multirow{2}{*}{ Phase 1} & From organizational boundary & $\begin{array}{l}\text { Assumption-based } \\
\text { reasoning }\end{array}$ & - \\
\hline & From hierarchical boundary & Following SOP/norms & - \\
\hline \multirow{3}{*}{ Phase 2} & To hierarchical boundary & \multirow[b]{2}{*}{ Following SOP/norms } & \multirow[b]{2}{*}{ Investigative } \\
\hline & To unit boundary & & \\
\hline & To community boundary & Ignoring uncertainty & Corrective \\
\hline \multirow{3}{*}{ Phase $1 \& 2$} & $\begin{array}{l}\text { From hierarchical boundary to } \\
\text { hierarchical boundary }\end{array}$ & \multirow{2}{*}{ Following SOP/norms } & 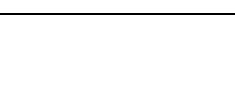 \\
\hline & From unit boundary to unit boundary & & - \\
\hline & $\begin{array}{l}\text { From organizational boundary to } \\
\text { organizational boundary }\end{array}$ & $\begin{array}{l}\text { Assumption-based } \\
\text { reasoning }\end{array}$ & \\
\hline
\end{tabular}

Table 32: Summary of emerging patterns in stage 3

The next section summarizes all findings in stage 3 .

\subsubsection{Stage 3 findings summary}

In this stage I began by confirming that the analysis could be conducted using the lens of NDM. All of the scenarios in both Phase 1 and Phase 2 contained features of NDM.

There were three tactics used by KB in both phases to decide the veracity of the information they received and also to decide to whom it would be relevant: following SOP/norms, assumption-based reasoning and ignoring uncertainty. 
After different types of comparisons were conducted, emerging patterns were found between tactics used and types of boundaries in both Phase 1 and Phase 2. In Phase 1, KB used certain tactics to identify the veracity of the information if they received the information from across certain types of boundary. In Phase 2, KB used certain tactics to identify to whom the information was relevant if they shared the information across certain types of boundary and also with certain types of information.

Finally, upon comparing tactics used and types of boundary in both Phase 1 and Phase 2 together, emerging patterns were found. KB used the same tactics to decide the veracity of information they received and to decide to whom the information is relevant if the information crossed the same type of boundary. 


\subsection{Findings: Stage 4}

Stage 4 combines the findings and emerging patterns from stages 1, 2 and 3 . Table 33 below provides a summary of the findings and emerging patterns.

\begin{tabular}{|c|c|}
\hline Stage & Findings / emerging patterns \\
\hline 1 & - $\quad 2$ phases: Phase 1 (filtering phase) and Phase 2 (recalling phase) \\
\hline 2 & $\begin{array}{l}\text { - } 4 \text { types of boundary (Organization, Community, Unit, Hierarchy) } \\
7 \text { types of information (Request, Recommendation, Update, Investigative, Notification, } \\
\text { Advisory, Awareness [training], Informative) } \\
6 \text { types of disaster (Fire, Earthquake, Mine explosion, Mid-air collision, Bomb in a house, } \\
\text { Motor accident). } \\
5 \text { types of medium of information sharing (Face-to-face, radio, telephone, pager and } \\
\text { Facebook) } \\
7 \text { cognitive resources used for filtering information in Phase } 1 \text { to decide the veracity of } \\
\text { information that KB received: the process of feeling confidence in the source's credibility, } \\
\text { having social ties with the source, triangulating the information, following a set of rules, } \\
\text { having insider knowledge, recalling previous experiences and scanning for vested } \\
\text { interests. } \\
6 \text { cognitive resources used for matching the information in Phase } 2 \text { to decide the relevance } \\
\text { of information that KB are about to share: being asked by someone, recalling training } \\
\text { sessions, having social ties, following a set of rules, following the organizational structure } \\
\text { and recalling previous experiences. }\end{array}$ \\
\hline 3 & 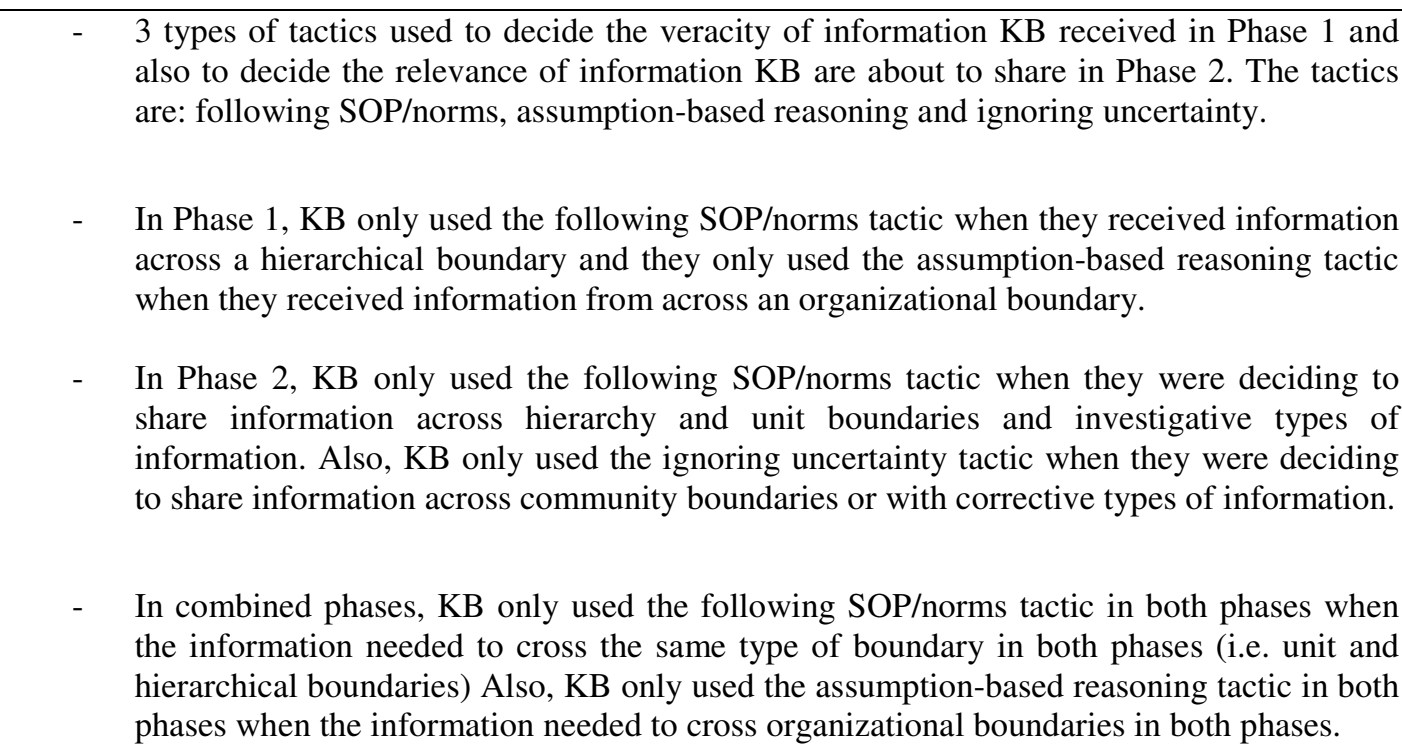 \\
\hline
\end{tabular}

Table 33: Summary of findings and emerging patterns from Stages 1, 2 and 3 
The next section describes the full process of each Phase 1 and Phase 2 in detail.

\subsubsection{Phase 1}

In Phase 1, the process starts when KB receive various types of information across various types of boundaries. The types of information are either request, recommendation, update, investigative, notification, advisory, awareness (from training) or informative. The type of boundaries are organizational, hierarchical, unit or community.

Then, KB filter the information they received by relying on their cognitive resources. There were seven cognitive resources found: feeling confidence in the source's credibility, having social ties with the source, triangulating the information, following a set of rules, having insider knowledge, recalling previous experiences and scanning for vested interests.

In making the decision on the veracity of the information, $\mathrm{KB}$ use three types of tactics: following the SOP/norms, assumption-based reasoning and ignoring uncertainty. KB use certain tactics when they received the information from across certain types of boundary. KB only used the following SOP/norms tactic when they received information across a hierarchical boundary. Moreover, KB only used the assumption-based reasoning tactic when they received information from across an organizational type of boundary.

The process in Phase 1 ends when KB decide whether certain types of information they received from a source across certain types of boundary was true or false. The process then enters Phase 2.

Figure 20 illustrates the full process in Phase 1.

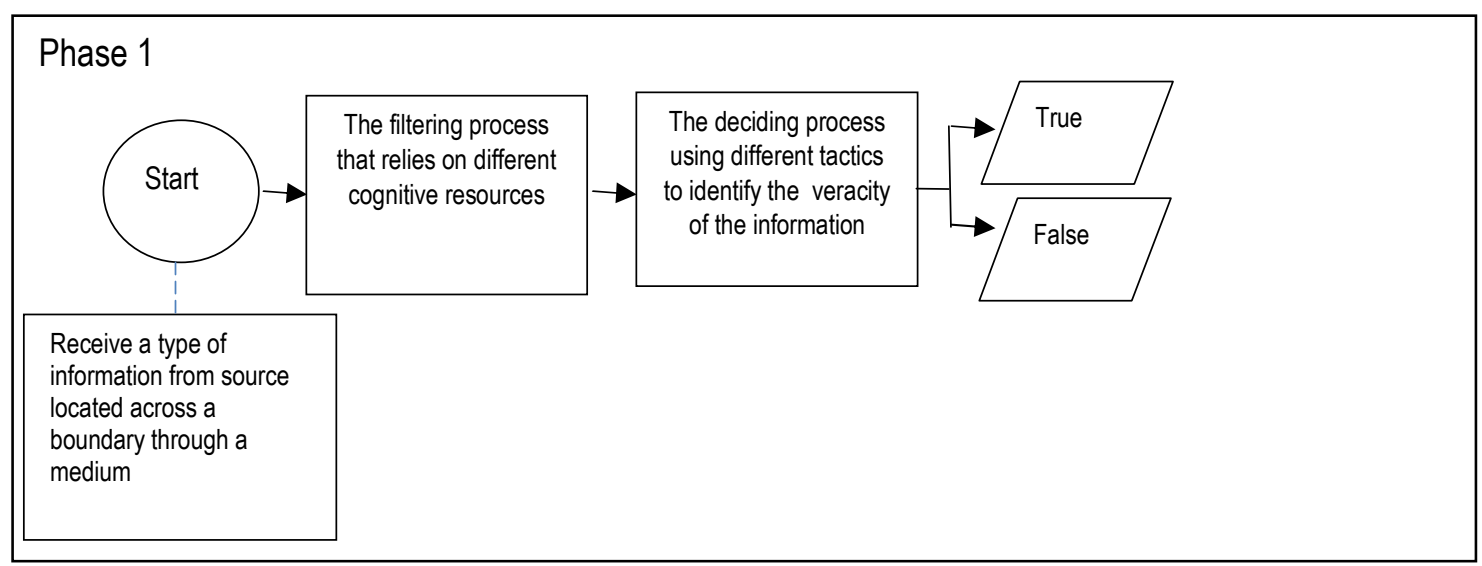


Figure 20: The process of cross-boundary information sharing by KB during a disaster in Phase 1

The next section describes the process in Phase 2.

\subsubsection{Phase 2}

In Phase 2, the process starts when KB decide the relevance of the information through the matching process. KB matched the information with the relevant receiver by relying on their cognitive resources. There were six cognitive resources found in the data: being asked by someone, recalling training sessions, having social ties with the receiver, following a set of rules, following the organizational structure and recalling previous experiences.

Just as in Phase 1, KB use three types of tactics: following the SOP/norms, assumption-based reasoning and ignoring uncertainty. $\mathrm{KB}$ use certain tactics when they decide to share certain types of information across certain types of boundary. KB only used the following $\mathrm{SOP} /$ norms tactic when they were deciding to share information across hierarchical and unit boundaries. Also, KB only used the ignoring uncertainty tactic when they were deciding to share information across a community boundary.

$\mathrm{KB}$ also use certain tactics with certain types of information that they were going to share. $\mathrm{KB}$ use the following SOP/norms tactic when deciding to share investigative information and use the ignoring uncertainty tactic when deciding to share the corrective type of information.

The process in Phase 2 ends when KB decide to whom the information they hold is relevant and they share the information across one or more boundaries (or keep it to themselves). Figure 21 illustrates the full process in Phase 2. 


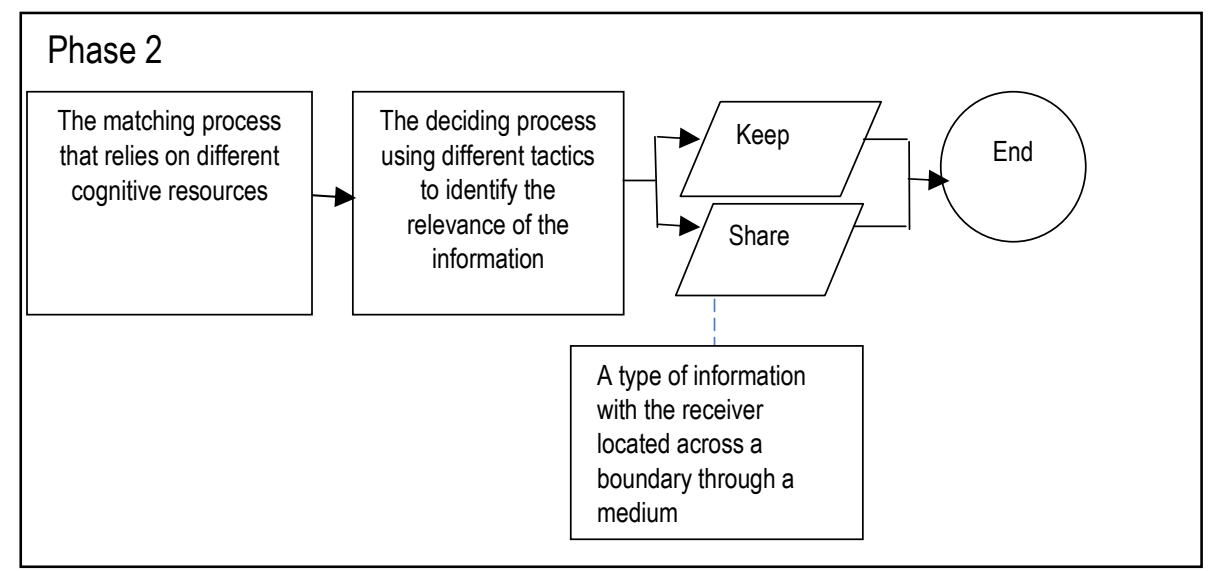

Figure 21: The process of cross-boundary information sharing by KB during a disaster in Phase 2

The next section describes the full process of cross-boundary information sharing by KB during a disaster.

\subsubsection{Theoretical model - Cross-boundary information sharing by KB during a disaster}

By combining all of the findings, the result is a theoretical process model. The process starts in Phase 1 when KB receive certain types of information from across a certain type of boundary. Then the KB filters the information using different cognitive resources in deciding the veracity of the information they received. Then the KB uses certain tactics to make the decision depending on which type of boundary the information crossed. The KB then decides whether the received information is true or false. The process continues in Phase 2. KB match the information they hold with an appropriate receiver using certain cognitive resources. Then KB use certain tactics to make the decision on to whom the information is relevant depending on certain types of boundary and the type of information they are sharing before either sharing or keeping it to themselves.

The details of the full process are illustrated in an example below. 


\section{Example}

Phase 1: A senior Fire Service officer (the $\mathrm{KB}$ ) receives information about the possible evidence (i.e. investigative type of information) regarding the fire's cause from his subordinate (i.e. across a hierarchical boundary) face to face (non-ICT type of medium). The KB then filters the information and trusts his subordinate who has been working in the Fire Service for more than 20 years. Here the KB is using the cognitive resource of feeling confidence in the source's credibility to filter the information he received. Finally, the KB uses the tactic of following the SOP/norms to decide that the information he received is true because it is a norm for the KB to trust the information he received from his subordinates. The process in Phase 1 ends here and then enters Phase 2.

Phase 2: The KB matches the information (of the possible evidence) with an appropriate receiver. Prior to this disaster, the $\mathrm{KB}$ was trained to handle the information about any possible evidence in one of the training sessions where the procedure stated that any possible evidence needs to be shared with the Police and the Fire Investigation Unit. Here, the $\mathrm{KB}$ is using the cognitive resource of recalling training sessions to match the information he holds. Next, the KB decides to share the information with the Police and the Fire Investigative Unit. Here, the KB uses the following the SOP/norms tactic in deciding to whom the information is relevant because it was stated in the procedure. Finally the KB shares the possible evidence of arson (i.e. investigative type of information) with the Police (i.e. across an organizational boundary) and the Fire investigative Unit (i.e. across a unit boundary) through radio (i.e. ICT type of medium). The process ends here.

The example above provides an insight into the process.

Figure 22 illustrates the theoretical model of the cross-boundary information sharing by KB during a disaster. 


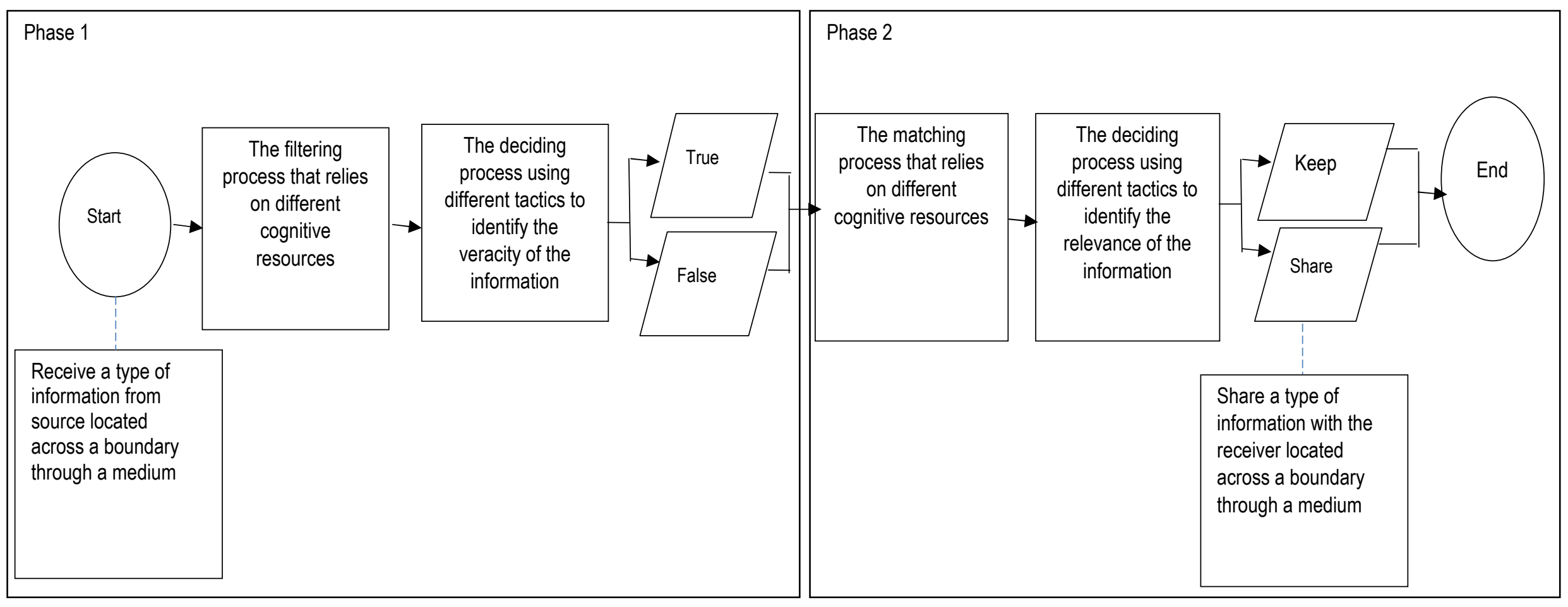

Figure 22: Theoretical model: Cross-boundary information sharing by KB during a disaster 


\subsubsection{Summary of the theoretical model}

The theoretical model shows a coordinated process of information flow that $\mathrm{KB}$ receive and share. This includes the cognitive resources used to filter the information and match to whom it is relevant. It also includes the tactics used by $\mathrm{KB}$ to decide on the veracity of information and its relevance.

\subsubsection{Theoretical propositions}

A theoretical proposition is "a statement that put forth a conditional event - an if-then or why-because proposal gets closer to prediction or theory" (Matthew B Miles et al., 2014, p. 100). Some scholars suggested that theoretical propositions are used at the beginning of a study as a guide to direct the research question and design (Punch, 2005; Yin, 2009). Others place it at the endpoint of a study as a result of the analysis (Creswell, 2003; Matthew B Miles et al., 2014). My research follows the latter as the final element of the theory.

The theory of cross-boundary information sharing flow by $\mathrm{KB}$ during a disaster has ten propositions. The emergent theoretical model is a decision-making process to access and identify the veracity of information $\mathrm{KB}$ received from a source located across a type of boundary and to a receiver located across a type of boundary.

In Phase 1, when KB received information from a source located across a type of boundary, they use certain tactics to decide on the information's veracity depending on the types of boundary. This leads to propositions 1 and 2 .

Proposition 1. If $K B$ receive information from a source located across a hierarchical boundary, then they will only use the following SOP/norms tactic to decide on the veracity of the information.

This proposition is illustrated in Figure 23. 
Phase 1

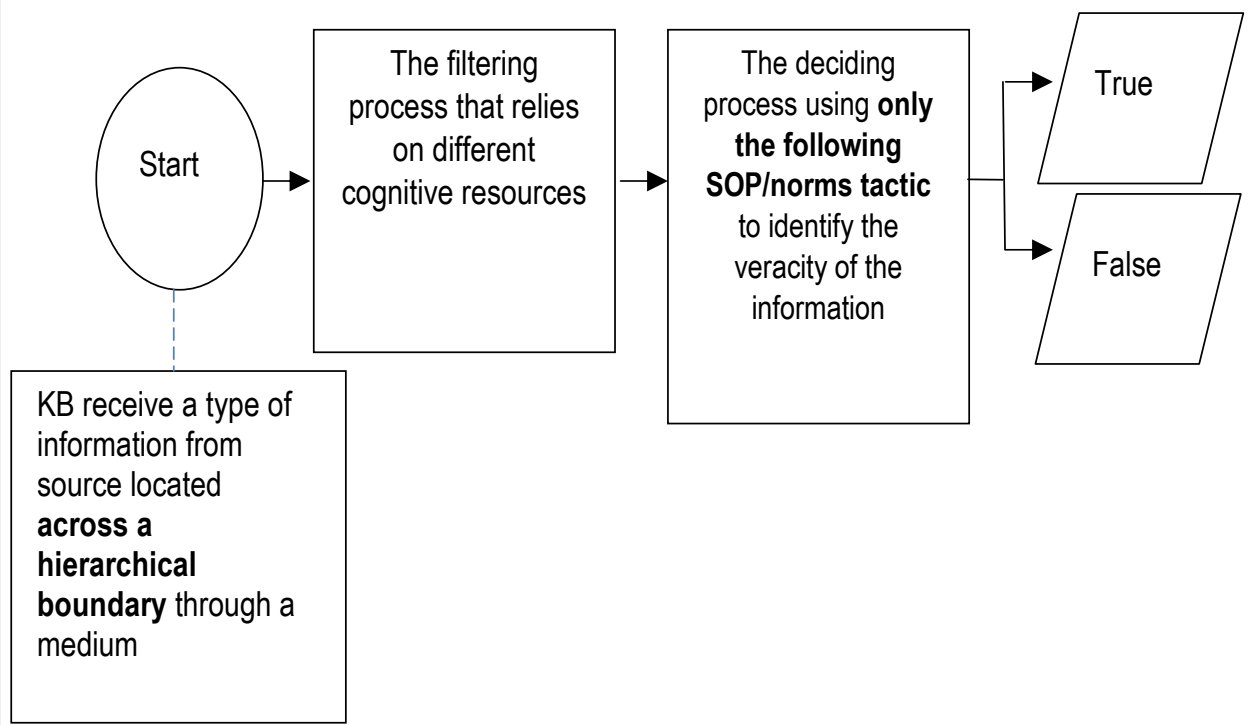

Figure 23: Proposition 1 
Proposition 2. If $K B$ receive information from a source located across an organizational boundary, then they will only use the assumption-based reasoning tactic to decide on the veracity of the information.

This proposition is illustrated in Figure 24.

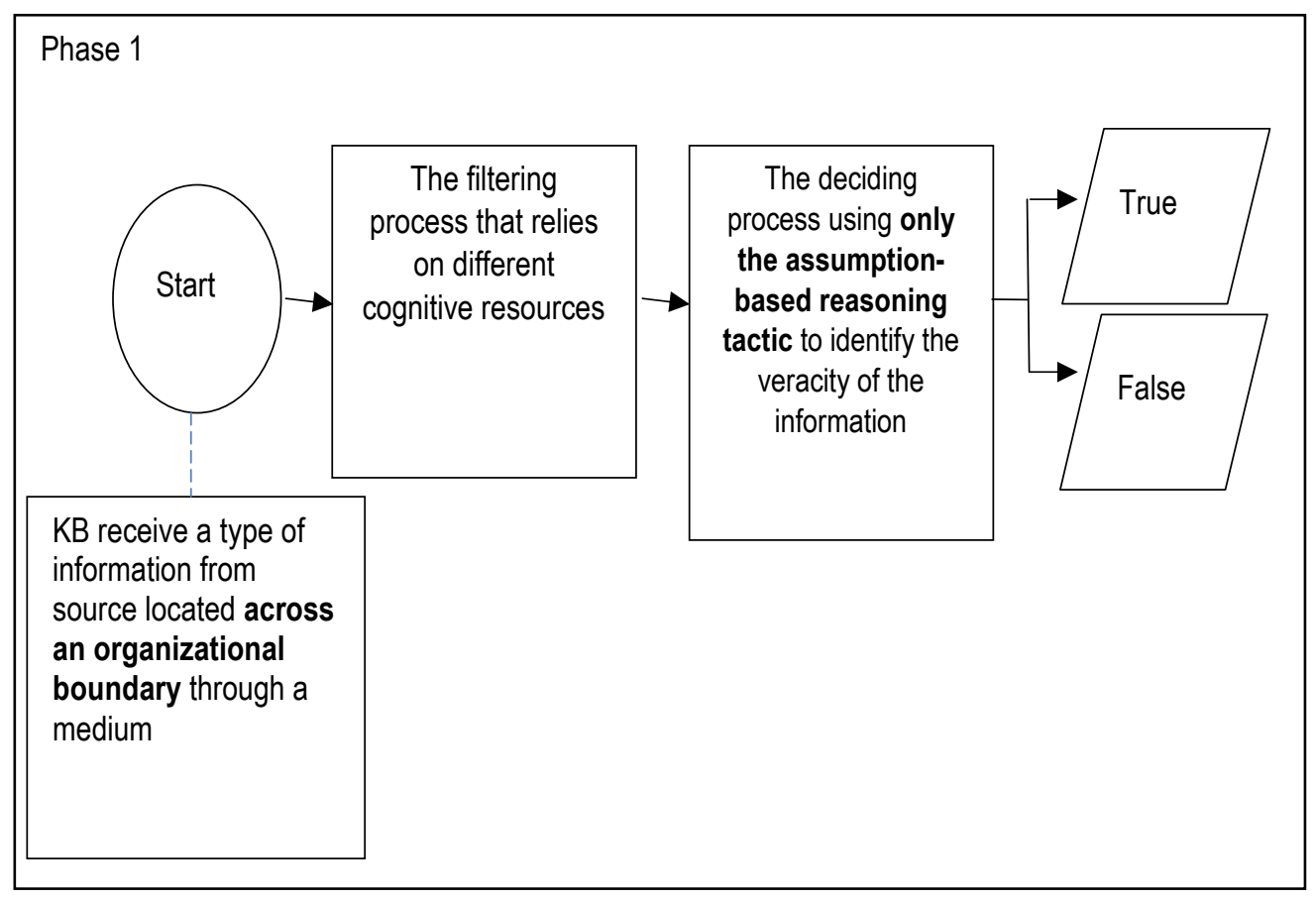

Figure 24: Proposition 2

When KB have decided on the veracity of the information they received (i.e. true or false), they go through the second phase of the process (i.e. Phase 2). In this phase, KB either decide to share with a receiver who is located across a type of boundary or to keep it to themselves.

$\mathrm{KB}$ use certain tactics to identify and decide to whom the information is relevant depending on the types of boundary. Unlike in Phase $1, \mathrm{~KB}$ also use certain tactics to identify to whom the information is relevant depending on the types of information they are about to share. This leads to propositions 3, 4, 5, 6 and 7 . 
Proposition 3. If $K B$ share the information with a receiver located across a hierarchical boundary, then they will only use the following SOP/norms tactic to decide to whom the information is relevant.

This proposition is illustrated in Figure 25.

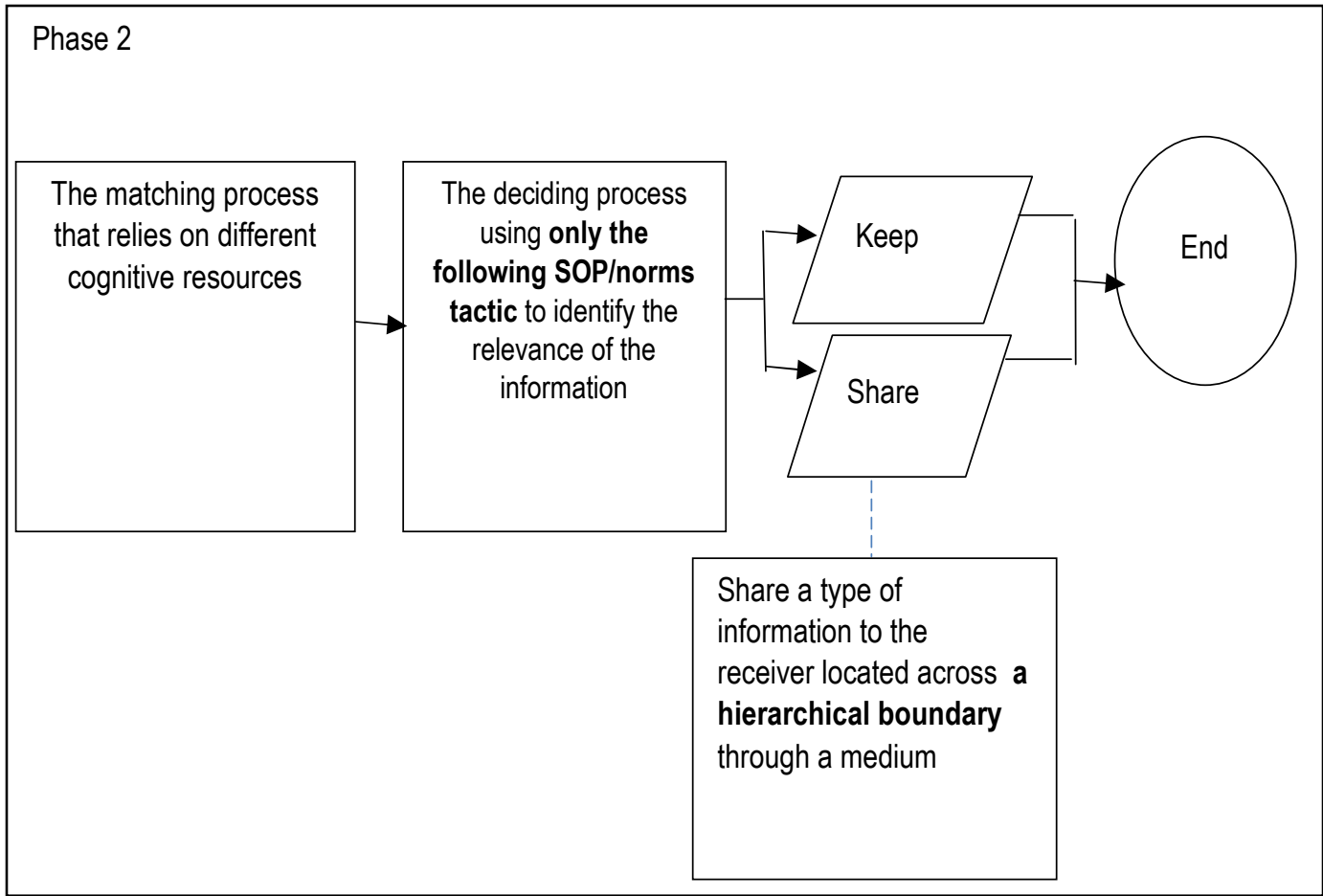

Figure 25: Proposition 3 
Proposition 4. If $K B$ share the information with a receiver located across a unit boundary, then they will only use the following SOP/norms tactic to decide to whom the information is relevant.

This proposition is illustrated in Figure 26.

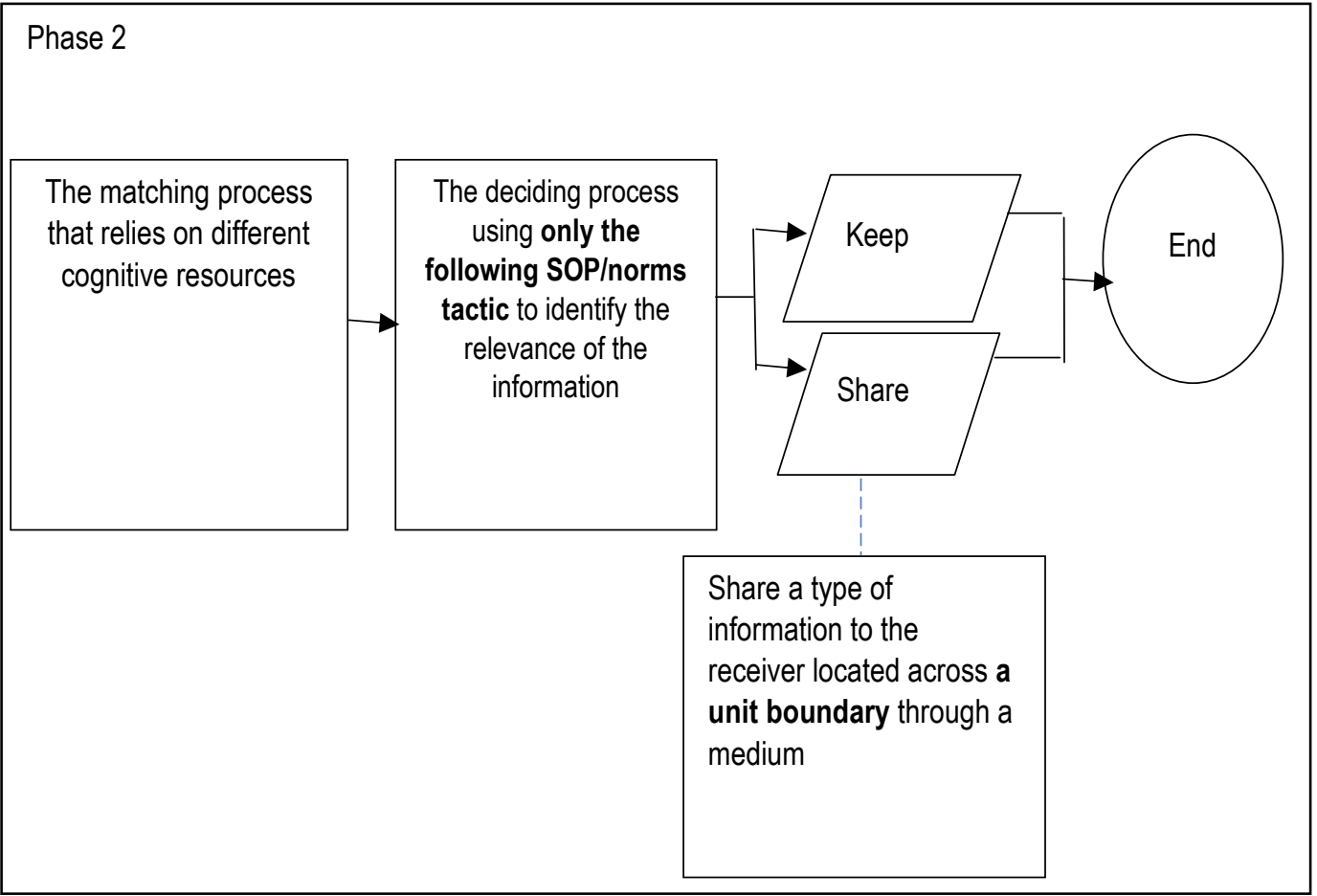

Figure 26: Proposition 4 
Proposition 5. If $K B$ share the information with a receiver located across a community boundary, then they will only use the ignoring uncertainty tactic to decide to whom the information is relevant.

This proposition is illustrated in Figure 27.

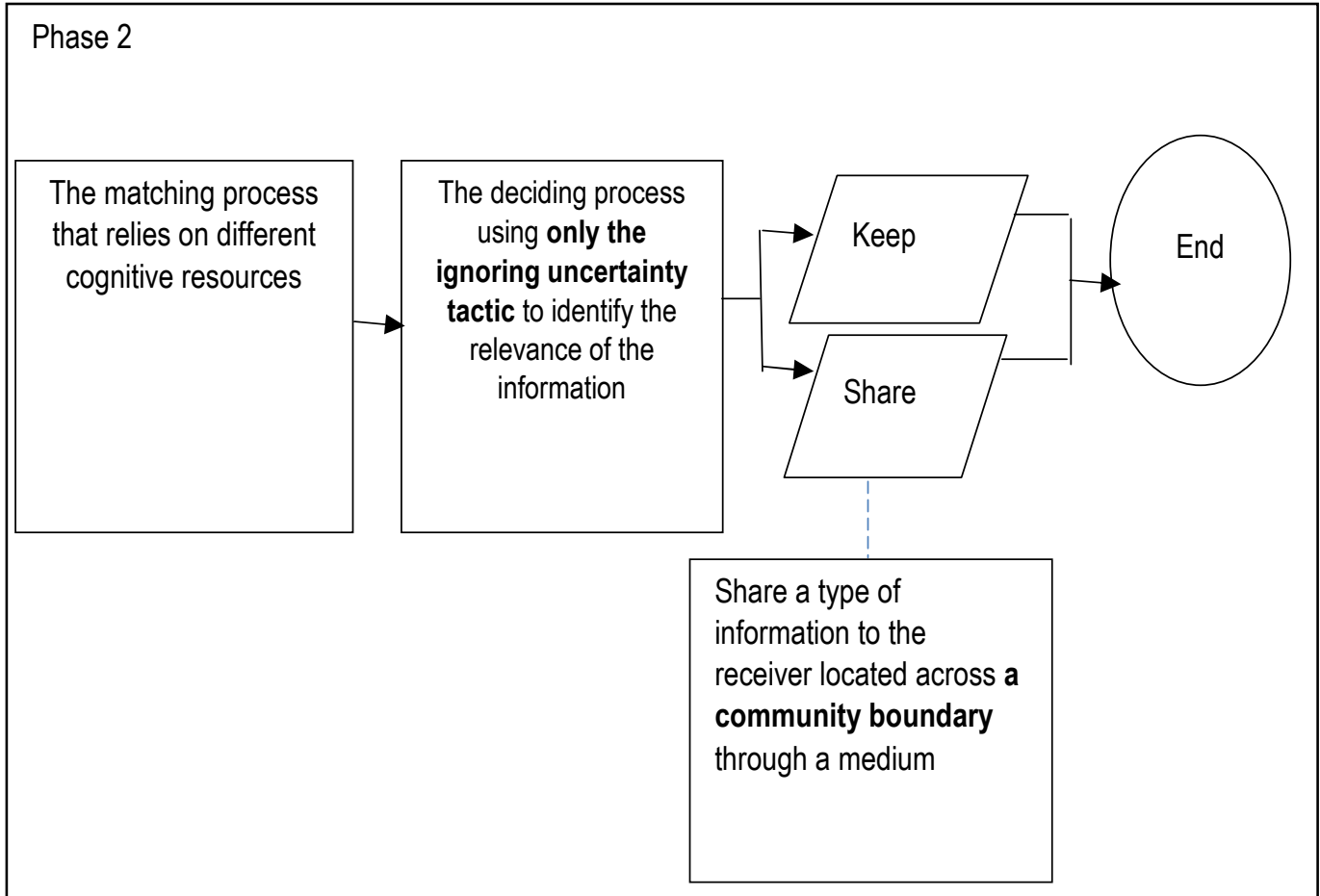

Figure 27: Proposition 5 
Proposition 6. If $K B$ share the investigative type of information with a receiver located across a boundary, then they will only use the following SOP/norms tactic to decide to whom the information is relevant.

This proposition is illustrated in Figure 28.

Phase 2

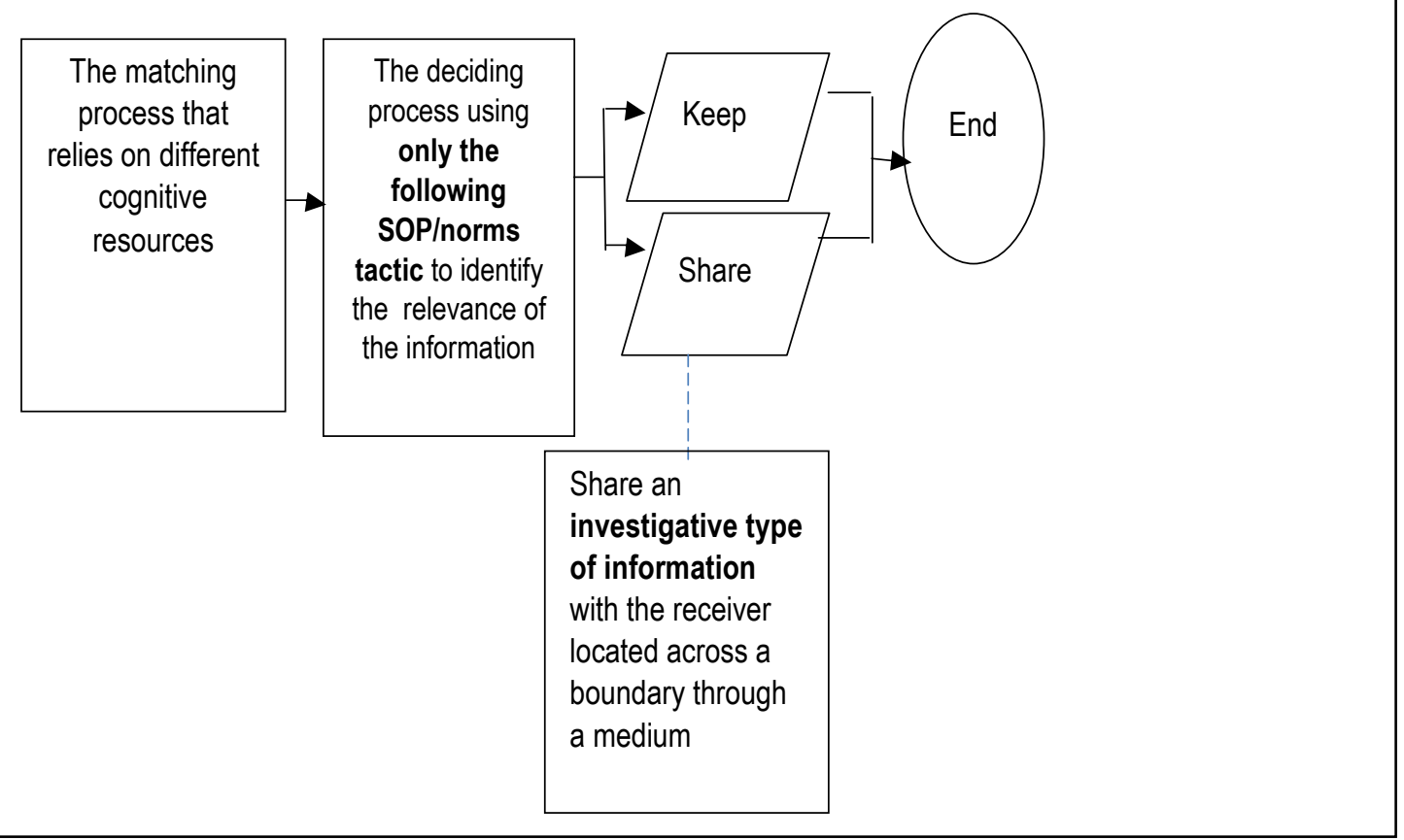

Figure 28: Proposition 6 
Proposition 7. If $K B$ share the corrective type of information with a receiver located across a boundary, then they will only use the ignoring uncertainty tactic to decide to whom the information is relevant.

This proposition is illustrated in Figure 29.

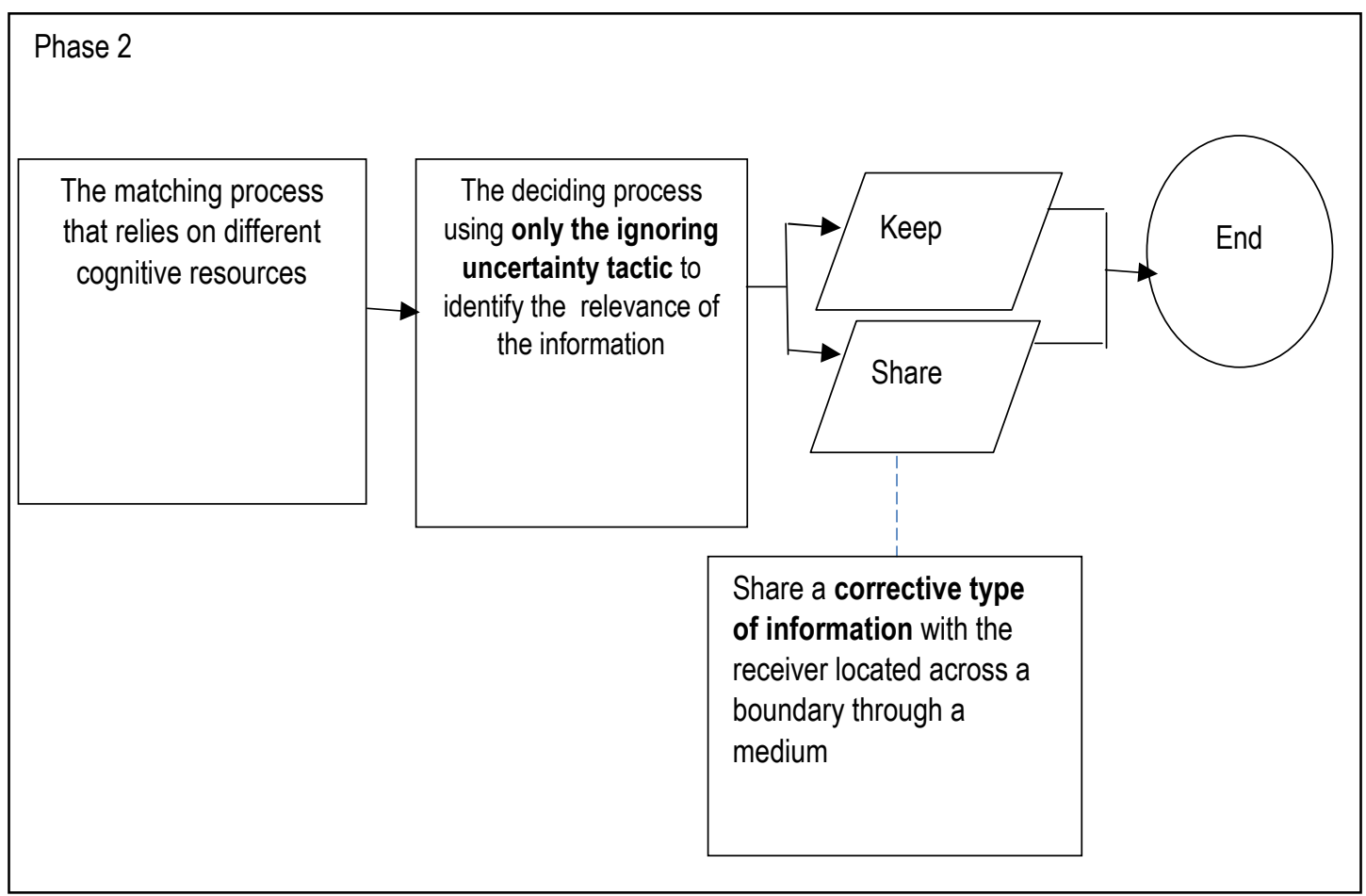

Figure 29: Proposition 7 
By combining both of the phases (i.e. Phases 1 and 2) as found in section 5.3.2.11 and described in section 5.3.3 above, KB use certain tactics to identify the information's veracity (i.e. Phase 1) and to identify to whom the information is relevant (i.e. Phase 2) depending on the types of boundary across which KB receive and also share it. This leads to propositions 8 , 9 and 10.

Proposition 8. If $K B$ both receive information from a source and share the information with a receiver located across hierarchical boundaries, then they will only use the following SOP/norms tactic to decide on the veracity of the information and to whom the information is relevant.

This proposition is illustrated in Figure 30.

Proposition 9. If $K B$ both receive information from a source and share the information with a receiver located across organizational boundaries, then they will only use the assumptionbased reasoning tactic to decide on the veracity of the information and to whom the information is relevant.

This proposition is illustrated in

Figure 31.

Proposition 10. If KB both receive information from a source and share the information with a receiver located across unit boundaries, then they will only use the following SOP/norms tactic to decide on the veracity of the information and to whom the information is relevant. This proposition is illustrated in Figure 32. 

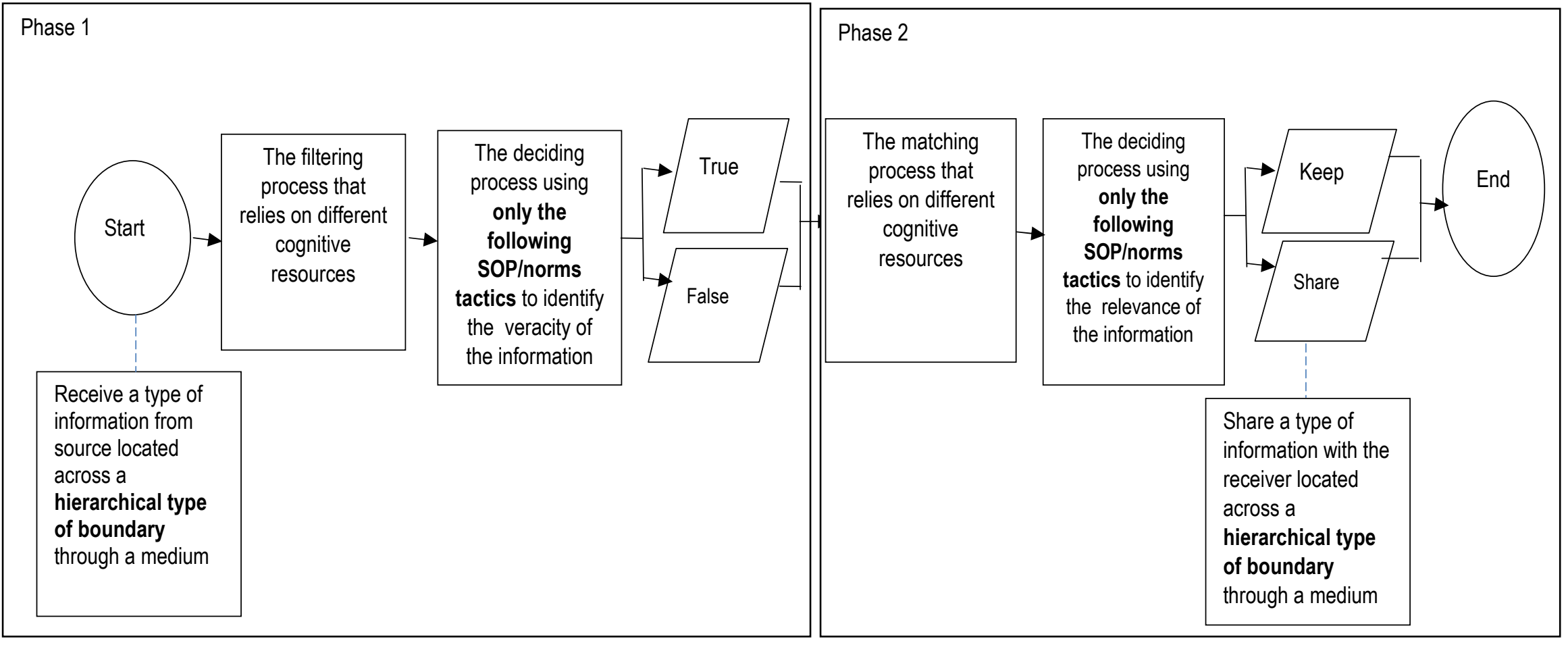

Figure 30: Proposition 8 

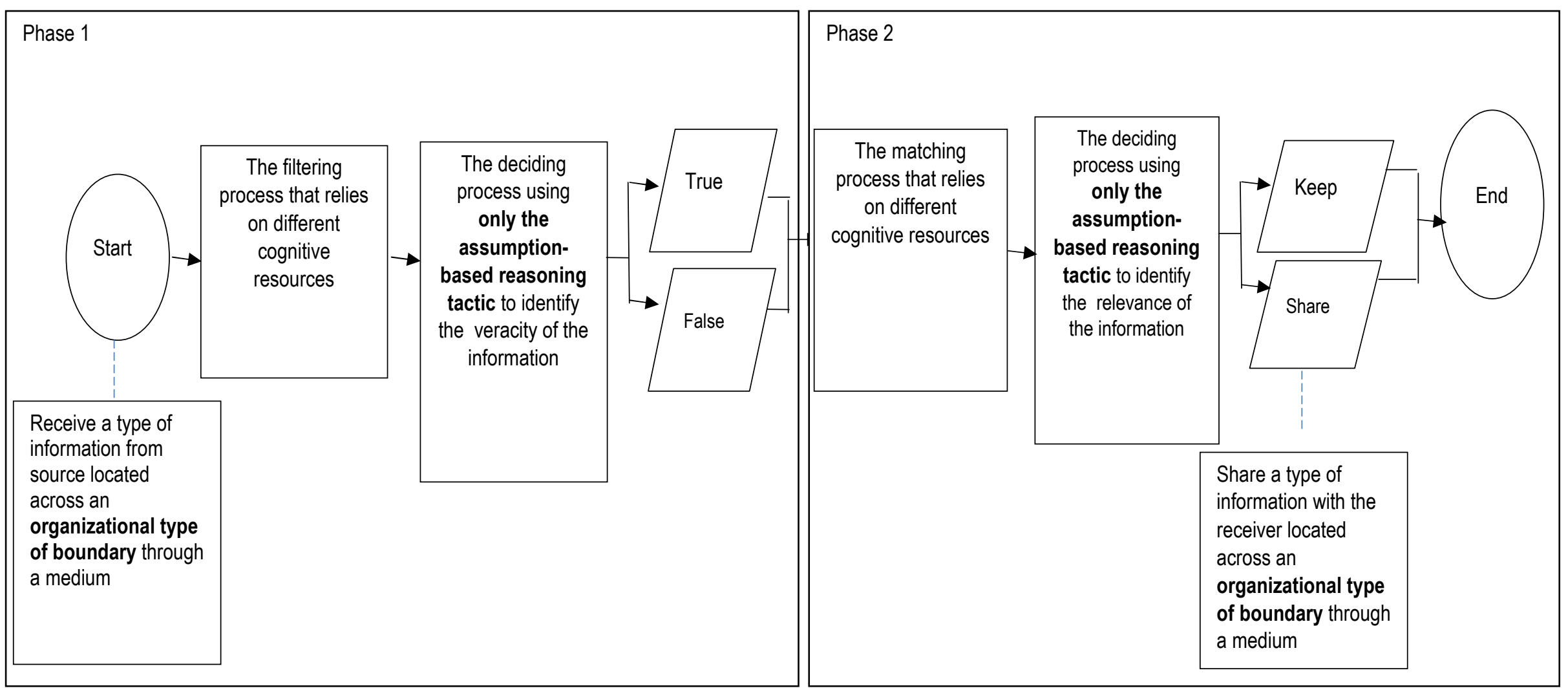

Figure 31: Proposition 9 


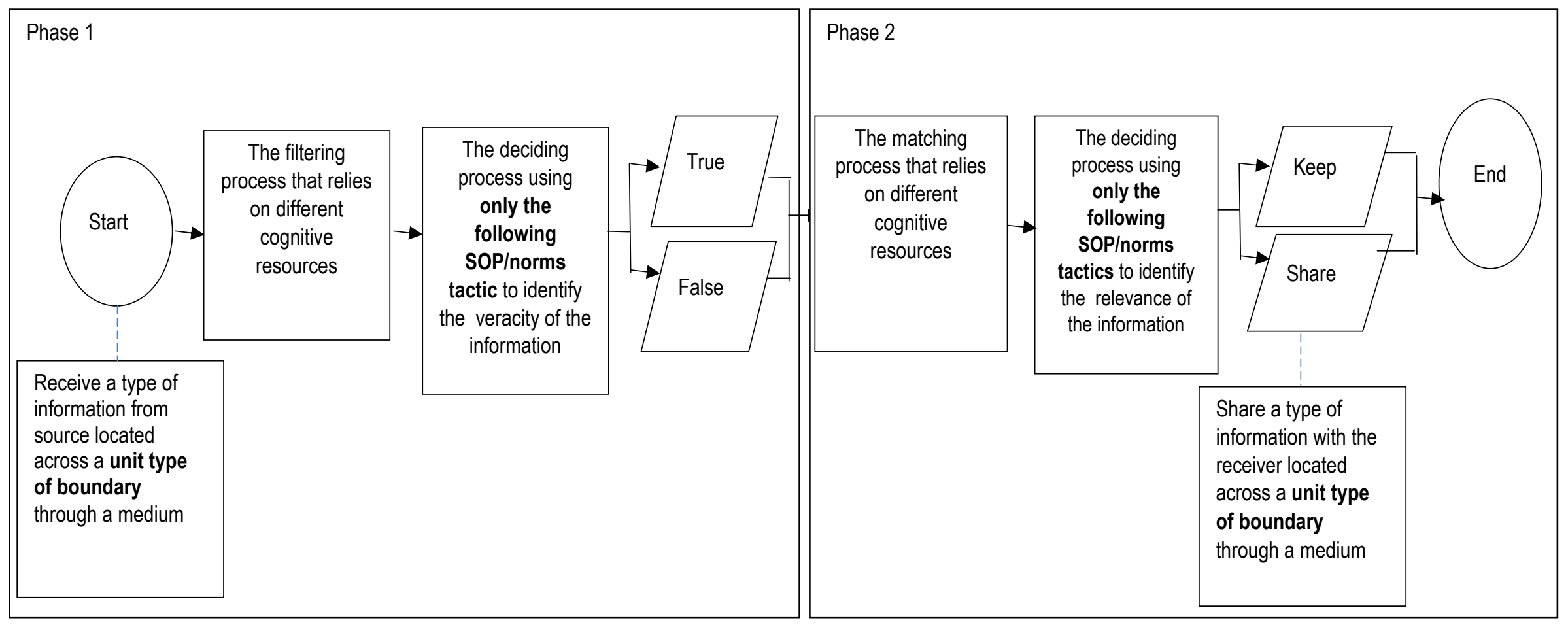

Figure 32: Proposition 10 


\subsubsection{Stage 4 summary}

In summary, the Stage 4 findings in this section have presented the contribution of my research which is a theory of cross-boundary information sharing by KB during a disaster. The theory is based on findings and evidence from the rigorous within-case and cross-case analysis. There are two principal processes in the theory: the deciding process to identify the veracity of the information (i.e. Phase 1) and the deciding process to identify to whom the information is relevant (i.e. Phase 2).

The deciding process in Phase 1 includes the filtering process that relies on cognitive resources and the decision-making process to identify the veracity of the information using certain tactics. The deciding process in Phase 2 includes the matching process that relies on cognitive resources and the decision-making process to identify to whom the information is relevant using certain tactics. Finally, ten theoretical propositions were presented to explain the conditional processes in Phase 1 and Phase 2.

The next section concludes the Chapter.

\subsection{Conclusion of chapter 5}

In this chapter I have described and presented the four stages of findings in great detail.

In stage 1 , I have found that there were two phases of process that $\mathrm{KB}$ experienced in information sharing during a disaster. Phase 1 (i.e. Process of filtering) was the process when KB identify the veracity of the information they received. Phase 2 (i.e. Process of matching) was when KB identify to whom the information is relevant.

In stage 2, I found the process of filtering the information using existing cognitive resources to decide the reliability of the information received (in Phase 1) and the process of finding the most suitable information receiver after going through a process to know with whom to share the information (in Phase 2).

After rigorous analysis and comparisons conducted in stage 3, I found some emerging patterns between the tactics used, types of boundary and types of information in the two phases. The summary of findings of both phases 1 and 2 is in Appendix G. 
Stage 4 is the combination of all the findings in the first three stages and the results is the theory of cross-boundary information sharing by $\mathrm{KB}$ during a disaster and the ten theoretical propositions.

The next Chapter discusses the findings and summarize the thesis. 


\section{CHAPTER 6: DISCUSSIONS AND CONCLUSION}

In this Chapter, I will first summarize the findings and describe how it has answered the two research questions posed in Chapter 1. Second, describe the implication of this research to theory and practice. Third, I outline the limitations of my research. Finally, I present the implications and suggestions for future research before concluding the chapter.

\subsection{Summary of findings}

In this section, I summarize the theory of cross-boundary information sharing by KB during a disaster and how it has answered my research questions.

\subsubsection{Cross-boundary information sharing flow}

This research went through four stages of analysis and the outcome of combining the findings of each stage is a complete flow process. At the first stage, I found two phases of information flow that $\mathrm{KB}$ experience during a disaster: Phase 1, the filtering phase; and Phase 2, the matching phase. In Phase 1, the process starts when KB receive information from a source located across a boundary. Then, at the second stage, I found that KB rely on their cognitive resources to filter the information in Phase 1 and match the information to recipients in Phase 2. There are seven cognitive resources found in my research: feeling confidence in the source's credibility (Mayhorn \& McLaughlin, 2014), having social ties with the source (Van Wijk et al., 2008; T.-M. Yang \& Maxwell, 2011), triangulating the information (Habraken \& Van der Schaaf, 2010; Mayhorn \& McLaughlin, 2014), following a set of rules (Groenendaal et al., 2013), having insider knowledge (Austin, Fisher Liu, \& Jin, 2012), recalling previous experience (Cunningham \& MacGregor, 2014) and scanning for vested interests. These cognitive resources are explained in the next section. Then at the third stage, I found that KB make the decision using one of three tactics: following SOP/norms, assumption-based reasoning and ignoring uncertainty (Lipshitz \& Strauss, 1997). Finally, in the fourth stage, I combined all of the findings from the earlier three stages and the outcome is the complete information flow from start to end which includes both Phase 1 and Phase 2.

In summary, the theory of cross-boundary information sharing by KB during a disaster covers a complete flow process from the moment they receive the information from someone across 
a boundary until the moment they either share the information with someone or keep the information to themselves (Altay \& Pal, 2014).

This finding has filled the gap in the literature which was discussed in Chapter 2 and summarized in section 2.5 (Summary of the gaps in the literature) in response to no studies having looked at knowledge brokering under uncertainty situations (i.e. disasters) at the individual level.

\subsubsection{Cognitive resources}

In filtering and matching the information, KB rely on a number of cognitive resources. These cognitive resources are a result of previous experience where KB recall the same situation or a similar context with the current situation which can help them with the filtering (i.e. Phase 1) or matching (i.e. Phase 2) the information that they hold.

The seven cognitive resources that $\mathrm{KB}$ rely upon for filtering the information they receive across a boundary (i.e. Phase 1) are: feeling confidence in the source's credibility, having social ties with the source, triangulating the information, following a set of rules, having insider knowledge, recalling previous experience and scanning for vested interests. As discussed in section 5.1.1, the most common cognitive resources that KB rely on in Phase 1 were found to be feeling confidence in the source's credibility, followed by following a set of rules.

The six cognitive resources that $\mathrm{KB}$ rely upon for matching the information with someone across a boundary that they are about to share it with (i.e. Phase 2) are: being asked by someone, recalling the training, having social ties with the information receiver, following a set of rules, following the organizational structure, and recalling previous experience. As discussed in section 5.1.2, the most common cognitive resources that $\mathrm{KB}$ rely on in Phase 2 were found to be following a set of rules and following the organizational structure.

In summary, $\mathrm{KB}$ were found to be relying on these cognitive resources when they dealt with the information they held in both phases.

This finding has filled the gap in the literature which was discussed in Chapter 2 and summarized in section 2.5 (Summary of the gaps in the literature) in response to the use of cognitive resources in the process of decision making being yet to be explored. 


\subsubsection{Types of boundary}

In both ends of the flow process, $\mathrm{KB}$ receive the information from a source across boundaries and share the information with a receiver across different boundaries. My research found that the information travelled across either one or more types of boundary. These are: unit (Owen et al., 2013), hierarchical, organizational (Curnin \& Owen, 2014) and community (Quarantelli, 1988). The definition of each boundary can be found in Chapter 5, section 5.2.1.1. These boundaries can be categorized into intra-organization (i.e. unit and hierarchical boundary), inter-organization (i.e. organizational boundary) and non-organization (i.e. community boundary).

This research found emerging patterns between the types of boundaries and the tactics used to make the decision to identify the veracity of the information and to whom the information is relevant (i.e. Phase 1 and Phase 2). This has been discussed in Chapter 5, section 5.4.5 (theoretical propositions).

\subsubsection{Types of information}

The information types are request (Padilha et al., 2010), recommendation, update, investigative, notification (Iannella \& Henricksen, 2007), advisory and informative. These types of information have been defined in the previous chapter, in section 5.2.1.2.

This research found emerging patterns between the types of information and the tactics used to make the decision to identify to whom the information is relevant (Phase 2). This has been discussed in section 5.4.5 (theoretical propositions).

This finding has filled the gap in the literature which was discussed in Chapter 2 and summarized in section 2.5 (Summary of the gaps in the literature) in response to the need to further explore the sub-categories of the types of information.

\subsubsection{Types of disaster}

It was also found that different types of disaster were experienced by the KB. These disaster types are fire, earthquake, mine explosion, mid-air collision, bomb in a house and motor 
accident. All of the 22 scenarios in these six disasters had the features of NDM, which support the analysis using the lens of NDM.

Surprisingly, no patterns emerged between types of disaster and tactics used by KB to make their decision. These types of disasters have been defined in the previous chapter, in section 5.2.1.3.

\subsubsection{Decision-making tactics}

Using the Naturalistic Decision Making (NDM) lens, my research found that KB make a decision to identify the information's veracity and to whom the information is relevant using several tactics. The tactics are: following SOP/norms, assumption-based reasoning and ignoring uncertainty (Lipshitz \& Strauss, 1997). These tactics have been defined in chapter 2, in section 2.4.3.

This research also found that the tactics used by KB in both the filtering process (i.e. Phase 1) and matching process (i.e. Phase 2) depend on certain types of boundary and types of information. This has been discussed in section 6.2 (theoretical propositions).

This finding has filled the gap in the literature which was discussed in Chapter 2 and summarized in section 2.5 (Summary of the gaps in the literature) in response to very little being known about decision making under time pressure, uncertainty situations and high stakes and also how the different tactics and the Hourglass Framework model are being used in different types of disaster.

Therefore, the theoretical model of cross boundary information sharing by $\mathrm{KB}$ during a disaster has answered my research questions. 


\subsection{Implications for theory}

\subsubsection{Knowledge brokering}

Marrone (2010) has identified that KB play the role of a boundary spanner. A boundary spanner "perform actions to establish linkages and manage interactions with parties in the external environment" (p. 914). She proposed a multilevel model of boundary spanning member, team and network - as a bottom-up (vertical) process. This research supports this idea where KB play a boundary spanner role through a hierarchical (member) boundary as a vertical process. In addition, my research also found that KB play a boundary spanner role across other boundaries such as unit (team), organizational (network) and community (network) boundaries, not in a vertical process but in a horizontal process. This extends Marrone's (2010) proposed multilevel model of boundary spanning from not only a vertical process but also to a horizontal process. The extension does not mean a considerable change to the model, but merely provides a context where KB play a boundary spanner role across team and network boundaries as a horizontal process during a disaster.

Cranefield and Yoong (2005) found that KB perform multiple roles as gate keepers. These include flag-bearer, advocate, translator, scout, facilitator, storyteller and expert. They defined gatekeepers as those who are also able to gather information from outside the boundary and share it within their borders and act as the knowledge interface of the boundaries. My research suggests a broader definition where KB gather information from outside their boundary and share it with those who are also outside their boundary. This means the definition of the role of gatekeeper is not only that they share information within their own group but also with different groups. Although the findings of my research are somewhat different than Cranefield and Yoong's (2005) in terms of sharing the information within groups and across boundaries, my research also provides evidence and supports the findings of Cranefield and Yoong (2005). The gate keeper role clearly exists when KB receive information from across a different boundary.

In addition, Cranefield and Yoong (2007a) found there are six stages that KB went through in cross-boundary information sharing. They are: engaging, defining, seeking, articulating, integrating and disseminating. My research found there were only two stages in cross- 
boundary information sharing: filtering and matching. This could potentially be due to the nature of the settings in both studies. Furthermore, Cranefield and Yoong's (2007) research was set in a stable environment where $\mathrm{KB}$ receive and share the organizational type of information. My research was set in an unstable environment with the criteria of time stress, high stakes, multiple players, organizational goals and norms and experienced decision makers. My research found no evidence that KB went through six stages in cross-boundary information sharing.

In Chapter 2 (literature review), it was discussed that there is a need to identify the types of information that $\mathrm{KB}$ receive and share during a disaster. There are five types of information identified in the literature during a disaster: true information, false information, rumours, (Karlova \& Fisher, 2013; Liu et al., 2013), notification and request (Iannella \& Henricksen, 2007). This research refined the idea by finding that there are seven sub-categories of the types of information available during a disaster. These are: request, recommendation, update, investigative, notification, advisory and informative. These sub-categories are an extension of the true and false types of information.

In summary, this research has contributed knowledge brokering literature as I extended the proposed multilevel model of boundary spanning (Marrone, 2010), suggested a broader definition of the gatekeeper role of KB (Cranefield \& Yoong, 2005), found only two stages instead of six stages that KB went through in cross-boundary information sharing (Cranefield $\&$ Yoong, 2007a) and refined the types of information available during a disaster by introducing seven sub-category types of information (Iannella \& Henricksen, 2007; Karlova \& Fisher, 2013; Liu et al., 2013).

Next is the implication on theory in disaster management area.

\subsubsection{Disaster management}

In the disaster management area, particularly in the information sharing during disasters literature, scholars found that there are some challenges at the individual level when sharing information. Bharosa et al. (2010) for example, found that information sharing across organizational boundaries failed despite people having good intentions to share. They also 
suggest that "it is very difficult to predict which information is relevant and which is not" (p. 63). More recently, Alison et al. (2015) found that information sharing across different organizational boundaries decreased during a disaster and some failed to make a decision - a situation called 'decision inertia'. My research found no evidence that $\mathrm{KB}$ are facing those challenges. $\mathrm{KB}$ were sharing information with a receiver located across an organizational boundary in most of the scenarios in Phase 2. However, this does not mean that the challenges and issues of information sharing across organizational boundaries were nonexistent during disasters, merely that no evidence were found in my research to support the findings in the literature. Further, my research settings were based in New Zealand and the situation could potentially differ from Bharosa et al. (2010) whose research settings were in the Netherlands.

Bharosa et al. (2010) also found that the main issues facing the KB at the individual level are that they did not have enough time and cognitive resources to process all information received during a disaster. My research refines this idea. Although my research did not focus on challenges in information sharing during a disaster, the idea of cognitive resources was used. Several cognitive resources were found in both phases (i.e. Phase 1 and Phase 2). In Phase 1, my research found seven cognitive resources that $\mathrm{KB}$ rely on to filter the information they received. They are: feeling confidence in the source's credibility, having social ties with the source, triangulating the information, following a set of rules, having insider knowledge, recalling previous experience and scanning for vested interests. In Phase 2, six cognitive resources were found: being asked by someone, recalling the training, having social ties with the information receiver, following a set of rules, following the organizational structure, and recalling previous experience. $\mathrm{KB}$ were relying on these cognitive resources to filter and match the information that they have with a receiver.

In summary, this research has contributed to the disaster management area as no evidence were found of challenges that $\mathrm{KB}$ faced in sharing information across an organizational boundary and refines the idea of the usage of cognitive resources in making the decision to share information across a boundary during a disaster. 


\subsubsection{Naturalistic Decision Making (NDM)}

The NDM area has been gaining momentum since it started around 26 years ago in 1989. Gary Klein, who is one of the prominent scholars in the NDM area, has recently suggested that many more studies need to be done to advance the knowledge in NDM (G. Klein, 2015). A recent special edition of the Journal of Occupational and Organizational Psychology (Volume 88, No. 2, 2015) was dedicated to research in the NDM area. The findings relating to the tactics used by $\mathrm{KB}$ in making decisions to identify the veracity and relevance of the information they hold has contributed to the NDM area. This research also extends one of the decision-making models in the NDM area - The Hourglass model (Serfaty et al., 1997).

In this model, experts take action after a set of processes which start from the experts generating a schema based on experience before asking the right questions. This research extends this by unpacking the process by having a number of cognitive resources and the tactics used to make the decision.

The Hourglass Framework (refer Figure 33) was developed to study how experts in military command units make decisions under pressure (Serfaty et al., 1997). The framework consists of three major processes: recognition, exploration and matching. This research extends this framework by adding more detailed processes such as filtering and recalling thinking processes and also the cognitive resources that are being used. In addition, this research looks at a deeper aspect of the process where decision makers used certain tactics under certain conditions. 


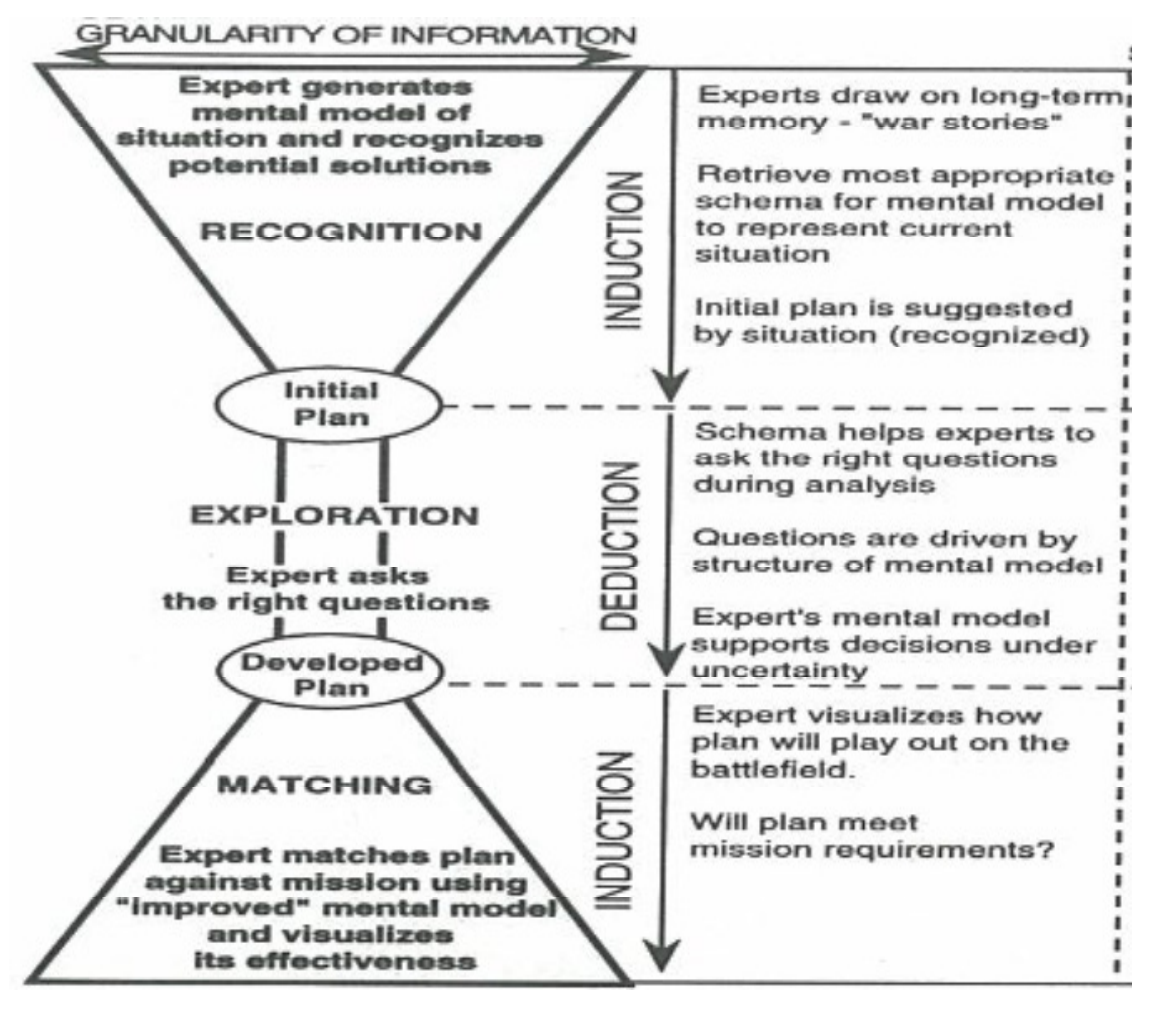

Figure 33: The Hourglass framework for the decision-making process, adapted from Serfaty et al. (1997)

The theory of cross-boundary information sharing by KB during a disaster unpack each of the three stages in the Hourglass Framework. It was found that KB went through the framework repeatedly in Phase 1 and Phase 2.

\section{Phase 1}

In the first major process of the framework - recognition, KB draw their memories from seven identified cognitive resources in Phase 1. Then KB filter the information they receive by relying on the cognitive resources.

In the second major process of the framework - exploration, KB rely on cognitive resources to support their decision under uncertainty. My research extends this process where KB were found using one of the three tactics - following SOP/norms, assumption-based reasoning and ignoring uncertainty - to make their decision. 
The third major process of the framework - matching - is the identification of the veracity of the information $\mathrm{KB}$ received during a disaster. The outcome is the decision whether the information they receive is true or false. Figure 34 illustrates the detailed framework process.

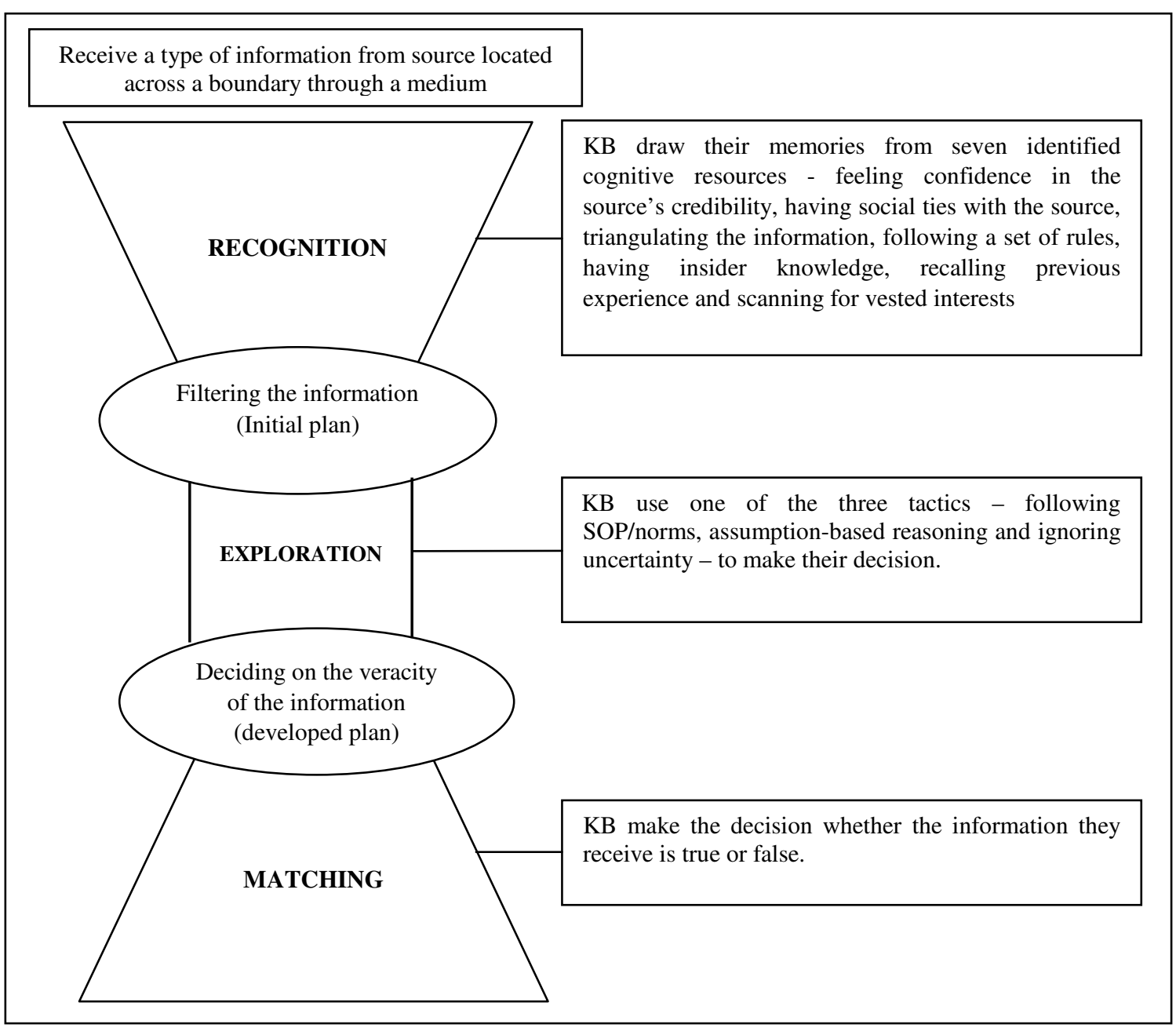

Figure 34: The Hourglass Framework for the decision-making process for Phase 1

As mentioned earlier, the findings of this research repeat the Hourglass Framework in Phase 2.

\section{Phase 2}

In the first major process of the framework - recognition - KB draw their memories from six identified cognitive resources in Phase 2. Then KB try to match the information they hold with their cognitive resources.

In the second major process of the framework - exploration - KB rely on cognitive resources to support their decision under uncertainty. My research extends this process where KB were 
found using one of the three tactics - following SOP/norms, assumption-based reasoning and ignoring uncertainty - to make their decision on to whom the information they hold is relevant.

The third major process of the framework - matching - is the identification of to whom the information they hold is relevant during a disaster, which was seen to be matching the information with someone across a boundary. The outcome is the decision on to whom the information is relevant. Figure 35 illustrates the detailed framework process.

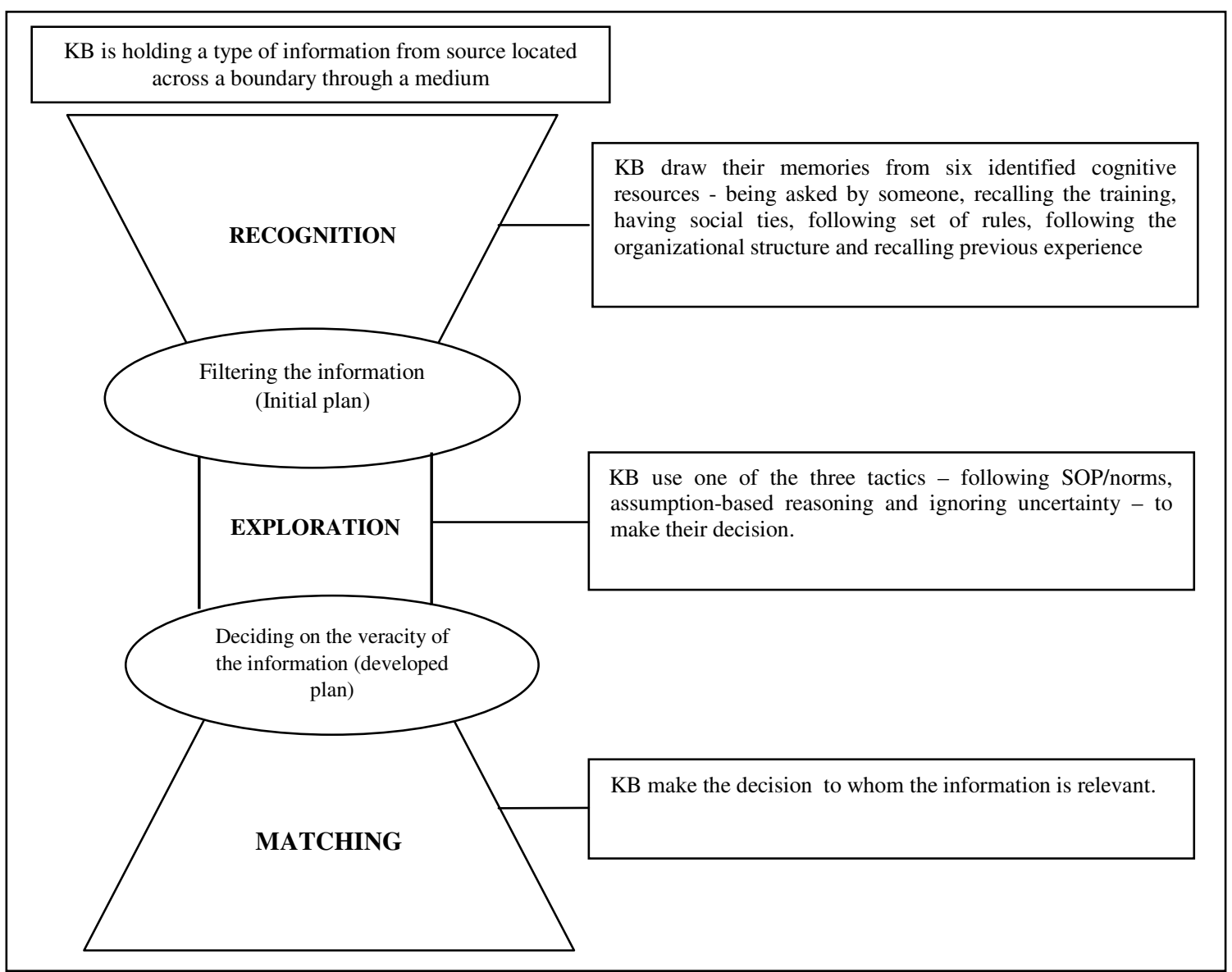

Figure 35: The Hourglass Framework for the decision-making process for Phase 2

Lipshitz and Strauss (1997) found that there are twelve tactics that experts use to cope with uncertainty situations. These are: collecting additional information, delaying action, soliciting advice, following SOP/norms, assumption-based reasoning, pre-empting, improving readiness, avoiding irreversible action, weighing pros and cons, ignoring uncertainty, relying on intuition and taking a gamble. My research found that only three tactics had been used by 
$\mathrm{KB}$ in making decisions: following SOP/norms, assumption-based reasoning and ignoring uncertainty. This does not mean that other tactics were not used by KB either to identify the veracity of the information they received or to identify to whom the information is relevant in general, only that no evidence in my research were found to support the usage of other tactics. Further, a possible reason for my research not finding any evidence of KB using all of the twelve tactics is because of the nature of the uncertainty situation in both studies. The uncertainty situation in Lipshitz and Strauss (1997) study is war, while the uncertainty situation in my research includes disasters such as fire, earthquake, mine explosion, mid-air collision, bomb in a house and motor accident.

In summary, this research has contributed to the NDM area by extending the Hourglass Model in NDM and found evidence that KB use three NDM tactics of decision making under uncertainty.

\subsubsection{ICT}

As discussed in Chapter 2 (i.e. literature review), ICT plays an important role in crossboundary information sharing. ICTs such as radio (i.e. trunked radio), telephone, and pager (Asplund et al., 2009; Huang \& Lien, 2012; McEntire, 2002) are useful as a means to share information during disasters. There was evidence that ICT was used in the information sharing and decision-making process under uncertainty and time pressure. Nearly all (21 of 22) scenarios that were analyzed either used radio, telephone, pager or face-to-face as the medium of sharing. Only one scenario (V2S1) involved the use of a social networking system (i.e. Facebook) to receive the information from a source located across a boundary but then the knowledge broker replied to the information source using a telephone. Based on the evidence in my research, ICT is seen to be used as a platform to share information across boundaries during disasters (Prasanna, Yang, \& King, 2013).

\subsection{Implications for practice}

The nature of this research also makes useful contributions for practitioners. First, the presentation of the ten vignettes that represent ten different cases (i.e. disasters) and 22 unique scenarios. Each case covers a real-life snapshot that was presented in scenarios. The 
scenarios are of value to practitioners as they can learn how others receive and share information during a disaster.

Second, the flow process of the cross-boundary information sharing by KB during a disaster can be used by practitioners for multiple purposes. For example, it could be used as a training module for emergency service personnel and for updating existing best practices. The identification of different cognitive resources used to filter and match the information and the tactics used to make decisions found in this research could lead to an improved training module for emergency personnel. In addition, because the flow process includes cognitive resources for filtering and matching the information, it can assist decision makers (or $\mathrm{KB}$ ) during a disaster to identify the veracity of information and to whom the information is relevant more quickly and efficiently, which is critical during a disaster.

Third, this research could potentially contribute to disaster management system development. As I have experienced a hypothetical disaster in three simulation exercises and conducted indepth interviews with those who have experienced a real-life disaster in the period of my research, I saw that most of the time, key decision makers are relying on information shared by others such as their subordinates or people from another organization. In some instances, these sources received information through the use of an information system. My research is useful for disaster management information system developers by providing a deeper understanding of the flow process of the cross-boundary information sharing by KB during a disaster. This could enable them to develop process management systems that take into consideration the items found in the flow process. As a result, the decision to identify the veracity of the information and to whom it is relevant can be made efficiently.

Finally, this research can contribute to the community. One of the types of boundary found was the community which supports that KB not only receive and share information with subordinates or other emergency management organizations but also members of the community. Some countries, such as New Zealand, have encouraged their communities to develop a community resilience plan (CRP) as a preparation for disasters that could strike anytime. The CRP includes information such as what to do, responsibilities and where to go during a disaster. My research serves as a basis for communities to develop a stronger community resilience plan by incorporating the process of cross-boundary information sharing and this flow can be refined and included in the CRP. 


\subsection{Research limitations}

The main limitation of my research is the lack of generalizability (Yin, 2009) which is common to qualitative case research. My research findings could not be generalized to a wider range of disasters. Although there are ten cases with 22 unique scenarios, there is a need to have a larger set of units of analysis (i.e. unique scenarios). These scenarios can also be seen as part of a larger set of scenarios with a larger and diverse range of disasters. In addition, my research has taken an interpretivist stance where the findings are mainly subject to my own interpretation of meaning. However, I have taken the necessary steps to mitigate this limitation and ensure the quality and trustworthiness of my research as discussed in Chapter 3, research methodology and having six different types of disaster in ten cases (i.e. vignettes).

Second, the KB who are the participants of my research are limited to senior emergency services personnel such as emergency management advisor, district police chief, fire officer, principal rural fire officer, local council emergency advisor and head of national emergency service coordination. Some cases were from the same KB who had experienced different disasters which may affect the information flow. It would be more interesting if KB are from a wider group of people from non-emergency services organizations such as community leader, student leader or frontline officers.

Third, my research did not select participants from a single organization with different ranks. This is because this would limit the boundaries in the theory to only 'unit' and 'hierarchical' and exclude the organizational boundaries.

Fourth, the applicability of the theory to all types of disaster is limited. Since the theory was developed based on the evidence from six types of disasters - fire, earthquake, mine explosion, mid-air collision, bomb in a house and motor accident - it may have been different if a more types of disaster were included in the research. Other factors such as the degree of the disaster's geographical and social impact may also have affected the results of my research.

Fifth, the theory may not be applied to other geographical locations. All of the scenarios have occurred in the Greater Wellington region [except for Vignette 5: Pike River Mine explosion. 
Wellington has been selected to be one of the 100 resilient cities in the world (100 Resilient Cities, 2015). The selection was based on the efforts that have been made in preparing for, responding to and recovering from a disaster. Therefore, the $\mathrm{KB}$ responses to the interview are likely to be affected by different experience and training as compared to other locations.

Finally, the method of recalling previous experience during the interview may have had an effect on the participants. All of the 22 scenarios were collected from KB who recalled their previous experience. There is a possibility that $\mathrm{KB}$ may have forgotten or been reluctant to share some of the exact situations that they experienced in those scenarios. To mitigate this limitation, as discussed in Chapter 3, research methodology, sections 3.3.2 and 3.3.3, we had an informal face-to-face social session prior to the interview to gain trust and let the $\mathrm{KB}$ 'tell the story' of a particular disaster experience according to their own 'version' and I later asked them to explain more. In addition, I have conducted a second member check after writing the vignettes to verify they were correct.

Although I have not mitigated all of the limitations identified in my research, I have taken careful steps and consideration to ensure that the limitations are minimized by refining my research design. However, it is possible that some errors could have occurred.

\subsection{Implications for future research}

The disaster management literature includes various sub-topics. Some of them are system and technological development, decision-making training, community resilience, disaster preparation and planning and technology adoption. My research contributes to a wide range of sub-topics. For example, the system and technological development area could use my research findings to develop a system for the decision maker to use. The decision-making trainers could use it for the development of a training module and syllabus. The technology adoption field could use it to extend their knowledge using the findings of my research.

In addition, the scholars in the area of Naturalistic Decision Making (NDM) are still calling for more contributions to their field, as seen recently in their journal in 2015 (this was discussed in the chapter 2 literature review). Therefore, the findings of my research have implications for the disaster management and NDM literature. 
Future research can confirm and refine the theory presented in my research. Researchers can plan to verify the cognitive resources found in both phases (i.e. Phase 1 and Phase 2). Further verification could be obtained on the concept of the usage of certain tactics to make the decision with certain types of boundary $\mathrm{KB}$ receive or share information across during a disaster. The emerging patterns between types of information and the tactics used to make decisions is another area for future work. This means that investigating and comparing different types of disasters using the theory found in my research would be worthwhile.

The ICT that have been used by KB in sharing information across a boundary, especially decision-making under uncertainty and time pressure, could potentially be of interest for future research. Although recently there have been extensive studies conducted on social media use when sharing information during a disaster, my research found little evidence of the use of social media in receiving and sharing information by KB across boundaries. This means a study of the information flow of $\mathrm{KB}$, especially those who are in the field during a disaster, focusing on the use of social media could be conducted.

It would also be possible in future research to test the theory and propositions that were developed in this research. Testing can be done through experiments, disaster simulation exercises or surveys.

Another potential future research angle is a longitudinal research method. A longer period of data collection and analysis might allow a deeper understanding of this theory and therefore test and confirm the theory.

\subsection{Conclusion}

This interpretive multiple case research used qualitative methods to explore and identify how $\mathrm{KB}$ assess and decide the veracity of the information they received from across a boundary and how $\mathrm{KB}$ decide to whom the information they hold is relevant during a disaster. It was motivated by the lack of research in the literature particularly in IS knowledge management and also in other related areas such as disaster management and Naturalistic Decision-Making $(\mathrm{NDM})$. 
The context of this research is any disaster that occurs in New Zealand. The cases took the form of a multiple and embedded design with ten cases (i.e. disasters) that were presented in ten vignettes. The unit of analysis was the 22 unique 'scenarios'. Upon analyzing the data in four stages, the result was a theoretical model of cross-boundary information sharing by KB during disasters and ten theoretical propositions.

Although this research is subject to some limitations which is usual in qualitative case research, it has addressed and identified gaps in the literature. The results have produced a rich contextual process of cross-boundary information sharing by KB during a disaster. It has produced the following findings and insights:

i) In Stage 1, KB received different types of information from sources located across different types of boundaries. Then they filter the information using their cognitive resources. Next, $\mathrm{KB}$ make a decision using different decision-making tactics to identify the veracity of the information they received.

ii) In Stage 2, KB match the information they hold to the relevant receiver by relying on their cognitive resources. Then, they decide to whom the information is relevant using different decision-making tactics. Finally, they either share the various types of information with the receiver across a type of boundary or keep the information to themselves.

iii) Uncovered that $\mathrm{KB}$ use different decision-making tactics with different types of boundaries and types of information.

iv) That the KB boundary-spanning role crossed both vertical and horizontal boundaries. They also went through two stages of a major process in identifying the veracity and relevance of the information they received.

v) Refine the idea of the use of cognitive resources in the information- sharing process by introducing several cognitive resources that $\mathrm{KB}$ rely on.

vi) Extend the Hourglass Framework of the expert decision-making process by unpacking the process and refining the framework. 
vii) Support the use of ICT during a disaster, but found very little evidence of the use of social media.

To conclude, in this chapter, I have summarized the findings and describe how it has answered the two research questions posed in Chapter 1. I have described the implication of this research in theory and practice. I have also presented the implications and suggestions for future research. I believe that there are many opportunities for future research in this area, particularly in the area of knowledge brokering, disaster management, Naturalistic DecisionMaking and ICT.

$* * * * * * * * * * * * * * * * * *$ 


\section{REFERENCES}

Abdolmohammadi, M., \& Sultan, J. (2002). Ethical reasoning and the use of insider information in stock trading. Journal of Business Ethics, 37(2), 165-173.

Abou-Zeid, E.-S. (2005). A culturally aware model of inter-organizational knowledge transfer. Knowledge Management Research \& Practice, 3, 146-155.

Ackoff, R. L. (1989). From data to wisdom. Journal of Applied Systems Analysis, 16, 3-9.

Alison, L., Power, N., Heuvel, C., Humann, M., Palasinksi, M., \& Crego, J. (2015). Decision inertia: Deciding between least worst outcomes in emergency responses to disasters. Journal of Occupational and Organizational Psychology, 88(2), 295-321.

Allen, D. K., Karanasios, S., \& Norman, A. (2014). Information sharing and interoperability: the case of major incident management. European Journal of Information Systems, 23(4), 418-432.

Allen, T. J. (1970). Communication networks in R \& D Laboratories. R\&D Management, 1(1), 14-21. doi:10.1111/j.1467-9310.1970.tb01193.x

Altay, N., \& Pal, R. (2014). Information Diffusion among Agents: Implications for Humanitarian Operations. Production and Operations Management, 23(6), 1015-1027.

Ancona, D., \& Caldwell, D. (1992). Bridging the Boundary: External Activity and Performance in Organizational Teams. Administrative Science Quarterly, 37(4), 634-665. doi:10.2307/2393475

Appan, R., \& Browne, G. J. (2012). The impact of analyst-induced misinformation on the requirements elicitation process. MIS quarterly, 36(1), 85-106.

Armstrong, D., Gosling, A., Weinman, J., \& Marteau, T. (1997). The place of inter-rater reliability in qualitative research: an empirical study. Sociology, 31(3), 597-606.

Asplund, M., Nadjm-Tehrani, S., \& Sigholm, J. (2009). Emerging information infrastructures: Cooperation in disasters. Paper presented at the Critical Information Infrastructure Security Third International Workshop, CRITIS 2008, Rome, Italy.

Austin, L., Fisher Liu, B., \& Jin, Y. (2012). How audiences seek out crisis information: Exploring the social-mediated crisis communication model. Journal of Applied Communication Research, 40(2), 188-207.

Austin, L., Liu, F., \& Jin, Y. (2012). How audiences seek out crisis information: Exploring the socialmediated crisis communication model. Journal of Applied Communication Research, 40(2), 188-207.

Baber, C., Cross, J., Smith, P., \& Robinson, D. (2007). Supporting Implicit Coordination Between Distributed Teams in Disaster Management. In J. Löffler \& M. Klann (Eds.), Mobile Response (Vol. 4458, pp. 39-50): Springer Berlin Heidelberg.

Bartol, K. M., \& Srivastava, A. (2002). Encouraging Knowledge Sharing: The Role of Organizational Reward Systems. Journal of Leadership \& Organizational Studies, 9(1), 64-76. doi:10.1177/107179190200900105

Benabou, R., \& Laroque, G. (1992). Using privileged information to manipulate markets: Insiders, gurus, and credibility. The Quarterly Journal of Economics, 921-958.

Benbasat, I., Goldstein, D., \& Mead, M. (1987). The case research strategy in studies of information systems. MIS Quarterly, 369-386.

Bharosa, N., Lee, J., \& Janssen, M. (2010). Challenges and obstacles in sharing and coordinating information during multi-agency disaster response: Propositions from field exercises. Information Systems Frontiers, 12(1), 49-65. doi:10.1007/s10796-009-9174-z

Bos, N., Shami, N. S., Olson, J. S., Cheshin, A., \& Nan, N. (2004). In-group/out-group effects in distributed teams: an experimental simulation.

Bouquet, C., \& Birkinshaw, J. (2008). Weight Versus Voice: How Foreign Subsidiaries Gain Attention From Corporate Headquarters. Academy of Management Journal, 51(3), 577-601.

doi:10.5465/amj.2008.32626039 
Bunker, D. (2010). Information systems management (ISM): Repertoires of collaboration for community warning (CW) and emergency incident response (EIR). Paper presented the Technologies for Homeland Security (HST), 2010 IEEE International Conference on 8 November 2010.

Burke, L. A., \& Miller, M. K. (1999). Taking the mystery out of intuitive decision making. The Academy of Management Executive, 13(4), 91-99.

Burla, L., Knierim, B., Barth, J., Liewald, K., Duetz, M., \& Abel, T. (2008). From text to codings: intercoder reliability assessment in qualitative content analysis. Nursing research, 57(2), 113117.

Burt, R. S. (2004). Structural holes and good ideas. American journal of sociology, 110(2), 349-399.

Butterfield, F. (1988). Iran Falls Short in Drive at U.N. To Condemn U.S. in Airbus Case. Retrieved from http://www.nytimes.com/1988/07/15/world/iran-falls-short-in-drive-at-un-tocondemn-us-in-airbus-case.html

Canestraro, D. S., Pardo, T. A., Raup-Kounovsky, A. N., \& Taratus, D. (2009). Regional telecommunication incident coordination: Sharing information for rapid response. Information Polity: The International Journal of Government \& Democracy in the Information Age, 14(1/2), 113-126. doi:10.3233/ip-2009-0166

Carlile, P. R. (2004). Transferring, Translating, and Transforming: An Integrative Framework for Managing Knowledge across Boundaries. Organization science, 15(5), 555-568.

Choi, J. N., Sung, S. Y., \& Kim, M. U. (2010). How do groups react to unexpected threats? Crisis management in organizational teams. Social Behavior and Personality: an international journal, 38(6), 805-828.

Choi, S. Y., Lee, H., \& Yoo, Y. (2010). The impact of information technology and transactive memory systems on knowledge sharing, application, and team performance: a field study. MIS quarterly, 34(4), 855-870.

Choo, C. W. (1996). The knowing organization: how organizations use information to construct meaning, create knowledge and make decisions. International Journal of Information Management, 16(5), 329-340.

Chuvieco, E., Aguado, I., Yebra, M., Nieto, H., Salas, J., Martín, M. P., . . Ibarra, P. (2010). Development of a framework for fire risk assessment using remote sensing and geographic information system technologies. Ecological Modelling, 221(1), 46-58.

Cillo, P. (2005). Fostering Market Knowledge Use in Innovation:: The Role of Internal Brokers. European Management Journal, 23(4), 404-412. doi:http://dx.doi.org/10.1016/j.emj.2005.06.008

Cioffi, J. (1997). Heuristics, servants to intuition, in clinical decision-making. Journal of Advanced Nursing, 26(1), 203-208.

Cioffi, J. (2001). A study of the use of past experiences in clinical decision making in emergency situations. International journal of nursing studies, 38(5), 591-599.

Clawson, V. K., Bostrom, R. P., \& Anson, R. (1993). The role of the facilitator in computer-supported meetings. Small Group Research, 24(4), 547-565.

Comfort, L. K., Colella, B., Voortman, M., Connelly, S., Drury, J. L., Klein, G. L., \& Wukich, C. (2013). Real-time Decision Making in Urgent Events: Modeling Options for Action. Paper presented at the Proceedings of the 10th International ISCRAM Conference.

Constant, D., Kiesler, S., \& Sproull, L. (1994). What's Mine Is Ours, or Is It? A Study of Attitudes about Information Sharing. Information Systems Research, 5(4), 400-421.

Corbin, J., \& Morse, J. M. (2003). The unstructured interactive interview: Issues of reciprocity and risks when dealing with sensitive topics. Qualitative inquiry, 9(3), 335-354.

Cosgrave, J. (1996). Decision making in emergencies. Disaster Prevention and Management, 5(4), 2835. 
Cranefield, J., \& Yoong, P. (2005). Organisational factors affecting inter-organisational knowledge transfer in the New Zealand state sector: a case study. The Electronic Journal for virtual organizations and networks, 7.

Cranefield, J., \& Yoong, P. (2007a). Interorganisational knowledge transfer: the role of the gatekeeper. International Journal of Knowledge and Learning, 3(1), 121-138.

Cranefield, J., \& Yoong, P. (2007b). The role of the translator/interpreter in knowledge transfer environments. Knowledge and Process Management, 14(2), 95-103.

Cranefield, J., \& Yoong, P. (2010). Knowledge Brokers in Overlapping Online Communities of Practice: The Role of the Connector-Leader. Leadership in the Digital Enterprise, 77-90.

Cranefield, J., Yoong, P., \& Huff, S. (2011). Driving Change Through Brokering Practices In An Online Community Ecosystem. Retrieved from http://www.pacis-net.org/file/2011/PACIS2011041.pdf

Creswell, J. W. (2003). Research design: Qualitative, Quantitative, and Mixed Methods Approaches

(2 ed.). Thousand Oaks, CA: Sage Publications.

Cristancho, S. M., Vanstone, M., Lingard, L., LeBel, M.-E., \& Ott, M. (2013). When surgeons face intraoperative challenges: a naturalistic model of surgical decision making. The American Journal of Surgery, 205(2), 156-162.

Cunningham, J. B., \& MacGregor, J. N. (2014). Productive and Re-productive Thinking in Solving Insight Problems. The Journal of Creative Behavior, 48(1), 44-63.

Curnin, S., \& Owen, C. (2014). Spanning organizational boundaries in emergency management. International Journal of Public Administration, 37(5), 259-270.

Curnin, S., Owen, C., \& Trist, C. (2014). Managing the constraints of boundary spanning in emergency management. Cognition, Technology \& Work, 16(4), 549-563.

Daft, R. L., \& Lengel, R. H. (1983). Information richness. A new approach to managerial behavior and organization design. Retrieved from http://www.dtic.mil/dtic/tr/fulltext/u2/a128980.pdf

Daly, J., McDonald, I., \& Willis, E. (1992). Why don't you ask them. A qualitative research framework for investigating the diagnosis of cardiac normality. In: Daly J, McDonald I, Willis E, eds. Researching health care: designs, dilemmas, disciplines. London: Routledge, 189-206.

Dane, E., \& Pratt, M. G. (2007). Exploring intuition and its role in managerial decision making. Academy of Management Review, 32(1), 33-54.

Darke, P., Shanks, G., \& Broadbent, M. (1998). Successfully completing case study research: combining rigour, relevance and pragmatism. Information Systems Journal, 8(4), 273-289.

Davenport, T. H., \& Prusak, L. (1998). Working knowledge: Managing what your organization knows. Harvard Business School Press, Boston, MA.

Dawes, S. S. (1996). Interagency information sharing: Expected benefits, manageable risks. Journal of Policy Analysis and Management, 15(3), 377-394. doi:10.1002/(sici)15206688(199622)15:3<377::aid-pam3>3.0.co;2-f

Dawes, S. S., Gharawi, M. A., \& Burke, G. B. (2012). Transnational public sector knowledge networks: Knowledge and information sharing in a multi-dimensional context. Government Information Quarterly, 29, S112-S120.

Denzin, N. K., \& Lincoln, Y. S. (2005). The Sage handbook of qualitative research. CA: Sage.

Detert, J. R., \& Burris, E. R. (2007). Leadership behavior and employee voice: Is the door really open? . Academy of Management Journal, 50(4), 869-884. doi:10.5465/amj.2007.26279183

Detert, J. R., \& Trevino, L. K. (2010). Speaking Up to Higher-Ups: How Supervisors and Skip-Level Leaders Influence Employee Voice. Organization science, 21(1), 249-270. doi:10.1287/orsc.1080.0405

Dubé, L., \& Paré, G. (2003). Rigor in information systems positivist case research: current practices, trends, and recommendations. MIS quarterly, 597-636.

Duffy, T., McMaster, R., Baber, C., \& Houghton, R. (2012). Towards an Ontology Broker to Improve Cross-agency Sharing in Emergency Response. Paper presented at the Proceedings of the 9th International ISCRAM Conference, Vancouver, Canada. 
Easterby-Smith, M., Lyles, M. A., \& Tsang, E. W. K. (2008). Inter-Organizational Knowledge Transfer: Current Themes and Future Prospects. Journal of Management Studies, 45(4), 677-690. doi:10.1111/j.1467-6486.2008.00773.x

Edmondson, A. C., \& McManus, S. E. (2007). Methodological fit in management field research. Academy of management review, 32(4), 1246-1264.

Edwards, W. (1954). The theory of decision making. Psychological bulletin, 51(4), 380-417.

Edwards, W. (1961). Behavioral decision theory. Annual review of psychology, 12(1), 473-498.

Egelhoff, W. G. (1988). Organizing the multinational enterprise: An information-processing perspective: Ballinger Publishing Company Cambridge, MA.

Ehnis, C., \& Bunker, D. (2013). The impact of disaster typology on social media use by emergency services agencies: the case of the Boston Marathon bombing. Paper presented at the 24th Australasian Conference on Information Systems (ACIS).

Eisenhardt, K. M. (1989). Building Theories from Case Study Research. The Academy of Management Review, 14(4), 532-550.

Elo, S., Kääriäinen, M., Kanste, O., Pölkki, T., Utriainen, K., \& Kyngäs, H. (2014). Qualitative Content Analysis. SAGE Open, 4(1), 2158244014522633.

Elstein, A. S. (1999). Heuristics and biases: selected errors in clinical reasoning. Academic Medicine, 74(7), 791-794.

Enders, A., \& Brandt, Z. (2007). Using geographic information system technology to improve emergency management and disaster response for people with disabilities. Journal of Disability Policy Studies, 17(4), 223-229.

Espinosa, J. A., Cummings, J. N., Wilson, J. M., \& Pearce, B. M. (2003). Team boundary issues across multiple global firms. Journal of Management Information Systems, 19(4), 157-190.

Faniel, I. M., \& Majchrzak, A. (2007). Innovating by accessing knowledge across departments. Decision Support Systems, 43(4), 1684-1691.

Fiedler, F. E. (2001). When IQ+ experience= performance. Leadership \& Organization Development Journal, 22(3), 132-139.

Fiedler, F. E., \& Garcia, J. E. (1987). New approaches to effective leadership: Cognitive resources and organizational performance. Oxford: John Wiley \& Sons.

Fitzgerald, B., \& Howcroft, D. (1998). Towards dissolution of the IS research debate: from polarization to polarity. Journal of Information Technology, 13, 313-326.

Flanagan, J. C. (1954). The critical incident technique. Psychological bulletin, 51(4), 327-360.

Fritsch, M., \& Kauffeld-Monz, M. (2010). The impact of network structure on knowledge transfer: an application of social network analysis in the context of regional innovation networks. The Annals of Regional Science, 44(1), 21-38.

Gaertner, S. L., Dovidio, J. F., Anastasio, P. A., Bachman, B. A., \& Rust, M. C. (1993). The common ingroup identity model: Recategorization and the reduction of intergroup bias. European review of social psychology, 4(1), 1-26.

Gefen, D., \& Straub, D. (2005). A practical guide to factorial validity using PLS-Graph: Tutorial and annotated example. Communications of the Association for Information Systems, 16(1), 91109.

Ghoshal, S., Korine, H., \& Szulanski, G. (1994). Interunit Communication in Multinational Corporations. Management Science, 40(1), 96-110.

Gigerenzer, G., \& Gaissmaier, W. (2011). Heuristic decision making. Annual review of psychology, 62, 451-482.

Gilley, A., \& Kerno, S. J. (2010). Groups, Teams, and Communities of Practice: A Comparison. Advances in Developing Human Resources, 12(1), 46-60. doi:10.1177/1523422310365312

Golafshani, N. (2003). Understanding reliability and validity in qualitative research. The qualitative report, 8(4), 597-607. 
Gómez, C., Kirkman, B. L., \& Shapiro, D. L. (2000). The Impact of Collectivism and In-Group/OutGroup Membership on the Evaluation Generosity of Team Members. The Academy of Management Journal, 43(6), 1097-1106.

Gore, J., Flin, R., Stanton, N., \& Wong, B. (2015). Applications for naturalistic decision-making. Journal of Occupational and Organizational Psychology, 88(2), 223-230.

Granovetter, M. S. (1973). The Strength of Weak Ties. American Journal of Sociology, 78(6), 13601380. doi:10.2307/2776392

Gregor, S. (2006). The nature of theory in information systems. MIS Quarterly, 611-642.

Groenendaal, J., Helsloot, I., \& Scholtens, A. (2013). A critical examination of the assumptions regarding centralized coordination in large-scale emergency situations. Journal of Homeland Security and Emergency Management, 10(1), 113-135.

Guba, E. G. (1981). Criteria for assessing the trustworthiness of naturalistic inquiries. Educational Technology Research and Development, 29(2), 75-91.

Gupta, A. K. G., Vijay. (2000). Knowledge Flows within Multinational Corporations. Strategic Management Journal, 21(4), 473-496.

Guzzo, R. A., \& Dickson, M. W. (1996). Teams in Organizations: Recent Research on Performance and Effectiveness. Annual review of psychology, 47(1), 307-338. doi:10.1146/annurev.psych.47.1.307

Habraken, M., \& Van der Schaaf, T. (2010). If only....: failed, missed and absent error recovery opportunities in medication errors. Quality and safety in health care, 19(1), 37-41.

Haeussler, C. (2011). Information-sharing in academia and the industry: A comparative study. Research Policy, 40(1), 105-122. doi:10.1016/j.respol.2010.08.007

Halevy, N., Bornstein, G., \& Sagiv, L. (2008). "In-Group Love" and "Out-Group Hate" as Motives for Individual Participation in Intergroup Conflict. Psychological Science, 19(4), 405.

Hansen, M. T. (1999). The Search-Transfer Problem: The Role of Weak Ties in Sharing Knowledge across Organization Subunits. Administrative Science Quarterly, 44(1), 82-111. doi:10.2307/2667032

Hargadon, A. (1998). Firms as knowledge brokers. California Management Review, 40(3), 209-227.

Hargadon, A. (2002). Brokering knowledge: Linking learning and innovation. Research in Organizational Behavior, 24(0), 41-85. doi:http://dx.doi.org/10.1016/S0191-3085(02)240034

Haslam, S. A. (2004). Psychology in organizations (2 ed.). London: Sage Publications.

Hewstone, M., Rubin, M., \& Willis, H. (2002). Intergroup bias. Annual review of psychology, 53(1), 575-604.

Hogan, H., Olsen, S., Scobie, S., Chapman, E., Sachs, R., McKee, M., .. Thomson, R. (2008). What can we learn about patient safety from information sources within an acute hospital: a step on the ladder of integrated risk management? Quality and Safety in Health Care, 17(3), 209215.

Hogg, M. A., \& Terry, D. J. (2000). Social Identity and Self-Categorization Processes in Organizational Contexts. The Academy of Management Review, 25(1), 121-140. doi:10.2307/259266

Hollenbeck, J. R., Beersma, B., \& Schouten, M. E. (2012). Beyond Team Types and Taxonomies: A Dimensional Scaling Conceptualization for Team Description. Academy of management review, 37(1), 82-106. doi:10.5465/amr.2010.0181

Hollingshead, A. B. (1998). Communication, learning, and retrieval in transactive memory systems. Journal of Experimental Social Psychology, 34(5), 423-442.

Holm, U., \& Sharma, D. D. (2006). Subsidiary marketing knowledge and strategic development of the multinational corporation. Journal of International Management, 12(1), 47-66.

Houston, J. B., Hawthorne, J., Perreault, M. F., Park, E. H., Goldstein Hode, M., Halliwell, M. R., . . McElderry, J. A. (2015). Social media and disasters: a functional framework for social media use in disaster planning, response, and research. Disasters, 39(1), 1-22. 
Howells, J. (2006). Intermediation and the role of intermediaries in innovation. Research Policy, 35(5), 715-728. doi:http://dx.doi.org/10.1016/j.respol.2006.03.005

Huang, J.-S., \& Lien, Y.-N. (2012). Challenges of emergency communication network for disaster response. Paper presented at the Communication Systems (ICCS), 2012 IEEE International Conference.

Hughes, A. L., \& Palen, L. (2009). Twitter adoption and use in mass convergence and emergency events. International Journal of Emergency Management, 6(3), 248-260.

Hughes, A. L., \& Palen, L. (2012). The evolving role of the public information officer: An examination of social media in emergency management. Journal of Homeland Security and Emergency Management, 9(1), 1-20.

Hughes, M. A., Price, R. L., \& Marrs, D. W. (1986). Linking theory construction and theory testing: Models with multiple indicators of latent variables. Academy of management review, 11(1), 128-144.

lannella, R., \& Henricksen, K. (2007). Managing information in the disaster coordination centre: Lessons and opportunities. Paper presented at the Proceedings of the 4th International ISCRAM Conference (B. Van de Walle, P. Burghardt and C. Nieuwenhuis, eds.).

International Organization for Standardization. (2011). ISO 22320:2011, Societal security-emergency management-requirements for incident response. Retrieved from https://www.iso.org/obp/ui/\#iso:std:iso:22320:ed-1:v1:en

Jaffe, J. F. (1974). Special information and insider trading. Journal of business, 410-428.

Janssen, M., Lee, J., Bharosa, N., \& Cresswell, A. (2010). Advances in multi-agency disaster management: Key elements in disaster research. Information Systems Frontiers, 12(1), 1-7.

Jarvenpaa, S. L., \& Majchrzak, A. (2008). Knowledge Collaboration Among Professionals Protecting National Security: Role of Transactive Memories in Ego-Centered Knowledge Networks. Organization science, 19(2), 260-276. doi:10.1287/orsc.1070.0315

Johnson, R. B., Onwuegbuzie, A. J., \& Turner, L. A. (2007). Toward a definition of mixed methods research. Journal of mixed methods research, 1(2), 112-133.

Kanter, R. M. (1988). Three Tiers for Innovation Research. Communication Research, 15(5), 509-523. doi:10.1177/009365088015005001

Kapucu, N. (2006). Interagency communication networks during emergencies boundary spanners in multiagency coordination. The American Review of Public Administration, 36(2), 207-225.

Kapucu, N. (2012). Disaster and emergency management systems in urban areas. Cities, 29, S41-S49.

Kapucu, N., \& Garayev, V. (2011). Collaborative decision-making in emergency and disaster management. International Journal of Public Administration, 34(6), 366-375.

Karlova, N. A., \& Fisher, K. E. (2013). Plz RT": A social diffusion model of misinformation and disinformation for understanding human information behaviour. Information Research, 18(1), 1-17.

Katzenbach, J. R., \& Smith, D. K. (1993). The discipline of teams. Harvard Business Review, 71, 111120.

Kauffeld-Monz, M., \& Fritsch, M. (2013). Who are the knowledge brokers in regional systems of innovation? A multi-actor network analysis. Regional Studies, 47(5), 669-685.

Kermarrec, G., \& Bossard, C. (2014). Defensive Soccer Players' Decision Making A Naturalistic Study. Journal of Cognitive Engineering and Decision Making, 8(2), 187-199.

Khalid, H. M., Helander, M. G., \& Hood, N. A. (2013). Visualizing disaster attitudes resulting from terrorist activities. Applied ergonomics, 44(5), 671-679.

Klein, G. (2008). Naturalistic decision making. Human Factors: The Journal of the Human Factors and Ergonomics Society, 50(3), 456-460.

Klein, G. (2015). Reflections on applications of naturalistic decision making. Journal of Occupational and Organizational Psychology, 88(2), 382-386. 
Klein, G., Calderwood, R., \& Clinton-Cirocco, A. (1986). Rapid decision making on the fire ground. Paper presented at the Proceedings of the Human Factors and Ergonomics Society annual meeting.

Klein, G., Calderwood, R., \& Macgregor, D. (1989). Critical decision method for eliciting knowledge. Systems, Man and Cybernetics, IEEE Transactions on, 19(3), 462-472.

Klein, G., \& Klinger, D. (1991). Naturalistic Decision Making. Retrieved from http://www.au.af.mil/au/awc/awcgate/decision/nat-dm.pdf

Klein, H. K., \& Myers, M. D. (1999). A set of principles for conducting and evaluating interpretive field studies in information systems. MIS Quarterly, 67-93.

Kogut, B., \& Zander, U. (1996). What firms do? Coordination, identity, and learning. Organization science, $7(5), 502-518$.

Kontogiannis, T., \& Kossiavelou, Z. (1999). Stress and team performance: principles and challenges for intelligent decision aids. Safety science, 33(3), 103-128.

Kotlarsky, J., Hooff, B., \& Huysman, M. (2009). Bridging Knowledge Boundaries in Cross-Functional Groups: The Role of a Transactive Memory System.

Kowalski-Trakofler, K. M., Vaught, C., \& Scharf, T. (2003). Judgment and decision making under stress: an overview for emergency managers. International Journal of Emergency Management, 1(3), 278-289.

Krackhardt, D. (1992). The strength of strong ties: The importance of philos in organizations. In N. Nohria \& R. Eccles (Eds.), Networks and organizations: Structure, form, and action (pp. 216239). Boston: Havard Buniess School Press.

Kramer, R. M. (2005). A Failure to Communicate: 9/11 and the Tragedy of the Informational Commons. International Public Management Journal, 8(3), 397-416. doi:10.1080/10967490500439867

Krefting, L. (1991). Rigor in qualitative research: The assessment of trustworthiness. American journal of occupational therapy, 45(3), 214-222.

LaRossa, R., Bennett, L. A., \& Gelles, R. J. (1981). Ethical dilemmas in qualitative family research. Journal of Marriage and the Family, 303-313.

Lee, A. S. (1989). A scientific methodology for MIS case studies. MIS quarterly, 33-50.

Lee, A. S. (1991). Integrating positivist and interpretive approaches to organizational research. Organization science, 2(4), 342-365.

Levin, D. Z., \& Cross, R. (2004). The strength of weak ties you can trust: The mediating role of trust in effective knowledge transfer. Management Science, 50(11), 1477-1490.

Lewis, K. (2003). Measuring transactive memory systems in the field: Scale development and validation. Journal of Applied Psychology, 88(4), 587-604. doi:10.1037/0033-2909.121.1.43

Lewis, K., \& Herndon, B. (2011). Transactive memory systems: Current issues and future research directions. Organization science, 22(5), 1254-1265.

Lien, Y. N., Chi, L. C., \& Huang, C. C. (2010). A multi-hop walkie-talkie-like emergency communication system for catastrophic natural disasters. Paper presented at the 2010 39th International Conference on Parallel Processing Workshops.

Lincoln, Y. S., \& Guba, E. G. (1985). Naturalistic inquiry (Vol. 75). CA: Sage.

Lind, M., \& Persborn, M. (2000). Possibilities and risks with a knowledge broker in the knowledge transfer process. Paper presented at the 42nd Annual Conference of the Operational Research Society.

Lipshitz, R., Klein, G., Orasanu, J., \& Salas, E. (2001). Taking stock of naturalistic decision making. Journal of behavioral decision making, 14(5), 331-352.

Lipshitz, R., \& Strauss, O. (1997). Coping with uncertainty: A naturalistic decision-making analysis. Organizational behavior and human decision processes, 69(2), 149-163.

Liu, F., Burton-Jones, A., \& Xu, D. (2013). Effects of Source and Content on the Retransmission of Rumor, Information and Misinformation on Social Media. Paper presented at the 24th Australasian Conference on Information System, Melbourne. 
Liu, F., Burton-Jones, A., \& Xu, D. (2014). Rumors on social media in disasters: Extending transmission to retransmission. Paper presented at the Pacific Asia Conference on Information Systems (PACIS), Chengdu, China.

Loftus, E. F., \& Hoffman, H. G. (1989). Misinformation and memory: the creation of new memories. Journal of Experimental Psychology: General, 118(1), 100.

Macquet, A., \& Fleurance, P. (2007). Naturalistic decision-making in expert badminton players. Ergonomics, 50(9), 1433-1450.

Maier, N. R. (1945). Reasoning in humans. III. The mechanisms of equivalent stimuli and of reasoning. Journal of Experimental Psychology, 35(5), 349-360.

Manoj, B. S., \& Baker, A. H. (2007). Communication challenges in emergency response. Communications of the ACM, 50(3), 51-53.

Marett, K., \& Joshi, K. (2009). The decision to share information and rumors: examining the role of motivation in an online discussion forum. Communications of the Association for Information Systems, 24(1), 4.

Marewski, J. N., \& Gigerenzer, G. (2012). Heuristic decision making in medicine. Dialogues Clin Neurosci, 14(1), 77-89.

Marrone, J. A. (2010). Team Boundary Spanning: A Multilevel Review of Past Research and Proposals for the Future. Journal of Management, 36(4), 911-940. doi:10.1177/0149206309353945

Mayhorn, C. B., \& McLaughlin, A. C. (2014). Warning the world of extreme events: A global perspective on risk communication for natural and technological disaster. Safety Science, 61, 43-50. doi:http://dx.doi.org/10.1016/j.ssci.2012.04.014

Mayner, L., \& Arbon, P. (2015). Defining disaster: The need for harmonisation of terminology. Australasian Journal of Disaster \& Trauma Studies, 19.

McDermott, R. (1999). Learning across teams. Knowledge Management Review, 8(3), 32-36.

McEntire, D. A. (2002). Coordinating multi-organisational responses to disaster: lessons from the March 28, 2000, Fort Worth tornado. Disaster Prevention and Management: An International Journal, 11(5), 369-379.

Mendonça, D., Jefferson, T., \& Harrald, J. (2007). Collaborative adhocracies and mix-and-match technologies in emergency management. Communications of the ACM, 50(3), 44-49.

Meyer, M. (2010). The rise of the knowledge broker. Science Communication, 32(1), 118-127.

Miles, M. B., \& Huberman, A. M. (1994). Qualitative data analysis: An expanded sourcebook: SAGE publications, Inc.

Miles, M. B., Huberman, A. M., \& Saldaña, J. (2014). Qualitative data analysis: A methods sourcebook: SAGE Publications, Incorporated.

Militello, L. G., Sushereba, C. E., Branlat, M., Bean, R., \& Finomore, V. (2015). Designing for military pararescue: Naturalistic decision-making perspective, methods, and frameworks. Journal of Occupational and Organizational Psychology, 88(2), 251-272.

Milliken, F., Morrison, E., \& Hewlin, P. (2003). An Exploratory Study of Employee Silence: Issues that Employees Don't Communicate Upward and Why*. Journal of Management Studies, 40(6), 1453-1476. doi:10.1111/1467-6486.00387

Ministry of Civil Defence \& Emergency Management. (2015). Historical emergencies. Retrieved from http://www.civildefence.govt.nz/resources/historical-emergencies

Morrison, E. W. (2011). Employee voice behavior: Integration and directions for future research. The Academy of Management Annals, 5(1), 373-412.

Morrison, E. W., \& Milliken, F. J. (2000). Organizational Silence: A Barrier to Change and Development in a Pluralistic World. The Academy of Management Review, 25(4), 706-725.

Morse, J. M., Barrett, M., Mayan, M., Olson, K., \& Spiers, J. (2008). Verification strategies for establishing reliability and validity in qualitative research. International journal of qualitative methods, 1(2), 13-22.

Myers, M. D. (1995). Dialectical hermeneutics: a theoretical framework for the implementation of information systems. Information Systems Journal, 5(1), 51-70. 
Myers, M. D., \& Newman, M. (2007). The qualitative interview in IS research: Examining the craft. Information and Organization, 17(1), 2-26. doi:10.1016/j.infoandorg.2006.11.001

Naughton, F., Alexandrou, E., Dryden, S., Bath, J., \& Giles, M. (2013). Understanding treatment delay among problem drinkers: What inhibits and facilitates help-seeking? Drugs: education, prevention and policy, 20(4), 297-303.

Nevo, D., Benbasat, I., \& Wand, Y. (2012). Understanding Technology Support for Organizational Transactive Memory: Requirements, Application, and Customization. Journal of management information systems, 28(4), 69-98.

Nevo, D., \& Wand, Y. (2005). Organizational memory information systems: a transactive memory approach. Decision Support Systems, 39(4), 549-562.

Nonaka, I., \& Takeuchi, H. (1995). The knowledge-creating company: How Japanese companies create the dynamics of innovation. NY: Oxford University Press.

O'Reilly, M., Karim, K., \& Lester, J. N. (2015). Separating 'emotion' from 'the science': Exploring the perceived value of information for parents and families of children with autistic spectrum disorder. Clinical Child Psychology and Psychiatry, 20(3), 500-514. doi:10.1177/1359104514530735

Oh, O., Agrawal, M., \& Rao, H. R. (2013). Community intelligence and social media services: A rumor theoretic analysis of tweets during social crises. MIS quarterly, 37(2), 407-426.

Orlikowski, W. J., \& Baroudi, J. W. (1991). Studying Information Technology in Organizations: Research Approaches and Assumptions. Information System reserach, 2(1), 1-28.

Orton, J. D., \& Weick, K. E. (1990). Loosely coupled systems: A reconceptualization. Academy of management review, 15(2), 203-223.

Oshri, I., Van Fenema, P., \& Kotlarsky, J. (2008). Knowledge transfer in globally distributed teams: the role of transactive memory. Information Systems Journal, 18(6), 593-616. doi:10.1111/j.1365-2575.2007.00243.x

Owen, C., Bearman, C., Brooks, B., Chapman, J., Paton, D., \& Hossain, L. (2013). Developing a research framework for complex multi-team coordination in emergency management. International Journal of Emergency Management, 9(1), 1-17.

Padilha, R. P., Borges, M. R., Gomes, J. O., \& Canós, J. H. (2010). The Design of collaboration support between command and operation teams during emergency response. Paper presented the Computer Supported Cooperative Work in Design (CSCWD), 2010 14th International Conference on.

Palvia, P., Leary, D., Mao, E., Midha, V., Pinjani, P., \& Salam, A. (2004). Research methodologies in MIS: an update. Communications of the Association for Information Systems, 14, 526-542.

Pardo, T. A., \& Burke, G. B. (2008). Sustainable cross-boundary information sharing Digital Government (pp. 421-438): Springer.

Pascual, R., \& Henderson, S. (1997). Evidence of naturalistic decision making in military command and control. Naturalistic decision making, 217-226.

Patton, M. Q. (2002). Qualitative reserach and evaluation methods (3 ed.). California: Sage Publications.

Pawlowski, S. D., \& Robey, D. (2004). Bridging user organizations: Knowledge brokering and the work of information technology professionals. MIS quarterly, 645-672.

Peltokorpi, V. (2008). Transactive memory systems. Review of General Psychology, 12(4), 378.

Peters, H. P. (1992). The credibility of information sources in West Germany after the Chernobyl disaster. Public Understanding of Science, 1(3), 325-343.

Pope, C., Ziebland, S., \& Mays, N. (2000). Qualitative research in health care: Analysing qualitative data. BMJ: British Medical Journal, 320(7227), 114.

Pornpitakpan, C. (2004). The Persuasiveness of Source Credibility: A Critical Review of Five Decades' Evidence. Journal of Applied Social Psychology, 34(2), 243-281. doi:10.1111/j.15591816.2004.tb02547.x 
Prasanna, R., Yang, L., \& King, M. (2013). Guidance for developing human-computer interfaces for supporting fire emergency response. Risk Management, 15(3), 155-179.

Punch, K. F. (2005). Introduction to Social Research: Quantitative and Qualitative Approaches: SAGE.

Quarantelli, E. (1988). DISASTER CRISIS MANAGEMENT: A SUMMARY OF RESEARCH FINDINGS. Journal of Management Studies, 25(4), 373-385.

Ramiah, S. P., \& Banks, A. P. (2015). Naturalistic decision making through argumentation: Resolving labour disputes. Journal of Occupational and Organizational Psychology, 88(2), 364-381.

Rau, D. (2005). The influence of relationship conflict and trust on the transactive memory performance relation in top management teams. Small Group Research, 36(6), 746-771.

Redshaw, S., Ingham, V., \& Loftus, S. (2015). Emergency decision making: an exploration of tensions between communities of practice. International Journal of Emergency Management, 11(1), 62-75.

Rohde, S., Weber, T., \& Wietfeld, C. (2010). SPIDER: Enabling interoperable information sharing between public institutions for efficient disaster recovery and response. Paper presented at the Technologies for Homeland Security (HST), 2010 IEEE International Conference on.

Rosnow, R. L. (1991). Inside rumor: A personal journey. American psychologist, 46(5), 484-496.

Rowley, J. (2007). The wisdom hierarchy: representations of the DIKW hierarchy. Journal of Information Science, 33(2), 163-180. doi:10.1177/0165551506070706

Sandelowski, M. (1986). The problem of rigor in qualitative research. Advances in Nursing Science, $8(3), 27-37$.

Sandelowski, M. (1995). Qualitative analysis: What it is and how to begin. Research in Nursing \& Health, 18(4), 371-375. doi:10.1002/nur.4770180411

Santangelo, G. D. (2012). The tension of information sharing: Effects on subsidiary embeddedness. International Business Review, 21(2), 180-195. doi:10.1016/j.ibusrev.2011.01.004

Sarker, S., Xiao, X., \& Beaulieu, T. (2013). Guest editorial: Qualitative studies in information systems: A critical review and some guiding principles. MIS quarterly, 37(4), iii-xviii.

Saunders, D. M., Sheppard, B. H., Knight, V., \& Roth, J. (1992). Employee voice to supervisors. Employee Responsibilities and Rights Journal, 5(3), 241-259. doi:10.1007/bf01385051

Sauter, V. L. (1999). Intuitive decision-making. Communications of the ACM, 42(6), 109-115.

Schneider, S. K. (1992). Governmental response to disasters: The conflict between bureaucratic procedures and emergent norms. Public Administration Review, 135-145.

Schraagen, J. M., Veld, M. H., \& De Koning, L. (2010). Information sharing during crisis management in hierarchical vs. network teams. Journal of Contingencies and Crisis Management, 18(2), 117-127.

Seal, K. (1990). Decision-makers rely on honed intuition. Hotel and Motel Management, 205.

Serfaty, D., MacMillan, J., Entin, E. E., \& Entin, E. B. (1997). The decision-making expertise of battle commanders. Naturalistic decision making, 233-246.

Shaluf, I. M., Ahmadun, F. I.-r., \& Mat Said, A. (2003). A review of disaster and crisis. Disaster Prevention and Management: An International Journal, 12(1), 24-32.

Shenton, A. K. (2004). Strategies for ensuring trustworthiness in qualitative research projects. Education for Information, 22(2), 63-75.

Shklovski, I., Palen, L., \& Sutton, J. (2008). Finding community through information and communication technology in disaster response. Paper presented at the Proceedings of the 2008 ACM conference on Computer supported cooperative work.

Simon, T., Goldberg, A., \& Adini, B. (2015). Socializing in emergencies-A review of the use of social media in emergency situations. International Journal of Information Management, 35(5), 609-619.

Smith, W., \& Dowell, J. (2000). A case study of co-ordinative decision-making in disaster management. Ergonomics, 43(8), 1153-1166.

Stenbacka, C. (2001). Qualitative research requires quality concepts of its own. Management Decision, 39(7), 551-556. 
Stenmark, D. (2002). Information vs. knowledge: the role of intranets in knowledge management. Paper presented at the System Sciences, 2002. HICSS. Proceedings of the 35th Annual Hawaii International Conference on 7 Jan. 2002.

Sundstrom, E., De Meuse, K. P., \& Futrell, D. (1990). Work teams. American psychologist, 45(2), 120133.

Tajfel, H., \& Turner, J. C. (1979). An integrative theory of intergroup conflict. The social psychology of intergroup relations, 33-47.

Thomson, R., \& Pryce, A. (2009). Patient safety-epidemiological considerations. In B. Hurwitz \& A. Sheikh (Eds.), Health Care Errors and Patient Safety. West Sussex, UK: Blackwell Publishing.

Tsai, W. (2002). Social Structure of "Coopetition" Within a Multiunit Organization: Coordination, Competition, and Intraorganizational Knowledge Sharing. Organization science, 13(2), 179190. doi:10.1287/orsc.13.2.179.536

Tuna, G., Nefzi, B., \& Conte, G. (2014). Unmanned aerial vehicle-aided communications system for disaster recovery. Journal of Network and Computer Applications, 41, 27-36.

Tversky, A., \& Kahneman, D. (1973). Availability: A heuristic for judging frequency and probability. Cognitive psychology, 5(2), 207-232.

Tversky, A., \& Kahneman, D. (1974). Judgment under uncertainty: Heuristics and biases. science, 185(4157), 1124-1131.

United Nations. (2015). Sendai Framework for Disaster Risk Reduction 2015 - 2030. Retrieved from http://www.preventionweb.net/files/43291_sendaiframeworkfordrren.pdf

United Nations Office For Disaster Risk Reduction. (2016). 2015 disasters in numbers. Retrieved from http://www.unisdr.org/files/47804_2015disastertrendsinfographic.pdf

Van Wijk, R., Jansen, J. J. P., \& Lyles, M. A. (2008). Inter- and Intra-Organizational Knowledge Transfer: A Meta-Analytic Review and Assessment of its Antecedents and Consequences. Journal of Management Studies, 45(4), 830-853. doi:10.1111/j.1467-6486.2008.00771.x

von Hippel, E. (1994). "Sticky Information" and the Locus of Problem Solving: Implications for Innovation. Management Science, 40(4), 429-439.

Vroom, V. H., \& Yetton, P. W. (1973). Leadership and decision-making (Vol. 110). Pittsburgh, PA: University of Pittsburgh Press.

Walsham, G. (1995). Interpretive case studies in IS research: nature and method. Eur J Inf Syst, 4(2), 74-81.

Walsham, G. (2006). Doing interpretive research. Eur J Inf Syst, 15(3), 320-330.

Wang, S. L., \& Noe, R. A. (2010). Knowledge sharing: A review and directions for future research. Human Resource Management Review, 20(2), 115-131. doi:10.1016/j.hrmr.2009.10.001

Wegner, D. (1987). Transactive memory: A contemporary analysis of the group mind. Theories of group behavior, 185, 208.

Wegner, D., Erber, R., \& Raymond, P. (1991). Transactive memory in close relationships. Journal of Personality and Social Psychology, 61(6), 923-929.

Wegner, D., Giuliano, T., \& Hertel, P. T. (1985). Cognitive interdependence in close relationships Compatible and incompatible relationships (pp. 253-276): Springer.

Wellington Region Civil Defence Emergency Management. (2013). Group Plan 2013-2018. Retrieved from http://www.getprepared.org.nz/sites/default/files/uploads/2013\%20\%202018\%20Group\%20Plan.pdf

Wenger, E. (1998). Communities of practice: Learning as a social system. Systems thinker, 9(5), 2-3.

Wenger, E. (2005). Communities of practice: Learning, meaning, and identity. NY: Cambridge University Press.

Whitehead Jr, J. L. (1968). Factors of source credibility. Quarterly Journal of Speech, 54(1), 59-63.

Wiig, K. M. (1993). Knowledge management foundations: thinking about thinking: how people and organizations create, represent, and use knowledge: Schema Press Arlington.

Yang, L., Prasanna, R., \& King, M. (2009). On-site information systems design for emergency first responders. JITTA: Journal of Information Technology Theory and Application, 10(1), 5-27. 
Yang, T.-M., \& Maxwell, T. A. (2011). Information-sharing in public organizations: A literature review of interpersonal, intra-organizational and inter-organizational success factors. Government Information Quarterly, 28(2), 164-175. doi:10.1016/j.giq.2010.06.008

Yates, D., \& Paquette, S. (2011). Emergency knowledge management and social media technologies: A case study of the 2010 Haitian earthquake. International Journal of Information Management, 31(1), 6-13. doi:http://dx.doi.org/10.1016/j.ijinfomgt.2010.10.001

Yin, R. K. (2009). Case study research: Design and methods (4 ed. Vol. 5). Thousand Oaks, CA.: Sage Publications.

Zhang, D., Zhou, L., \& Nunamaker Jr, J. F. (2002). A Knowledge Management Framework for the Support of Decision Making in Humanitarian Assistance/Disaster Relief. Knowledge and Information Systems, 4(3), 370-385. doi:10.1007/s101150200012

Zsambok, C. E., \& Klein, G. (1997). Naturalistic decision making. New Jersey: Lawrence Erlbaum Associates. 


\section{SIM HUMAN ETHICS COMMITTEE}

Comments on Application for Human Ethics Approval

Date: $19 / 06-2013$

Principal Researcher: Fahimi Md Ali

Research Project: The Nature of Cross-Boundary Information Sharing By Knowledge Brokers in Organizations

Supervisor: Pak Yoong, Jean-Gregoire Bernard

Reference No: \# 20012

\begin{tabular}{|l|l|}
\hline $\mathbf{X}$ & Accept \\
\hline & Accept with minor changes. (Stated below) \\
\hline & Accepted with required changes. (Stated below) \\
\hline & Do not accept in present form. (Changes required as below) \\
\hline
\end{tabular}

Required Changes (dealing with ethical issues only)

None 


\section{Participant Information Sheet}

Researcher: Fahimi Md Ali, PhD Candidate, School of Information Management, Victoria University of Wellington, NZ.

I am a PhD student in the School of Information Management at Victoria University of Wellington. As part of this degree, I am undertaking research for the completion of my thesis. The research that I am undertaking is examining the nature of cross-boundary information sharing by knowledge brokers during disasters or emergency situations. The university requires that ethical approval be obtained for research involving human participants and this approval has been granted by the School of Information Management Human Ethics Committee for this research.

I am inviting individuals from the community, stakeholders and those who are involved in emergency management teams who have experience in any kind of disaster or emergency situation to participate in this study. The participants are also expected to be able to recall any of the disaster or emergency situations that they have experienced where they obtained any kind of emergency related information that may not be relevant to them but might be relevant to other members of a different team during the disaster or emergency situation. Participants will be interviewed and the interview session may take about 60 minutes. I will be recording the interview only with your approval. Should you feel the need to withdraw from the project, you may do so without question at any time within 3 months after the interview date. You also have the right to refuse to answer any question asked during the interview.

Responses collected will form the basis of my research and will be put into a written report. All materials collected during the interview will be treated as confidential. I will be using pseudonyms for each participant's name, position, department and organization in my report to ensure anonymity in reporting the results. No other person besides me, my supervisors, Professor Pak Yoong and Dr Jean-Gregoire Bernard and the interview transcriber will have access to the materials collected. The thesis will be submitted for academic verification by a selected group of examiners and later, be deposited in the University Library. It is intended that one or more articles will be submitted for publication in scholarly journals. Audio recordings and interview notes will be destroyed 2 years after the end of this research.

If you have any questions or would like to receive further information about the research, please contact me at either of the numbers below or my supervisors at the School of Information Management, Victoria University of Wellington as stated in this document's letterhead or their email; Professor Pak Yoong; Pak.Yoong@vuw.ac.nz and/or Dr. Jean-Gregoire Bernard; Jean-Gregoire.Bernard@vuw.ac.nz

Thank you.

Yours sincerely,

Fahimi Md Ali

PhD Candidate, School of Information Management, Victoria University of Wellington, NZ.

Email: fahimi.mdali@vuw.ac.nz,Phone number: 04-4635103 or 022-3145901 


\section{CONSENT FORM}

Name of the researcher: Fahimi Md Ali, PhD Student, School of Information Management, Victoria University of Wellington, NZ.

Title of the project: The Nature of Cross-Boundary Information Sharing by Knowledge Brokers During Disasters or Emergency Situations.

I have been given and have understood an explanation of this research. I have had an opportunity to ask questions and have them answered to my satisfaction. I understand that I may withdraw myself (or any information I have provided) from this research before data collection and analysis is complete (i.e. within 3 months after the interview date) without having to give reasons or without penalty of any sort).

And:

I understand that any information I provide will be kept confidential to the researcher, the supervisors and the person who transcribes the tape recordings of our interview, the published results will not use my name, position, department and organization and that no opinions will be attributed to me in any way that will identify me.

$\square \quad$ I understand that I can refuse to answer any question asked at any time during the interview.

- I understand that the tape recording of interview will be electronically wiped at the end of the research unless I indicate that I would like it returned to me.

$\square \quad$ I understand that I will have an opportunity to check the transcript of the interview before the withdrawal dateline ( 3 months after the interview date).

$\square \quad$ I understand that the data I provide will not be used for any other purpose or released to others without my written consent.

$\square \quad$ I would like to receive a summary of the results of this research when it is completed.

$\square \quad$ I agree to take part in this research.

Signed:

Name of participant:

Organization's name and department:

Date: 


\title{
Interview Participant's Consent to Transcriber's Involvement in Research Project
}

\section{Research title: The Nature of Cross-Boundary Information Sharing by Knowledge Brokers} During Disasters or Emergency Situations.

\author{
[Please mark each box with a $\checkmark$ to indicate agreement]
}

1. I agree to Fahimi Md Ali engaging the services of an experienced transcriber to help him with the transcription of interviews, and I agree that this person may transcribe my interview, if requested.

2. I understand that the transcriber has signed a confidentiality agreement, agreeing not to disclose any details relating to identity or other information, to store material securely, and to destroy it after completing the transcriptions.

3. I understand that this agreement is supplementary to the consent form that I have already signed, and that all other details relating to the project and to confidentiality remain as per the original agreement.

Participant's Name:

Signed:

Date: 


\section{Interview protocols}

- Can you describe your role in that disaster and your experience

- Please tell me about the disaster that you have listed down here, start with the first one?

\section{$\underline{\text { (Questions asked in each scenario) }}$}

- Let us go back to the incident where you receive information during [the scenario], can you explain in detail?

- What happened next? (for sequential structure data)

- Who was involved in that situation?

- Please describe how do you become aware of the information you receive.

- How well do you know the person? Tell me about your relationship with that person.

- How did you manage the information you receive?

- What happened next?

- Did you share the information? How? Why? Who was involved?

- When and how did you realize that the information was relevant to that person?

- How well do you know the person? Tell me about your relationship with that person.

- How was the situation different than the simulation exercise?

- Is there anything else that you want to add in particular to that incident?

*In situation where I needed more elaboration on certain contexts, I asked, 'How is that?' or 'Please explain more' 


\section{5 levels of concept mapping}
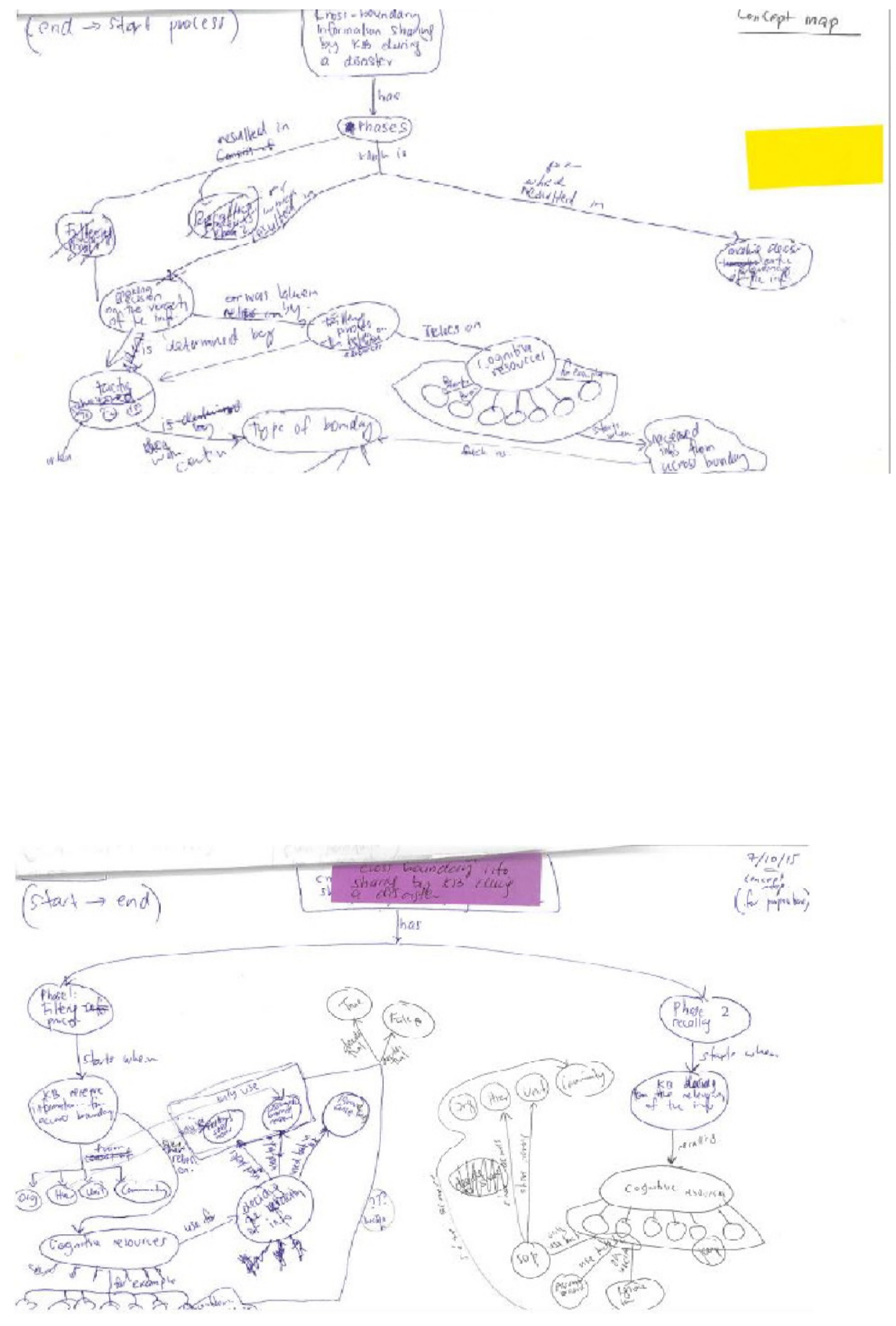


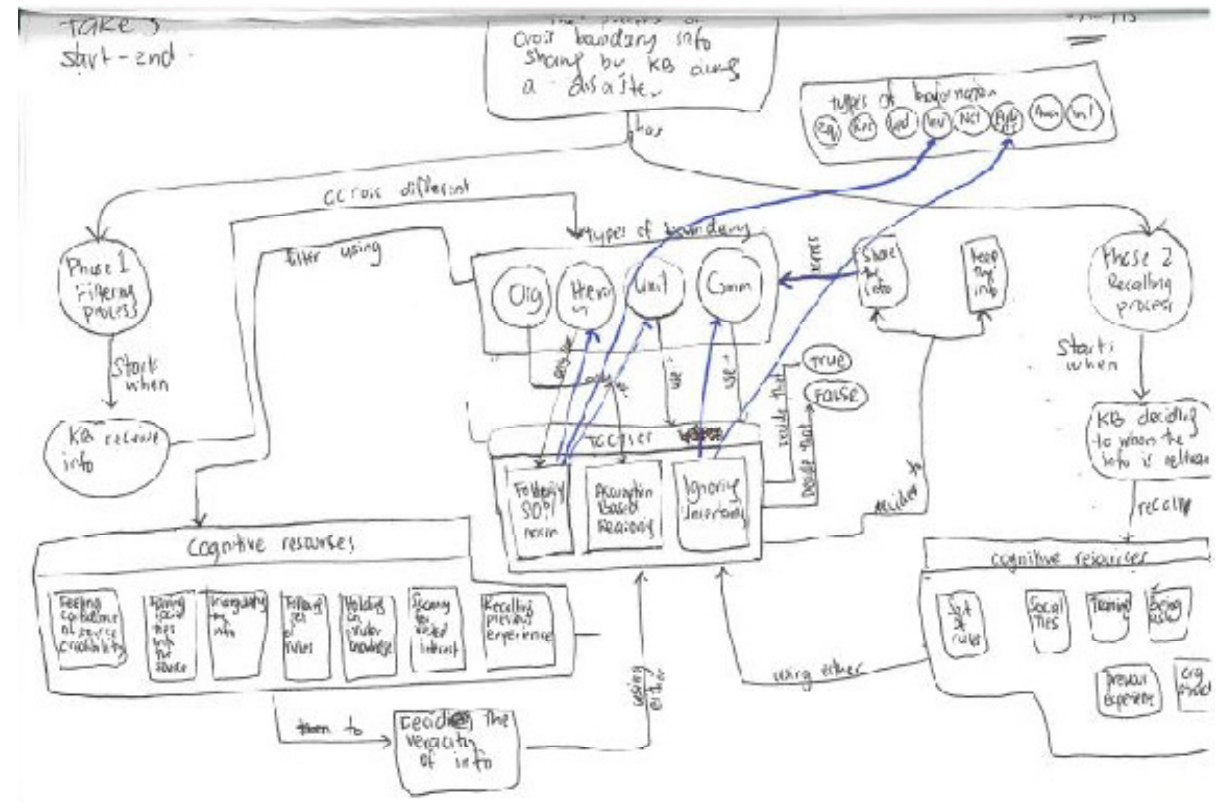

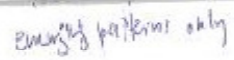
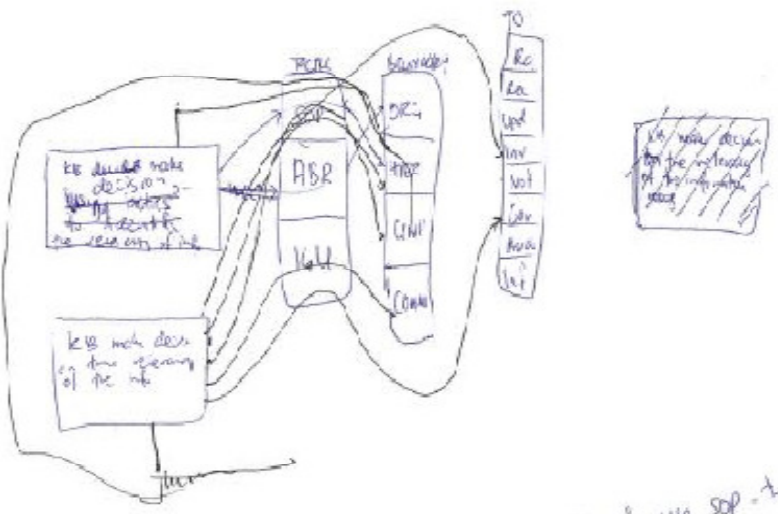

Sipp

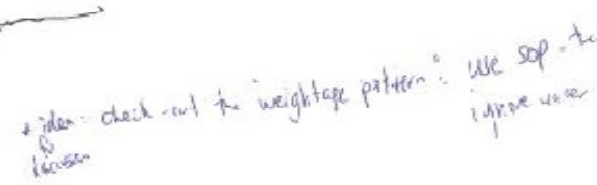




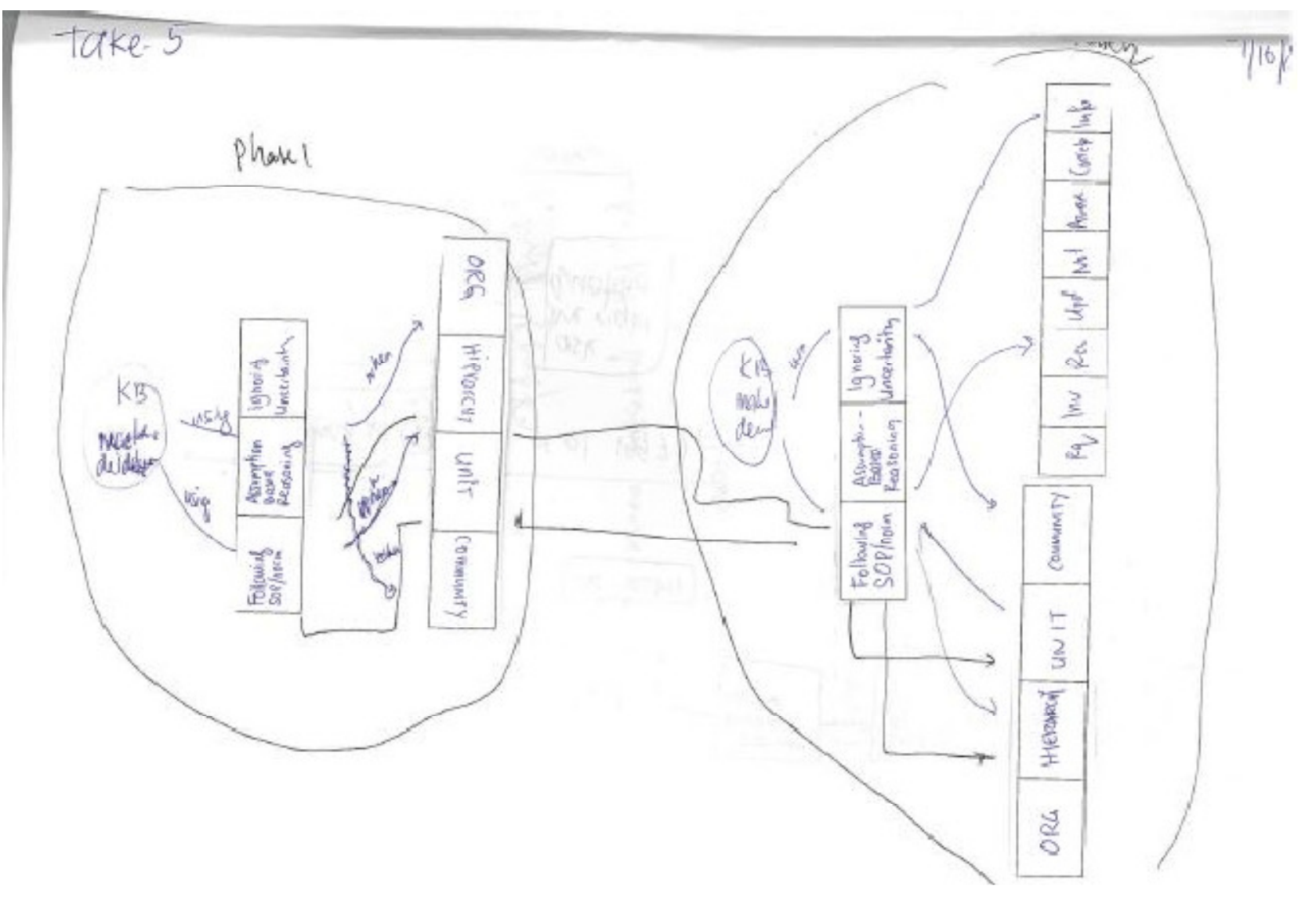


APPENDIX $\quad$ G

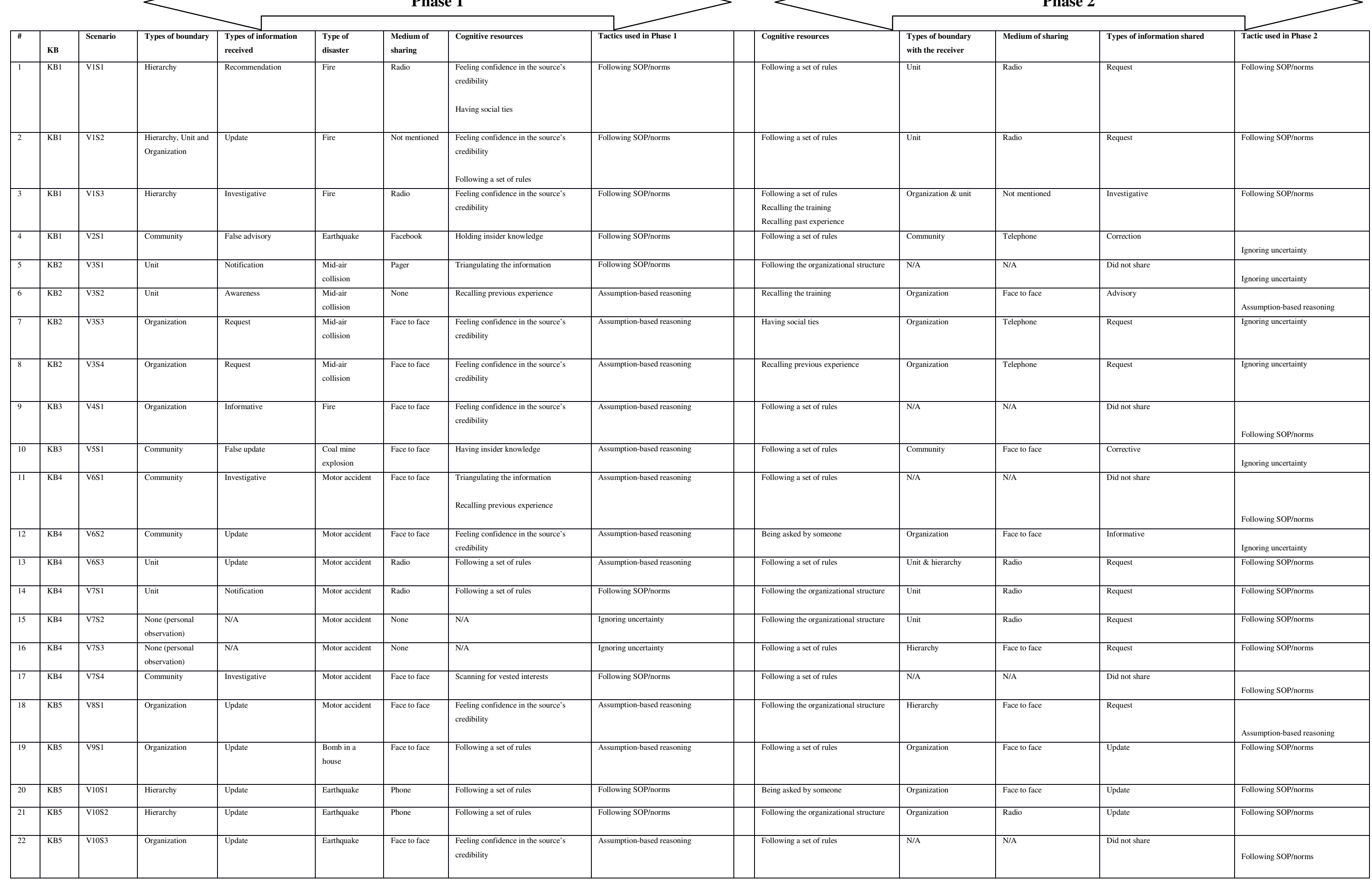

